\title{
Effect of the potassium and magnesium nutrition on potato (Solanum tuberosum L.) tuber quality and plant development
}

\author{
Dissertation \\ zur Erlangung des Doktorgrades \\ der Fakultät für Agrarwissenschaften \\ der Georg-August-Universität Göttingen
}

vorgelegt von
Mirjam Thekla Koch
geboren in Marburg (Lahn)

Göttingen, Februar 2018 
1. Referentin: Prof. Dr. Elke Pawelzik

2. Referent: Prof. Dr. Klaus Dittert

3. Referent: Prof. Dr. Johannes Isselstein

Tag der mündlichen Prüfung: 22.02.2018 
„Das letzte Ziel aller wissenschaftlichen Erkenntnis besteht darin, das größtmögliche Tatsachengebiet aus der kleinstmöglichen Anzahl von Axiomen und Hypothesen zu erhellen."

Albert Einstein 


\section{Contents}

General introduction........................................................................................ 2

Origin and history of potato ......................................................................................................................................

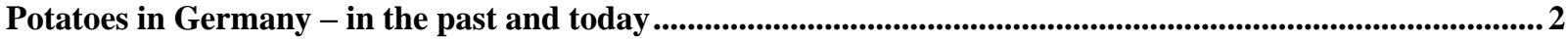

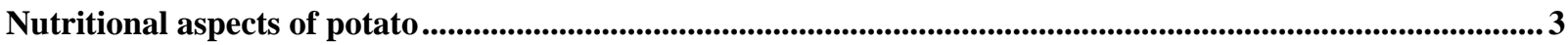

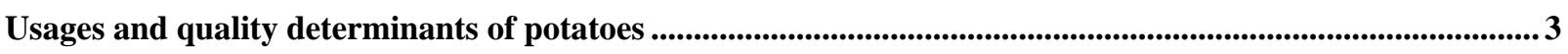

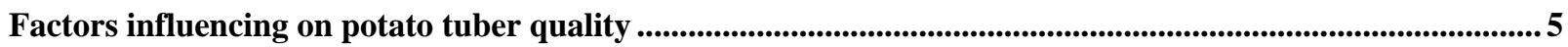

Roles of $\mathrm{K}$ and $\mathrm{Mg}$ in plant growth and metabolism ....................................................................................................

Impact of individual and interactive effects of $\mathrm{K}$ and $\mathrm{Mg}$ nutrition...................................................................... 7

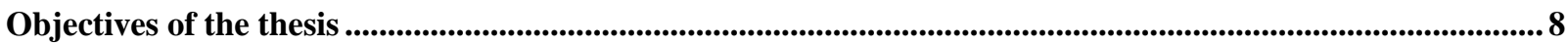

The importance of nutrient management for potato production

Part I: Plant nutrition and yield parameters ........................................................................11

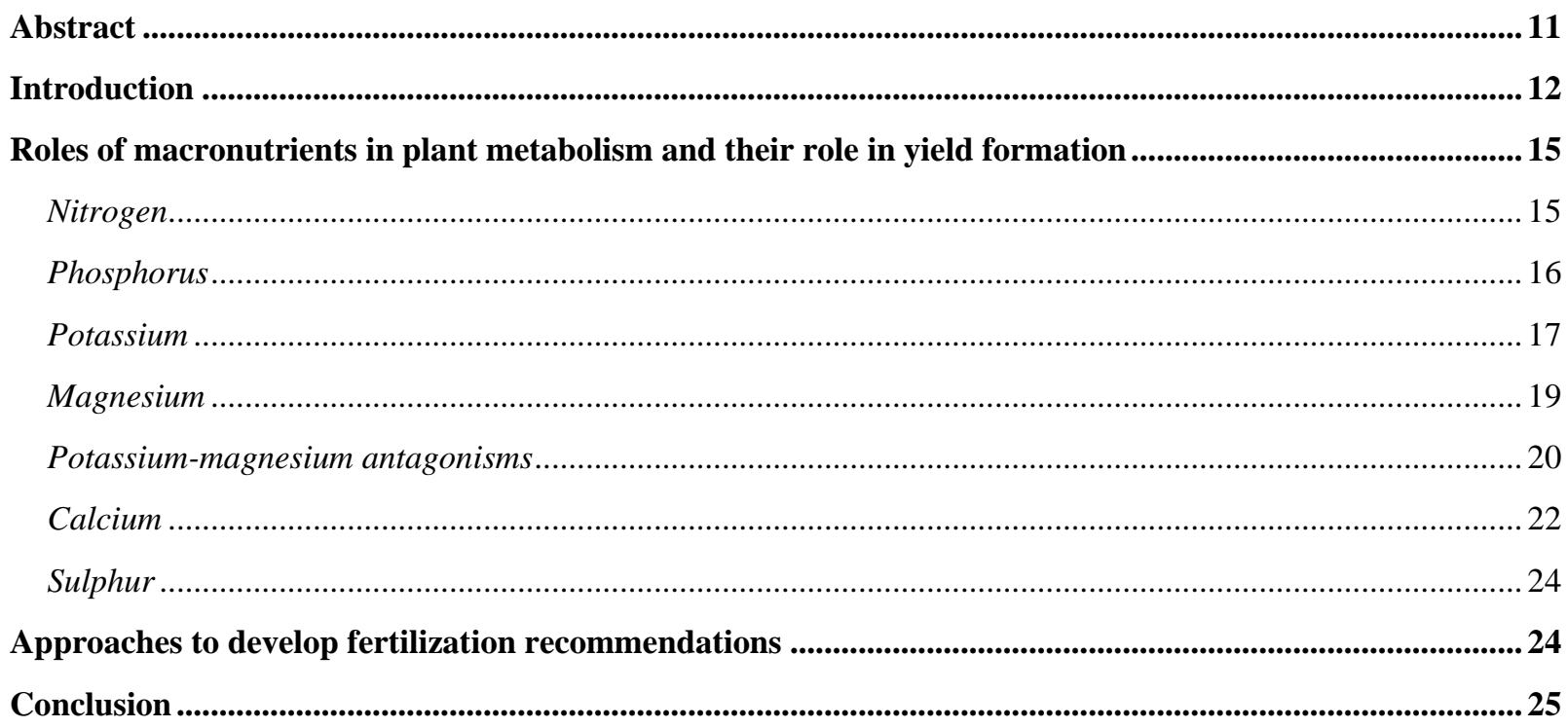

The importance of nutrient management for potato production

Part II: Plant nutrition and quality parameters........................................................................27

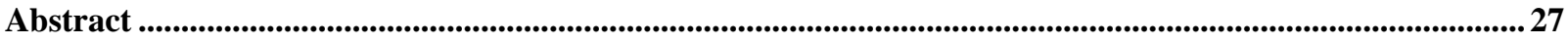

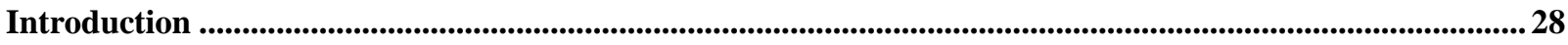

Important potato quality traits..................................................................................................................................28

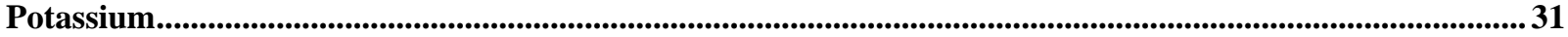

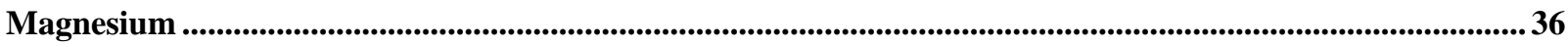

Nitrogen and interactions with potassium ........................................................................................................................37 


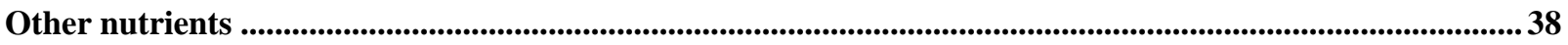

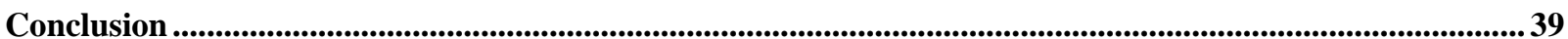

\section{Differential effects of varied potassium and magnesium nutrition on production and partitioning of photoassimilates in potato plants ..........................................................................................41}

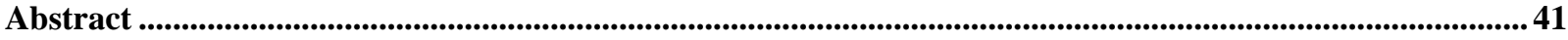

Introduction ................................................................................................................................................................................42

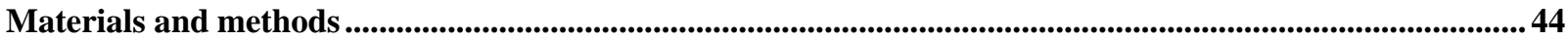

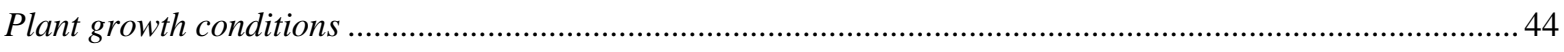

Phenotypic observation, shoot and root biomass recording, and root scanning ........................................... 44

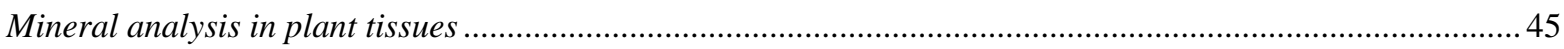

Gas-exchange measurements and chlorophyll determinations in fully expanded leaves .................................... 45

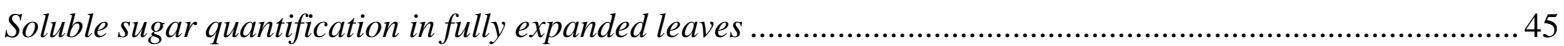

RNA extraction and quantitative real-time polymerase chain reaction ..........................................................46

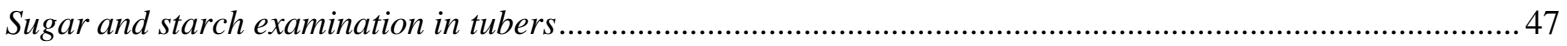

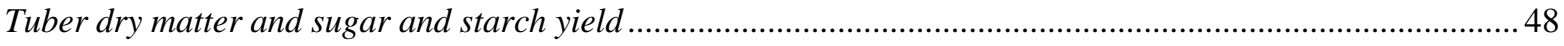

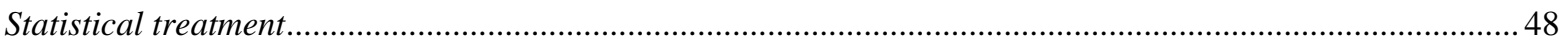

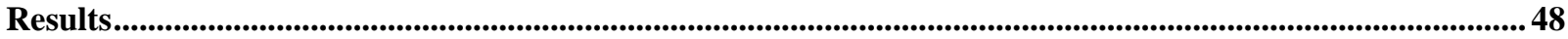

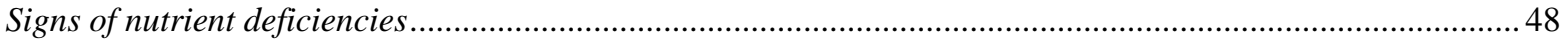

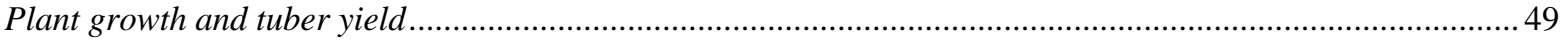

Potassium and magnesium status of fully expanded leaves ......................................................................... 50

Potassium and magnesium status of plant organs...................................................................................... 51

$\mathrm{CO}_{2}$ assimilation rate and chlorophyll concentrations of fully expanded leaves ..............................................53

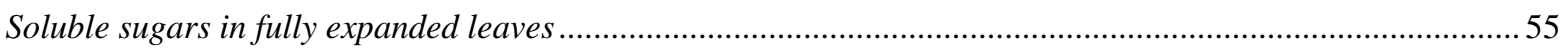

Relative gene expression of the $\mathrm{H}^{+}$-sucrose cotransporters StSUT1 and StSUT4 ............................................. 55

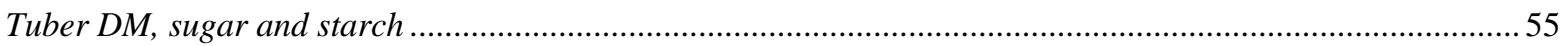

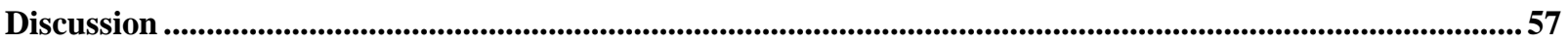

Shoot and root growth decreased under $\mathrm{Mg}$ - and especially under $\mathrm{K}$-deficiency ...........................................57

$K$ showed an antagonistic effect on $\mathrm{Mg}$ in shoots but a synergistic effect on $\mathrm{Mg}$ in roots and tubers .................58

Potassium-deficiency reduced photosynthesis while Mg-deficiency caused a reduction only late in growth stage

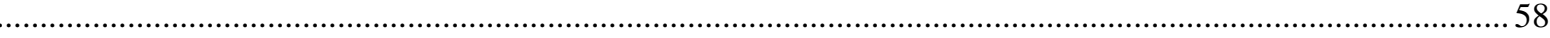

Soluble sugars accumulated in $\mathrm{K}$ - and especially in $\mathrm{Mg}$-deficient fully expanded leaves.................................. 59

$K$ - and Mg-deficiency caused sugar accumulations in different cell compartments and thus differentially

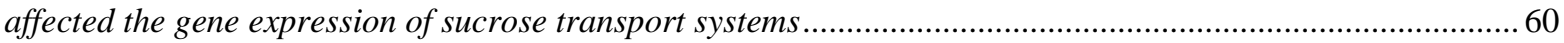

$K$ - and Mg-deficiency decreased tuber starch and sugar yield but not starch and sugar concentrations ...........61

Supplementary material.........................................................................................................................................................6 63 


\section{Effect of magnesium deficiency and magnesium complementary fertilization on potato (Solanum}

tuberosum L.) root growth..............................................................................................68

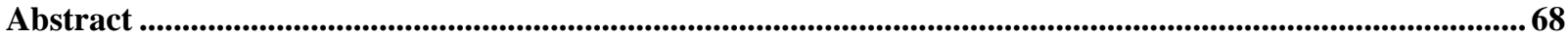

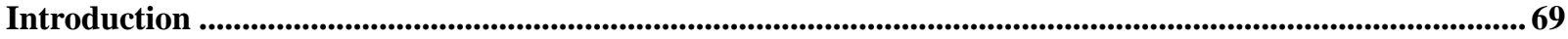

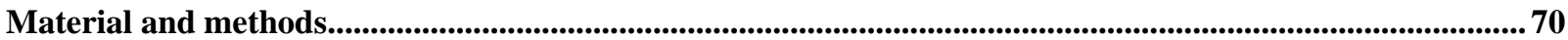

Experimental design and growth conditions ………............................................................................... 70

Mg determination in fully expanded leaves and roots .................................................................................. 72

Chlorophyll quantification in fully expanded leaves ................................................................................. 72

Soluble sugar determination in fully expanded leaves ...................................................................................... 72

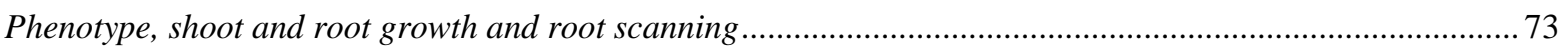

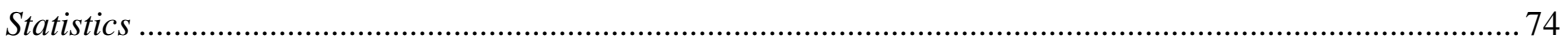

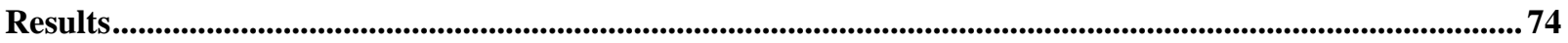

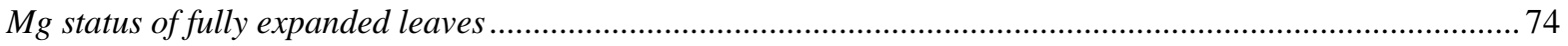

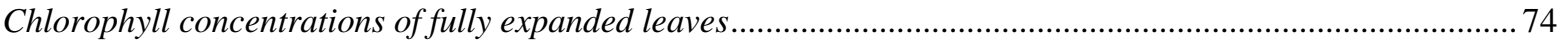

Soluble sugar concentrations in fully expanded leaves ..................................................................................... 76

Shoot and root growth ....................................................................................................................... 78

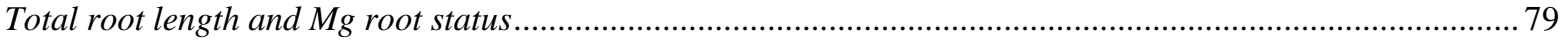

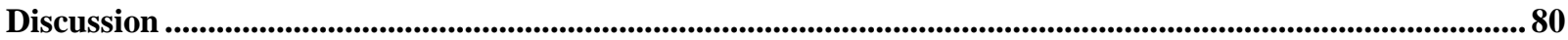

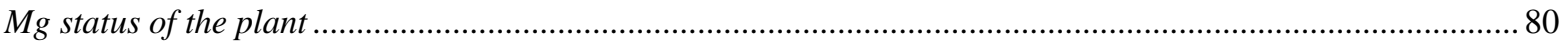

Leaf chlorophyll and soluble sugar concentrations under $\mathrm{Mg}$ restriction ....................................................... 82

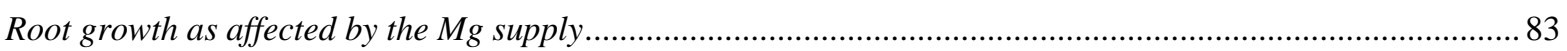

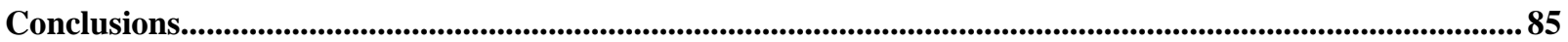

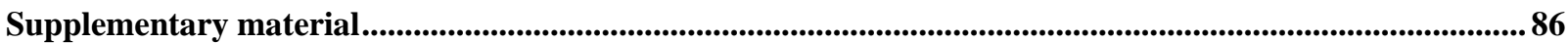

Cracking and Fracture Properties of Potato (Solanum tuberosum L.) Tubers and their Relation to Dry Matter, Starch and Mineral Distribution ......................................................................899

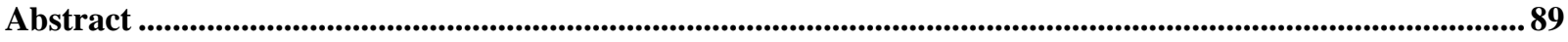

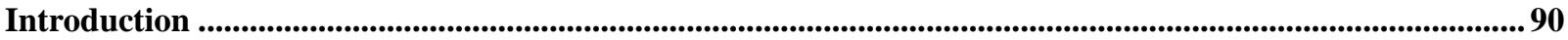

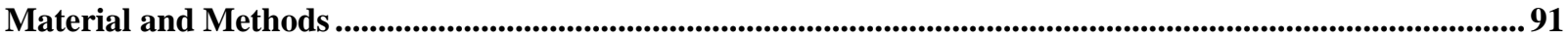

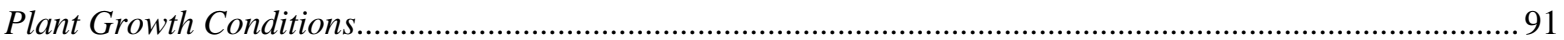

Tuber Handling after Harvest and Assignment of Analyses........................................................................... 92

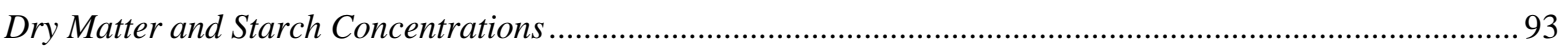

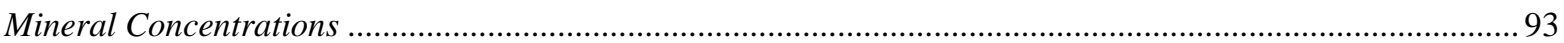

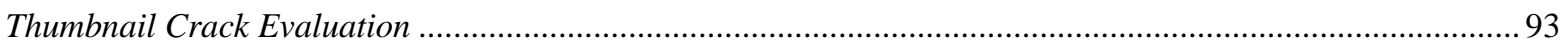

Tuber Skin Fracturability Measured by Penetration Test ................................................................................ 94

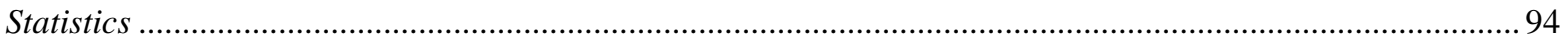


Results

Tuber Cracking and Fracturability and DM, Starch, and Mineral Concentrations based on the Fertilization Treatment and the Cultivar (2015)......

Tuber Cracking and Fracturability and DM, Starch, and Mineral Concentrations based on the Fertilization Treatment (2016)

Tuber Cracking and Fracturability and DM, Starch, and Mineral Concentrations based on the Cultivar and their Distribution in the Tuber (Müncheberg, 2016)......

Fracturability and DM, Starch, and Mineral Concentrations based on the Cultivar (Uedem, 2016)

Discussion . 100

Effect of Fertilization Treatment 100

Thumbnail Crack Occurrence and Fracturability in Relation to the DM, Starch, and Mineral Concentrations and Distributions.

Conclusions. 102

Supplementary material

General discussion.

Effect of $\mathrm{K}$ and $\mathrm{Mg}$ deficiency on (i) production and partitioning of photoassimilates, (ii) above and belowground biomass development, and (iii) tuber quality of potato

Influence of $\mathrm{K}$ and $\mathrm{Mg}$ interactive effects on $\mathrm{K}$ and $\mathrm{Mg}$ concentrations of different plant tissues and biomass development.

Relation between tuber DM and mineral concentrations and distributions on the one hand and resistance of the tuber skin against mechanical impacts on the other hand 


\section{Abbreviations}

ADP, adenosine diphosphate

$\mathrm{Al}$, aluminum

ANOVA, analyses of variances

ATP, adenosine triphosphate

$\mathrm{Bp}$, base pairs

C, carbon

$\mathrm{Ca}$, calcium

$\mathrm{Ct}$, cycle threshold

Ctr, control

DAP, days after planting

DM, dry matter

DS, dry substance

DW, dry weight

E, primer efficiency

$\mathrm{F}$, fertilization treatment

f, foliar application

FW, fresh weight

G6P-DH, glucose-6-phosphate dehydrogenase

HATS, high affinity transport system

HEPES, hydroxyethylpiperazine-ethanesulfonic acid

HK, hexokinase

HPLC, high-performance liquid chromatography

ICP-OES, inductively coupled plasma optical emission spectrometry

INV, invertase

IPNI, International Plant Nutrition Institute
IW, the initial weight

$\mathrm{K}$, potassium

LAI, leaf area index

LATS, low affinity transport system

$\mathrm{Mg}$, magnesium

Mn, manganese

$\mathrm{N}$, nitrogen

NADP, nicotinamide adenine dinucleotide phosphate

$\mathrm{NH}_{4}^{+}$, ammonium

$\mathrm{NO}_{3}{ }^{-}$, nitrate

Ns, not significant

OD, optical density

$\mathrm{P}$, phosphorus

PGI, phosphoglucose isomerase

PPO, polyphenol oxidases

qRT-PCR, quantitative real-time polymerase chain reaction

rpm, rotations per minute

RuBP, ribulose-1,5-bisphosphate

RuBisCO, ribulose-1,5-bisphosphate

carboxylase/oxygenase

S, sulphur

SM, supplemental material

St, Solanum tuberosum

SUT, sucrose transporter 


\section{Chapter 1}

\section{General introduction}




\section{General introduction}

\section{Origin and history of potato}

Potatoes were first cultivated by the Inca people in the Andes mountains in ancient time (Lee 2006). They are supposed to have been introduced from their origin South-America to Europe in the 1570s. The first records can be assigned to Spain from where it was disseminated to Italy, England and finally to Germany in 1600 (Brown 1993). The nowadays cultivated potato is classified as Solanum tuberosum L. consisting of seven subspecies of which the subspecies ssp. tuberosum has been introduced to Europe (Hawkes 1956; Hawkes 1990). However, there are high controversies about the number of existing subspecies (Huamán and Spooner 2002). Besides, there are still around 200 wild species distributed from the southwestern Unites States to Argentina and Chile (Hawkes 1990; Spooner and Hijmans 2001), comprising further desirable traits and a high potential for progress in breeding, especially with respect to resistances against pests or diseases (Spooner and Salas 2006). The potato belongs to the nightshade family (Solanaceae), which are known to have poisonous properties, why they were regarded in Europe a quit long time with great suspicion. People awarded it a potential to cause leprosy or to have narcotic properties (Brown 1993; Lee 2006). Hence, the potential of potato as food crop was underestimated and unexploited for years and it was more considered as a botanic novelty (Brown 1993). The potential of potato as a food crop was first discovered in Europe in Ireland at the end of the $17^{\text {th }}$ century. Probably a suitable climate and appropriate soils on the one hand and societal and economic reasons based on an immense growth of the Irish population on the other hand led to an increase of the importance of potato as a food crop (Bradshaw and Ramsay 2009). Today potatoes are grown in more than 100 countries and it is propagated from latitudes $65^{\circ} \mathrm{N}$ to $50^{\circ} \mathrm{S}$ and at altitudes from sea level to $4000 \mathrm{~m}$ (Hijmans 2001).

\section{Potatoes in Germany - in the past and today}

In Germany the potato mainly served as animal feed until an economical cultivation started in the 70 s and 80 s of the $18^{\text {th }}$ century (Schick and Klinkowski 1962). In the following 100 years the potato production and consumption experienced first a progressing growth followed by a sudden decrease which is persistent until today (Burton 1983). Since the $18^{\text {th }}$ century the potato yield recorded a steady increase what mainly can be referred to breeding progress, the introduction of certified seed use, inorganic fertilizers and plant protection agents (Evans and Fischer 1999; Walker et al. 1999). While the harvested amount of potatoes in Germany accounted 33 million tons in 1964, in 2014 it decreased more than twice to 11 million tons. Contrary to this, the yield accounted about 20 t/ha in 1964 and increased 
more than twice to $47 \mathrm{t} / \mathrm{ha}$ until 2014 (FAO 2017). So while there was still an increase in the potato's yield potential in the last 50-60 years, the demand and consumption of potato heavily decreased. There are assumptions about a distinct relation between the consumption of potatoes and the people's income. While under low income levels the contribution of potatoes to the energy intake of the diet is much higher it severely drops down with rising income level (Burton 1983; Walker et al. 1999). Besides, in developed nations there has been a clear change in dietary habits. 50 years ago, people spent much more time on preparation of food and not every kind of food, for instance tropical fruits or vegetables, were available all year around. Today pre-cut vegetables or complete prepared meals are available everywhere (Regmi 2001). With respect to potatoes, the consumption of fresh potatoes has declined while the demand for processed potato products like chips has increased (Camire et al. 2009).

\section{Nutritional aspects of potato}

Nowadays, potatoes have sometimes a poor reputation as they have a high content of rapidly digestible starch why they can be classified as a high-glycemic-index food. Long-term and high consumption of food with an high glycemic index might increase the risk of diet related disorders such as cardiovascular disease and type-2 diabetes (Kakoschke et al. 2014). Furthermore, there has been a rising interest in low-carbohydrate diets with respect to the intention of weight loss in the last years (Last and Wilson 2006) what likely lowered the appeal of potato consumption (McGregor 2007). Besides, fried potatoes and potato chips might have a carcinogenic potential due to potentially high concentrations of acrylamide which can be found in starch-containing foods that have been processed under high temperatures (Pelucchi et al. 2003). Nonetheless, potatoes combine several advantageous nutritional properties. The tubers are rich in vitamin $\mathrm{C}$ and are a good source for several B vitamins and minerals like potassium, magnesium and iron (Andre et al. 2014; Camire et al. 2009). Moreover, tubers are low in fat and offer protein with an excellent biological value of 90-100 (Andre et al. 2014). Especially colored potato cultivars additionally contain a number of phytochemicals like phenolics, flavonoids, or carotenoids which are supposed to be health-promoting (Ezekiel et al. 2013). However, the health benefit of potato consumption may heavily depend on the preparation method (Tian et al. 2016).

\section{Usages and quality determinants of potatoes}

As indicated previously, there are various usages of potatoes. First, there is the fresh potato market (McGregor 2007), which, however, lost in importance in developed countries (Kirkman 2007). Besides, potatoes are processed to mainly 
French fries or potato chips (Keijbets 2008) or they are used for starch production which is utilized in the food or textile industry (Grommers and van der Krogt 2009; Jobling et al. 2002). Finally, there is a seed potato market and an usage as animal feed - but today only to a very small extend (Lange and Kawchuk 2014). The majority of potato production in Germany can be assigned to potatoes for fresh consumption and processed potato products, although likewise in Germany there was a sharp decline for the consumption of fresh potatoes (Lange and Kawchuk 2014). Each usage has special quality requirements although there might be some conformability. For the fresh potato market especially the external experience is of central importance and mainly influences on the consumers purchase behavior (Fiers et al. 2010). Consumer preferences can differ between individual or origin, but generally tuber sizes of 150-200 $\mathrm{g}$, tuber shapes without protuberances, recessed eyes or stolon attachments and without superficial blemishes such as tuber cracks are preferred (Burton 1974). But also for other intended usages than for fresh consumption the absence of superficial blemishes is of interest as injuries of the tuber skin might be entrance point for secondary infections (Hide and Lapwood 1992). The mineral status of tubers might be a further important quality trait, especially for tubers for fresh consumption. Potato tubers can be a good source for several minerals in diet (Andre et al. 2007; Subramanian et al. 2011). However, minerals can show distinct distribution patterns in the tubers (Subramanian et al. 2011; Johnston et al. 1968).

For the production of French fries as well as for chips the dry matter (DM) content is a central quality parameter. High DM contents are desired to achieve a high yield of product but low oil content (Lulai and Orr 1979; Sayre et al. 1975). Furthermore, the texture of chips produced with tubers of high DM content is supposed to be harder and more desirable compared to chips produced with tubers of low DM content which are supposed to have a more greasy or sticky texture (Kita 2002). Likewise for the starch production a high DM content is aspired (Haase 2003) as starch is the most important component of DM (Poberezny and Wszelaczynska 2011). For the seed tuber market the most important quality requirements are the absence of diseases and pests, a sufficient growth vigor of the seed and an appropriate tuber size. With respect to the tuber size, smaller tubers are preferred as they can produce more stems per unit weight compared to bigger tubers (van Loon 2007).

Besides the previously mentioned quality determinants, there are several further factors which might influence on the potato tuber quality. However, not all determinants are objective of the present thesis why only a section of important quality determinants is considered. 


\section{Factors influencing on potato tuber quality}

Tuber quality can be affected by several parameters such as the cultivar (Cabezas-Serrano et al. 2009; Elmore et al. 2015), the type and time of storage (Arvanitoyannis et al. 2008; Elmore et al. 2015), agronomic practices prior and during plant growth - for instance irrigation or tillage methods (Alva et al. 2002) - and tuber handling during and after harvest (Daniels-Lake et al. 2014; Peters 1996). According to Peters (1996) mechanical injuries, which can occur during or after harvest - for example whilst tuber grading - are the most serious threats for losses of marketable tubers. Such mechanical impacts can favor for instance the emergence of tuber cracks (Hiller et al. 1985). But also internal factors like changes in moisture content can favor the emergence of tuber cracks (Bohl and Thornton 2006). Indeed, the current knowledge regarding physiological reasons that make potatoes more susceptibly for mechanical impacts which can results in cracking of the tuber is rare.

With respect to agronomic practices prior or during plant growth the nutrient supply is a further central factor of influence (Westermann 2005). Potassium (K) is that mineral which is needed in the largest amount by the potato plant (Westermann 2005). The predominantly applied nutrients in potato production are nitrogen $(\mathrm{N})$, phosphorus $(\mathrm{P})$ and $\mathrm{K}$ (Ierna et al. 2011; Lin et al. 2004). While for $\mathrm{K}$ there has been profound research related to its functions and need for crop production - including potato - the role and importance of Mg often has been neglected (Cakmak and Yazici 2010; Guo et al. 2016). A search of the ISI Web of Science on 17 December 2017 at 11:00 h CET by using the topic key word 'potato' in combination with the title key word 'potassium' by simultaneous exclusion of 'magnesium' from the title (and vice versa) returned a total of 270 'potassium articles' but only 55 'magnesium articles' published since 1945. The search was filtered for the research areas 'agronomy', 'agriculture multidisciplinary', 'food science technology', 'plant sciences', 'environmental sciences', 'biochemistry molecular biology', 'soil sciences', and 'horticulture'. Moreover, each 'potassium article' was cited on average 9.52 times with 2571 total cites while each 'magnesium article' was cited on average only 5.25 times with 289 total sites. A further search of the ISI Web of Science on December 172017 at 11:10 h CET by using the topic key words 'potato' and 'quality' in combination with the title key word 'potassium' by simultaneous exclusion of 'magnesium' from the title (and vice versa) returned a total of 43 'potassium articles' but only 12 'magnesium articles' published since 1945. The search was filtered for the research areas 'agronomy', 'agriculture multidisciplinary', 'food science technology', 'plant sciences', and 'biochemistry molecular biology'. Each 'potassium article' was cited on average 14.19 times with 610 total cites while each 'magnesium article' was cited on average only 6.67 times with 80 total sites. Finally, first a search of the ISI Web of Science on December 172017 at 11:20 h CET by using the topic key words 'potato' in combination with the title key 
words 'potassium' and 'magnesium' returned a total of only 3 'potassium and magnesium articles' which were sited on average 3 times with 9 total sites. Second, a search of the ISI Web of Science on 17 December 2017 at 11:25 h CET by using the topic key words 'potato' and 'quality' in combination with the title key words 'potassium' and 'magnesium' returned a total of 20 'potassium and magnesium articles' which were sited on average 10 times with 200 total sites. Both search (topic key word 'potato' in combination with title key words 'potassium' and 'magnesium' and topic key words 'potato' and 'quality' in combination with title key words 'potassium' and 'magnesium') were filtered for the research areas 'agronomy', 'agriculture multidisciplinary', 'food science technology', 'plant sciences', 'soil sciences', 'horticulture' and 'biochemistry molecular biology'.

These findings emphasize that there is huge lack of research and awareness about the importance of $\mathrm{Mg}$ for potato production and especially for potato quality. Besides, the outcomes of the search of the ISI Web of Science illustrate, that there has been only less research about the importance of $\mathrm{K}$ in combination with $\mathrm{Mg}$ for potato production and potato quality since 1945 . Thus, there is a high need for current research about the importance and effect of Mg but also of $\mathrm{K}$ and $\mathrm{Mg}$ in combination for potato production and quality.

\section{Roles of $\mathrm{K}$ and $\mathrm{Mg}$ in plant growth and metabolism}

Both $\mathrm{K}$ and $\mathrm{Mg}$ are essential macronutrients for plant growth and are needed for a myriad of processes in plant metabolism (Marschner 2011). A main focus of this thesis is set on the roles of $\mathrm{K}$ and $\mathrm{Mg}$ for photosynthesis and the partitioning of photoassimilates from source to sink organs. Potato tubers are strong sink organs. Thus, an impact of the $\mathrm{K}$ and $\mathrm{Mg}$ supply on potato tuber development and likely quality can be expected. $\mathrm{K}$ has an outstanding role due to its osmotic properties in plants. Based on these properties it facilitates cell and root elongation (Mengel and Arneke 1982; Song et al. 2017), leaf area expansion (Jordan-Meille and Pellerin 2004), and plant movements such as stomata opening and leaf movement (Ahmad and Maathuis 2014). With regard to the mentioned functions $\mathrm{K}$ is crucial for photosynthesis for two main reasons: First, $\mathrm{K}$ ensures $\mathrm{CO}_{2}$ diffusion through the leaf mesophyll (Jákli et al. 2017) and second, $\mathrm{K}$ is thought to cause a reduction in the activity of the enzyme ribulose-1,5-bisphosphate carboxylase/oxygenase (Rubisco) which catalyzes the first step in $\mathrm{CO}_{2}$ fixation (Hu et al. 2016). This may be attributed to a decrease of $\mathrm{CO}_{2}$ at the catalytic site of the enzyme based on a restricted $\mathrm{CO}_{2}$ diffusion through the leaf mesophyll (Asif et al. 2017; Oosterhuis et al. 2013). The predominant role of K in source to sink transport of assimilates is likewise based on its previously mentioned function, namely its osmotic properties. Here, K establishes an osmotic gradient 
which is causing a driving force for sucrose, the main transport form of carbohydrates in the phloem (Cakmak et al. 1994a; Hayashi and Chino 1990; Vreugdenhil 1985).

$\mathrm{Mg}$ is activator for a huge number of enzymes (Senbayram et al. 2015; Verbruggen and Hermans 2013). One of these enzymes is Rubisco (Belknap and Portis 1986) what makes Mg essential for photosynthesis. Beside, Mg is central atom of chlorophyll (Walker and Weinstein 1994) why it may additionally influence on photosynthesis. A further major role of $\mathrm{Mg}$ is located in the loading of the phloem why it is pivotal, like $\mathrm{K}$, for the source to sink transport of assimilates in plants. Here, $\mathrm{Mg}$ is required by ATPases as allosteric activator. These ATPases create a proton gradient that provides energy for the phloem loading process (Hermans et al. 2005).

Finally, nutrient shortages, including $\mathrm{K}$ and $\mathrm{Mg}$, have been shown to negatively impact on the plants root architecture (Cakmak et al. 1994b; Gruber et al. 2013; Mengutay et al. 2013; Sattelmacher et al. 1993). Cakmak et al. (1994b) refers this to a negatively affected photoassimilate partitioning which has been caused by $\mathrm{K}$ and $\mathrm{Mg}$ deficiency.

\section{Impact of individual and interactive effects of $\mathrm{K}$ and $\mathrm{Mg}$ nutrition}

Mineral nutrition can significantly affect the plant's mineral status and in turn plant growth (Fageria 2001; White et al. 2009). It was shown that mineral nutrition of $\mathrm{N}, \mathrm{P}, \mathrm{K}, \mathrm{Calcium}$ (Ca) and $\mathrm{Mg}$ can increase the particular element concentrations in tubers (for detailed literature references see White et al. (2009)). However, the application of one nutrient can change the concentrations of other minerals by affecting the absorption, distribution or function of another nutrient (Robson and Pitman 1983; White et al. 2009). These nutrient interactions can be of synergistic, antagonistic but also neutral nature. Interactions between nutrients are often observed between ions of similar chemical properties, such as K, Mg and Ca (Jakobsen 1992; Robson and Pitman 1983) as they might compete for the same uptake mechanism from the soil solution (Mayland 1990). With respect to potato, the interaction between $\mathrm{K}$ and $\mathrm{Mg}$ often has been research issue - however with contradictory outcomes: Hossner and Doll (1970) examined an antagonistic effect between $\mathrm{K}$ and $\mathrm{Mg}$ in form of decreasing tuber yield under decreasing $\mathrm{Mg}$ but increasing $\mathrm{K}$ plant mineral status. Contrary, Allison et al. 2001 concluded, that there is no interactive effect between K and Mg. Ding et al. (2006) could determine a synergistic effect of increasing Mg supply on the uptake and translocation of $\mathrm{K}$ from the root to shoot though, this study was conducted with rice (O. sativa L. ssp. Japonica) plants. 


\section{Objectives of the thesis}

An initial objective of the present thesis is to review the current state of knowledge about i) the importance of $\mathrm{K}$ and $\mathrm{Mg}$ for plant growth in general and for potato production in particular. Furthermore, ii), it is aimed to point out the current state of knowledge about the importance of $\mathrm{K}$ and $\mathrm{Mg}$ for potato quality. These aspects beside the importance of other nutrients than $\mathrm{K}$ and $\mathrm{Mg}$ are reviewed in the first two chapters of this thesis. The following chapters deal with the subsequent mentioned research objectives:

1. The functional impacts of $\mathrm{K}$ and $\mathrm{Mg}$ on photosynthesis and the partitioning of photoassimilates from source to sink organs are well resolved. However, it is unclear to which extent a $\mathrm{K}$ or $\mathrm{Mg}$ deficiency affect these processes in potato. Moreover, as tubers are strong sink organs for photoassimilates, an impairment on tuber development and quality is expected.

Thus, central objectives of this study are:

1a) Examining the severity of photosynthetic restriction and parameters, which give indication about the source to sink transport of photoassimilates under $\mathrm{K}$ and $\mathrm{Mg}$ deficiency.

1b) How $\mathrm{K}$ and $\mathrm{Mg}$ restriction affect tuber development and quality.

2. Several studies in literature are available about nutrient uptake interactions between $\mathrm{K}$ and $\mathrm{Mg}$, though with contradictory outcomes: Some studies report about antagonistic nature between $\mathrm{K}$ and $\mathrm{Mg}$, some could not determine an interaction at all and some even demonstrated a synergistic effect. Therefore, the $\mathrm{K}$ and $\mathrm{Mg}$ status of different plant tissues under various combined $\mathrm{K}$ and $\mathrm{Mg}$ supplies is investigated to preserve clarification about the nature of interactive effects between $\mathrm{K}$ and $\mathrm{Mg}$ in potato.

3. Common bean (Phaseolus vulgaris), wheat (Triticum aestivum), maize (Zea mays) and the model plant Arabidopsis show a reduced root growth under Mg deficiency (Cakmak et al. 1994b; Gruber et al. 2013; Mengutay et al. 2013). This was never reported for potato. Thus, further aims of this thesis are

3a) Testing if $\mathrm{Mg}$ deficiency causes a reduced root growth in potato.

3b) Examining if such a putative root growth reduction can be ameliorated by $\mathrm{Mg}$ resupply via roots or leaves, respectively. 
4. The absence of superficial blemishes such as tuber cracks is an important quality determinant of potatoes. Knowledge regarding physiological reasons that make potatoes more susceptibly for mechanical damage, which can result in cracking or fracture of the tuber skin, is rare. Therefore we aimed to elucidate:

4a) Physiological parameters that might be linked with the resistance of tubers against mechanical impacts.

4b) If a $\mathrm{K}$ and $\mathrm{Mg}$ supply is affecting these physiological parameters. 


\section{Chapter 2}

\section{The importance of nutrient management for potato production \\ Part I: Plant nutrition and yield parameters}

Mirjam Koch, Marcel Naumann, Elke Pawelzik, Andreas Gransee, Heike Thiel

Submitted 


\title{
The importance of nutrient management for potato production Part I: Plant nutrition and yield parameters
}

\author{
Mirjam Koch ${ }^{1}$, Marcel Naumann ${ }^{1}$, Elke Pawelzik ${ }^{1 *}$, Andreas Gransee ${ }^{2}$, Heike Thiel $^{2}$ \\ ${ }^{1}$ Quality of Plant Products, Department of Crop Sciences, Faculty of Agricultural Sciences, University of \\ Goettingen, Carl-Sprengel-Weg 1, 37075 Goettingen \\ ${ }^{2}$ K+S KALI GmbH, Bertha-von-Suttner-Str. 7, 34131 Kassel, Germany
}

*Corresponding author: epawelz@gwdg.de

\begin{abstract}
Research from the last few decades has shown that, in potato production, optimal yield and optimal quality do not necessarily correlate. Agronomic strategies in potato production have mainly focused on improving yield and related parameters. In recent years, however, the quality aspect attracts more attention. As part of a successful agronomic strategy, adequate nutrient management of the potato crop is essential throughout the whole growth period. In this review, the importance of balanced fertilization for potato yield formation and yield security is addressed by taking advantage of the results of own field trials and current literature. Due to their various functions in plant metabolism, the impact of plant nutrients on specific yield parameters is complex, particularly under abiotic and biotic stress conditions. Specific and non-specific nutrient interactions in the soil and the plant have to be taken into account as well. In conclusion, the development of site-specific fertilization recommendations as part of an agronomic strategy strongly depends on soil and plant nutrient status.
\end{abstract}

Keywords: productivity; yield; nitrogen, phosphorus, magnesium; potassium 


\section{Introduction}

Potato (Solanum tuberosum) is a highly attractive crop in agricultural production systems since it combines an extraordinarily high yield potential of, on average, more than $45 \mathrm{t} \mathrm{ha}^{-1}$ in high-input agriculture (Table 1) with a high nutritional value. For example, it is a good source of energy, minerals, proteins, fats, and vitamins (Ekin 2011, Drewnowski and Rehm 2013; King and Slavin 2013). Besides, potatoes are not just an important food source (Andre et al. 2014). They are also increasingly serving as feedstock for industrial products (Izmirlioglu and Demirci 2015; Jagatee et al. 2015). Therefore, unlike most other crops, potatoes have an unusually high range of utilization possibilities, which makes their production even more attractive (Stearns et al. 1994; Feltran et al. 2004; Kaur and Singh 2009). Table 1 summarizes data on the potato production in different regions of the northern hemisphere and Africa. These data base on cultivation area and taking the top five countries into account as well as the total potato production worldwide.

The yield, a potato crop can potentially realize at a specific production site, is mainly determined by its specific genetic background (Evans and Fischer 1999). There is a gap between the actual yields and the yield potential (Van Keulen and Stol 1995; Michel 2015). According to the yield potential concept, the potential yield is never fully reached in natural production systems, as biotic and abiotic factors, interfering with the potato crop negatively affect plant growth and tuber development. Important biotic stress factors in potato production include late blight (caused by Phytophthora infestans) (Nowicki et al. 2012) and other fungal infections, like early blight (caused by Alternari solani), silver scurf (Helminthosporium solani) and black scurf (Rhizoctonia solani), as well as Fusarium and Verticillium wilt (Rich 2013). Furthermore, other kinds of pathogens (Giordanengo et al. 2013), and various bacterial and viral diseases (Rich 2013) affect potato yield and production. The abiotic stresses that reduce yield include high radiation, heat and cold stress. But the most important abiotic factor affecting yield and quality is drought stress (van Loon 1981; Obidiegwu et al. 2015).

To a certain degree, growers can reduce the negative effects of the environmental impacts by using balanced agronomic management strategies. Apart from the choice of cultivar, plant protection, and continuous water supply, the most important agronomic measure for potato production is adequate nutrient management. An sufficient supply of mineral nutrients (1) fortifies the potato plants against adverse growth conditions (only well-nourished plants have the potential to withstand the challenges of climate change), (2) is crucial for achieving high yield, and (3) is essential for producing potatoes that meet the desired quality requirements. According to the law of the minimum developed by Carl Sprengel and, later, spread by Justus von Liebig in the early $19^{\text {th }}$ century, optimal crop growth can take place only if all required 
nutrients are at the optimum level (Sprengel 1828; cited in van der Ploeg et al. 1999; von Liebig 1841; von Liebig 1855). In detail, it states that plant growth is controlled not by the total amount of nutrients available, but by the amount of the scarcest nutrient. This law points to the importance of balanced nutrition for optimal plant growth. The law of the diminishing yield increase is of similar importance. It states that the higher the nutrient supply the lower the yield increase obtained from the increase in fertilization, which means that the yield response to fertilization follows a saturation curve (Spillman 1923). Both laws are the basis for modern approaches to develop fertilization recommendations—-like the '4R plant nutrition concept' compiled by International Plant Nutrition Institute (IPNI), for example (IPNI 2012; Johnston and Bruulsema 2014).

In the following sections, this review aims to give an overview on the role of nutrients on yield formation, yield security and fertilization practice in potato production. 
Table 1: Potato production details from Europe, America, Asia and Africa in total plus top five countries according to the cultivation area, the amount of harvested product, and the average yield in 1994 and 2014.

\begin{tabular}{|c|c|c|c|c|c|c|c|}
\hline \multirow[t]{2}{*}{ Country } & \multicolumn{2}{|c|}{ Cultivation area (ha)* } & \multicolumn{2}{|c|}{ Quantity (t)* } & \multicolumn{2}{|c|}{ Average yield $(\mathrm{t} / \mathrm{ha})^{*}$} & \\
\hline & 1994 & 2014 & 1994 & 2014 & 1994 & 2014 & \\
\hline Russia $^{1}$ & $3,336,960$ & $2,101,461$ & $33,827,620$ & $31,501,354$ & 10.1 & 15.0 & \\
\hline Ukraine & $1,527,000$ & $1,342,800$ & $16,102,000$ & $23,693,350$ & 10.5 & 17.6 & \\
\hline Germany & 322,775 & 244,800 & $10,635,400$ & $11,607,300$ & 33.0 & 47.4 & $\stackrel{\mathrm{m}}{\mathrm{g}}$ \\
\hline France & 165,000 & 168,519 & $5,463,000$ & $8,085,184$ & 33.1 & 48.0 & \\
\hline Poland & $1,697,247$ & 276,927 & $23,057,540$ & $7,689,180$ & 13.6 & 27.8 & \\
\hline Total & $9,795,116$ & 5616844 & $138,208,334$ & $124,542,089$ & 14.1 & 22.2 & \\
\hline USA $^{2}$ & 558,350 & 425,370 & $21,185,000$ & $20,056,500$ & 37.9 & 47.2 & \\
\hline Peru & 188,531 & 318,380 & $1,767,247$ & $4,704,987$ & 9.4 & 14.8 & \\
\hline Canada & 132,900 & 138,942 & $3,676,600$ & $4,589,200$ & 27.7 & 33.0 & 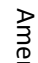 \\
\hline Brazil & 171,853 & 132,058 & $2,488,461$ & $3,689,836$ & 14.5 & 27.9 & \\
\hline Colombia & 184,397 & 107,598 & $2,938,631$ & $2,157,568$ & 15.9 & 20.1 & \\
\hline Total & $1,721,011$ & $1,576,901$ & $38,591,256$ & $42,241,119$ & 22.4 & 26.8 & \\
\hline China $^{3}$ & $3,207,600$ & $5,645,000$ & $43,800,000$ & $95,515,000$ & 13.7 & 16.9 & \\
\hline India & $1,047,100$ & $2,024,000$ & $17,392,400$ & $46,395,000$ & 16.6 & 22.9 & \\
\hline Bangladesh & 131,245 & 461,710 & $1,438,055$ & $8,950,000$ & 11.0 & 19.4 & $\frac{\vec{n}}{\alpha}$ \\
\hline Iran & 149,512 & 158,958 & $3,184,840$ & $4,717,266$ & 21.3 & 29.7 & \\
\hline Turkey & 190,000 & 128,392 & $4,350,000$ & $4,166,000$ & 22.9 & 32.4 & \\
\hline Total & $5,743,038$ & $9,932,183$ & $84,477,948$ & $186,886,889$ & 14.7 & 18.8 & \\
\hline Algeria & 75,300 & 156,176 & 715,936 & $4,673,516$ & 9.5 & 29.9 & \\
\hline Egypt & 64,779 & 172,005 & $1,324,649$ & $4,611,065$ & 20.4 & 26.8 & \\
\hline South Africa & 55,197 & 63,907 & $1,316,000$ & $2,247,495$ & 23.8 & 35.2 & $\frac{\text { D }}{\overline{2}}$ \\
\hline Rwanda & 17,000 & 164,152 & 114,900 & $2,213,556$ & 6.76 & 13.5 & \\
\hline Morocco & 58,800 & 63,515 & $1,037,950$ & $1,950,982$ & 17.7 & 30.7 & \\
\hline Total & 747,477 & $1,933,185$ & $8,359,620$ & $2,639,1538$ & 11.2 & 13.7 & \\
\hline World & $18,056,805$ & $19,098,328$ & $271,244,596$ & $381,682,144$ & 15.0 & 20.0 & \\
\hline
\end{tabular}




\section{Roles of macronutrients in plant metabolism and their role in yield formation}

Reports on the nutrient uptake and removal mainly rely on data produced decades ago. Therefore, a comprehensive study on the nutrient demand of and removal by modern varieties of potatoes is urgently needed. Perrenoud (1993) summarized the literature on the nutrient uptake of and removal by potatoes. The mean values are presented in Figure 1. From the removal per ton of tubers, the removal in $\mathrm{kg} \mathrm{ha}^{-1}$ was calculated a tuber yield of $40 \mathrm{t} \mathrm{ha}^{-1}$. The most important nutrients, as shown in Figure 1 (with the exception of sulphur), are highlighted with respect to their physiological functions in plant metabolism and for tuber yield formation in this review. Unfortunately, often less current literature is available dealing with nutrient functions in the potato crop. In this case, the most important nutrient roles are addressed exemplary on other crop plants with view on the importance for the potato crop. A critical review on all essential nutrients in potato growth is beyond the scope of this review.

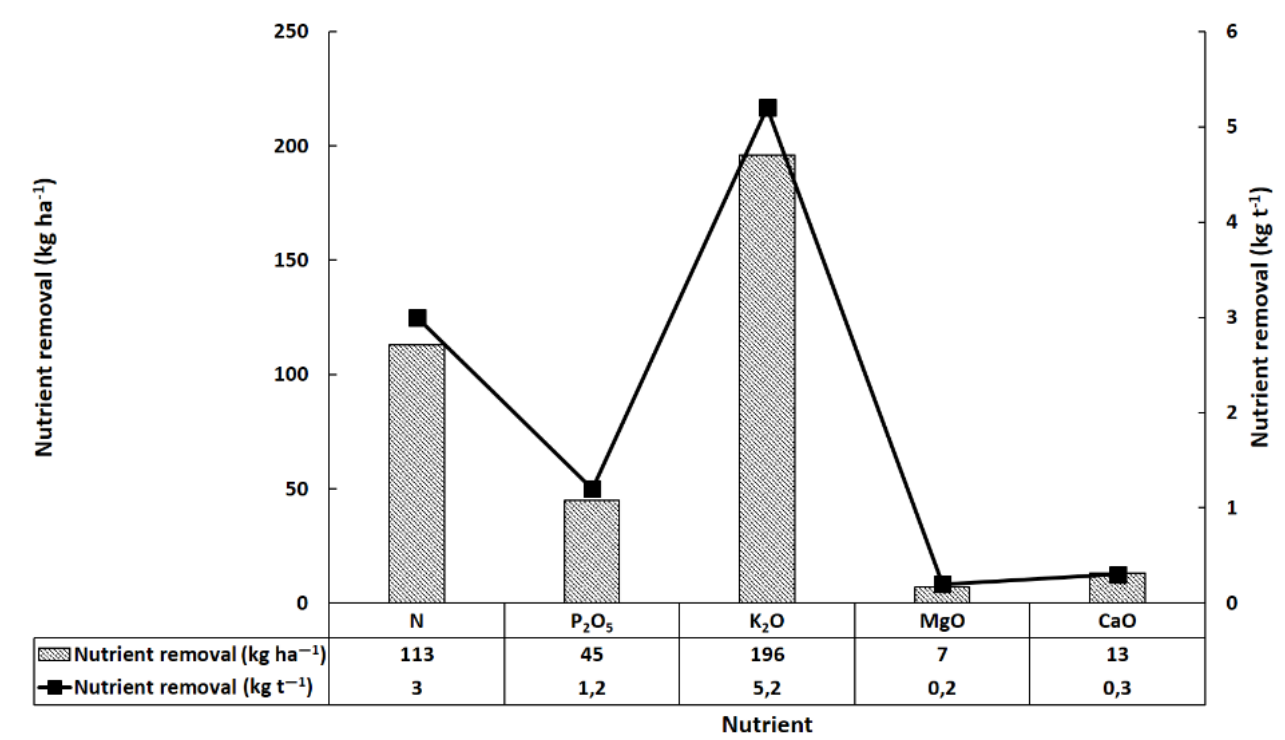

Figure 1: Removal of $\mathrm{N}, \mathrm{P}_{2} \mathrm{O}_{5}, \mathrm{~K}_{2} \mathrm{O}, \mathrm{MgO}$, and $\mathrm{CaO}$ by potato tubers. Mean values per ton of tubers (as shown on the right axis), calculated according to Perrenoud (1993) [and literature cited therein]. Calculations on nutrient removal per ha (as shown on the left axis) were based on a $40 \mathrm{t} \mathrm{ha}^{-1}$ tuber yield.

\section{Nitrogen}

Nitrogen $(\mathrm{N})$ is one of the most crucial macronutrients for plant growth and biomass development. It can limit potato yield formation most amongst all essential macronutrients (Bucher and Kossmann 2011; Silva et al. 2013). It has a decisive impact on the number of emerging leaves and the rate of leaf expansion, and, therefore, on the leaf area index (LAI) of plants. Hence, it has a positive impact on photosynthesis efficiency by increasing the interception rate of 
radiation and photons (Vos 1995; Vos and van der Putten 1998; Mauromicale et al. 2006), and, as a consequence, on tuber yield formation (Ahmed et al. 2015). Besides this, $\mathrm{N}$ is mandatory for the plant as it is a component of chlorophyll, amino acids, proteins, nucleic acids, coenzymes, and membrane constituents (Andrews et al. 2013; Ahmed et al. 2015). Plants can use $\mathrm{N}$ in different forms. Their major sources are nitrate $\left(\mathrm{NO}_{3}^{-}\right)$and ammonium $\left(\mathrm{NH}_{4}{ }^{+}\right)$(Silva et al. 2013). While adequate use of $\mathrm{N}$ fertilization can improve yield as well as plant quality, an inappropriate supply of $\mathrm{N}$ can lead to increasing vegetative growth but delayed flowering and impaired tuber formation (Nitsch 2003; Bucher and Kossmann 2011; Ahmed et al. 2015). In addition, an excessive supply of $\mathrm{N}$ can lead to the accumulation of reactive $\mathrm{N}$ compounds in the atmosphere or leaching to the groundwater, both of which have negative impacts on our ecosystems (Singh and Lal 2012 Silva et al. 2013). Leaching, in particular, is likely to occur under a high supply of N, as potatoes have shallow roots that are unable to capture $\mathrm{N}$ from deeper soil layers. Therefore, the potato crop can be referred to as $\mathrm{N}$-inefficient crop (Cameron et al. 2013). Optimal $\mathrm{N}$ fertilization practices should be achieved to meet both economic and environmental demands (Zebarth et al. 2012). Therefore, an appropriate $\mathrm{N}$ supply should be based on calculations that meet the actual plant demand and should include other $\mathrm{N}$ sources-for example, delivered by catch crops or intercrops, like N-fixing leguminous plant species (Bucher and Kossmann 2011; Zebarth et al. 2012; Cameron et al. 2013). In order to meet the actual demand of the plant, splitting $\mathrm{N}$ application is commonly used approach (Kelling et al. 2015; Rens et al. 2016). Furthermore, optimal $\mathrm{N}$ usage can be improved upon by inducing and maintaining high plant growth and biomass production through appropriate irrigation strategies, controlling pest and observation of disease development, and avoiding nutrient deficiencies (Cameron et al. 2013).

Due to the disturbance of chloroplasts, $\mathrm{N}$ deficiency becomes obvious as leaf chlorosis that is equally distributed over the whole leaf. Unlike symptoms of potassium $(\mathrm{K})$ or magnesium $(\mathrm{Mg})$ deficiency, severe necrosis of the leaves due to $\mathrm{N}$ deficiency usually appears late in the growth stages. The symptoms of $\mathrm{N}$ deficiency may also be similar to ferric, calcium (Ca), or sulphur (S) deficiency. These symptoms occur first on younger leaves as those nutrients cannot be translocated within the plant (Mengel and Kirkby 2001).

\section{Phosphorus}

Phosphorus (P) is required in relatively high amounts by the potato crop compared to others (Figure 1) (Rosen et al. 2014). P serves various functions in plant metabolism, where the most prominent role is cellular energy transfer by dephosphorylation of Adenosine triphosphate (ATP) to Adenosine diphosphate (ADP), which is the primary source of energy in the processes of photosynthesis, respiration, or biosynthesis - like starch synthesis. Besides this, P is a 
structural component of nucleic acids as units in deoxyribonucleic acid and ribonucleic acid molecules, of many coenzymes, and of phospholipids in biomembranes ( Raghothama 2000; Marschner 2011; Rosen et al. 2014). Economically speaking, especially in the early growth states, $\mathrm{P}$ has a significant impact on number of potato tubers and settings ( Jenkins and Ali 2000; Hopkins et al. 2014).

Most soils cannot sufficiently cover the P demand of potatoes or P may only be plant-available to a limited extend due to its absorption by soil particles, clay minerals, or $\mathrm{Ca}$ and $\mathrm{Mg}$ carbonates (Bucher and Kossmann 2011; Rosen et al. 2014). Besides this, similar to the $\mathrm{N}$ usage in deeper soil layers, $\mathrm{P}$ uptake is difficult for the potato crop due to its shallow and inefficient rooting system (Hopkins et al. 2014). However, there are various strategies for exploiting limited accessible $\mathrm{P}$ sources. Any factor that is able to increase the rooting zone can lead to better $\mathrm{P}$ absorption. Therefore, the best management practice, including the avoidance of root pruning by tillage and toxicities of salts or other compounds that can impair the root development, and pest and disease management in order to maintain healthy roots, are of central relevance (Hopkins et al. 2014). Another option is using the advantages of the symbiotic associations of potato roots with arbuscular mycorrhizal fungi (McArthur and Knowles 1993). These fungi colonize roots with hair-like hyphae, which increase the root area, and lead to higher water and nutrient uptake, especially the uptake of P. In turn, the fungi receive sugars in form of photosynthates from the plant (Smith and Smith 2012). Furthermore, the placement (banding or broadcast) and soil $\mathrm{pH}$ value seem to have an influence on $\mathrm{P}$ acquisition, but inconsistent results are noted in different studies, as described by Hopkins et al. (2014) and Rosen et al. (2014).

The potato plant can tolerate moderate P stress without any severe deficiency symptoms until photosynthesis and respiration processes are reduced heavily so much that carbohydrates start to accumulate. This becomes obvious in dark green to purple leaf discolorations, as described by Hoppo et al. (1999) and cited in Grant et al. (2001).

\section{Potassium}

Out of all the macronutrients, potassium (K) has the highest concentrations in potato tubers, accounting for about 400 mg per $100 \mathrm{~g}$ fresh weight (White et al. 2009) or for about 1.7\% of dry matter (Schilling et al., 2016). In the remaining plant tissues, it is also the most abundant inorganic cation —in potato leaves with up to $6 \%$ of dry matter, for instance (Leigh and Wyn Jones 1984; Zorn et al. 2016). These facts are also reflected in the high amounts of K removal by potatoes (Figure 1). Beside this, $\mathrm{K}$ is one of the most important nutrients affecting potato tuber quality as is described e.g. by Zörb et al. (2014). 
The major functions of $\mathrm{K}$ in plants are controlling enzyme activity, cation-anion homeostasis, and membrane polarization, or they are based on its osmotic nature, which is why it is needed for cell extension, turgor regulation, or stomatal movement (Walker et al. 1996; Liu et al. 2006; Wang and Wu 2013; Adams and Shin 2014; Shabala and Pottosin 2014). One important role of $\mathrm{K}$ for the potato crop in enzyme functions is, for example, stimulating the starch synthase for starch synthesis (Hawker et al. 1979). A sufficient supply of K is also needed for yield-decisive high biomass production and leaf area development. Under K deficiency, there can be a decreased number of leaves as well as a decrease in the leaf size. This can be attributed to K's role in osmoregulation and cell extension (Gerardeaux et al. 2010; Jákli et al. 2016). Besides the mentioned functions, $\mathrm{K}$ is crucial for photosynthesis and the distribution of photosynthates via the phloem. To maintain a proper working photosynthesis, an accurate working stomatal movement is needed to take up considerable amounts of $\mathrm{CO}_{2}$ for fixation in the Calvin cycle (Cakmak 2005; Zörb et al. 2014). Moreover, the processes involved in photosynthesis require a fine-tuned $\mathrm{pH}$ regulation because photosynthetic enzymes need a specific pH to function efficiently (Rumberg and Siggel 1969; Woodrow and Berry 1988). For instance, this is true for ribulose-1,5-bisphosphate (RuBP) carboxylase/oxygenase (Rubisco) as a key enzyme involved in photosynthetic carbon fixation. However, the maintenance of photosynthesis is also dependent on the export of photosynthates from source to sink organs. Under K deficiency, there can be an accumulation of sucrose in leaves, which result in a decline in photosynthetic activity (Hermans et al. 2006). The accumulation of sucrose in the leaves of K-deficient plants occurs due to an impaired phloem loading and transport of sucrose in phloem. For phloem loading, $\mathrm{K}$ is again needed for stabilizing a specified $\mathrm{pH}$ value for energy-providing ATP production, whereas for distribution of sucrose within the phloem, K establishes the needed osmotic pressure (Cakmak et al. 1994a). Based on the mentioned roles of $\mathrm{K}$ in enzyme regulation, photosynthesis and partitioning of carbohydrates within the plant, it can be assumed that a $\mathrm{K}$ has central relevance in the potato crop for establishing desired tuber and starch yields.

In addition, the form of $\mathrm{K}$ application — for example, as sulphate or chloride—can have tremendous effects on assimilate distribution and, therefore, on the important quality aspects of potato. In general, independent of the $\mathrm{K}$ source that is supplied (either as $\mathrm{K}_{2} \mathrm{SO}_{4}$ or $\mathrm{KCl}$ ), the yield can be increased with increasing $\mathrm{K}$ fertilization (Panique et al. 1997). But it is assumed that fertilization of $\mathrm{K}$ in chloride form leads to a higher osmotic potential in the crops, compared to the sulfate form, as the osmotically active chloride is accumulated in higher amounts than sulphate. This leads to higher water uptake and, therefore, higher vegetative growth. Higher vegetative growth rates, particularly of the above-ground plant parts, leads to an increased competition for assimilates between shoot and tuber, as the shoot is a strong sink for such assimilates. In addition, the chloride-induced high growth rates of the shoot as a result of 
increased water uptake leads to a dilution of $\mathrm{K}$ (and other nutrients) in the plant. As $\mathrm{K}$ is important for phloem loading and distribution processes in plants, such reduced $\mathrm{K}$ concentrations in the plant matter could impair assimilate translocation to the roots and, therefore, to the tubers (Beringer et al. 1990).

When $\mathrm{K}$ is depleted in the potato plant leaves start to develop chlorosis, even on leaf edges or in the form of dots (Zorn et al. 2016). As $\mathrm{K}$ is phloem-mobile, the symptoms of $\mathrm{K}$ deficiency occur first on older leaves because $\mathrm{K}$ will be translocated from older to younger developing leaves. In addition, an increased root-to-shoot ratio can be observed (Cakmak et al. 1994a; Cakmak et al. 1994b).

\section{Magnesium}

Magnesium $(\mathrm{Mg})$ can be designated as 'the forgotten element in crop production' as its supply and the need for are usually underestimated. But due to its several key roles, especially in photosynthesis, the partitioning of photoassimilates, protein synthesis, and enzyme regulation, $\mathrm{Mg}$ deficiency can lead to impaired growth and yield formation (Cakmak and Yazici 2010; Senbayram et al. 2015). Mg serves as a cation, together with K, in similar physiological processes - for example, in the regulation of the cation-anion balance — and as an osmotically active ion in the turgor regulation of cells (Marschner 2012). In addition, $\mathrm{Mg}$ contributes, like $\mathrm{K}$, to maintain a stable $\mathrm{pH}$ for proper activity of photosynthetic enzymes - for example, for Rubisco (Woodrow and Berry 1988; Yuguan et al. 2009). Moreover, Mg specifically binds to RuBP, and thereby, enhances its catalytic activity (Belknap and Portis 1986). Besides, Mg is an allosteric activator of more than 300 enzymes (Verbruggen and Hermans 2013; Senbayram et al. 2015). The most commonly known function of $\mathrm{Mg}$ in photosynthesis is its role as a central atom of the chlorophyll molecule - the organic molecule capable of scavenging sunlight and transforming it into electron transport, and, hence, chemical energy ( Walker and Weinstein 1994; Verbruggen and Hermans 2013). In protein synthesis, Mg is vital for bridging two subunits of ribosomes - the location of the translation of proteins - to its active form (Sperrazza and Spremulli 1983). One more essential role that $\mathrm{Mg}$ shares with $\mathrm{K}$ is located in the partitioning of carbohydrates. $\mathrm{Mg}$ is required for phloem loading with sucrose as it is an allosteric activator of ATPases, which create a proton gradient that provides energy for the transport of sucrose and protons via sucrose/ $\mathrm{H}^{+}$symporters (Hermans et al. 2005). As pointed out, $\mathrm{Mg}$ serves like $\mathrm{K}$ in crucial functions for photosynthesis and carbohydrate partitioning, why it can be presumed that also $\mathrm{Mg}$ is of main importance for establishing favored tuber and starch yields.

Cakmak et al. (1994a) and Ceylan et al. (2016) reported as a consequence of impaired phloem loading that plants which were deficient in $\mathrm{Mg}$ (and also $\mathrm{K}$ ) accumulated sucrose in the leaves, whereas simultaneously the concentration of 
sucrose in the phloem sap decreased. Evidence was also provided that particularly a re-supply of Mg to Mg-deficient plants for only one day was very effective in restoring the phloem transport of sucrose (Cakmak and Kirkby 2008). This rapid correction of the phloem transport system following a re-supply of $\mathrm{Mg}$ indicates that foliar applications of soluble $\mathrm{Mg}$ fertilizers in field crops can provide a fast and effective remedial treatment for $\mathrm{Mg}$ deficiency.

Furthermore, there is evidence that Mg has an impact on root growth and morphology, but with contradictory results. Cakmak et al. $(1994 a, b)$ showed a decrease in dry matter production in the roots compared to the shoots of bean plants grown in a nutrient solution under conditions of Mg deficiency, while Hermans et al. (2005) documented almost no effect on root biomass development after transferring sugar beet plants into an Mg-depleted nutrient solution. This might be explained by the fact that both authors used different approaches: Cakmak et al. (1994a, b) induced Mg deficiency already at germination or at a very early growth stage, while Hermans et al. (2005) grew their plants first under conditions of sufficient $\mathrm{Mg}$ supply before transferring them into an Mg-depleted nutrient solution. It seems as if plants are able to overcome $\mathrm{Mg}$ depletion in the later growth stages without any severe impact on the root growth or morphology when they had been earlier sufficiently supplied with Mg. The symptoms of Mg deficiency as well as $\mathrm{K}$ deficiency, can first be observed on older leaves as $\mathrm{Mg}$ can be easily translocated to active growing plant parts in the form of intercostal leaf vein chlorosis (Cakmak and Kirkby 2008; White and Broadley 2009; Gransee and Führs 2013). It is likely, depending on growth conditions, that under Mg depletion, plants develop an increased root-to-shoot ratio (Cakmak et al. 1994a, b).

\section{Potassium-magnesium antagonisms}

The competition of cations for uptake is a well-known phenomenon (Jacoby 1961; Diem and Godbold 1993; Fageria 2001; Marschner 2011; Chen and Ma 2013). One of the most commonly observed phenomena based on cation antagonism is $\mathrm{K}$-induced $\mathrm{Mg}$ deficiency. This could be the effect of the specificity of $\mathrm{K}$ transporters on the one hand and the unspecifity of $\mathrm{Mg}$ transporters on the other hand involved in $\mathrm{K}$ and $\mathrm{Mg}$ uptake from the soil solution. The delivery of $\mathrm{K}$ and $\mathrm{Mg}$ to the roots typically follows different mechanisms: While Mg mainly is delivered by massflow and to a smaller proportion by interception; K mainly is delivered by diffusion (Strebel and Duynisveld 1989; Barber 1995; Marschner 2011). To ensure delivery to the roots, plants need to decrease the K concentration in the soil solution of the rhizosphere in order to drive $\mathrm{K}$ flux to the roots via diffusion. In contrast, $\mathrm{Mg}$ is present in the soil solution in much higher concentrations. Hence, the delivery to the plant roots is mainly enabled by mass flow (Zhang and George 2002). It may occur that the delivery by mass flow is higher than the uptake by plants, which would result in the 
accumulation of Mg in the rhizosphere (Zhang and George 2002). In addition, Mg adsorbs less to the soil matrix due to its high hydrated radius and therefore can be leached out what reduces, compared to K for instance, the availability of $\mathrm{Mg}$ to the roots (Deng et al. 2006). However, the main reason leading to different uptake rates of $\mathrm{K}$ and $\mathrm{Mg}$ may be due to the unspecificity of $\mathrm{Mg}$ transporters, which also take up, beside $\mathrm{Mg}$, other cations like $\mathrm{K}$. Therefore, under high plant available $\mathrm{K}$ concentrations in the soil solution Mg uptake can be blocked while K uptake can be advantaged by Mg transporters (Gransee and Führs 2013). At the same time there are existing very specific K transporters which ensure, depending on the K concentration in the soil solution, K uptake as well at low (HATS $=\underline{\text { High }} \underline{\text { Affinity }} \underline{\text { Transport }}$

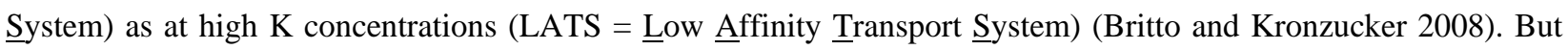
these specific K transporters do not transport Mg (Gransee and Führs 2013). Hence, while the uptake of K is ensured - even under low K concentrations - due to the uptake by specific K transport systems as well as by unspecific $\mathrm{Mg}$ transporters, $\mathrm{Mg}$ uptake can be impaired even if there is enough $\mathrm{Mg}$ available in the soil solution due to the unspecificity of $\mathrm{Mg}$ transporters as well as of $\mathrm{K}$ transporters for $\mathrm{Mg}$.

But with view on the described antagonistic effects, it is often wrongly concluded that particularly $\mathrm{K}$ and $\mathrm{Mg}$ should not be applied together in order to prevent antagonistic effects during uptake. However, this is the wrong conclusion, as can be seen in Figure 2: The yield of the control treatment receiving $\mathrm{Mg}$ in the form of $400 \mathrm{~kg} \mathrm{ha}^{-1}$ as Magnesiumsulphat (ESTA ${ }^{\circledR}$ Kieserit) but no K was higher than the yield of the plants that received the highest amount of $\mathrm{K}$ in the form of $300 \mathrm{~kg} \mathrm{~K}_{2} \mathrm{O}$ as $\mathrm{K}_{2} \mathrm{SO}_{4} \mathrm{ha}^{-1}$ but no $\mathrm{Mg}$. Moreover, in view of the comparably low soil $\mathrm{Mg}$ status, the high K supply further reduced Mg uptake by the potato plants. Hence, at least a slight Mg deficiency in the single $\mathrm{K}$ treatment could be expected, finally leading to a reduced yield. Only the combination of $\mathrm{K}$ and $\mathrm{Mg}$ supply revealed the highest yield. 


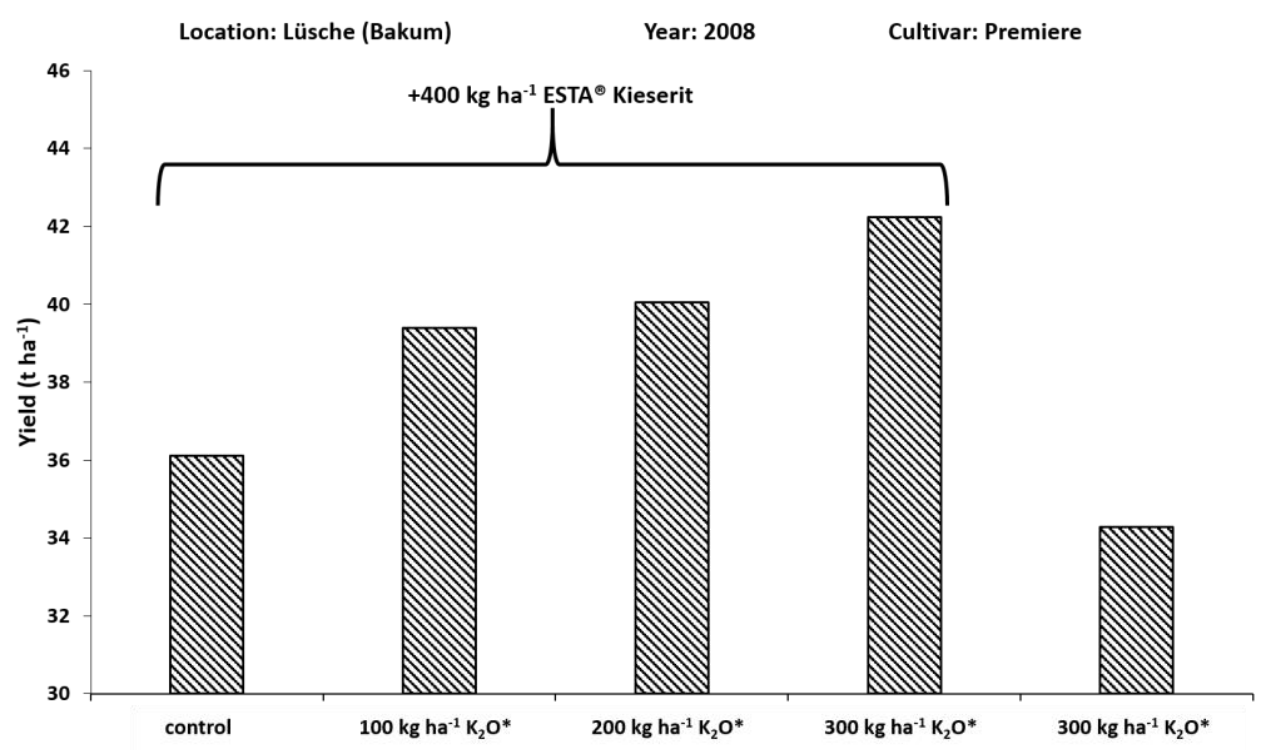

Figure 2: Effect of combined $\mathrm{K}$ and $\mathrm{Mg}$ fertilization on yield of potato. The experimental site was Lüsche (Bakum),

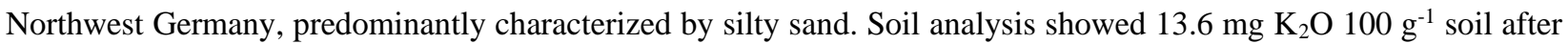
calcium acetate lactate $(\mathrm{CAL})$ extraction and $3.2 \mathrm{mg} \mathrm{Mg} / 100 \mathrm{~g}^{-1}$ soil after $\mathrm{CaCl}_{2}$ extraction; ESTA® Kieserit $=25 \%$ $\mathrm{MgO}$ (water-soluble) and 50\% $\mathrm{SO}_{3}$ (water soluble); *as KALISOP${ }^{\circledR}$ gran. $=50 \% \mathrm{~K}_{2} \mathrm{O}$ (water-soluble) and $45 \% \mathrm{SO}_{3}$ (water-soluble)

\section{Calcium}

Calcium $(\mathrm{Ca})$ is essential for the potato crop mainly due to its role in cell wall and membrane stabilization (Kirkby and Pilbeam 1984; White and Broadley 2003), its function as a counter-cation for inorganic and organic anions in the vacuole (White and Broadley 2003; Marschner 2011), and as a second messenger in intracellular signal transduction processes (Pottosin and Schonknecht 2007).

The most abundant polysaccharide of primary cell walls is pectin (Jarvis 1984). Due to its divalent nature, Ca is able to form a bridge between the galacturonates of pectin via carboxylate groups, thus contributing to the characteristic structure of cell walls (Subramanian et al. 2011). Besides the structural function in cell walls, Ca is fundamental for the stability of membranes. Here, it bridges the phosphate and carboxylate groups of phospholipids and proteins at membrane surfaces ( Legge et al. 1982; Kirkby and Pilbeam 1984). Based on these roles for stabilizing membranes it can be suspected that $\mathrm{Ca}$ is also of importance for establishing and maintaining potato skin firmness, for instance.

Ca has extremely low cytosolic concentrations of less than $1 \mu \mathrm{M}$. A major part of $\mathrm{Ca}$ is present in bound form—to cell walls, for instance. However, the most water-soluble $\mathrm{Ca}$ is stored in vacuoles (Pottosin and Schonknecht 2007), where it contributes to the anion-cation balance (White and Broadley 2003; Marschner 2011). The resulting huge concentration differences between cytosol and vacuole form the basis for $\mathrm{Ca}$ 's role as a second messenger (Pottosin 
and Schonknecht 2007). Ca enables the plant to communicate information about the environment at the plant cell level (Whalley and Knight 2013). This forwarding of information can be triggered by different abiotic and biotic stimuli of the surrounding outside environment like, drought or oxidative stress as well as pathogens (McAinsh and Pittman 2009). Due to Ca's roles in stabilizing the plant cell wall and membranes, and as a second messenger, Ca can contribute towards reducing disease severity (Ngadze et al. 2014).

The potato crop is known to tolerate low soil $\mathrm{pH}$ values and is often grown under very acidic soil conditions, for example at pH values of 4.6 (van Lierop et al. 1982; Lazarevic et al. 2014). Although liming usually can increase potato yields, people often refrain from liming these soils—as soils with higher $\mathrm{pH}$-values could favor the development of common scab (Streptomyces spp.) (van Lierop et al. 1982; Waterer 2002). However, there may arise other and severe problems related to low soil $\mathrm{pH}$ conditions why it is difficult to determine a recommendation for an ideal $\mathrm{pH}$ value for growing potatoes. The acidification of soils is frequently associated with deficiency of essential plant cations like $\mathrm{Ca}$ and $\mathrm{Mg}$ due to an antagonistic and inhibited uptake of these cations by metals like aluminum (Al) and manganese (Mn). Moreover, $\mathrm{Al}$ and $\mathrm{Mn}$ can cause toxic reactions in the plant. Therefore, under acidic soil conditions, liming with materials such as $\mathrm{CaCO}_{3}, \mathrm{CaO}$, or $\mathrm{Ca}(\mathrm{OH})_{2}$ can not only improve the supply of $\mathrm{Ca}$ but also neutralize the soil $\mathrm{pH}$ and reduce the risk of $\mathrm{Al}$ or Mn toxicity in the plant (Mengel and Kirkby 2001; Lazarevic et al. 2014). On the other hand, when $\mathrm{pH}$ is raised it is possible that essential plant nutrients—-like phosphorus or zinc — can be less plant available (Haynes 1990).

Ca moves within the plant via the xylem; therefore, $\mathrm{Ca}$ transport strongly depends on the transpiration of the plant ( White and Broadley 2003; Subramanian et al. 2011). There are studies available that indicate Ca concentrations also in phloem sap but without further transport (Clarkson 1984). Clarkson (1984) argue these observations with the fact that $\mathrm{Ca}$ easily interacts with macromolecules and therefore transport must occur along extracellular pathways together with water. In addition, $\mathrm{Ca}$ cannot be translocated from older to younger leaves, as $\mathrm{Ca}$ is not mobile within the phloem and young leaves usually have a low transpiration rate. Consequently, deficiency symptoms regularly occur first on young leaves (White and Broadley 2003). Potato tubers have very low Ca concentrations, which can also be attributed to Ca transport mainly occurring via the xylem and the fact that tubers transpiring very less. The most $\mathrm{Ca}$ is distributed in the aboveground parts of the plant (Ozgen et al. 2006; Kärenlampi and White 2009). Besides growth reduction, a Ca deficiency can appear as browning phenomena or severe necrosis of the plant tissue (Brown et al. 2012). 


\section{Sulphur}

Compared to other crops, like the Brassica species, potato has a comparatively low demand for S, but several highyielding years can remove considerable amounts of S from the soil (Barczak and Nowak 2015; Klikocka et al. 2015; Koprivova and Kopriva 2016). In addition, $\mathrm{S}$ is essential for many cellular metabolites and, therefore, often represents the nutrient that limits plant yield and quality (Koprivova and Kopriva 2016). For instance, $\mathrm{S}$ is a component of amino acids like methionine and cysteine, which are the essential building blocks of proteins (De Kok et al. 2005; Galili and Amir 2013) or of the vitamins biotin and thiamine (Imsande 1998).

Although atmospheric $\mathrm{S}$ can be absorbed by higher plants in the form of $\mathrm{SO}_{2}$, the highest amount of $\mathrm{S}$ is absorbed by the roots (De Kok et al. 2005). Atmospheric S concentrations strongly depend on anthropogenic $\mathrm{SO}_{2}$ emissions and vary among continents and regions (Smith et al. 2011). While there has been a decrease in emissions by up to 50\% in the last years in USA, Canada, and Central and Western Europe, there has been a two or three fold increase in emissions in Africa, China, Australia and New Zealand, for instance. Plants with S deficiency develop a similar yellowish phenotype, as described under $\mathrm{N}$ deficiency, for example. Both are based on a loss of chlorophyll. Though under $\mathrm{S}$ deficiency there is no direct impact on chlorophyll, an S deficiency inhibits the synthesis of thylakoid membranes and, therefore, promotes chlorophyll deficiency (Imsande 1998). S can be translocated within the plant via both phloem and xylem although, translocation via the phloem from older to younger leaves can be restricted. This is why deficiency symptoms (as yellowing similar N deficiency) often occur first on younger leaves (Mengel and Kirkby 2001).

\section{Approaches to develop fertilization recommendations}

There are numerous approaches for developing fertilization recommendations. Describing such approaches is beyond the scope of this review but they are described in detail by Marschner (2011), for instance. The most used approaches are soil analysis, plant analysis, or both in order to get information on the potential and/or actual nutritional level at a given production site. Some approaches include yield expectations, crop rotation and fertilization history, and additional site-specific parameters as well (Table 2). In general, both plant and soil analyses have advantages and disadvantages. Soil analysis gives an idea of the potential actual nutrient availability to the crop, but cannot forecast the availability. Plant analysis gives a good indication of the actual nutritional level of the crop, but does not provide information on the actual availability of nutrients to the crop. Hence, where applicable, soil and plant analysis in combination —when performed regularly—allows the development of the most reliable fertilization recommendations. 
Table 2: Fertilization recommendations of different production areas in Europe, South Africa, and India. Shown are the locally recommended amounts of nutrients for potato production derived from the region-specific fertilization recommendation system. The procedure applied to develop a fertilization recommendation differs among regions.

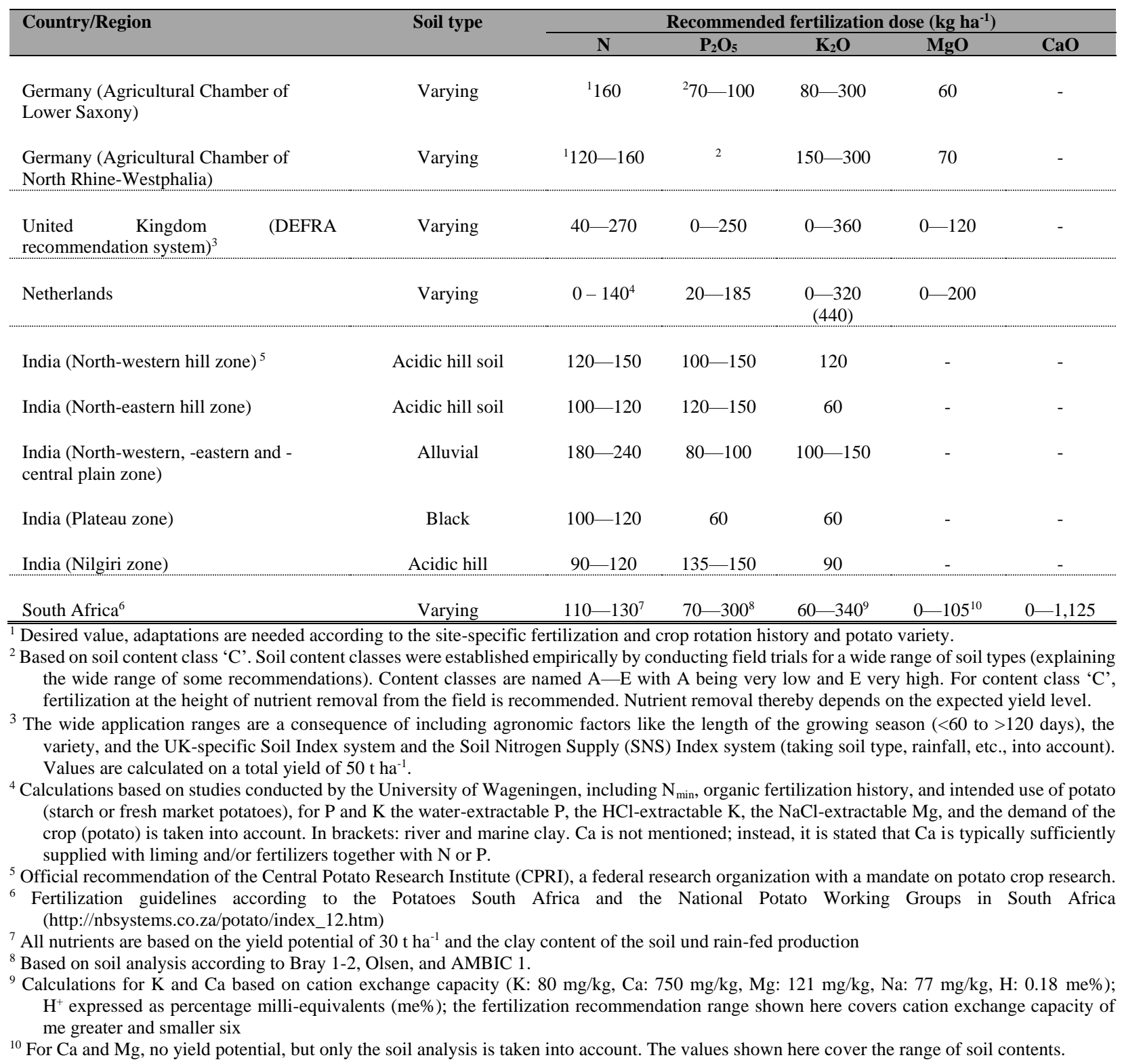

\section{Conclusion}

Beside other agronomic strategies, an adequate supply of nutrients is of main importance for achieving desired potato yield. In order to find the optimal level of nutrient supply it is important to understand and know basic laws of nutrient management, the individual physiological functions of each nutrient and resulting features, like nutrient antagonism for instance. Based on this fundamental knowledge the potato grower can decide for an accurate choice and application of fertilizers. 


\section{Chapter 3}

\section{The importance of nutrient management for potato production \\ Part II: Plant nutrition and quality parameters}

Marcel Naumann, Mirjam Koch, Heike Thiel, Andreas Gransee and Elke Pawelzik

Submitted 


\title{
The importance of nutrient management for potato production Part II: Plant nutrition and quality parameters
}

\author{
Marcel Naumann ${ }^{1}$, Mirjam Koch ${ }^{1}$, Heike Thiel $^{2}$, Andreas Gransee $^{2}$ and Elke Pawelzik ${ }^{*}$ \\ ${ }^{1}$ Quality of Plant Products, Department of Crop Sciences, Faculty of Agricultural Sciences, University of \\ Goettingen, Carl-Sprengel-Weg 1, 37075 Goettingen \\ ${ }^{2} \mathrm{~K}+\mathrm{S}$ KALI GmbH, Bertha-von-Suttner-Str. 7, 34131 Kassel, Germany
}

*Corresponding author: epawelz@gwdg.de

\begin{abstract}
In the first part of these reviews, the focus was on yield and related parameters, as affected by nutrient management, which formed part of an agronomic strategy for potato production. The focus of the second review is on the quality of potato production. The term 'quality' is a complex parameter in potato production and the desired quality traits depend heavily on the intended use. Important quality traits for potatoes are dry matter and starch content, as well as firmness and resistance against mechanical stress—-for example, during harvest. These quality traits are closely interrelated. It has been demonstrated that all these parameters are also strongly linked to the nutrient status of the plant and/or the tubers. Another important factor is the susceptibility to the formation of discolorations in potatoes for both fresh market and processing. In principle, enzymatic and non-enzymatic processes cause such undesired discolorations as 'black spot bruising' and 'after-cooking darkening'. The potential of formation of carcinogenic compounds like acrylamide from precursors during the deep-frying of potato products and the accumulation of toxic substances like glycoalkaloids represent important quality criteria. The effect of fertilization management on these various quality aspects is addressed and important nutrients are highlighted.
\end{abstract}

Keywords: nutrient management, potato quality parameters, discoloration, fresh market, processing quality 


\section{Introduction}

The nutrient composition and other quality traits of potato tubers are influenced by the supply and availability of macro- and micronutrients. However, the impact of nutrients on potato quality is influenced or overlapped by many other factors. The fertilization management and nutrient availability for the plant has a certain effect on tuber yield and size as well as on the content of N-compounds (Pawelzik and Möller 2014). Many studies emphasize besides the nutrient management the effect of individual characteristics of the cultivar and/or interaction with environmental factors (e.g. Bártová et al. 2013; Lombardo et al. 2013; Brazinskiene et al. 2014). The aim of the second part of this review is to evaluate the current state of knowledge about the functions of potassium, magnesium, and nitrogen in plant physiology with focus on potato quality formation but not in relation to interactions with other environmental factors.

\section{Important potato quality traits}

Particularly in potato production, the term 'quality' is a multifaceted trait that depends heavily on the intended use of the final product ( Talburt and Smith 1987; Hiltrop 1999; Gerendas and Führs 2013). For potatoes used for fresh consumption, among the external quality parameters, even the cooking type-described as floury or mealy, medium, waxy or hard-boiling - is important. The cooking type as an internal quality trait is mainly determined and influenced by the starch content, which, in turn, is positively correlated with the specific gravity and the dry matter content of the tubers (Smith 1977; Talburt and Smith 1987; Feltran et al. 2004). When potatoes are produced for starch production, the starch concentration in the tubers is the most important quality parameter. Meanwhile, the dry matter content represents an important quality criterion when producing potatoes for further processing, such as for French fries or crisps. High dry matter content and its distribution within the tuber ensure a lower oil absorption, which results in a higher yield per unit of oil and improves the texture and shape of the product (Kita 2014). In addition to the various internal quality traits described here, the tendency of potatoes to form undesirable discolorations of various origins represents an important quality criterion. The mechanical impact on potato tubers during harvest and post-harvest handling causes, besides external damage and physiological aging during storage, also the internal discoloration of tuber tissue. Enzymatic oxidative processes lead to black spot incidence, especially in the tissue beneath the perimedullary tissue — inside the vascular ring (Baritelle and Hyde 2003). Upon mechanical impact, free phenolic compounds are oxidized by polyphenol oxidases (PPOs) to dopaquinone. These will be transformed to the dark pigment melanin (McGarry et al. 1996). 
Figure 3 shows a schematic illustration of these processes. The same reaction occurs during the processing of raw potatoes and it is called as raw pulp discoloration. Beside enzymatic caused reactions the discoloration of potato tuber products can be caused non-enzymatically during the Maillard reaction and as after-cooking darkening. The Maillard reaction takes place during the frying and baking of potato products (crisps, French fries, baked potatoes), processes that involve reducing sugars (e.g. glucose, fructose) and amino acids. This non-enzymatic browning reaction influences flavor, color, and aroma formation (Belitz et al. 2009). When the reducing sugars specifically react with asparagine, the reaction intermediates may form acrylamide. Acrylamide is known to be neurotoxic and carcinogenic, thus indicating potential risks to human health ( Rice 2005; Medeiros Vinci et al. 2012). The after-cooking darkening of potato tubers is an undesirable quality trait, which may occur when tubers are exposed to air after boiling (WangPruski and Nowak 2004). The darkening is a result of the reaction of chlorogenic acid and ferric ions in presence of oxygen, leading to a bluish-grey color (Smith 1977).

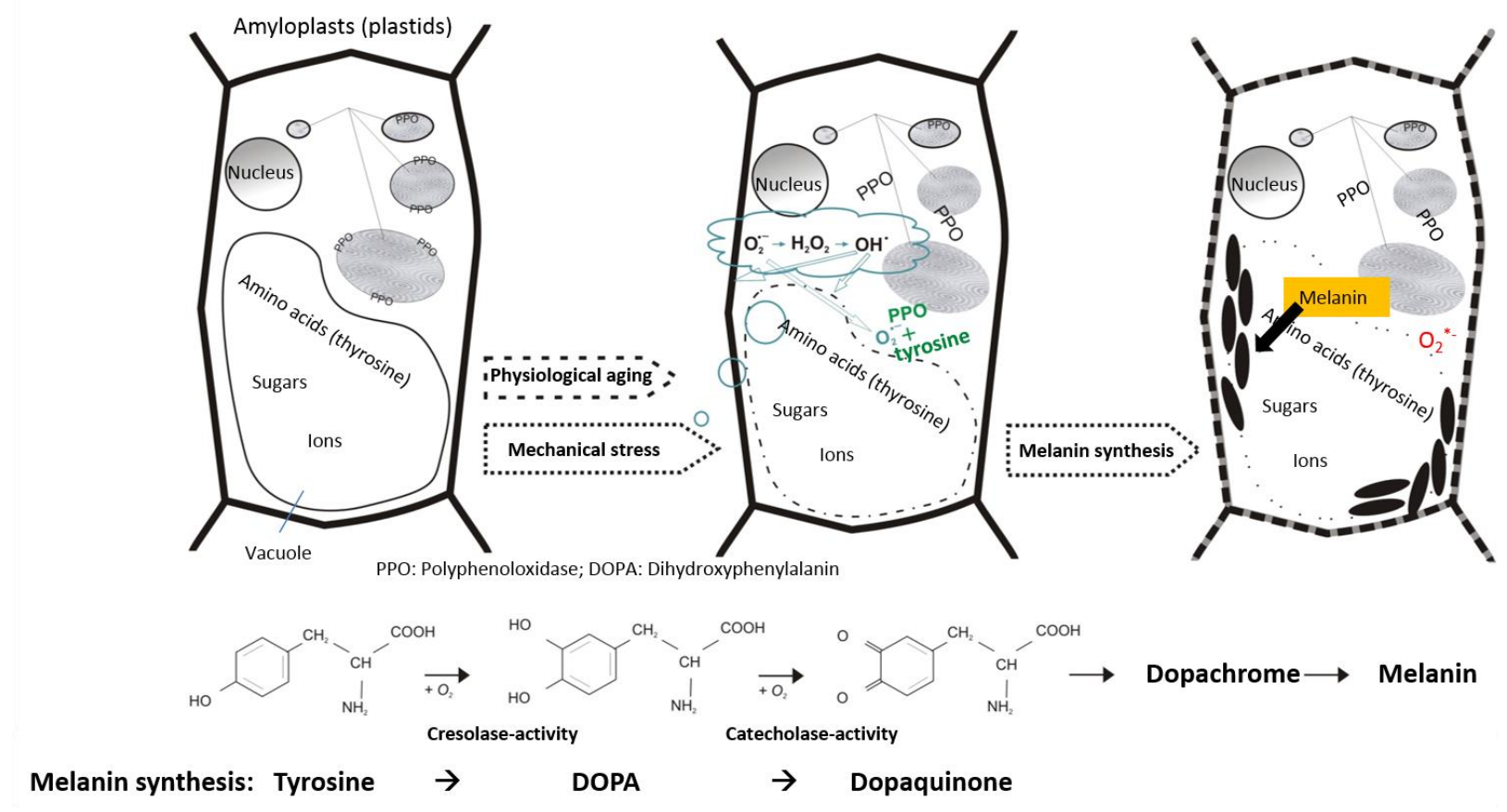

Figure 3: Mechanism leading to black spot formation (adapted from Ernst et al. (2008)).

Glycoalkaloids are potentially health-threatening compounds in potatoes. They occur in the tubers mainly as alphasolanine and alpha-chaconine. A glycoalkaloid content higher than $100 \mathrm{mg} / \mathrm{kg}$ fresh weight (FW) leads to a bitter flavor 
in potatoes (Friedman 2006). Most importantly, as they are toxic for humans (McMillan and Thompson 1979), the recommended safety level for human consumption is $200 \mathrm{mg} / \mathrm{kg}$ FW since many years (FAO/WHO 2011).

In addition, the accumulation of glycoalkaloids is associated with the greening of tubers (Maga and Fitzpatrick 1980), as both are light-induced processes (Bamberg et al. 2015). But a link between the two processes does not exist (Edwards et al. 1998). The greening of tubers occur due to non-toxic chlorophyll formation, and therefore, greening can be used as a helpful indicator that tubers have been exposed to light and, thus, should not be consumed anymore (Bamberg et al. 2015). But glycoalkaloid formation can also occur in even the non-green parts of tubers. That is why it is agreed that glycoalkaloid formation and the greening of potatoes are physiologically unrelated processes (Dao and Friedman 1994; Edwards and Cobb 1999). Figure 4 gives an overview about potato tuber properties as affected by important macronutrients. Particularly the fertilization strategy has a substantial impact on important potato quality parameters (Marschner 2012). Especially for the macronutrients $\mathrm{K}, \mathrm{Mg}$ and $\mathrm{N}$ various studies over the last 40 years showed a direct impact on important quality traits of potatoes. But the results of these studies usually show varying responses to nutrient supply, as illustrated for Mg in Table 3.

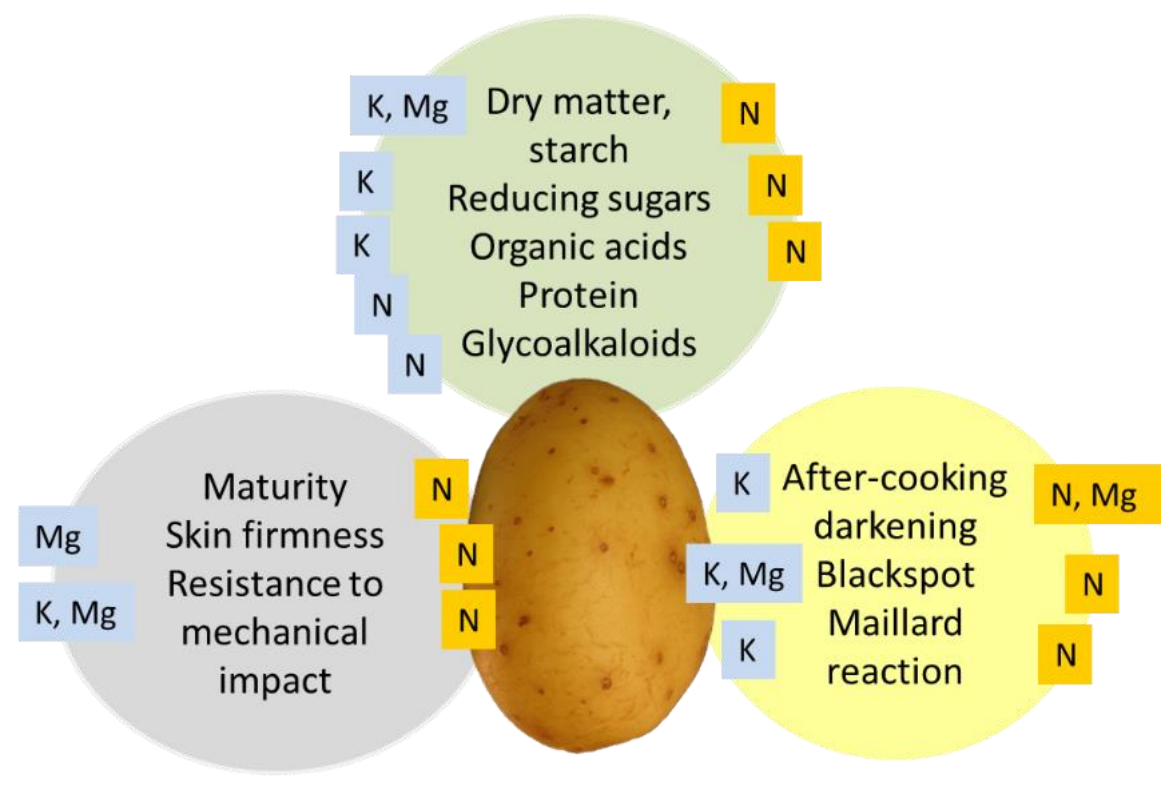

Figure 4: Potato tuber quality properties as affected by macronutrient supply: traits (grey), main compounds (green) and susceptibility to discoloration (yellow) of tubers and food. Blue: positive effects, orange: negative effects of minerals. 
Table 3: Contribution of increasing Mg supply to yield, quality formation, and storability of potato tubers shown as relative changes compared to the control; green-red scale represents increased or decreased of the trait, while yellow represents no change.

\begin{tabular}{|c|c|c|c|}
\hline Trait & $\begin{array}{l}\text { Changes by } \\
\text { increasing } \mathrm{Mg} \\
\text { supply compared to } \\
\text { control samples }\end{array}$ & $\begin{array}{l}\text { Mg supply, field }(\mathrm{F}) \\
\text { or pot }(\mathrm{P}) \text { experiments }\end{array}$ & References \\
\hline \multirow[t]{4}{*}{ Dry matter } & $+(40-50 \%)$ & $0-0.3 \mathrm{~g} /$ pot, $(\mathrm{P})$ & Addiscott (1974) \\
\hline & $\infty$ & $0-60 \mathrm{~kg} / \mathrm{ha},(\mathrm{P})$ & Miča (1979) \\
\hline & $+(5-8 \%)$ & $0-100 \mathrm{~kg} / \mathrm{ha},(\mathrm{F})$ & $\begin{array}{l}\text { Poberezny and Wszelaczynska } \\
\text { (2011) }\end{array}$ \\
\hline & $\infty$ & $0-60 \mathrm{~kg} / \mathrm{ha},(\mathrm{F})$ & Miča and Vokal (1983) \\
\hline \multirow[t]{3}{*}{ Starch } & $\infty$ & $0-60 \mathrm{~kg} / \mathrm{ha},(\mathrm{P})$ & Miča (1979) \\
\hline & $+(0.5 \%)$ & $0-100 \mathrm{~kg} / \mathrm{ha},(\mathrm{F})$ & $\begin{array}{l}\text { Poberezny and Wszelaczynska } \\
\text { (2011) }\end{array}$ \\
\hline & $\infty$ & $0-60 \mathrm{~kg} / \mathrm{ha},(\mathrm{F})$ & Miča and Vokal (1983) \\
\hline \multirow[t]{2}{*}{ Nitrate } & $-(0.5-10 \%)$ & $0-75 \mathrm{~kg} / \mathrm{ha},(\mathrm{F})$ & Rogozińska et al. (2005) \\
\hline & $\infty$ & $0,56 \mathrm{~kg} / \mathrm{ha},(\mathrm{F})$ & Mondy and Ponnampalam (1985) \\
\hline \multirow[t]{3}{*}{ Glycoalkaloids } & $+(70-200 \%)$ & $0-112 \mathrm{~kg} / \mathrm{ha},(\mathrm{F})$ & Evans and Mondy (1984) \\
\hline & $+(50-70 \%)$ & $0,56 \mathrm{~kg} / \mathrm{ha},(\mathrm{F})$ & Mondy and Ponnampalam (1985) \\
\hline & $\infty$ & $0-40 \mathrm{~kg} / \mathrm{ha},(\mathrm{F})$ & Rogozińska and Wojdya (1999) \\
\hline Phenols & $-(10-20 \%)$ & $\begin{array}{l}0,56 \mathrm{~kg} / \mathrm{ha},(\mathrm{F}) \\
0-112 \mathrm{~kg} / \mathrm{ha},(\mathrm{F})\end{array}$ & $\begin{array}{l}\text { Mondy et al. (1987) } \\
\text { Klein et al. (1981) }\end{array}$ \\
\hline Lipids & $+(0.5-10 \%)$ & $\begin{array}{l}0,56 \mathrm{~kg} / \mathrm{ha},(\mathrm{F}) \\
0-112 \mathrm{~kg} / \mathrm{ha},(\mathrm{F})\end{array}$ & $\begin{array}{l}\text { Mondy et al. (1987) } \\
\text { Klein et al. (1981) }\end{array}$ \\
\hline
\end{tabular}

Changes in yield and content of quality traits: + increase, - decrease, $\infty$ no trend

The following passage aims to provide an overview of the most crucial impacts of $\mathrm{K}, \mathrm{Mg}$, and $\mathrm{N}$ on potato quality traits while considering results that are either contradictory or could not yet to be proven.

\section{Potassium}

Potassium (K) has an important impact on tuber quality. It acts as an osmotically active ion so that its accumulation in the cytosol drives water uptake into the cell and increases the cell turgor. Also, it contributes substantially to the equilibrium of soluble and insoluble ions (Marschner 2011). The positive effect of K supply on the content of organic acids as ascorbic acid in the tuber is well known (e.g. Hamouz et al. 2009). An average K concentration in tubers of about $2.2-2.5 \%$ dry weight (DW) is assumed to be optimal for high yield and good quality (Winkelmann 1992). Field trials conducted by K+S KALI GmbH in Germany in 2002 and 2004 have also shown that an increased K supply increased the ascorbic acid concentration in tubers (Figure 5). By increasing the cell turgor in the tuber the risk of 
internal enzymatic discoloration (black spot; shown in Figure 3) caused by mechanical impact stresses potentially decreases (Praeger et al. 2009) (Figure 6). As ascorbic acid counteracts the formation of reactive oxygen species, it may be involved in limiting the enzymatic formation of melanin (Delgado et al. 2001). In addition, high ascorbic acid contents in potato tubers can be regarded as a positive quality trait because the antioxidative capacity of ascorbic acid has a positive impact on human health as well (Delgado et al. 2001).

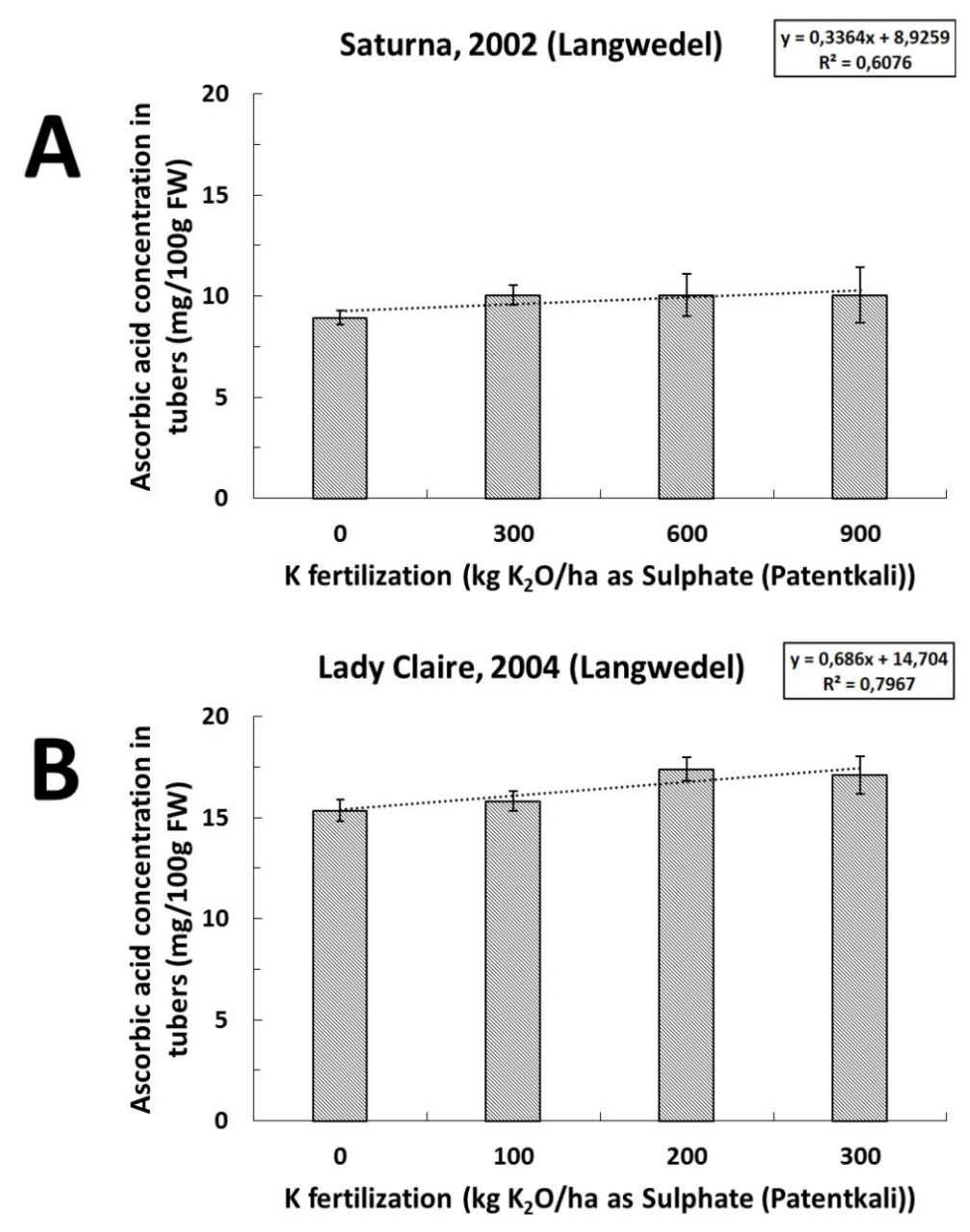

Figure 5: Effect of increasing $K$ supply on the ascorbic acid content of potato tubers; (A) cultivar: Saturna; year of cultivation: 2002; experimental site: Langwedel (Lowery saxony, Germany); (B) cultivar: Lady Claire; year of cultivation: 2004; experimental site: Langwedel (Lowery saxony, Germany). 


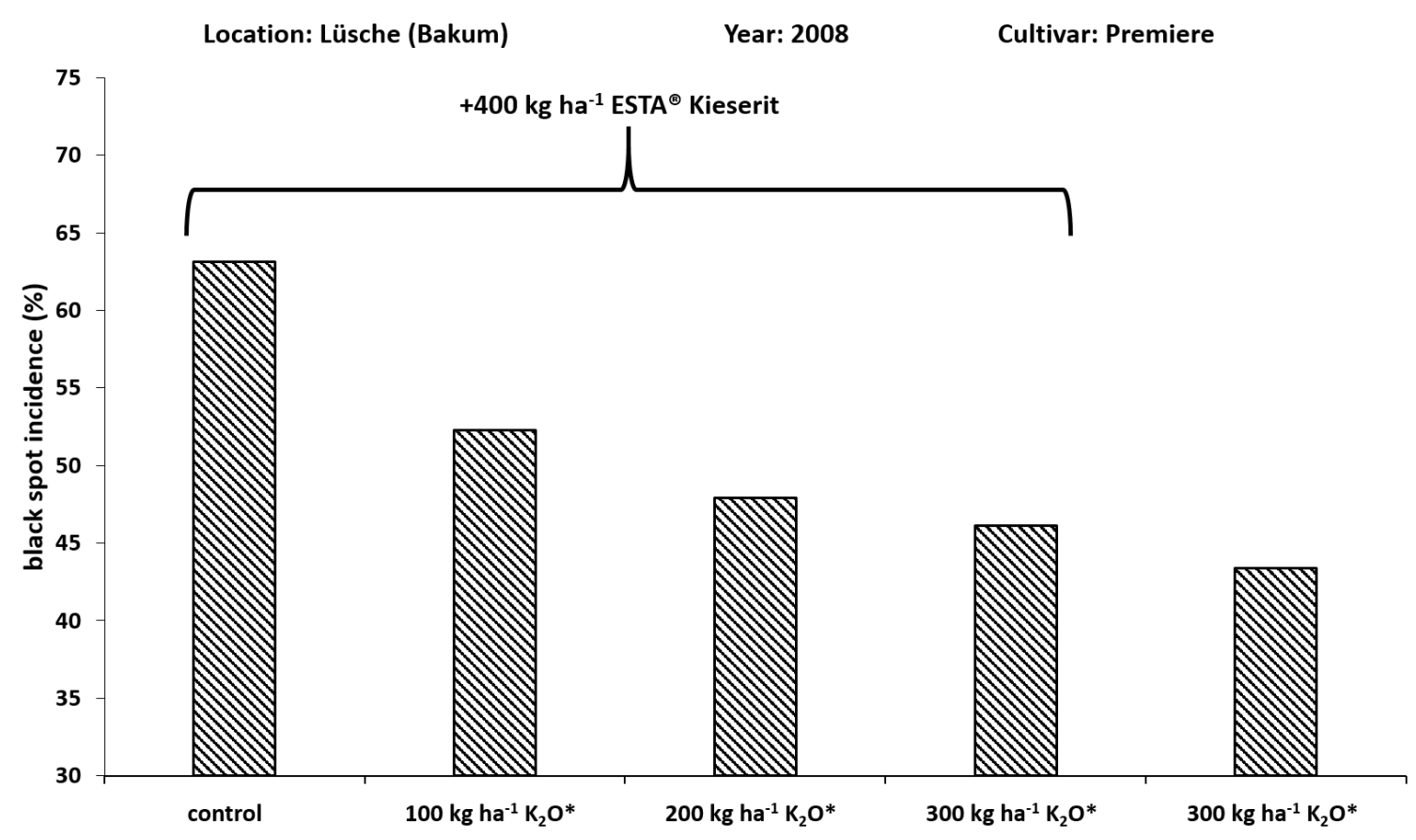

Figure 6: Effect of combined $\mathrm{K}$ and $\mathrm{Mg}$ fertilization on black spot incidence. The experimental site was Lüsche (Bakum), Northwest Germany, predominantly characterized by silty sand. Soil analysis showed $13.6 \mathrm{mg} \mathrm{K}_{2}{\mathrm{O} 100 \mathrm{~g} \mathrm{~g}^{-1}}^{-1}$ soil after calcium acetate lactate (CAL) extraction and $3.2 \mathrm{mg} \mathrm{Mg} / 100 \mathrm{~g}^{-1}$ soil after $\mathrm{CaCl}_{2}$ extraction; ESTA® Kieserit $=25 \% \mathrm{MgO}$ (water-soluble) and $50 \% \mathrm{SO}_{3}$ (water soluble); *as KALISOP® gran. $=50 \% \mathrm{~K}_{2} \mathrm{O}$ (water-soluble) and $45 \% \mathrm{SO}_{3}$ (water-soluble).

Increasing K concentration in tubers, generated by K supply, lead to lower content of reducing sugars (Figure 7) which are important precursors of acrylamide formation during Maillard reaction (Matthäus and Haase 2014). The cause of the after-cooking darkening can be encountered through high contents of citric acid, as citric acid competes with the phenolic compound chlorogenic acid to bind ferric ions (in fact, citric acid is in plants the transport form of Fe) (WangPruski and Nowak 2004). Indeed, in potato, a positive correlation between the K content in tubers and the citric acid content was also found in field trials in 2002 and 2004 (Figure 8). 


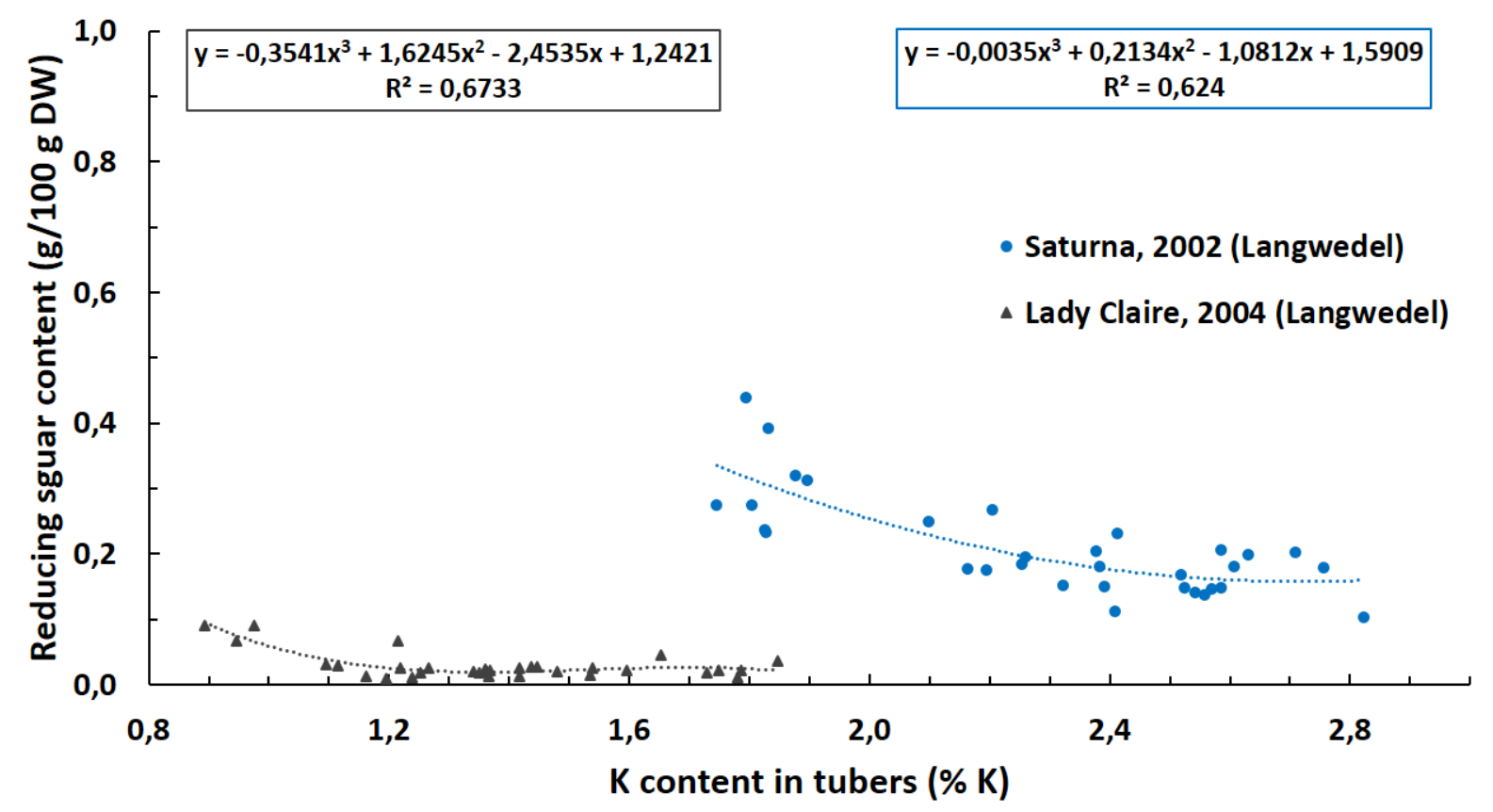

Figure 7: Effect of increasing K concentration in potato tubers on the reducing sugar content of potato tubers. Data from $\mathrm{K}+\mathrm{S}$ KALI GmbH, unpublished.

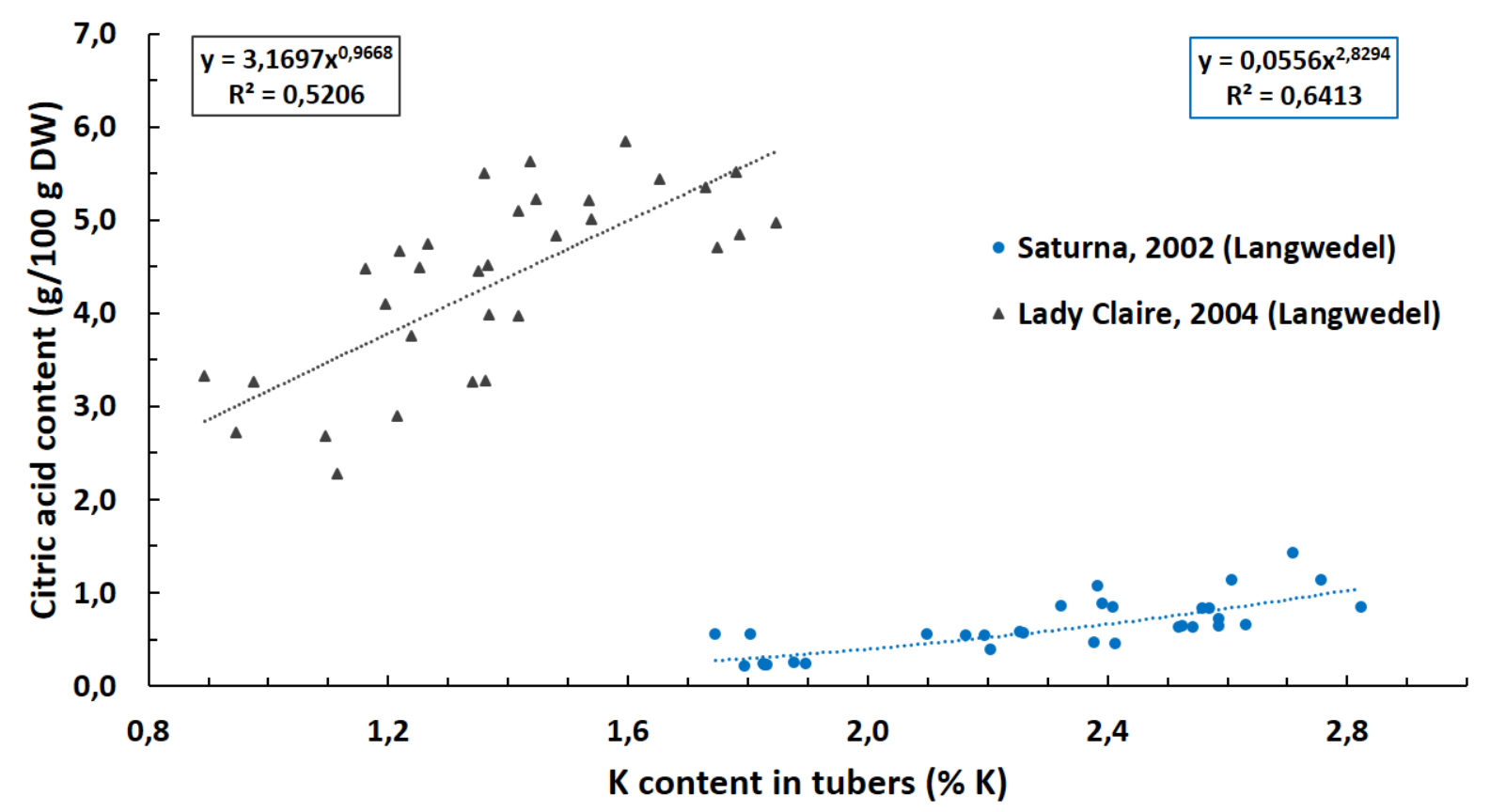

Figure 8: Effect of increasing K concentration in potato tubers on the citric acid content of potato tubers. Data from $\mathrm{K}+\mathrm{S}$ KALI GmbH, unpublished. 
As $\mathrm{K}$ is involved in many physiological processes, including enzyme-activation processes, a deficiency of $\mathrm{K}$ can lead to the accumulation of low-molecular-weight compounds, such as soluble sugars, organic acids, or amino acids, and decrease the synthesis of high-molecular-weight compounds, such as proteins, starches, or cellulose (Wang et al. 2013). For instance, $\mathrm{K}$ is required for the activity of starch synthase; therefore, a deficit of $\mathrm{K}$ can limit the formation of starch (Nitsos and Evans 1969; Subramanian et al. 2011), impair the ATP formation and the phloem loading of carbohydrates and increase the plant respiration as well (Römheld and Kirkby 2010; Marschner 2011); hence, the formation of potato tubers can be delayed and restricted, particularly under very severe K deficiency stress. Considering the effect of $\mathrm{K}$ supply on glycolalkaloids, Ahmed and Müller (1979) ascertained a decreasing effect of increasing K supply on the glycoalkaloid content of tubers, whereas the contents in leaves and stems remained unaffected. The storability of potatoes is positive influenced by K supply. Poberezny and Wszelaczynska (2011) showed that intermediate K doses ranging from $0-240 \mathrm{~kg} \mathrm{~K}_{2} \mathrm{O} \mathrm{ha}{ }^{-1}$ (optimum: $160 \mathrm{~kg} \mathrm{~K}_{2} \mathrm{O} \mathrm{ha}^{-1}$ ) reduced fresh weight losses in two mid-early cultivars during their storage for six months.

The form of $\mathbf{K}$ application particularly—-for example as sulphate or chloride—has a significant impact on tuber quality traits. Figure 9 summarizes the effect of different $\mathrm{K}$ fertilizers on yield, starch yield, and starch content. Independent of the $\mathrm{K}$-form supplied (either as $\mathrm{K}_{2} \mathrm{SO}_{4}$ or $\mathrm{KCl}$ ), the yield is increased with increasing $\mathrm{K}$ fertilization. However, fertilization with $\mathrm{KCl}$ reduced the starch content of the potatoes by about $2 \%$, finally leading to a starch yield that was about $1 \mathrm{t} \mathrm{ha}^{-1}$ lower than after $\mathrm{K}$ application in the sulphate form. What could be the reason for this phenomenon? It is assumed that application of $\mathrm{K}$ in chloride form leads - in comparison to the sulphate form - to a lower osmotic potential in crops, as the osmotically active chloride is accumulated in higher amounts than sulphate; subsequently, it leads to a higher water uptake and, therefore, a higher vegetative growth. Higher vegetative growth rates, particularly of the above-ground plant parts, lead to an increasing competition for assimilates between shoot and tubers, as the shoot is a strong sink for such assimilates $\mathrm{K}$ is also osmotically active (Marschner 2011). Hence, a very high accumulation of $\mathrm{K}$ in tubers leads to an increased uptake of water by the tuber, which can result in a dilution of the starch content independent of the form of $\mathrm{K}$ application. 


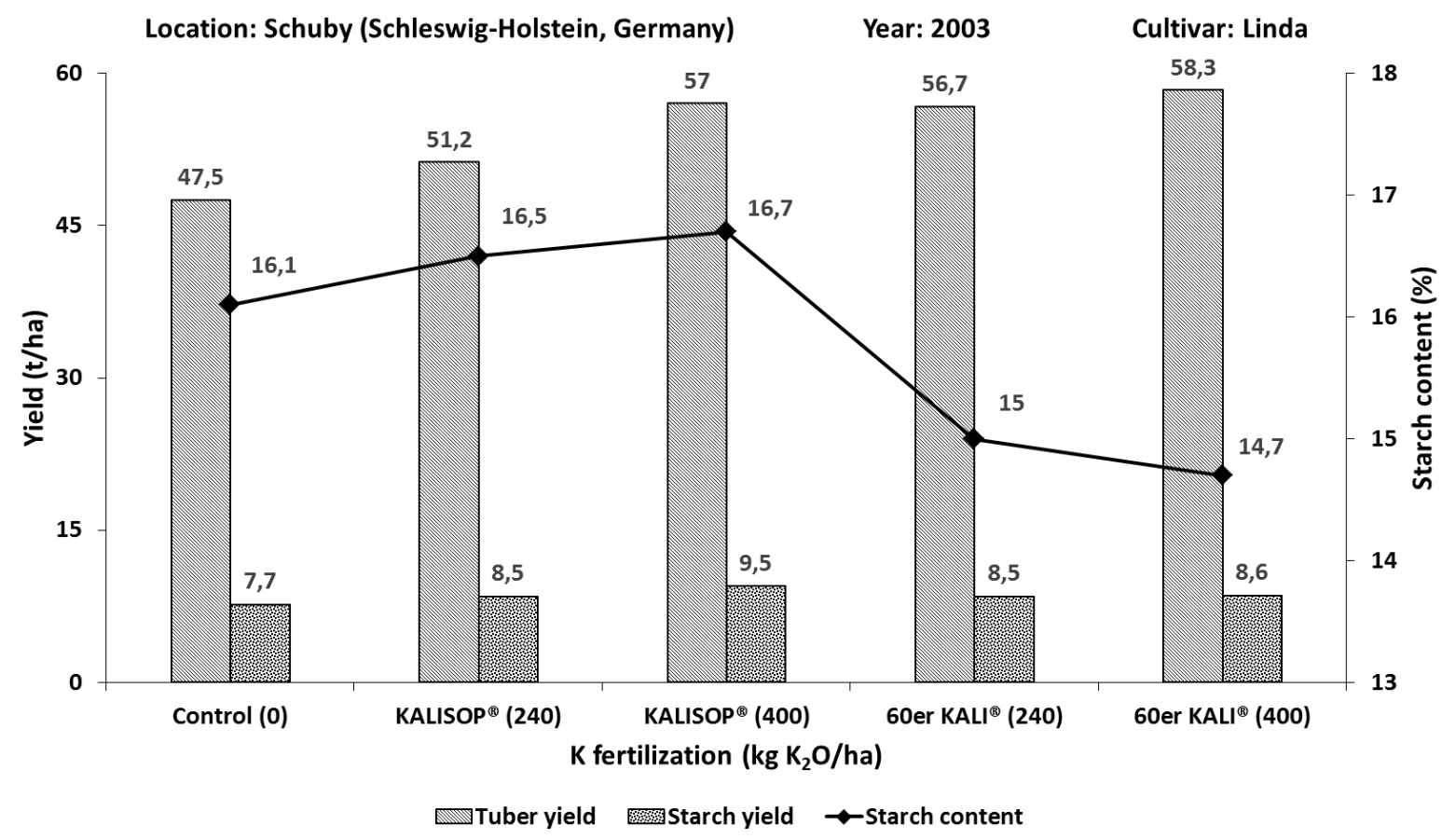

Figure 9: Effect of increasing K supply either as sulphate or as chloride on yield, starch yield, and starch content of potato; Mg supply in all variants: $320 \mathrm{~kg}$ ha-1 ESTA® Kieserit gran.. Data from the Agricultural Chamber of Lower Saxony, Germany, 2003.

\section{Magnesium}

Limited studies are available to review the functions of $\mathrm{Mg}$ on tuber quality. $\mathrm{Mg}$ might contribute to the stabilization of cell wall associations (Andersson et al. 1994) and it can be assumed that Mg tends to improve the resistance towards mechanical stress that affect tubers. Findings regarding the effect of Mg supply on enzymatic discoloration and the accumulation of minor compounds are not consistent, as reviewed by Gerendas and Führs (2013). For example, Klein et al. (1981) found that fertilization with $\mathrm{MgSO}_{4}$ reduced enzymatic discoloration and the concentration of phenolics, whereas Mondy et al. (1967) showed a positive correlation between them. These contradictory results may indicate that possible interactions with other production system-related factors may mask the involvement of $\mathrm{Mg}$ in this specific quality response. It is commonly known that the enzymatic cascade finally leading to melanin formation and, subsequently, to black spot occurrence is inhibited by a low pH value and antioxidants (Altunkaya and Gökmen 2008). As proof of concept, increasing citric and/or ascorbic acid in the tubers contribute to the reduction of enzymatic discolorations. The synthesis of ascorbic acid originates from glucose (Marschner 2011), and a positive influence of favorable environmental conditions for photosynthesis (e.g. high light intensity) on ascorbic acid concentrations in various crops was reported (e.g. Noctor and Foyer 1998). The significance of Mg for assimilation and carbohydrate 
translocation may imply a positive effect of increased Mg supply on ascorbic acid formation. However, Mondy and Ponnampalam (1986) did not observe significant effects of increasing Mg supply on the concentration of ascorbic acid, which agrees with the early reports of (Karikka et al. 1944). Gerendas and Führs (2013) concluded from these contrasting results on phenol and ascorbic acid contents with respect to the occurrence of black spots that all these parameters are associated with several environmental factors that were not controlled in the field experiments referred to and therefore these factors may have masked the effect of $\mathrm{Mg}$.

With respect to non-enzymatic browning, to our knowledge, no results have been published yet on the effect of $\mathrm{Mg}$ supply on the content of reducing sugars, asparagine or acrylamide formation in tubers and processed food, even though an effect can be expected considering the $\mathrm{Mg}$ function in protein biosynthesis and carbohydrate partitioning (Gerendas and Führs 2013). Future studies are necessary to clarify this point.

Numerous reports are available on the effect of Mg supply on glycoalkaloid accumulation in potato tubers. Evans and Mondy (1984) as well as Mondy et al. (1987) observed a significant increase in glycoalkaloid concentration in tubers (see Table 3). The authors suggested that this is due to a stimulation of sugar metabolism, and/or an increase in amino acid production. This theory is supported by reports referring to the same field experiments, where it was shown that Mg application increased both the total N and the protein concentration (Klein et al. 1982; Mondy and Ponnampalam 1985). Thereby, the maximal total amino acid concentration correlated with the maximal total glycoalkaloid concentration (Evans and Mondy 1984). However, contradictory results were described by (Rogozińska and Wojdya 1999). They found no influence of the Mg supply on the glycoalkaloid concentration of potato tubers.

Regarding the storability of potatoes, also very limited results on the effect of $\mathrm{Mg}$ are available. However, in the above cited study, Poberezny and Wszelaczynska (2011) showed that intermediate Mg doses ranging from 0-100 kg MgO ha $^{-1}$ (optimum: $60 \mathrm{~kg} \mathrm{MgO} \mathrm{ha}^{-1}$ ) reduced similar to $\mathrm{K}$ also fresh weight losses during six months of storage.

\section{Nitrogen and interactions with potassium}

Nitrogen is essential for many physiological functions in the cell and subsequently, for plant growth and yield formation (see part I of the review). However, many quality traits are affected adversely (Figure 4). It is obvious that the $\mathrm{N}$ nutrition has a substantial impact on the formation of amino acids (Marschner 2012). Potato tubers contain considerable amounts of free amino acids (Farré et al. 2001); thereby, the amino acid pattern is typically characterized by high amide contents which include mainly asparagine and glutamine. About $14-31 \%$ of the total amino acids in tubers were shown to be asparagine (Elmore et al. 2015). An accumulation of particularly asparagine in response to a 
high $\mathrm{N}$ supply has been observed, which is typically referred to the favorable low $\mathrm{C} / \mathrm{N}$ ratio of this storage and transport form of $\mathrm{N}$ in plants (Muttucumaru et al. 2013). As mentioned, the formation of acrylamide is specifically formed by the reaction of reducing sugars with asparagine (Matthäus and Haase 2014). Therefore, the formation of acrylamide also depends heavily on the $\mathrm{N}$ nutrition (De Wilde et al. 2006). This is particularly true during a K deficiency, as not only the production of amides is increased by a high $\mathrm{N}$ supply, but also the transformation of amides into proteins is reduced by a K deficiency. Therefore, in principle, the higher the N/K supply ratio, the higher is the risk of acrylamide formation. Decreasing the ratio by decreasing the $\mathrm{N}$ supply and increasing the $\mathrm{K}$ supply instead reduces the risk of acrylamide formation (Gerendás et al. 2007).

\section{Other nutrients}

Beside potassium, magnesium and nitrogen, further nutrients are having tremendous impact on quality formation in potato. Calcium (Ca) is needed for cell wall and membrane stabilization (Palta 2010; Hirschi 2004). In cell walls Ca contributes to their characteristic structure by bridging galcturonates of pectin via carboxylate groups (Subramanian et al. 2011) while membrane stabilization is caused by bridging the phosphate and carboxylate groups of phospholipids and proteins at membrane surfaces (Legge et al. 1982; Kirkby and Pilbeam 1984). Based on these functions for cell wall and membrane stability it can be expected that $\mathrm{Ca}$ is essential for establishing and maintaining potato skin firmness and in addition giving tubers higher resistance against pathogens as for example has been shown by McGuire and Kelman (1984). They found a reduced severity of bacterial soft rot caused by Erwinia carotovora pv. atroseptica with increased calcium concentrations of tubers. Unfortunately potato tubers showing naturally very low Ca contents which can be contributed to the fact that $\mathrm{Ca}$ is mainly transported together with water via the xylem and potato tubers are transpiring very less (White and Broadley 2003; Subramanian et al. 2011). Ca deficiency can even lead to cell death (Palta 2010) and causing therefore internal brown spots for instance which can also reduce potato tuber quality (Clough 1994). But already Collier et al. (1978) could show that an additional supply of Ca can increase tuber Ca concentrations and reduce the occurrence of internal brown spots. Moreover studies by Kratzke and Palta (1986 and 1985) and Palta (2010) could show that $\mathrm{Ca}$ concentrations of tubers can be increased if $\mathrm{Ca}$ is directly applied to the tuber-stolon area. Beside nitrogen also sulphur (S) has decisive impact on amino acid formation and hence protein synthesis. Therefore under S-deprivation the proportion of S-containing essential amino acids, namely cysteine and methionine, can be reduced while the proportions of other amino acids can be increased (Eppendorfer and Eggum 1994; Marschner 2011). As described above acrylamide is formed by reducing sugars reacting with asparagine. Prosser et al. (2001) are 
discussing different studies with different cultures than potato which observed under S-deficiency an increase of the transport amino acids glutamine and asparagine. In potato, Elmore et al. (2007) could show a variety dependent increase of acrylamide precursors under $\mathrm{S}$ deprivation but no increase of acrylamide itself. They arguing their findings that the acrylamide formation depends on the separate amounts of amino acid and sugar precursors and that in their case of study precursor amino acids were present in a much higher amount than precursor sugars which may also react with acrylamide non-precursor amino acids.

Up to $75 \%$ of the potato tuber is formed by carbohydrates while starch represents the predominant carbohydrate (McGill et al. 2013). Potato starch quality is dependent on different physical and chemical characteristics which are mainly determined by its amylose content, granule size and glucose-6-phosphate content (Christensen and Madsen 1996; Haase and Plate 1996). The bound phosphorus (P) in starch, mainly present as glucose-6-phosphate, is responsible for its unique properties in view of gelatinization temperatures and cross linking ability (Christensen and Madsen 1996). ThereforeTherefore, also $\mathrm{P}$ is of central relevance for potato tuber quality development, especially in case of potatoes for starch production.

\section{Conclusion}

An adequate supply of potatoes with nutrients is important for achieving not only high yield but also the desired quality. Besides appropriate nutrients and their ratios even the choice of fertilizer can be of particular relevance. Among the principles of adequate potato nutrition, other agronomic measures like choice of cultivar and plant protection need to be considered as well. 


\title{
Chapter 4
}

\section{Differential effects of varied potassium and magnesium nutrition on production and partitioning of photoassimilates in potato (Solanum tuberosum L.) plants}

\author{
Mirjam Koch, Matthies Busse, Marcel Naumann, Bálint Jákli, Inga Smit, Ismail Cakmak, \\ Christian Hermans and Elke Pawelzik
}

Submitted 


\title{
Differential effects of varied potassium and magnesium nutrition on production and partitioning of photoassimilates in potato plants
}

\author{
Mirjam Koch ${ }^{1^{*}}$, Matthies Busse ${ }^{1}$, Marcel Naumann ${ }^{1}$, Bálint Jákli², Inga Smit ${ }^{1}$, Ismail Cakmak ${ }^{2,3}$, Christian \\ Hermans $^{4}$ and Elke Pawelzik ${ }^{1}$ \\ ${ }^{1}$ Department for Crop Sciences, Division Quality of Plant Products, Carl-Sprengel-Weg 1, 37075 \\ Göttingen, University of Göttingen, Germany \\ ${ }^{2}$ Institute of Applied Plant Nutrition, Carl-Sprengel-Weg 1, 37075 Göttingen, Germany. \\ ${ }^{3}$ Biological Sciences and Bioengineering Program, Faculty of Engineering and Natural Sciences, \\ Sabanci University Tuzla, Istanbul, Turkey. \\ ${ }^{4}$ Laboratory of Physiology and Molecular Genetics of Plants, Interfaculty School of Bioengineers, \\ Université libre de Bruxelles, Campus plaine CP 242, Bd du triomphe, 1050 Brussels, Belgium. \\ * Corresponding author: Mirjam Koch, Department for Crop Sciences, Division Quality of Plant Products, \\ Carl-Sprengel-Weg 1, 37075 Göttingen, University of Göttingen, Germany. Tel.: 49(0)551-39-25568. Fax: \\ 49(0)551/39-25570. Email: mirjam.koch@agr.uni-goettingen.de.
}

\section{Keywords}

Mineral deficiencies, nutrient interaction, potato, sugar transport systems, source-sink relationship

\begin{abstract}
Potassium $(\mathrm{K})$ and magnesium $(\mathrm{Mg})$ are essential macronutrients for plants; they play crucial roles for photoassimilate production and transport. The knowledge on both individual and interactive effects of $\mathrm{K}$ and $\mathrm{Mg}$ nutrition in potato is limited. As potato tubers are strong sink organs for photoassimilates, we aimed to determine if and how $\mathrm{K}$ - or $\mathrm{Mg}$ deficiency impairs photoassimilate production and transport, and consequently, plant and tuber development. Potato plants were grown in pots using sand under various $\mathrm{K}$ and $\mathrm{Mg}$ supplies. They were surveyed for biomass production, $\mathrm{CO}_{2}$ net assimilation, leaf sugar concentrations, and transcript levels of $\mathrm{H}^{+} /$sucrose symporters in leaves. Both $\mathrm{K}$ - and $\mathrm{Mg}$-deficiency reduced $\mathrm{CO}_{2}$ net assimilation and biomass production, with stronger reductions in case of K-deficiency. Sugars accumulated in leaves of K- and, more importantly, of Mg-deficient plants. Low K supply resulted in increased transcript levels of $\mathrm{H}^{+} /$sucrose symporters, with less expression under Mg-deficiency. The latter case probably was caused by an impaired sucrose transport already at an earlier step, namely the efflux of sucrose from mesophyll cells into the apoplasm. Thus, we assume that $\mathrm{K}$ - and Mg-deficiency caused sugar accumulation in seperated cell compartments of source leaves leading to a different impact on the gene expression of sucrose transport systems. Tuber
\end{abstract}


sugar and starch concentrations, however, remained unaffected under the various treatments. Nevertheless, the total amount of tuber sugar and starch per plant decreased significantly upon $\mathrm{K}$ - and Mg-deficiency.

\begin{abstract}
Abbreviations
Ct, cycle threshold; DAP, days after planting; E, primer efficiency; G6P-DH, glucose-6-phosphate dehydrogenase; HEPES, hydroxyethylpiperazine-ethanesulfonic acid buffer; HK, hexokinase; INV, invertase; OD, optical density; PGI, phosphoglucose isomerase; rpm, rotations per minute; StSUT, Solanum tuberosum sucrose transporter
\end{abstract}

\title{
Introduction
}

Potato (Solanum tuberosum L.) can produce a more nutritionally important biomass in a shorter period of time than cereals, which makes potatoes one of the most important non-grain foods in the world (Rajiv and Kawar 2016). Furthermore, potato tubers offer excellent nutritional value with the potential to contribute to global food and nutrition security (Camire et al. 2009).

To ensure the successful cultivation of potatoes, careful consideration of cultivar choice and agronomic management are essential (Firman and Allen 2007; Kirkman 2007). In particular, a balanced fertilization is crucial for the mineral nutrition of that crop (Firman and Allen 2007). Among macronutrients, nitrogen (N) (Silva et al. 2013), phosphorus (P) (Rosen et al. 2014), potassium (K) (Panique et al. 1997) and, magnesium (Mg) (Mondy and Ponnampalam 1986) are of central importance to ensure a better productivity and quality in potato. While there is an abundance of literature on the effects of $\mathrm{N}$ and $\mathrm{P}$, knowledge on the interaction between $\mathrm{K}$ and $\mathrm{Mg}$ nutrition is limited. Potassium acts as the main osmoticum to maintain a better cell growth and turgor pressure (Mengel and Arneke 1982; Anschütz et al. 2014), hydraulic conductance (Oddo et al. 2011; Chen et al. 2016), leaf expansion (Jordan-Meille and Pellerin 2004), root elongation (Song et al. 2017), transport of photoassimilates between source and sink organs (Cakmak et al. 1994b; Hu et al. 2017), and regulation of stomatal guard cells (Raschke 1975). Additionally, K is crucial for maintaining photosynthesis (Tränkner et al. 2018) by facilitating $\mathrm{CO}_{2}$ diffusion through the leaf mesophyll (Jákli et al. 2017). Magnesium is important for the energy metabolism, light harvesting (Verbruggen and Hermans 2013), and photoassimilate allocation (Cakmak et al. 1994a). Due to greater sensitivity of sink organs to low Mg supply, significant impairments occur in development of sink organs in different plant species such as in root growth (Cakmak et al. 1994b; Farhat et al. 2016) and seed development (Ceylan et al. 2015). 
In many crop species with sink organs that are of agronomical interest (e.g. tuber and taproot), a critical component of the photoassimilate partitioning between source and sink is the proton-driven sucrose symport (Van Bel 2003). This active transport system in the phloem couples sucrose translocation across the plasma membrane to the proton motive force generated by the $\mathrm{H}^{+}$-ATPase, which requires Mg-ATP to function (Cowan 2002; Hermans et al. 2005). During Mg-deficiency, phloem loading is impaired and sucrose accumulates in the apoplasm (Hermans et al. 2005). As sucrose concentration builds up in leaves, greater expression levels of genes encoding $\mathrm{H}^{+} /$sucrose symporters are observed in several plant species (Hermans et al. 2004; Hermans et al. 2005). A similar scenario is possible under $\mathrm{K}$ limitation, as $\mathrm{K}$ is necessary for not only phloem-loading but also the transport of sucrose within the phloem. The activity of the $\mathrm{H}^{+}-$ ATPases is dependent on a finely tuned $\mathrm{pH}$ value, for which $\mathrm{K}$ is needed. Furthermore, $\mathrm{K}$ establishes an osmotic potential within the phloem, which is needed to translocate sucrose from source to sink organs (Hayashi and Chino 1990; Cakmak et al. 1994a). Consequently, low K supply leads to the accumulation of sucrose in source leaves due to impaired sucrose-loading into the phloem and/or due to limited osmotic effects of $\mathrm{K}$ in the phloem sieve tubes. Besides, a reduction in phloem transport of sucrose could also be a consequence of a limited symplastic unloading of sucrose into the sink cells due to reduced sink strength (Hütsch et al. 2016).

Mineral elements can compete for root uptake (Fageria 2001). For example, an antagonistic interaction is reported between $\mathrm{K}$ and Mg. This can be attributed to different transport systems that are responsible for the uptake of these two elements. While putative transporters for $\mathrm{Mg}$ are unspecific and take up cations other than $\mathrm{Mg}, \mathrm{K}$ transporters are very specific and the uptake of $\mathrm{K}$ is ensured under both low and high $\mathrm{K}$ concentrations in the soil solution (Senbayram et al. 2015). Nonetheless, there are also reports on the synergy between K and Mg. For instance, Ding et al. (2006) showed a synergistic mechanism of increasing Mg supply on $\mathrm{K}$ uptake and translocation in rice. Similar results were demonstrated by Narwal et al. (1985) in cowpea (Vigna unguiculata L. Walp.).

As potato tubers are strong sink organs, it seems that tuber yield and starch formation must be highly dependent on photosynthesis and the export of photoassimilates from source leaves. Owing to the indispensable functions of $\mathrm{K}$ and $\mathrm{Mg}$ in photosynthesis and translocation of photoassimilates in plants, this study focuses mainly on the impact of varied applications of $\mathrm{K}$ and $\mathrm{Mg}$ on $\mathrm{CO}_{2}$ net assimilation and on parameters that provide indications about the partitioning of photoassimilates, such as soluble sugar concentrations and gene expression of $\mathrm{H}^{+} /$sucrose symporters in source leaves, in potato. In light of this, plant shoot and root growth, tuber yield, and tuber sugar and starch formation were investigated. Furthermore, the changes in tissue concentrations of $\mathrm{K}$ and $\mathrm{Mg}$ were studied under different combined applications of $\mathrm{K}$ and $\mathrm{Mg}$ in order to collect further information about $\mathrm{K}$ and $\mathrm{Mg}$ interactions in potato plants. 


\section{Materials and methods}

Plant growth conditions

Potato plants (Solanum tuberosum L.) of the cultivar "Laura" were grown for a period of 98 days individually in pots (capacity $11 \mathrm{~L}$ ) filled with nutrient-poor sandy soil. The experimental design was completely randomized. For inducing germination, the tubers were stored for 10 days in darkness at room temperature. Tuber slices with one germ bud $(\sim 1$ $\mathrm{cm}$ length) were planted. Plants were first cultivated in a greenhouse with an average temperature of $20^{\circ} \mathrm{C}, 48 \%$ relative humidity, and $12 \mathrm{~h}$ light $\left(300 \mu \mathrm{mol} \mathrm{m} \mathrm{s}^{-1}\right.$; MASTER Agro $400 \mathrm{~W}$, Philips, Netherlands) and $12 \mathrm{~h}$ darkness. After 27 days, the plants were transferred to an outdoor installation (mean temperature, precipitation, and irradiance are shown in under supplementary material (SM) SM_1). Five fertilization regimes of $\mathrm{K}$ and $\mathrm{Mg}$ were applied (Table 1$)$ to 10 biological replicas: low $\mathrm{K}$ with sufficient $\mathrm{Mg}$ supply (K1+Mg), moderate $\mathrm{K}$ supply with sufficient $\mathrm{Mg}$ supply (K2+Mg) or low Mg supply (K2-Mg), high K supply with sufficient Mg supply (K3+Mg) or low Mg supply (K3-Mg). The two elements were applied in the form of $\mathrm{K}_{2} \mathrm{SO}_{4}$ or $\mathrm{MgSO}_{4}$.. $\mathrm{H}_{2} \mathrm{O}$ (Table 1). All quantities of other mineral elements applied to the soil are presented in SM_2. The soil $\mathrm{K}$ and $\mathrm{Mg}$ status before the fertilization treatment was $1.5 \mathrm{mg} \mathrm{K}$ $100 \mathrm{~g}^{-1}$ soil and < $1 \mathrm{mg} \mathrm{Mg} 100 \mathrm{~g}^{-1}$ soil.

Table 1: Overview of the $\mathrm{K}$ and $\mathrm{Mg}$ supply ( $\mathrm{mg} \mathrm{kg}^{-1}$ soil) before planting of the different fertilization treatments. * signifies additional $5 \mathrm{mg} \mathrm{K} \mathrm{kg}^{-1}$ soil $27 \mathrm{DAP}$.

\begin{tabular}{lll}
\hline Fertilization treatment & $\mathbf{K}$ & $\mathbf{M g}$ \\
\hline $\mathbf{K} 1+\mathbf{M g}$ & $30\left(+5^{*}\right)$ & 100 \\
$\mathbf{K} 2+\mathbf{M g}$ & 300 & 100 \\
$\mathbf{K} 2-\mathbf{M g}$ & 300 & 5 \\
$\mathbf{K} 3+\mathbf{M g}$ & 600 & 100 \\
$\mathbf{K} 3-\mathbf{M g}$ & 600 & 5 \\
\hline
\end{tabular}

\section{Phenotypic observation, shoot and root biomass recording, and root scanning}

The whole plant phenotype was documented by taking pictures throughout the treatment. Changes in growth were recorded by measuring plant height and counting the internodes. At harvest, biomasses of leaves, roots, and tubers were measured separately and roots were stored at $-20^{\circ} \mathrm{C}$. Root scanning was conducted using a flat-bed scanner 
(Epson Perfection V700 Photo, Epson, Germany) and analyzed with the software WinRhizo 2016 (Regent Instruments Inc., Québec City, Canada). Only half of each root was used and the total root length was calculated for the whole root on the basis of the determined dry weight of the scanned root part and the non-scanned root part.

\section{Mineral analysis in plant tissues}

Leaf and root samples were dried for four days at $60^{\circ} \mathrm{C}$ and crushed into fine powder. Tubers were cut into pieces and freeze-dried for four days in a freeze-dryer (EPSILON 2-40, Christ, Germany). Subsequently, the residual moisture was assessed by determining the weight of a subsample of the freeze-dried potato flour before and after drying for 12 hours at $105^{\circ} \mathrm{C}$. Root samples were dried at $60^{\circ} \mathrm{C}$ for four days and later ground into $0.5 \mathrm{~mm}$ flour in a hammer mill (DFH 48, Culatti, Switzerland). Mineral concentrations were determined according to an adjusted method, as described by Wheal et al. (2011). $100 \mathrm{mg}$ of each sample were digested in $4 \mathrm{ml}$ of $65 \%(\mathrm{v} / \mathrm{v})$ nitric acid and $2 \mathrm{ml}$ of $30 \%(\mathrm{v} / \mathrm{v})$ hydrogen peroxide for $75 \mathrm{~min}$ at $200^{\circ} \mathrm{C}$ and 40 bar in a microwave (Ethos 660; MWT AG, Switzerland). Afterward, the samples were filled up to $25 \mathrm{ml}$ with distilled water. The element concentrations were measured with inductively coupled plasma optical emission spectrometry (Vista-PRO CCD Simultaneous ICP-OES; Varian Inc., USA).

\section{Gas-exchange measurements and chlorophyll determinations in fully expanded leaves}

Net $\mathrm{CO}_{2}$ assimilation of fully expanded leaves $\left(4 \mathrm{~cm}^{2}\right)$ was quantified by using a portable gas-exchange device (GFS3000, Heinz Walz GmbH, Germany) under ambient temperature, relative humidity, and $\mathrm{CO}_{2}$ concentration $(\sim 390$ ppm), and light intensity of $400 \mu \mathrm{mol} \mathrm{m}{ }^{-2} \mathrm{~s}^{-1}$ (cloudy condition) or $1,000 \mu \mathrm{mol} \mathrm{m} \mathrm{m}^{-2} \mathrm{~s}^{-1}$ (sunny condition).

For chlorophyll determination about $20 \mathrm{mg}$ of leaf tissue was ground in liquid nitrogen and extracted successively twice with $80 \%(\mathrm{v} / \mathrm{v})$ and a third time with $50 \%(\mathrm{v} / \mathrm{v})$ ethanol. The samples were shaken in a heat block at $95^{\circ} \mathrm{C}$ for 30 minutes. After the third extraction step, the supernatants were combined, the pellet discarded, and the samples stored at $-20^{\circ} \mathrm{C}$ until further analysis.

Chlorophyll was examined as described by Arsovski et al. (2018). For the results, the sum of chlorophyll $a$ and $b$ was considered.

\section{Soluble sugar quantification in fully expanded leaves}

The soluble sugars were determined following the procedure developed by Stitt et al. (1989) after some modifications.

The same ethanolic extract as for chlorophyll extraction was used. Sugars were converted by the added enzymes 
hexokinase (HK; Roche Diagnostics GmbH, Germany and Merck, Germany; EC number 2.7.1.1), phosphoglucose isomerase (PGI; Roche Diagnostics GmbH, Germany; EC number 5.3.1.9), and invertase (INV; Sigma Aldrich, USA; EC number 3.2.1.26). For dissolving the enzymes, a $100 \mathrm{~m} M$ hydroxyethylpiperazine-ethanesulfonic acid (HEPES) buffer (Roth, Germany) and a $3 \mathrm{mM} \mathrm{MgCl} 2$ buffer (adjusted with $\mathrm{KOH}$ to $\mathrm{pH}$ 7) was used. Half of the samples were prepared with HK in suspension (Roche Diagnostics GmbH): $72 \mu \mathrm{l}$ (108 units) HK was centrifuged for three min at $11000 \mathrm{rpm}$ and the pellet was dissolved in $120 \mu \mathrm{H}$ HEPES- $\mathrm{MgCl}_{2}$ buffer. The other half of the samples was prepared with HK in solid form (Merck, Germany): $0.50 \mathrm{mg}$ was dissolved in $120 \mu \mathrm{HEPES}-\mathrm{MgCl}_{2}$ buffer. For preparation of PGI $36 \mu \mathrm{l}$ (25.2 units), PGI was centrifuged for three minutes at $11000 \mathrm{rpm}$ and the pellet was dissolved in $120 \mu \mathrm{l}$ HEPES- $\mathrm{MgCl}_{2}$ buffer. For the preparation of INV, $8.3 \mathrm{mg}$ (2,500 units) INV was dissolved in $120 \mu \mathrm{HEPES}-\mathrm{MgCl}_{2}$ buffer. A further needed enzyme was glucose-6-phosphate dehydrogenase (G6P-DH) (Roche Diagnostics GmbH, Germany; EC number 1.1.1.49), which was prepared together with $100 \mathrm{~m} M$ ATP (Sigma-Aldrich, USA) and $45 \mathrm{~m} M$ nicotinamide adenine dinucleotide phosphate (NADP) (Roche Diagnostics GmbH, Germany) to form a solution. For this, $85 \mu \mathrm{l}$ (60 units) G6P-DH was centrifuged for three minutes at $11000 \mathrm{rpm}$ and the pellet was dissolved in $15.5 \mathrm{ml}$ HEPES $+\mathrm{MgCl}_{2}$ buffer, $480 \mu \mathrm{l}$ ATP, and $480 \mu \mathrm{l}$ NADP solution. Next, $50 \mu \mathrm{l}$ of the ethanolic extract plus $160 \mu 1$ of the G6P-DH-ATP-NADP solution was added per well on a 96-well plate and shaken for 10 minutes. The converted NADPH was quantified by measuring the OD at $340 \mathrm{~nm}$ in a plate reader (Epoch, 1402203, Biotek, USA) after reaching stable values.

$\mathrm{NADPH}$ was calculated with the help of $\Delta \mathrm{OD}$ (used formula: $\mu M \mathrm{NADPH}=\Delta \mathrm{OD} /\left(2.85^{*} 6.22\right)$ ).

The calculated values were:

$1 M \mathrm{NADPH}$ derived from glucose/fructose $=1 M$ glucose/fructose .

$1 M$ NADPH derived from sucrose $=0.5 M$ sucrose $(1$ mole glucose equivalent $)$.

\section{RNA extraction and quantitative real-time polymerase chain reaction}

Total RNA was isolated from $100 \mathrm{mg}$ leaf tissue using the innuPREP Plant RNA Kit (Analytic Jena AG, Germany) and cDNA was synthesized from $75 \mathrm{ng}$ of the total RNA using the iScript cDNA Synthesis Kit (Bio-Rad Laboratories, Germany), according to the manufacturer's instructions. Prior to cDNA synthesis, the extracted RNA was quantified by using a Qubit ${ }^{\circledR}$ RNA HS Assay Kit and the samples were measured in a fluorimeter (Qubit 3.0 Fluorimeter, ThermoFisher Scientific, Germany). A real-time PCR detection system (CFX96, Bio-Rad Laboratories, Germany) was used to quantify the expression levels of StSUT1 and StSUT4. For quantitative real-time PCR (qRT-PCR), $4 \mu \mathrm{l}$ of 
diluted cDNA was used for the reaction, together with $50 \mu M$ target-specific primers (SM_3) and the fluorescent intercalating dye SYBR Green (SsoAdvanced ${ }^{\mathrm{TM}}$ Universal SYBR ${ }^{\circledR}$ Green Supermix, Bio-Rad Laboratories, Germany). The protocol is shown detailed in SM_4 and the primers listed in SM_3. The relative gene copy number of cDNA was normalized to the $S t \_U B I Q U I T I N$ gene and relative quantification was performed using the $\Delta \Delta C t$-method after Pfaffl (2007). The $\mathrm{K} 2+\mathrm{Mg}$ plants were used as the control. The relative expression levels of the $\mathrm{K} 2+\mathrm{Mg}$ plants were set to one.

\section{Sugar and starch examination in tubers}

Prior to starch and sugar determination, tubers were prepared as described for mineral analysis.

Starch was quantified according to ICC standard no. 123 (modified). In $100 \mathrm{ml}$ flasks, $25 \mathrm{ml}$ of hydrochloric acid was added twice to $1 \mathrm{~g}$ of potato flour, placed for 15 minutes in a scalding water bath (Memmert, Germany), and shaken for the first eight minutes. The flasks were filled up to $90 \mathrm{ml}$ with distilled water and cooled to room temperature. Following this, $5 \mathrm{ml}$ of tungstophosphoric acid $\left(\mathrm{H}_{3} \mathrm{PW}_{12} \mathrm{O}_{40}\right)$ was added and panned. Finally, the flasks were filled up to $100 \mathrm{ml}$ with distilled water and the optical rotation was examined in polarized light in a polarimeter (Zeiss, Germany) at $589 \mathrm{~nm}$.

Sugars were quantified by high-performance liquid chromatography (HPLC). For extraction, $0.4 \mathrm{~g}$ of potato flour was shaken with $4 \mathrm{ml}$ of distilled water in $15 \mathrm{ml}$ centrifugal tubes horizontally for one hour. To precipitate proteins, $0.5 \mathrm{ml}$ Carrez I (3.6 g K ${ }_{4} \mathrm{Fe}(\mathrm{CN})_{6}$ in $100 \mathrm{ml}$ distilled water) and $0.5 \mathrm{ml}$ Carrez II ( $7.2 \mathrm{~g} \mathrm{H}_{14} \mathrm{O}_{11} \mathrm{SZn}$ in $100 \mathrm{ml}$ distilled water) solutions were added in order, then mixed and centrifuged for 20 minutes at $5000 \mathrm{rpm}$. Supernatants were transferred in $10 \mathrm{ml}$ flasks and the pellet was again dissolved in distilled water, shaken for one hour, and centrifuged for 20 minutes at $5000 \mathrm{rpm}$. Finally, the supernatants were combined. The flasks were filled up to $10 \mathrm{ml}$ with distilled water. The samples were filtered with filter paper (Type 615 , Macherey-Nagel, Germany) in screw cap tubes and stored at $-20^{\circ} \mathrm{C}$ until the measurement.

For HPLC measurement, the samples were thawed. Next, $5 \mathrm{ml}$ was vaporized using a rotary vacuum concentrator (RVC 2-25 CD plus, Christ, Germany) and filled with $1 \mathrm{ml}$ of distilled water. The fivefold concentrated solution was filled using a $13 \mathrm{~mm}$ syringe filter holder (VWR International, USA) in $2 \mathrm{ml}$ vials and the extract was quantified through HPLC (Jasco, Japan) (injection volume $=20 \mu \mathrm{l}$; eluent $=80 \%$ acetonitrile and $20 \%$ water; flow rate $=1$ $\mathrm{ml} / \mathrm{min}$; column $=$ LiChrospher $100 ;$ column temperature $=22^{\circ} \mathrm{C}$; refractive index detector $)$. 
All biological replicates of tubers of $\mathrm{K} 1+\mathrm{Mg}$ plants were pooled to four samples as the tuber yields of the single plants were not sufficient. Tubers of all remaining treatments were not pooled.

\section{Tuber dry matter and sugar and starch yield}

An average of three to five tubers per treatment (the tuber quantity used was dependent on tuber size-e.g. three bigger tubers or five smaller tubers) was used. These were cut into pieces and the fresh sample weight of a subsample was determined. Afterward, the sample was dried at $60^{\circ} \mathrm{C}$ for 24 hours and subsequently at $105^{\circ} \mathrm{C}$ for four hours and the weight was determined. The tuber sugar and starch yields (g sugar or starch, respectively, per plant in dry matter [DM]) were calculated based on the tuber DM, the sugar and starch concentrations, and the tuber yield per plant.

\section{Statistical treatment}

Statistical analysis was performed using R software version 3.4.0 (R Core Team 2016). All data were checked for normal distribution and homoscedasticity. Then, ANOVA was performed to detect differences between treatments followed by multiple contrast tests. A non-parametric Kruskal-Wallis test was performed in the case that normality and/or homoscedasticity were not verified. All tests were performed on a significance level of $p<0.05$ (unless otherwise indicated).

\section{Results}

Signs of nutrient deficiencies

The experimental plants were affected differentially in terms of expression of leaf symptoms under given experimental conditions. In $\mathrm{K} 1+\mathrm{Mg}$ plants, firs spot-like and leaf-edge necrosis and chlorosis became visible on the oldest leaves, which quickly developed into severe necrosis and chlorosis or total necrotic material (Fig. 1a). The K2 and K3+Mg plants appeared lush green and only their oldest leaves were senescent (Fig. 1b and d). For K2 and K3-Mg plants, clear chlorosis and flat spot-like necrosis were noted, especially on older leaves (Fig. 1c and e). 

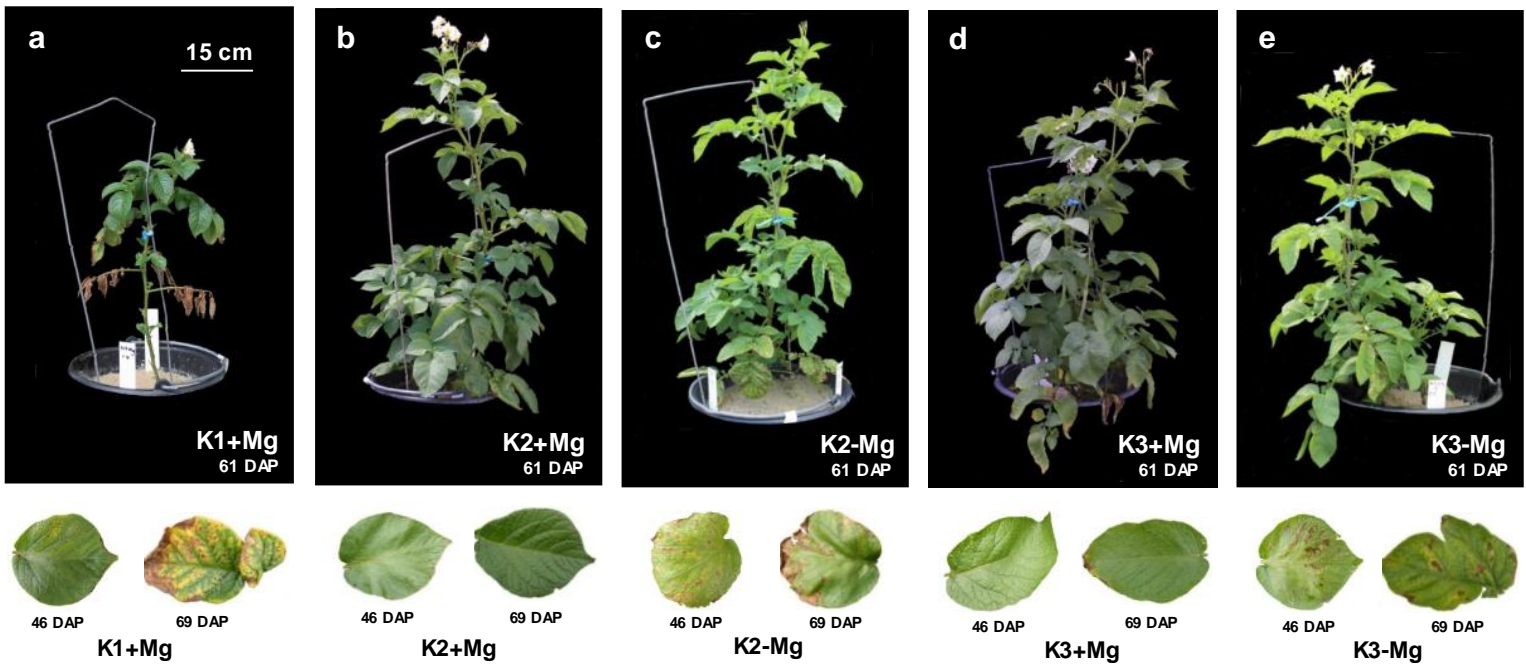

Figure 1: Plant phenotypes during $\mathrm{K}$ and Mg treatments. Pictures of whole potato plants were taken 61 days after planting (DAP) and close-ups of most recently expanded leaves on 46 and 69 DAP. Treatment description as in Table 1.

\section{Plant growth and tuber yield}

Shoot and root DM as well as total root length were significantly reduced in plants supplied with low $\mathrm{K}(\mathrm{K} 1+\mathrm{Mg})$, as compared to $\mathrm{K} 2$ and $\mathrm{K} 3+\mathrm{Mg}$ plants (Fig. 2a, b and c). Root DM and total root length were further reduced under low Mg supply (K2 and K3-Mg), but the difference was significant for root length only (Fig. 2b and c). The number of internodes (Fig. 2d) and plant height (Fig. 2e) were also significantly decreased in $\mathrm{K} 1$ compared to $\mathrm{K} 2$ and $\mathrm{K} 3+\mathrm{Mg}$ plants whereas Mg-deficient plants did not show a significant reduction in quantity of internodes as well as in plant height (data not shown). The shoot-to-root biomass ratio was increased especially in $\mathrm{K}$-deficient $(\mathrm{K} 1+\mathrm{Mg})$ and also in Mg-deficient plants (K2 and K3-Mg) (Fig. 2b). Both K- and Mg-deficient plants exhibited a significant reduction in tuber yield. However, low K supply reduced tuber yield by $89 \%$, whereas low Mg supply led to only $14-16 \%$ of tuber yield reduction in $\mathrm{K} 2$ and $\mathrm{K} 3$ treatments (Fig. 2f). 


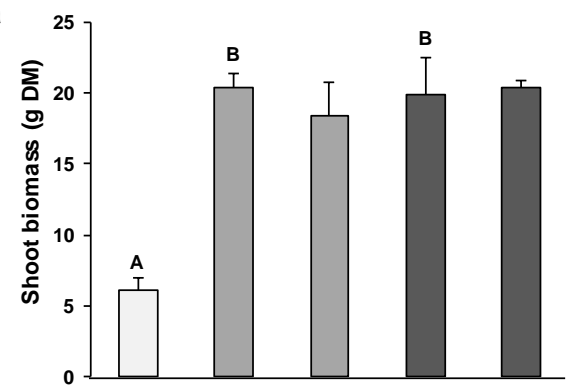

b
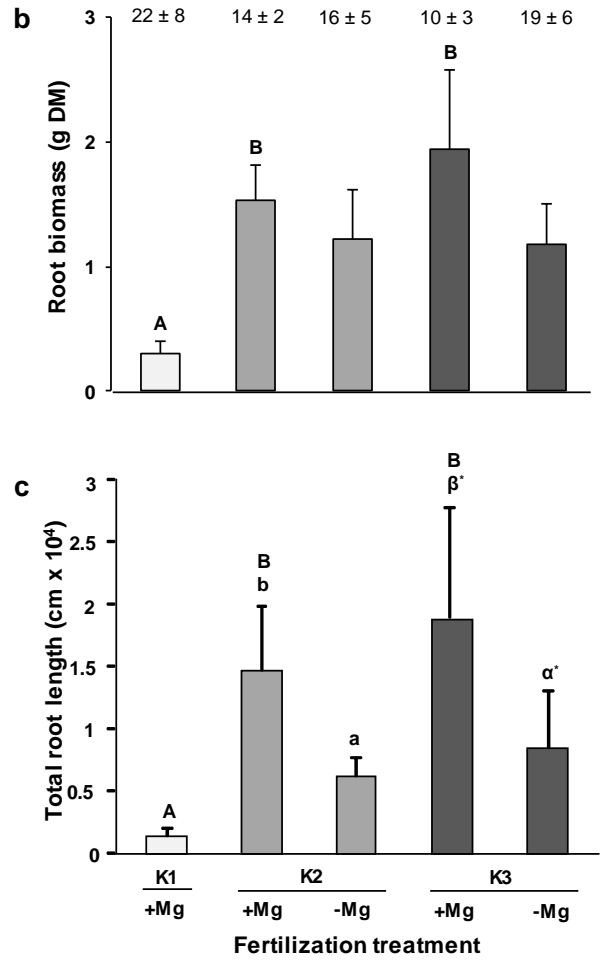
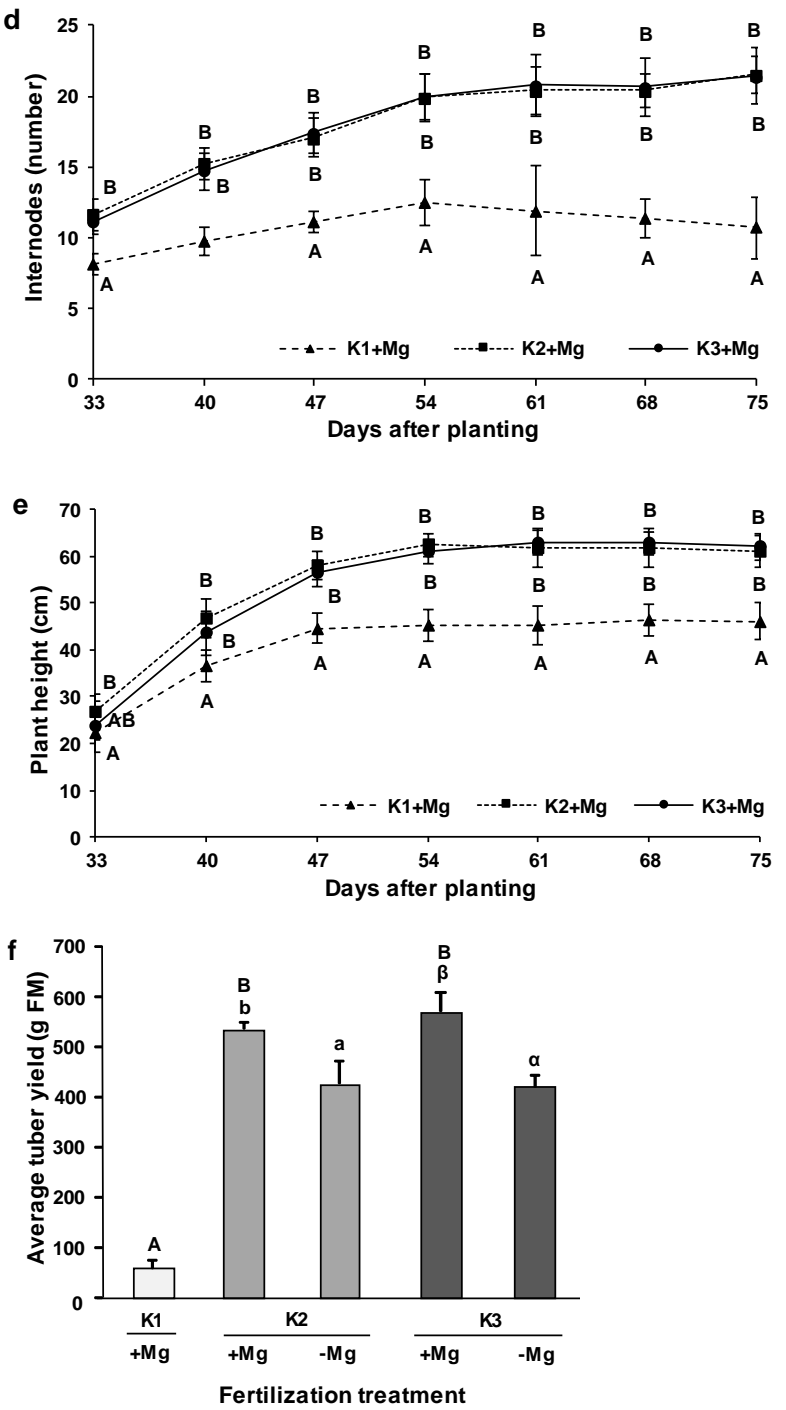

Figure 2: Effects of $\mathrm{K}$ and Mg treatment on biomass production and plant morphology. Shoot biomass $(\mathrm{n}=8$ 10) (a), root biomass with shoot-to-root biomass ratios (mean \pm SE values above bar plot; $n=5$ ) (b), total root length $(\mathrm{n}=5)(\mathrm{c})$, and tuber yield $(\mathrm{n}=8-10)(\mathrm{f})$ at harvest. Number of internodes (d) and plant heights (e) $(\mathrm{n}=8-10)$ on seven sampling dates after planting. Mean $\pm \mathrm{SE}$ values. Capitals $=$ significant differences between $\mathrm{K}$ treatments of $+\mathrm{Mg}$ plants. Small letters $=$ significant differences between differing $\mathrm{Mg}$ treatments of $\mathrm{K} 2$ plants. Greek letters $=$ significant differences between differing Mg treatments of K3 plants. No indication = no significant effect. $p<0.05$; $*=p<0.01$.

\section{Potassium and magnesium status of fully expanded leaves}

The $\mathrm{K}$ concentrations in leaves of $\mathrm{K} 2$ and $\mathrm{K} 3+\mathrm{Mg}$ plants were at least two times higher compared to those that received a low K supply (K1+Mg) (Table 2). On 69 days after planting (DAP), K1+Mg plants even exhibited seven times lower $\mathrm{K}$ concentrations compared to $\mathrm{K} 2+\mathrm{Mg}$ plants and nine times lower $\mathrm{K}$ concentrations compared to $\mathrm{K} 3+\mathrm{Mg}$ plants. 
Plants fed with moderate or high $\mathrm{K}$ supplies (K2 and $\mathrm{K} 3+\mathrm{Mg}$ ) did not show significant differences in this regard. The $\mathrm{Mg}$ concentrations of the same plants behaved in the opposite way: the plants with the highest $\mathrm{K}$ supply $(\mathrm{K} 3+\mathrm{Mg})$ showed the lowest significant Mg concentrations while the plants with the lowest $\mathrm{K}$ supply $(\mathrm{K} 1+\mathrm{Mg})$ showed the highest Mg concentrations (Table 2). The Mg concentrations of the $\mathrm{K} 2$ and $\mathrm{K} 3-\mathrm{Mg}$ plants were nearly one-tenth (K2+Mg vs. K2-Mg at $69 \mathrm{DAP})$ compared to the $\mathrm{K} 2$ and $\mathrm{K} 3+\mathrm{Mg}$ treatments (Table 2).

\section{Potassium and magnesium status of plant organs}

Leaves, tubers and roots of $\mathrm{K}$-deficient $(\mathrm{K} 1+\mathrm{Mg})$ plants had significantly lower $\mathrm{K}$ concentrations compared to $\mathrm{K} 2$ and $\mathrm{K} 3+\mathrm{Mg}$ plants, and Mg-deficient (K2 and $\mathrm{K} 3-\mathrm{Mg}$ ) ones significantly lower Mg concentrations compared to K2 and K3+Mg plants (Fig. 3). These decreases were much more severe in leaves than in roots or tubers (Fig. 3). Considering $\mathrm{Mg}$ concentrations of $\mathrm{K} 1+\mathrm{Mg}$ plants, leaves revealed the highest significant $\mathrm{Mg}$ concentrations, while tubers and roots showed the lowest significant (one-tenth lower) Mg concentrations compared to leaves (Fig. 3b).
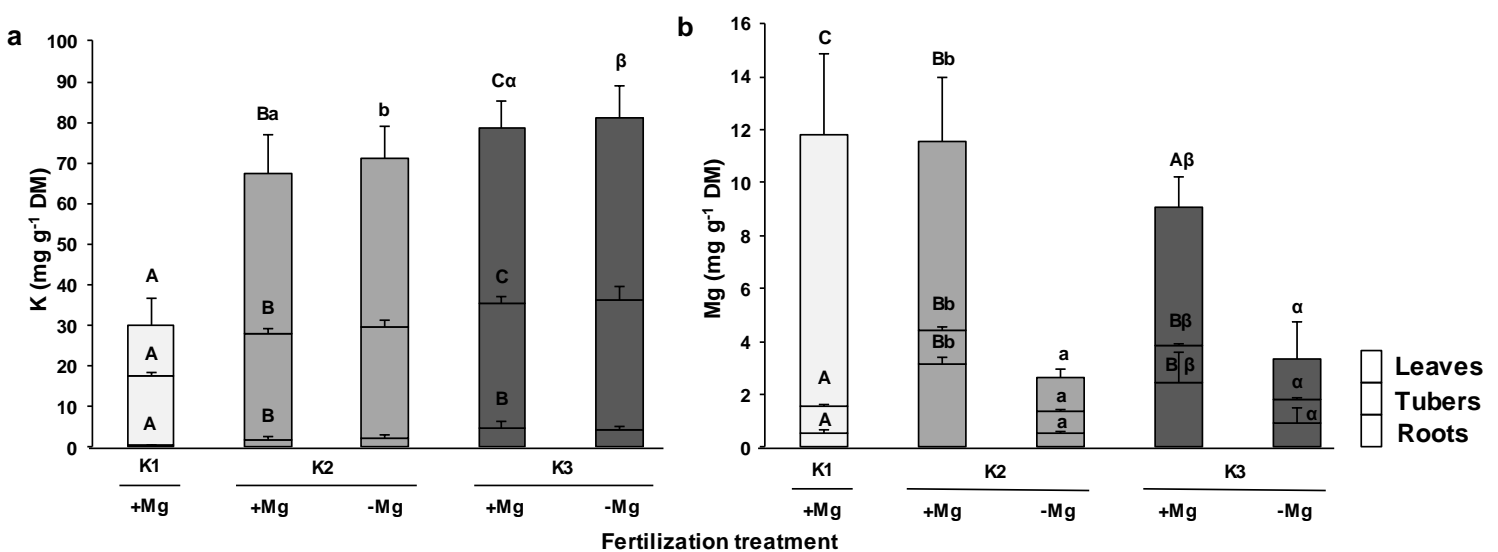

Figure 3: Effect of $\mathrm{K}$ and $\mathrm{Mg}$ treatments on element concentrations in leaves, tubers, and roots. $\mathrm{K}$ (a) and $\mathrm{Mg}$ (b) concentrations of fully expanded leaves (mean \pm SE values averaged over all sampling dates; for data, see Table 2; $\mathrm{n}=4-5$ ) and tubers and roots after harvest (mean \pm SE values; $\mathrm{n}=8-10$ ). Capitals $=$ significant differences between $\mathrm{K}$ treatments of $+\mathrm{Mg}$ plants within one plant organ (leaves, tubers, or roots). Small letters = significant differences between differing $\mathrm{Mg}$ treatments of $\mathrm{K} 2$ plants of one plant organ. Greek letters = significant differences between $\mathrm{Mg}$ treatments of K3 plants within one plant organ. No indication = no significant effect. 
Table 2: Effect of $\mathrm{K}$ and $\mathrm{Mg}$ treatments on element concentrations $\left(\mathrm{mg} \mathrm{g}^{-1} \mathrm{DM}\right)$ in leaf tissues on five sampling dates from day 34 until day 69 after planting ( $=$ 4-5). Mean \pm SE values. Capitals $=$ significant differences between differing $\mathrm{K}$ treatments of $+\mathrm{Mg}$ plants. Asterisks $=$ significant differences between $\mathrm{K} 2$ and $\mathrm{K} 3$ $\mathrm{Mg}$ plants. Small letters = significant differences in $\mathrm{K} 2-\mathrm{Mg}$ plants compared to $\mathrm{K} 2+\mathrm{Mg}$ plants. Greek letters = significant differences in K3-Mg plants compared to $\mathrm{K} 3+\mathrm{Mg}$ plants. No indication $=$ no significant effect. DAP signifies days after planting

$$
\mathbf{K}
$$

Fertilization treatment

\begin{tabular}{|c|c|c|c|c|c|c|c|c|c|c|}
\hline DAP & $\mathrm{K} 1+\mathrm{Mg}$ & & $\mathrm{K} 2+\mathrm{Mg}$ & & $\mathrm{K} 2-\mathrm{Mg}$ & & $\mathrm{K} 3+\mathrm{Mg}$ & & K3-Mg & \\
\hline 34 & $21.61 \pm 5.29$ & A & $56.46 \pm 1.69$ & $B$ & $54.37 \pm 4.78$ & & $52.81 \pm 4.31$ & $B$ & $44.12 \pm 11.85$ & \\
\hline 41 & $16.33 \pm 0.69$ & $A$ & $32.66 \pm 2.36$ & $\mathrm{~B}$ & $35.10 \pm 1.98$ & & $36.51 \pm 1.29$ & $B$ & $38.46 \pm 4.47$ & \\
\hline 48 & $8.29 \pm 0.71$ & A & $35.10 \pm 4.20$ & B & $38.16 \pm 0.78$ & & $40.46 \pm 2.37$ & $B$ & $41.96 \pm 4.46$ & \\
\hline 55 & $14.42 \pm 1.45$ & A & $40.62 \pm 2.04$ & B & $40.73 \pm 2.81$ & * & $46.68 \pm 3.28$ & $B$ & $51.51 \pm 3.71$ & * \\
\hline 69 & $4.26 \pm 0.51$ & A & $33.11 \pm 3.36$ & $B$ & $40.66 \pm 5.26$ & & $41.59 \pm 3.59$ & $B$ & $49.77 \pm 1.98$ & \\
\hline
\end{tabular}

$\underline{M g}$

\begin{tabular}{lrlrlllllll}
34 & $8.64 \pm 2.05$ & $\mathrm{AB}$ & $5.55 \pm 0.22$ & $\mathrm{Bb}$ & $1.44 \pm 0.12$ & $\mathrm{a}$ & $4.62 \pm 0.25$ & $\mathrm{~A} \beta$ & $2.79 \pm 2.39$ & $\alpha$ \\
41 & $6.93 \pm 0.85$ & $\mathrm{~B}$ & $4.43 \pm 0.61$ & $\mathrm{Ab}$ & $1.58 \pm 0.08$ & $\mathrm{a}$ & $3.99 \pm 0.08$ & $\mathrm{~A} \beta$ & $1.52 \pm 0.16$ & $\alpha$ \\
48 & $13.77 \pm 0.78$ & $\mathrm{C}$ & $7.01 \pm 0.63$ & $\mathrm{Bb}$ & $1.41 \pm 0.14$ & $\mathrm{a}$ & $5.73 \pm 0.31$ & $\mathrm{~A} \beta$ & $1.48 \pm 0.28$ & $\alpha$ \\
55 & $8.92 \pm 1.32$ & $\mathrm{~B}$ & $7.99 \pm 1.32$ & $\mathrm{Bb}$ & $0.97 \pm 0.12$ & $\mathrm{a}$ & $4.95 \pm 0.45$ & $\mathrm{~A} \beta$ & $0.74 \pm 0.92$ & $\alpha$ \\
69 & $12.62 \pm 1.46$ & $\mathrm{~B}$ & $10.74 \pm 1.27$ & $\mathrm{Bb}$ & $0.77 \pm 0.23$ & $\mathrm{a}$ & $7.09 \pm 0.79$ & $\mathrm{~A} \beta$ & $0.75 \pm 0.13$ & $\alpha$ \\
\hline
\end{tabular}


$\mathrm{CO}_{2}$ assimilation rate and chlorophyll concentrations of fully expanded leaves

On 40 DAP, the $\mathrm{CO}_{2}$ net assimilation rate of $\mathrm{K} 1+\mathrm{Mg}$ plants showed the lowest values while the $\mathrm{CO}_{2}$ assimilation rate was the highest in the leaves of K2-Mg plants, but both were not significant (Fig. 4a). On 47 DAP, the $\mathrm{CO}_{2}$ net assimilation rate of the leaves of $\mathrm{K} 1+\mathrm{Mg}$ plants was significantly lower compared to that of the $\mathrm{K} 3+\mathrm{Mg}$ plants. In addition, the leaves of the $\mathrm{K} 3-\mathrm{Mg}$ plants exhibited a lower $\mathrm{CO}_{2}$ net assimilation compared to the $\mathrm{K} 3+\mathrm{Mg}$ plants, but without significance. On 83 and 84 DAP, further determinations of the $\mathrm{CO}_{2}$ net assimilation rate between $\mathrm{K} 2$ and $\mathrm{K} 3+\mathrm{Mg}$ and $\mathrm{K} 2$ and $\mathrm{K} 3-\mathrm{Mg}$ plants were performed. The $\mathrm{CO}_{2}$ assimilation rate decreased in $\mathrm{K} 2-\mathrm{Mg}$ as well as in the $\mathrm{K} 3-\mathrm{Mg}$ plants, but with a significant decrease only in the K3 plants.

The plants treated with a low $\mathrm{K}$ supply $(\mathrm{K} 1+\mathrm{Mg})$ exhibited higher chlorophyll concentrations compared to the plants that received moderate $(\mathrm{K} 2+\mathrm{Mg})$ or high $(\mathrm{K} 3+\mathrm{Mg})$ levels of $\mathrm{K}$ on 41 and $55 \mathrm{DAP}(\mathrm{Fig}$. 4b). However, the chlorophyll concentrations showed a significant decrease in $\mathrm{K} 1+\mathrm{Mg}$-treated plants compared to the $\mathrm{K} 2$ - and $\mathrm{K} 3+\mathrm{Mg}$-treated plants on 69 DAP. There was no significant difference in the chlorophyll concentrations of leaves between the plants that received moderate $(\mathrm{K} 2+\mathrm{Mg})$ or high $(\mathrm{K} 3+\mathrm{Mg})$ supplies of $\mathrm{K}$, but an increase in the chlorophyll concentrations was observed from 41 till 69 DAP. Lower chlorophyll concentrations were detected in the K2 and K3-Mg plants (Fig. 4c). However, these differences were not significant. 
a
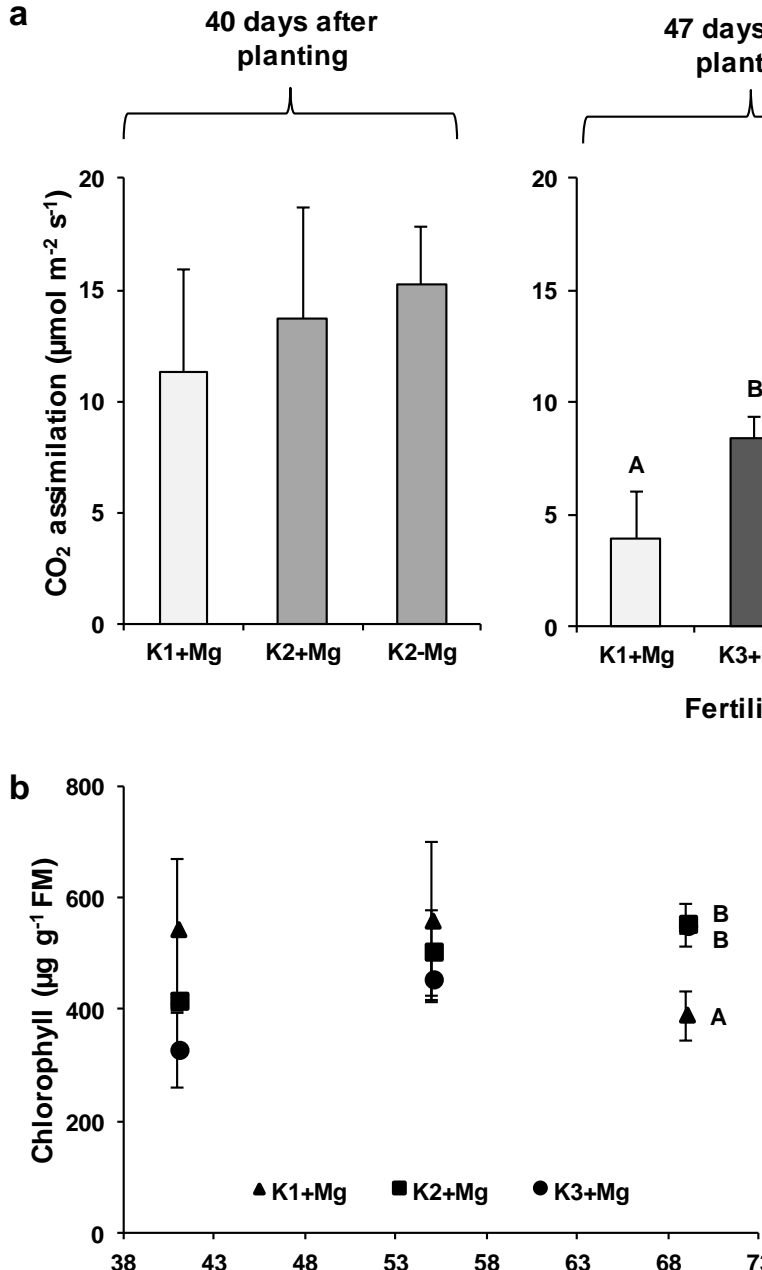

47 days after planting

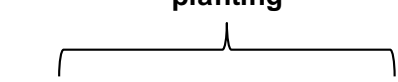

20

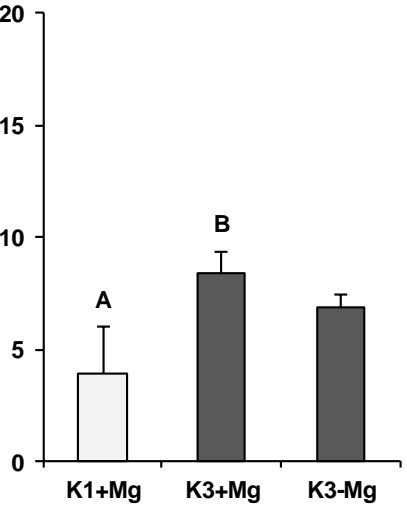

Fertilization treatment
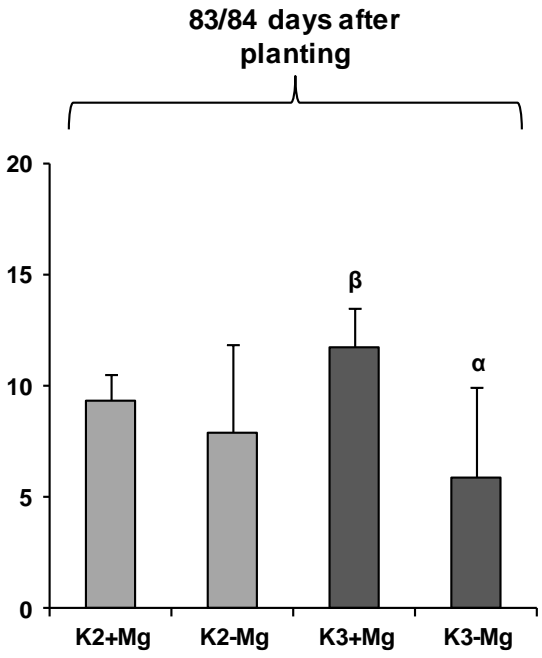

C 800

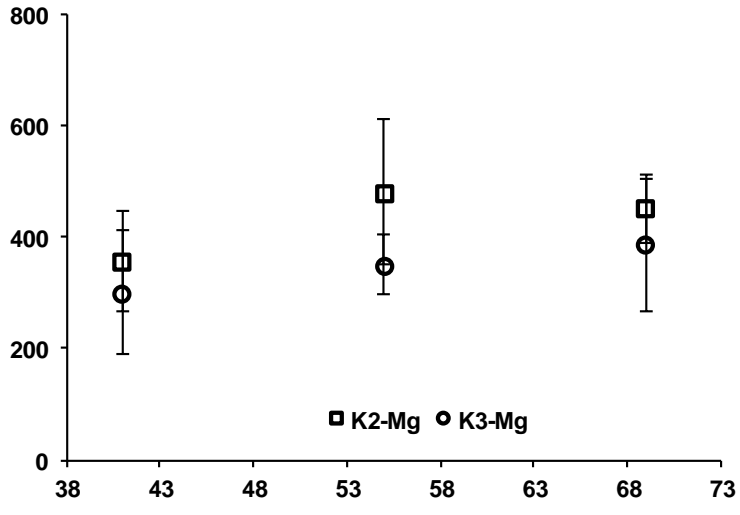

Days after planting

Figure 4: Effect of $\mathrm{K}$ and $\mathrm{Mg}$ treatments on $\mathrm{CO}_{2}$ net assimilation and leaf chlorophyll concentrations.

$\mathrm{CO}_{2}$ net assimilation rate of fully expanded leaves over time (a) of $\mathrm{K} 2+\mathrm{Mg}$ plants compared to $\mathrm{K} 1+\mathrm{Mg}$ and $\mathrm{K} 2-\mathrm{Mg}$ plants on day 40 after planting, of $\mathrm{K} 3+\mathrm{Mg}$ plants compared to $\mathrm{K} 1+\mathrm{Mg}$ and $\mathrm{K} 3-\mathrm{Mg}$ plants on day 47 after planting, and of $\mathrm{K} 2+\mathrm{Mg} / \mathrm{K} 3+\mathrm{Mg}$ plants compared to $\mathrm{K} 2-\mathrm{Mg} / \mathrm{K} 3-\mathrm{Mg}$ plants on days $83 / 84$ after planting (K2 and $\mathrm{K} 3+\mathrm{Mg}$ were measured on day 83 and $\mathrm{K} 2$ and $\mathrm{K} 3-\mathrm{Mg}$ plants were measured on day 84 after planting), and chlorophyll concentrations in fully expanded leaves on days 41,55 , and 69 after planting of $\mathrm{K} 1, \mathrm{~K} 2$, and $\mathrm{K} 3+\mathrm{Mg}$ (b) and $\mathrm{K} 2$ and $\mathrm{K} 3-\mathrm{Mg}$ plants (c) $(\mathrm{n}=4-5)$. Mean \pm SE values. Capitals = significant differences between differing $\mathrm{K}$ treatments of $+\mathrm{Mg}$ plants. Greek letters $=$ significant differences between differing Mg treatments in K3 plants. No indication = no significant effect. 


\section{Soluble sugars in fully expanded leaves}

The total soluble sugars increased in the leaves of $\mathrm{K} 1+\mathrm{Mg}$ and of $\mathrm{K} 2$ and $\mathrm{K} 3-\mathrm{Mg}$ plants compared to $\mathrm{K} 2$ and $\mathrm{K} 3+\mathrm{Mg}$ plants (Fig. 5a). While this observation was not significant on 41 DAP, the total soluble sugars significantly increased in leaves of $\mathrm{K} 1+\mathrm{Mg}$-treated plants compared to $\mathrm{K} 2$ and the $\mathrm{K} 3+\mathrm{Mg}$-treated plants, and in the leaves of $\mathrm{K} 2$ and $\mathrm{K} 3$ Mg-treated plants compared to K2 and K3+Mg-treated plants on 69 DAP. At the same time, the sum of hexose sugars (glucose and fructose) was higher in $\mathrm{K} 1+\mathrm{Mg}$ plants and in $\mathrm{K} 2$ and $\mathrm{K} 3-\mathrm{Mg}$ plants but significant only on 69 DAP.

\section{Relative gene expression of the $\mathrm{H}^{+}$-sucrose cotransporters StSUT1 and StSUT4}

The relative transcript levels of the sucrose cotransporter StSUT1 and StSUT4 in leaves showed an up-regulation in K1 and $\mathrm{K} 3+\mathrm{Mg}$ plants compared to control plants $(\mathrm{K} 2+\mathrm{Mg})$ on 41 and $69 \mathrm{DAP}$ (Fig. 5b). In the first case, the sucrose cotransporter StSUT4 showed a more than 150-fold increase on 69 DAP. The increase of transcript levels of both genes was more modest in $\mathrm{Mg}$-deficient plants (K2 and $\mathrm{K} 3-\mathrm{Mg}$ ) (Fig. 5c) compared to both low $\mathrm{K}(\mathrm{K} 1+\mathrm{Mg}$ ) and high $\mathrm{K}$ supplied plants $(\mathrm{K} 3+\mathrm{Mg})$ (Fig. 5b). The relative transcript levels of the sucrose cotransporter StSUT4 were higher compared to the relative transcript levels of the sucrose cotransporter $S t S U T 1$ in $\mathrm{K}$ low $(\mathrm{K} 1+\mathrm{Mg})$, in $\mathrm{K}$ high $(\mathrm{K} 3+\mathrm{Mg})$ and in $\mathrm{Mg}$ deficient plants (K2 and $\mathrm{K} 3-\mathrm{Mg}$ ) on 41 and 69 DAP (Fig. 5b and c).

\section{Tuber DM, sugar and starch}

The sugar and starch yields per plant revealed significant differences between the various fertilization treatments. First, $\mathrm{K} 2$ and $\mathrm{K} 3+\mathrm{Mg}$ showed significant higher yields of hexose sugars (glucose and fructose) as well as of the sum of all sugars (glucose, fructose and sucrose) per plant compared to K1+Mg plants (Fig. 6a). Second, K2 and K3+Mg plants exhibited significant higher starch yields per plant in comparison to $\mathrm{K} 1+\mathrm{Mg}$ plants (Fig. 6b). Besides, plants with sufficient Mg supply (K2 and $\mathrm{K} 3+\mathrm{Mg}$ ) showed significant higher starch yields compared to Mg-deficient plants (K2 and $\mathrm{K} 3-\mathrm{Mg}$ ) (Fig. 6b). However, the concentrations of the sum of sugars (glucose, fructose, and sucrose) as well as of the sum of hexose sugars (glucose and fructose) and of starch in tubers did not show significant differences across the fertilization treatments (SM_5b and SM_5c). Only a slight tendency can be reported in the form of lower concentrations of hexose sugars in plants with high $\mathrm{K}$ and sufficient $\mathrm{Mg}$ supply ( $\mathrm{K} 3+\mathrm{Mg}$ ) compared to the other treatments (SM_5). Besides, there was no effect of the different K and Mg treatments on tuber DM (SM_5a). 
a

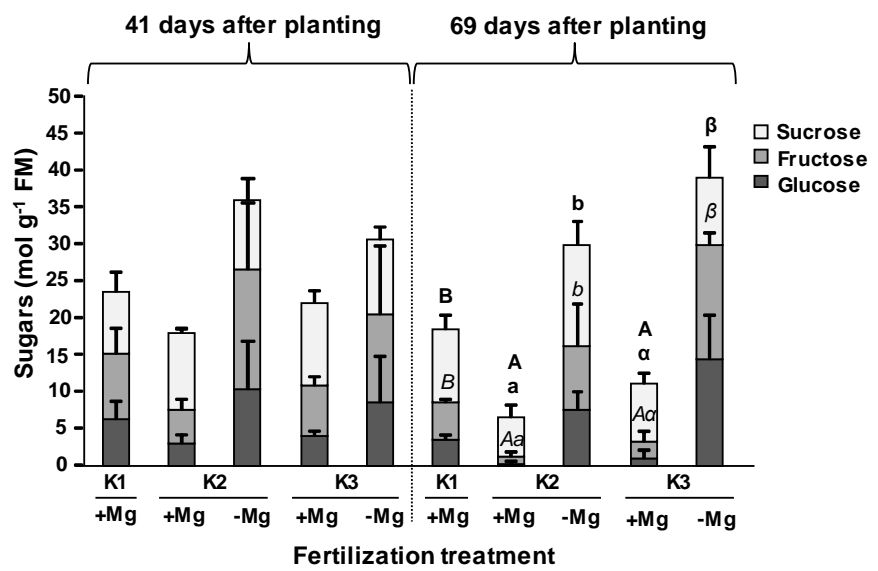

b
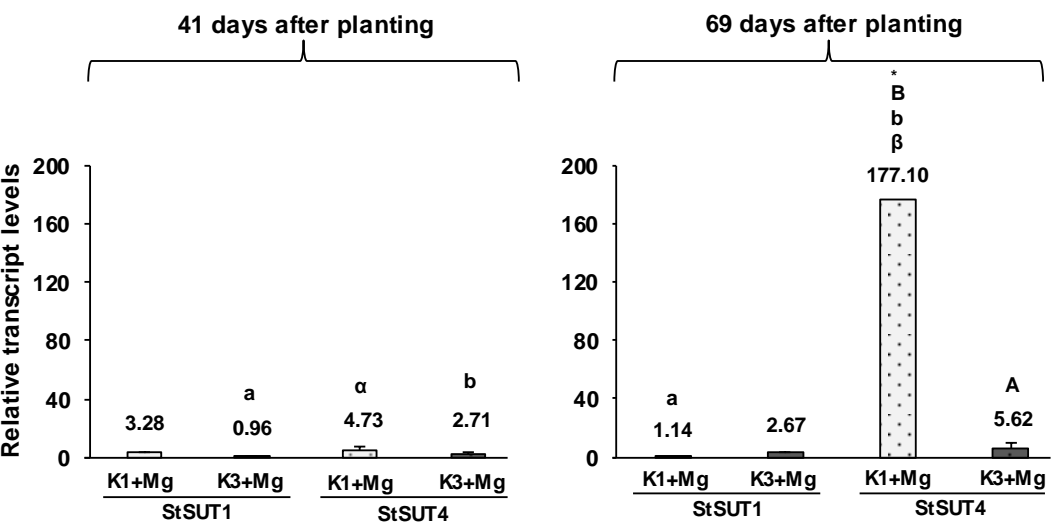

C

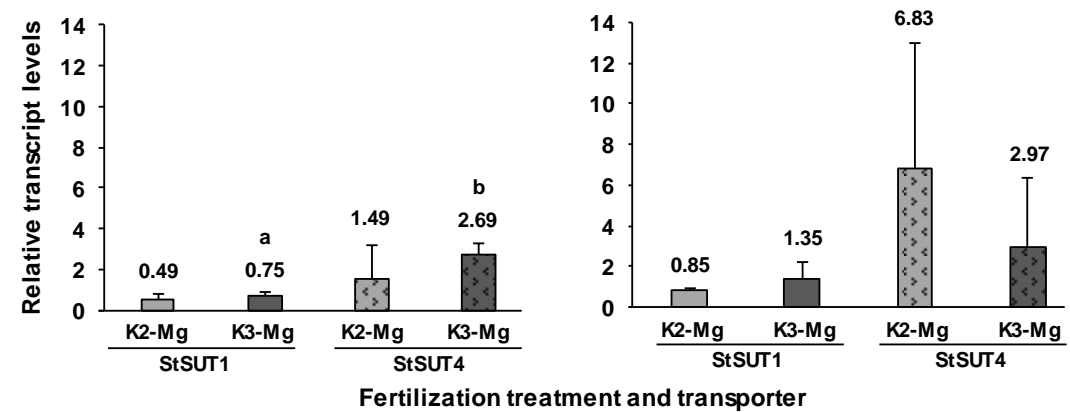

Figure 5: Effect of $\mathrm{K}$ and $\mathrm{Mg}$ treatments on soluble sugar concentrations and transcript levels of genes encoding $\mathrm{H}^{+} /$sucrose symporters in leaves. Total soluble and hexose sugar concentrations in fully expanded leaves of all fertilization treatments on day 41 and 69 after planting (a) $(n=4-5)$. Mean \pm SE values. Capitals $=$ significant differences between differing $\mathrm{K}$ treatments of $+\mathrm{Mg}$ plants. Small letters $=$ significant differences between differing $\mathrm{Mg}$ treatments of K2 plants. Greek letters = significant differences between differing Mg treatments in K3 plants. Nonitalic letters $=$ significant differences between total soluble sugars. Italic letters $=$ significant differences between hexose sugars. Transcript levels of the $\mathrm{H}^{+} /$sucrose symporters StSUT1 and StSUT4 in fully expanded leaves of Kdepleted plants $(\mathrm{K} 1+\mathrm{Mg})(\mathrm{b})$ and of Mg-depleted plants in the medium $(\mathrm{K} 2-\mathrm{Mg})$ and high $(\mathrm{K} 3-\mathrm{Mg}) \mathrm{K}$ levels (c) compared to control plants $(\mathrm{K} 2+\mathrm{Mg})$ on day 41 and 69 after planting $(\mathrm{n}=1-5)$. Mean $\pm \mathrm{SE}$ values. Asterisks $=$ significant differences to control plants. Capitals $=$ significant differences between $\mathrm{K} 1+\mathrm{Mg}$ and $\mathrm{K} 3+\mathrm{Mg}$ plants. Small letters $=$ significant differences between transporters at one sampling date and of one fertilization treatment. Greek letters $=$ significant differences between 41 and 69 days after planting of one transporter and fertilization treatment. No indication $=$ no significant effect. 


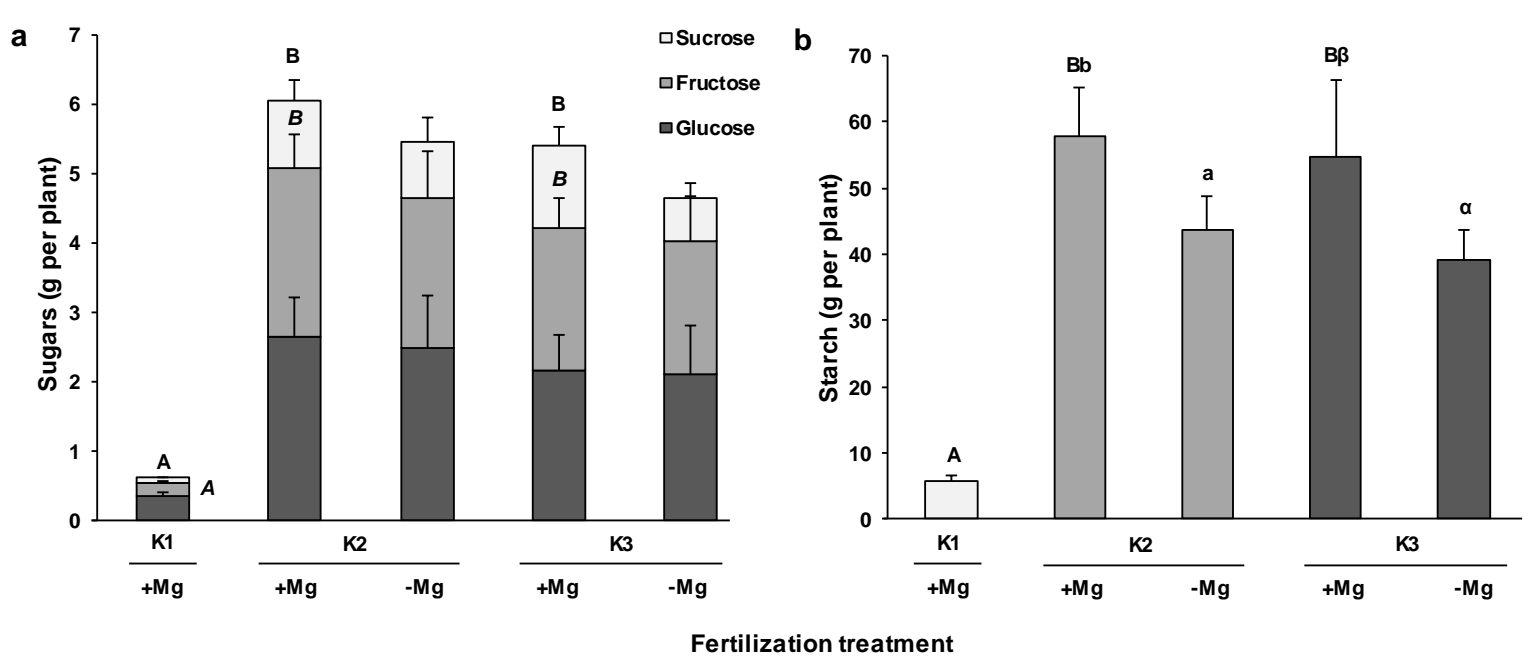

Figure 6: Effects of $\mathrm{K}$ and $\mathrm{Mg}$ treatments on tuber sugar and starch yields per plant. Yields of sugar (glucose, fructose, and sucrose) (a) and starch (b) in tubers of all fertilization treatments at harvest $(\mathrm{n}=8-10)$. Mean $\pm \mathrm{SE}$ values. Non-italic capitals $=$ significant differences in the sum of sugars (glucose, fructose, and sucrose) between differing $\mathrm{K}$ treatments of $+\mathrm{Mg}$ plants. Italic capitals = significant differences in the sums of hexose sugars (glucose and fructose) between differing $\mathrm{K}$ treatments of $+\mathrm{Mg}$ plants. Small letters $=$ significant differences between differing $\mathrm{Mg}$ treatments of K2 plants. Greek letters = significant differences between differing Mg treatments in K3 plants. No indication $=$ no significant effect.

\section{Discussion}

Our experimental set-ups were suitable to impose $\mathrm{K}$ and $\mathrm{Mg}$ deficiencies in potato plants. Indeed, the $\mathrm{K}$ concentrations in leaves of $\mathrm{K} 1+\mathrm{Mg}$ plants were below levels which are considered to ensure a sufficient supply with $\mathrm{K}$ of the potato plant (Table 2), which should be above $30 \mathrm{mg} \mathrm{K} \mathrm{g}^{-1} \mathrm{DM}$ (Bergmann 1993; von Wulffen et al. 2008). The same is true for $\mathrm{Mg}$ concentrations in leaves of $\mathrm{Mg}$-limited plants (K2 and $\mathrm{K} 3-\mathrm{Mg}$ ) (Table 2), which should be higher than $2 \mathrm{mg}$ Mg g-1 DM (Bergmann 1993; von Wulffen et al. 2008).

Shoot and root growth decreased under Mg-and especially under K-deficiency

Plants fed with low K supply showed decreased shoot and root biomasses, plant heights, and internode numbres compared to those with sufficient or high K supplies (Fig. 2). Such decreases under low K supply are well known, as shown by Cakmak et al. (1994a) in bean (Phaseolus vulgaris L.) and Jákli et al. (2016) in spring wheat plants (Triticum aestivum L. var. Sonett). In Mg-depleted plants, we observed no significant effect on the aboveground biomass production (Fig. 2a, d and e) for the duration of the treatment. The total root biomass decreased during $\mathrm{K}$ and $\mathrm{Mg}$ deficiencies, although not significantly in the latter case, and the shoot-to-root biomass ratio raised consequently (Fig. 
2b). Moreover, the root length significantly decreased in $\mathrm{K}$ - as well as in Mg-deficient plants (Fig. 2c). Likewise, Kellermeier et al. (2013) documented a strong reduction of root elongation in K-deficient Arabidopsis thaliana; Silva et al. (2005) demonstrated increasing root lengths with increasing supply of Mg in soybean (Glycine max. L. Merr.). Similar to our results, Mengutay et al. (2013) noted a higher sensitivity of the root compared to the shoot growth in Mg-deficient wheat (Triticum aestivum ev. Adana 99) and maize plants (Zea mays ev. Shemal).

\section{$K$ showed an antagonistic effect on $\mathrm{Mg}$ in shoots but a synergistic effect on $\mathrm{Mg}$ in roots and tubers}

While $\mathrm{Mg}$ concentrations decreased in leaves, there was no $\mathrm{Mg}$ decrease in the roots and tubers under high $\mathrm{K}$ supply (Fig. 3b). Conversely, the highest significant Mg leaf concentrations were determined in K-deficient plants (Table 2 and Fig. 3b). When faced with restriction of major cationic nutrients like K, plants usually absorb higher amounts of other cationic nutrients than the one under restriction (Kirkby and Mengel 1967). This could explain why the Kdeficient plants revealed higher $\mathrm{Mg}$ (Table 2 and Fig. 3b) as well as higher Calcium concentrations in the leaves (SM_6). The lower $\mathrm{Mg}$ concentrations in the leaves, especially in $\mathrm{K} 3+\mathrm{Mg}$ plants, might have resulted from an antagonistic interaction between $\mathrm{K}$ and $\mathrm{Mg}$ during root uptake. The occurrence of an Mg-deficiency risk in plants due to high K supply has often been reported (Ding et al. 2006; Senbayram et al. 2015). However, tubers and roots do not show any significant decrease in the Mg concentrations in plants with a high $\mathrm{K}$ supply (Fig. 3b). This is probably due to the usually much lower amounts of K in roots compared to shoots (Fig. 3a) (White 1997; Karley and White 2009). Both effects, antagonism and synergism, seem related: Increasing $\mathrm{K}$ concentrations led to a depletion in $\mathrm{Mg}$ leaf concentrations while the $\mathrm{Mg}$ root and tuber concentrations increased compared to the $\mathrm{Mg}$ leaf concentrations.

Interestingly, under $\mathrm{K}$ - and $\mathrm{Mg}$-deficiency, the quantitative highest proportion of decreasing $\mathrm{K}$ and $\mathrm{Mg}$ concentrations can be allocated to the leaves, while the decrease in $\mathrm{K}$ and $\mathrm{Mg}$ concentrations in tubers was quantitatively less (Fig. 3). It is conceivable that the plant strives to save its reproductive organs by investing higher amounts of nutrients in the tubers rather than in the roots and leaves.

Potassium-deficiency reduced photosynthesis while Mg-deficiency caused a reduction only late in growth stage During K-deficiency, lower photosynthetic rate is mirrored by lower shoot biomass production (Fig. 2a and 4a). This confirms earlier reports on cotton (Zhao et al. 2001) and sunflower (Jákli et al. 2017) plants fed with a low K supply. Mg-deficient plants did not show a significantly decreased $\mathrm{CO}_{2}$ net assimilation rate at the earlier growth stages (40 and 47 DAP). However, there was a decrease in $\mathrm{CO}_{2}$ net assimilation in $\mathrm{Mg}$-deficient leaves at a later growth stage 
(Fig. 4a). Similar findings were presented by Hermans et al. (2005), who detected a decrease in photosynthetic electron flux in the photosynthetic reaction centers PS II and I in Mg-deficient sugar beet plants (Beta vulgaris L. ev. Adonis). The fact that $\mathrm{CO}_{2}$ net assimilation was not restricted under $\mathrm{Mg}$-deficiency in the early growth stages may explain why these plants did not suffer the same loss of photosynthetic active biomass compared to the K-deficient plants (Fig. 2a). Interestingly, higher concentrations of chlorophyll were found in the lowest K-treated plants compared to the medium and high K-treated plants on the early sampling dates (Fig. 4b). This is probably because leaf expansion in the Kdepleted plants was restricted, which resulted in higher chlorophyll concentrations compared to plants given higher $\mathrm{K}$ treatments. Moreover, chlorosis and necrosis were less developed at these earlier growth stages (Fig. 1a).

\section{Soluble sugars accumulated in $\mathrm{K}$ - and especially in $\mathrm{Mg}$-deficient fully expanded leaves}

The total soluble sugar concentrations showed a sharp increase in the leaves of Mg-depleted plants compared to Mgadequate plants (Fig. 5a). Similarly, K-deficient plants also showed increased concentrations of soluble sugars in their leaves, but the results were less severe than found under Mg-deficiency. The reason for the significant differences in total soluble sugar concentrations on 69 DAP but not yet on 41 DAP might be related to increased tuber sink demand due to a progressed tuber development stage on 69 DAP (approximately 50\% of full tuber development), as shown, for instance, by Kolbe and Stephan-Beckmann (1997). On 41 DAP, there could be a lower need for sucrose export to tubers for starch synthesis, which resulted in overall higher soluble sugar concentrations in leaves and, therefore, no significant differences in the sugar concentrations across the differently treated plants. Furthermore, plants with low $\mathrm{Mg}$ showed an accumulation of soluble sugars in leaves before any reduction of the $\mathrm{CO}_{2}$ net assimilation occurred. These observations strengthen the idea that during Mg-deficiency the translocation of assimilates to sink organs is adversely affected prior to photosynthesis (Hermans et al. 2004; Cakmak and Kirkby 2008).

A possible impairment of phloem export could mark the origin of sucrose accumulation and subsequent hydrolysis into glucose and fructose (Fig. 5a). Indeed, Huber (1984) indicated that the accumulation of hexoses in K-deficient leaves was linked to increased INV activity. Recently, Farhat et al. (2016) showed that INV activity is affected in Sulla carnosa plants and concentrations of hexose sugars increased in source leaves through Mg-deficiency. Mg-sufficient plants exhibited comparably higher INV activity in the shoots while low-Mg plants showed increased INV activity in source leaves, possibly due to impaired loading of the phloem as a result of Mg-deficiency. 
$K$ - and Mg-deficiency caused sugar accumulations in different cell compartments and thus differentially affected the gene expression of sucrose transport systems

The transcript levels of StSUT1 and StSUT4, both genes encoding $\mathrm{H}^{+} /$sucrose symporters, were more abundant in leaves during K-deficiency $(\mathrm{K} 1+\mathrm{Mg})$ compared to control plants $(\mathrm{K} 2+\mathrm{Mg})$ (Fig. 5b). Concomitantly, sucrose accumulated in these leaves (Fig. 5a), possibly leading to—besides a breakdown into hexose units—increased gene expression of the $\mathrm{H}^{+} /$sucrose symporter StSUTl and StSUT4. The transcript level increase, in particular StSUTl, was not as marked during Mg-deficiency as during K-deficiency (Fig. 5c). Nonetheless, sugar accumulation was more pronounced in source leaves of Mg-deficient than of K-deficient plants (Fig. 5a). Therefore, we assume that the accumulation of sucrose and the following breakdown into hexose sugar units by INV occurred in different leaf compartments under the situation of $\mathrm{K}$ - or Mg-deficiency. Magnesium is required by $\mathrm{H}^{+}$-ATPases, which are pumping protons across the plasma membrane into the apoplasm. Under Mg-deficiency, this proton extrusion may be hampered. Thus, we argue that fewer protons are pumped into the apoplasm and in consequence less sucrose is loaded into the companion cell-sieve element complex. Following our initial assumption, this would result in an accumulation of sucrose in the apoplasm affecting the relative transcript abundance of $\mathrm{H}^{+} /$sucrose symporters. However, as an alternative scenario, it is feasible that an impaired function of $\mathrm{H}^{+}$-ATPases already affects an earlier step of sucrose transport, namely the efflux of sucrose from mesophyll cells into the apoplasm what is carried out via SWEET transporters (Manck-Götzenberger and Requena 2016). We hypothesize that these SWEET transporters are forced to reduce the export of sucrose from the mesophyll into the apoplasm as a consequence of a reduced activity of $\mathrm{H}^{+} /$sucrose symporters due to a decreased loading of protons by $\mathrm{H}^{+}$-ATPases into the apoplasm caused by Mg-deficiency. Sucrose would then accumulate mainly in mesophyll cells. Meanwhile, the increased transcript abundance of the sucrose cotransporter StSUT4 on 69 DAP could be a later response of the plant to a decreased import of sucrose into sink organs.

The major role of $\mathrm{K}$ in the partitioning of photoassimilates can be referred to establish an osmotic potential within the phloem which helps to translocate sucrose from source to sink tissues (Hayashi and Chino 1990; Cakmak 2005). Therefore, under K-deficiency sucrose translocation from source to sink organs might be restricted and sucrose may accumulate in the apoplasm or in cells of the companion cell-sieve element complex. Since sugars accumulate in the close vicinity of $\mathrm{H}^{+} /$sucrose symporters in the case of $\mathrm{K}$-deficiency, it is likely that this results in a more pronounced increase of the transcript abundance of the $\mathrm{H}^{+} /$sucrose symporters StSUT1 and StSUT4. Moreover, the expression levels 
of StSUT4 were more abundant than those of StSUT1. This fits to the assumption made by Weise et al. (2000) that StSUT4 is a low-affinity transporter, being mainly active at higher sucrose concentrations.

Finally, the increased expression levels of the sucrose cotransporters in high $\mathrm{K}$ supplied plants (K3+Mg) (Fig. 5b and c) could be due to comparatively higher sugar concentrations in these leaves (Fig. 5a). It is conceivable that the plant produced temporally more sugars via photosynthesis under K luxury supply than actually needed by the plant's sink organs what in turn could have led to a slight accumulation of sucrose in source leaves.

\section{K- and Mg-deficiency decreased tuber starch and sugar yield but not starch and sugar concentrations}

The tuber sugar and starch yields per plant (amount of sugar and starch per plant) revealed clear differences due to the various $\mathrm{K}$ and $\mathrm{Mg}$ treatments. Plants with deficient $\mathrm{K}(\mathrm{K} 1+\mathrm{Mg})$ and $\mathrm{Mg}(\mathrm{K} 2$ and $\mathrm{K} 3-\mathrm{Mg})$ supply showed significant lower sugar and starch yields compared to plants with sufficient $\mathrm{K}$ and $\mathrm{Mg}$ (K2 and $\mathrm{K} 3+\mathrm{Mg}$ ) supply (Fig. 6a and b). Contrary to the initial expectations that an impairment of photosynthesis and photoassimilate translocation due to Kor Mg-deficiency would adversely affect tuber sugar and starch concentrations, no significant influence of K- or Mgdeficiency on tuber sugar and starch concentrations was detectable (SM_5b and SM_5c). With respect to tuber sugar concentrations, the present findings are in agreement with the results of Stanley and Jewell (1989), who also could not find a significant change in hexose sugar concentrations under conditions of varying $\mathrm{K}$ supply in potato. However, Gerendás et al. (2007) determined a decrease in the level of hexose sugars with increasing K supply in potato. The present results coincide only in tendency with the findings of Gerendás et al. (2007) (SM_5b). The significant differences in tuber starch and sugar yields may be a reference to the significant effects of treatments on the tuber yield (Fig. 2f).

\section{Author contributions}

E.P. obtained funding. I.C., C.H. and M.K designed the experiment. M.B. and M.K. performed the experiments and collected and evaluated the data. J.B. and M.N. helped with the experimental work and data evaluation. E.P., M.N., I.C., C.H. and I.S. supervised the experiment and data evaluation. All authors have contributed to, read and approved the manuscript. 
Chapter 4: Differential effects of varied potassium and magnesium nutrition on production and partitioning of photoassimilates in potato plants

\section{Acknowledgements}

We thank the $\mathrm{K}+\mathrm{S} \mathrm{GmbH}$ for the scientific and financial support. We thank the Division of Agronomy, University of Göttingen for allowing us to use their devices - with special thanks to Juliane Streit, also for her scientific advices. 


\section{Supplementary material}

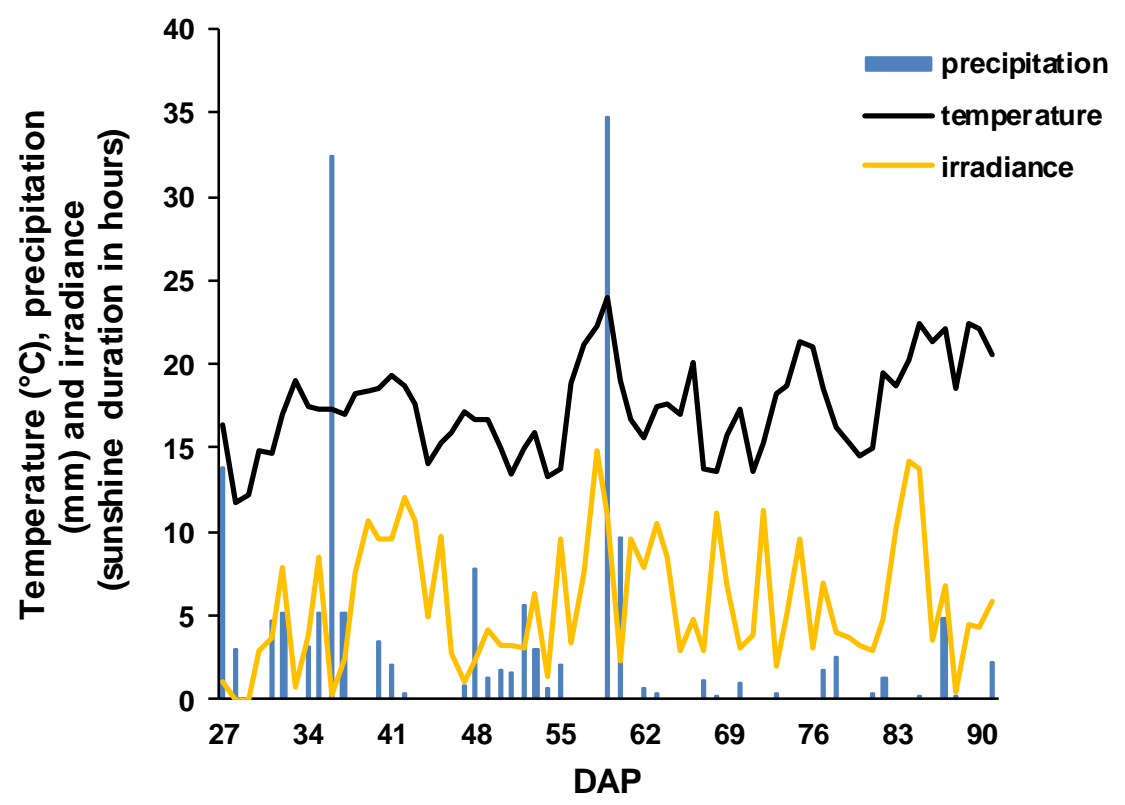

SM_1: Mean temperature, precipitation, and irradiance over the vegetation period (outdoor installation).

SM_2: Applied amounts (in $\mathrm{mg} \mathrm{kg}^{-1-}$ soil) and used form of nutrients besides $\mathrm{K}$ and $\mathrm{Mg}$.

\begin{tabular}{lll}
\hline Element & Applied amount of salt & Salt formulation \\
\hline Nitrogen & 300 & $\mathrm{Ca}(\mathrm{NO})_{3}$ \\
Phosphorus & 100 & $\mathrm{Ca}\left(\mathrm{PO}_{4}\right)_{2} \cdot \mathrm{H}_{2} \mathrm{O}$ \\
Calcium & 1,300 & $\mathrm{CaCO}_{3}$ \\
Boron & 2 & $\mathrm{H}_{3} \mathrm{BO}_{3}$ \\
Zinc & 2 & $\mathrm{ZnSO}_{4} \cdot 7 \mathrm{H}_{2} \mathrm{O}$ \\
Molybdenum & 0.01 & $\mathrm{Na}_{2} \mathrm{MoO}_{4} \cdot 2 \mathrm{H}_{2} \mathrm{O}$ \\
Copper & 2 & $\mathrm{CuSO}_{4} \cdot 5 \mathrm{H}_{2} \mathrm{O}$ \\
Manganese & 6 & $\mathrm{MnSO} 4 \cdot \mathrm{H} 2 \mathrm{O}$ \\
Iron & 3 & $\mathrm{Fe}(\mathrm{III}) \mathrm{EDTA}(13 \% \mathrm{Fe})$ \\
& & \\
\hline
\end{tabular}


SM_3: Gene short names, PCR primer sequences (forward and reverse), Genbank accession numbers, amplicon sizes (bp), and PCR efficiencies (\%) with $\mathrm{R}^{2}$ of PCR efficiency.

\begin{tabular}{|c|c|c|c|c|c|c|}
\hline Gene & Forward primer & Reverse primer & Accession no. & $\begin{array}{l}\text { Amplicon } \\
\text { size }\end{array}$ & $\begin{array}{l}\text { PCR } \\
\text { efficiency }\end{array}$ & $\begin{array}{l}R^{2} \mathbf{P C R} \\
\text { efficiency }\end{array}$ \\
\hline StSUT1 & CAT GGG ATG ATT TGT TTG GA & TGG CAA CAT TGT GAG TGC TA & X69165 & 98 & 98.4 & 0.973 \\
\hline StSUT4 & GCA GCC TCT AGA TCC CAG TC & CAG GAT CAC CCA AAC AAC AC & $\begin{array}{l}\text { NM_001288141 } \\
\text { XM_006364904 }\end{array}$ & 139 & 111.4 & 0.987 \\
\hline StUBIQUITIN & CAC CAA GCC AAA GAA GAT CA & TCA GCA TTA GGG CAC TCC TT & Z11669 S45502 & 120 & 94.5 & 0.966 \\
\hline
\end{tabular}

SM_4: Thermal cycling protocol.

\begin{tabular}{l|ccc|cc}
\hline Initial denaturation & Denaturation & $\begin{array}{c}\text { Amplification } \\
\text { Annealing }\end{array}$ & Extension & Cycles & Melting curve analysis \\
\hline $98^{\circ} \mathrm{C}$ for $\mathbf{3 0 ~ s e c}$ & $95^{\circ} \mathrm{C}$ for $10 \mathrm{sec}$ & $55^{\circ} \mathrm{C}$ for $15 \mathrm{sec}$ & $72^{\circ} \mathrm{C}$ for $15 \mathrm{sec}$ & 44 & $65^{\circ} \mathrm{C}$ to $95^{\circ} \mathrm{C}, 0.5^{\circ} \mathrm{C}, 5 \mathrm{sec} / \mathrm{step}$ \\
\hline
\end{tabular}




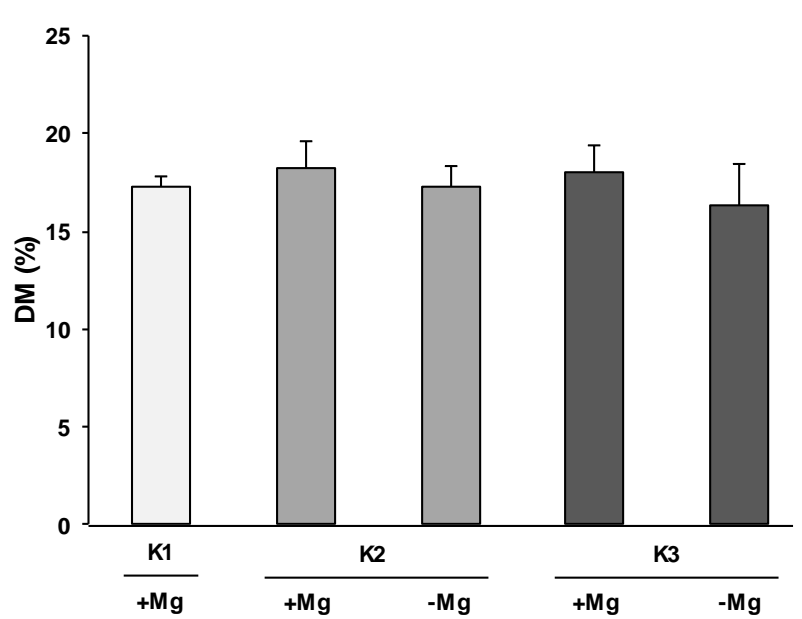

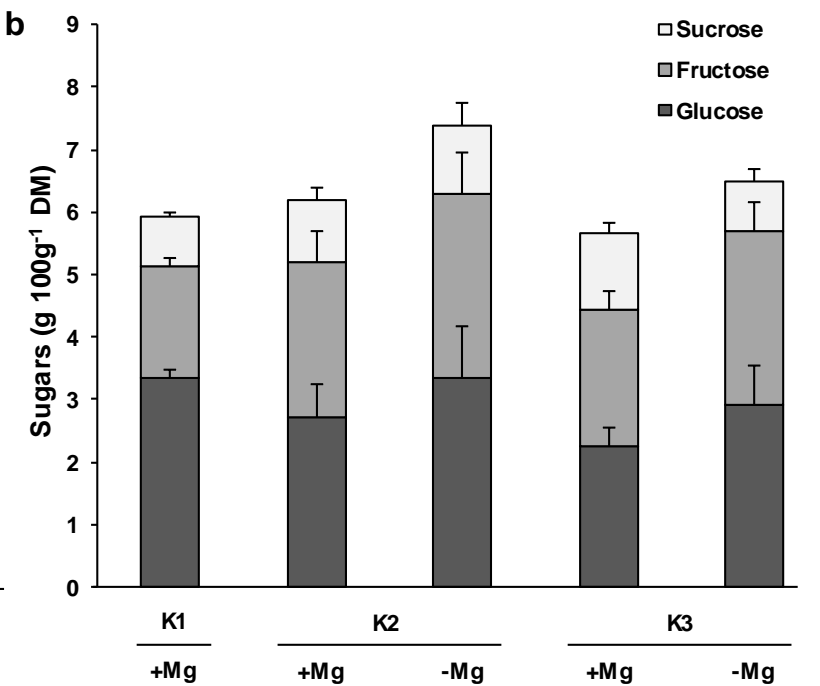

Fertilization treatment

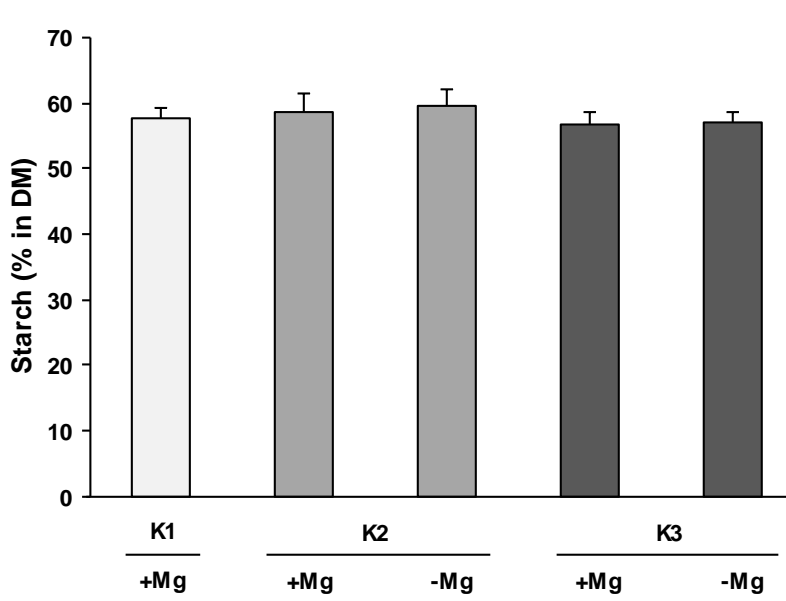

SM_5: Tuber DM and sugar (glucose, fructose and sucrose) and starch concentrations of all five fertilization treatments at harvest $(\mathrm{n}=8-10)$. Mean \pm SE values. Treatments had no significant effect. 
SM_6: Calcium (Ca) concentrations ( $\left.\mathrm{mg} \mathrm{g}^{-1} \mathrm{DM}\right)$ in fully expanded leaves on five sampling dates from day 34 until day 69 after planting ( $\mathrm{n}=4-5$ ). Mean \pm SE values. Capitals $=$ significant differences between differing $\mathrm{K}$ treatments of $+\mathrm{Mg}$ plants. Small letters $=$ significant differences between differing $\mathrm{Mg}$ treatments in $\mathrm{K} 2$ plants. No indication $=$ not significant.

$\mathrm{Ca}$

Fertilization treatment

\begin{tabular}{|c|c|c|c|c|c|c|c|c|}
\hline DAP $^{*}$ & $\mathrm{~K} 1+\mathrm{Mg}$ & & $\mathrm{K} 2+\mathrm{Mg}$ & & K2-Mg & $\mathrm{K} 3+\mathrm{Mg}$ & & K3-Mg \\
\hline 34 & $19.69 \pm 3.07$ & C & $10.65 \pm 0.73$ & B & $11.92 \pm 2.21$ & $8.46 \pm 0.42$ & A & $10.18 \pm 2.59$ \\
\hline 41 & $15.64 \pm 1.93$ & B & $7.65 \pm 1.09$ & $\mathrm{Aa}$ & $10.31 \pm 0.61 \quad b$ & $6.62 \pm 0.46$ & $A$ & $8.16 \pm 0.89$ \\
\hline 48 & $33.74 \pm 2.26$ & B & $13.18 \pm 1.48$ & A & $16.01 \pm 1.49$ & $10.07 \pm 1.55$ & A & $11.75 \pm 2.99$ \\
\hline 55 & $21.37 \pm 1.68$ & C & $12.73 \pm 2.08$ & B & $16.12 \pm 1.76$ & $8.52 \pm 0.82$ & A & $10.64 \pm 1.92$ \\
\hline 69 & $38.04 \pm 2.51$ & C & $21.13 \pm 1.96$ & B & $25.89 \pm 2.37$ & $14.69 \pm 2.50$ & A & $17.91 \pm 1.79$ \\
\hline
\end{tabular}

${ }^{\star} \mathrm{DAP}=$ days after planting. 


\section{Chapter 5}

\section{Effect of magnesium deficiency and magnesium complementary fertilization on potato (Solanum tuberosum L.) root growth}

Mirjam Koch, Marcel Naumann and Elke Pawelzik 


\title{
Effect of magnesium deficiency and magnesium complementary fertilization on potato (Solanum tuberosum L.) root growth
}

\author{
Mirjam Koch, Marcel Naumann and Elke Pawelzik \\ Department for Crop Sciences, Division Quality of Plant Products, Carl-Sprengel-Weg 1, \\ 37075 Göttingen, University of Göttingen.
}

\section{Abstract}

Potato roots have a shallower and less extended root system compared to other crops what makes them less efficient in the acquisition of water and nutrients. As the ability for water and nutrient acquisition is mainly determined by root morphological characteristics such as root length, optimal root growth is of high importance for potato plants. The development and growth of plant roots can be affected by various factors. One of these factors is the supply of the plant with nutrients. Based on the pivotal roles of magnesium $(\mathrm{Mg})$ for photosynthesis and the partitioning of photoassimilates within the plant, $\mathrm{Mg}$ is expected having a pivotal influence on the development of plant roots. A negative impact of Mg deficiency on root growth has been demonstrated in other plants. To our knowledge, the effect of Mg deficiency on root growth in potato (Solanum tuberosum L.) has never been investigated as well as the effect of a resupply of $\mathrm{Mg}$ to $\mathrm{Mg}$-deficient potato plants. A hydroponic culture system with potato plants was conducted with three levels of Mg supply ('Mg low', 'Mg med', 'Mg high') in order to identify a dose that is sufficient for ensuring appropriate root growth and two Mg complementary fertilization treatments $(\mathrm{Mg}$ foliar application or increase of $\mathrm{Mg}$ concentrations via addition into the nutrient solution). 'Mg low' plants exhibited a sharp decrease in root biomass and root length whereas 'Mg med' and 'Mg high' plants developed twice as much root biomass and doubled root length. Besides, an accumulation of soluble sugars occurred in source leaves of ' $\mathrm{Mg}$ low' treated plants. This is indicative for a restricted phloem loading which is supposed having negative effects on root growth. On the other hand, a restricted sink demand due to reduced root growth may lead to an accumulation of soluble sugars in source leaves. The results indicate that the Mg supply of 'Mg med' plants represented already a sufficient supply of $\mathrm{Mg}$ for potato with respect to root growth. The Mg foliar application demonstrated only negligible effects on potato root growth, whereas the rise of the Mg nutrient solution concentrations of 'Mg low' plants showed more distinct effects, especially in form of an increased Mg nutrient status and increased root length development.

\section{Keywords}

Root length, root-to-shoot ratio, Mg foliar application, $\mathrm{Mg}$ resupply, chlorophyll, phloem loading, hydroponic culture system 


\section{Introduction}

Plant roots are crucial for the acquisition of water and nutrients and thus, determine plant growth and performance (Gruber et al. 2013). The ability of plant roots for acquisition of nutrients mainly is affected by the size of absorbing surface and the ability to explore the soil for nutrients (Sattelmacher et al. 1993; Sattelmacher et al. 1994). Hence, root morphological characteristics such root length, diameter and number highly determine a plant's nutrient efficiency (Sattelmacher et al. 1994). However, potato roots are known to have a shallower and less extended root system compared to other crops and are classified as poor rooting efficient (Hopkins et al. 2014). Tanner et al. (1982) found that $90 \%$ of potato root length is located in the upper $25 \mathrm{~cm}$ of the soil. This might contribute to the fact that potato is a very sensitive crop for water shortages and can be (in comparison with other crops) classified as inefficient in the acquisition of nutrients (van Loon 1981; Hopkins et al. 2014). Therefore, ensuring an unrestricted and optimal root growth of potato gains high importance, especially for nutrients which are mainly taken up by the plant via mass flow such as nitrogen and magnesium (Mg) (Strebel and Duynisveld 1989; Barber 1995). The development and architecture of plant roots can be affected by various reasons. Several studies demonstrated a positive relation between the plant's mineral nutrition and root growth (Sattelmacher et al. 1993; López-Bucio et al. 2003; Gruber et al. 2013). However, studies related to the impact of mineral nutrition on root growth in potato are rare.

$\mathrm{Mg}$ is one of the essential elements in plants and is involved in several physiological and biochemical processes of plant development and growth. For instance, $\mathrm{Mg}$ is the central atom of the light harvesting pigments chlorophyll (Braumann et al. 2014). In addition, Mg is needed for the activation and function of several enzymes (Senbayram et al. 2015) - for example for the activation of the $\mathrm{CO}_{2}$ fixing enzyme ribulose-1,5-bisphosphate (RuBP) carboxylase (Belknap and Portis 1986). The earliest response of Mg deficiency is reported to be an accumulation of sucrose in Mg deficient source leaves (Cakmak and Kirkby 2008), as has been shown in sugar beet (Beta vulgaris L. cv. Adonis) (Hermans et al. 2004). This sucrose accumulation can be referred to an impaired phloem loading process and thus, a restricted translocation of photoassimilates from source to sink organs. Mg interacts with ATP of $\mathrm{H}^{+}$-ATPases which balance charges and are providing energy and therefore are needed by $\mathrm{H}^{+} /$sucrose symporters, which are loading the phloem with sucrose (Hermans et al. 2005). Marschner et al. (1996) stated that the extent, to which a nutrient is affecting the root growth and development, is mainly dependent on translocation processes of the needed minerals and photoassimilates within the plant. Based on the presented roles of $\mathrm{Mg}$ in photosynthesis and for the partitioning of photoassimilates, a strong impact of $\mathrm{Mg}$ on the root development can be expected as roots are important sink organs for photoassimilates. 
This study focused on the impact of $\mathrm{Mg}$ deficiency on the root growth of potato plants (Solanum tuberosum L.). Due to the indispensable functions of $\mathrm{Mg}$ for the production and partitioning of photoassimilates in plants, it is hypothesized that $\mathrm{Mg}$ deficiency will lead to a significant reduction of root biomass and total root length, what is regarded as an important morphological parameter for nutrient acquisition (Sattelmacher et al. 1994). Thus, it is aimed to screen three different $\mathrm{Mg}$ supplies to identify a dose that is sufficient to allow appropriate root growth. A further aim of this study is to examine, how a resupply of $\mathrm{Mg}$ via the roots and via the leaves, respectively, may affect an existing deficiency of $\mathrm{Mg}$ and related symptoms such as depressed root growth. Beside root growth, leaf sugar concentrations were determined as indicator for a potential impaired phloem loading process.

\section{Material and methods}

\section{Experimental design and growth conditions}

Potato plants (Solanum tuberosum L.) of the variety 'Laura' were grown in nutrient solution in a climate chamber for a period of 60 days. The plants grew under an alternate day/night cycle of 12 hours with a photosynthetic photon flux density of $180 \mu \mathrm{mol} \mathrm{m} \mathrm{m}^{-2} \mathrm{~s}^{-1}$ (MASTER Agro $400 \mathrm{~W}$; Philips, Netherlands) during illumination. Average air temperature was $20^{\circ} \mathrm{C}$ during the day and $16{ }^{\circ} \mathrm{C}$ during the dark period and relative humidity was 60 $\%$. Before onset of the experiment, plants were propagated in a soil culture system under low Mg supply (plants which were later grown under nutrient solution concentrations of 5 or $100 \mu \mathrm{M} \mathrm{Mg}$ ) or sufficient Mg supply (plants which were later grown under nutrient solution concentrations of $500 \mu \mathrm{M} \mathrm{Mg}$ ) (supplementary material (SM)_1). For planting only potato pieces with a germ bud instead of whole tubers were used to avoid nutrient delivery from the whole tuber. When the plants reached a height of approximately $10 \mathrm{~cm}$, they were transferred into a nutrient solution with stepwise increasing nutrient concentrations $(20 \%-50 \%-100 \%)$ over the first seven days. The full nutrient solution concentration was: $2.75 \mathrm{mM} \mathrm{Ca}\left(\mathrm{NO}_{3}\right)_{2} .4 \mathrm{H}_{2} \mathrm{O}, 0.25 \mathrm{mM} \mathrm{NH} \mathrm{NO}_{3}, 2 \mathrm{mM} \mathrm{K} \mathrm{SO}_{4}, 0.25 \mathrm{mM}$ $\mathrm{Ca}\left(\mathrm{H}_{2} \mathrm{PO}_{4}\right)_{2} \cdot \mathrm{H}_{2} \mathrm{O}, 0.1 \mathrm{mM}$ Fe(III) EDTA (13\% Fe), $10 \mu \mathrm{M} \mathrm{H}_{3} \mathrm{BO}_{3}, 1 \mu \mathrm{M} \mathrm{ZnSO} \mathrm{Zn}_{4} .7 \mathrm{H}_{2} \mathrm{O}, 1 \mu \mathrm{M} \mathrm{MnSO} \mathrm{M}_{4} \cdot \mathrm{H}_{2} \mathrm{O}, 0.2$ $\mu \mathrm{M} \mathrm{CuSO}_{4} .5 \mathrm{H}_{2} \mathrm{O}$ and $0.14 \mu \mathrm{M} \mathrm{H}_{24} \mathrm{Mo}_{7} \mathrm{~N}_{6} \mathrm{O}_{24} .4 \mathrm{H}_{2} \mathrm{O}$. Besides, the plants were treated with three different $\mathrm{Mg}$ supplies: A low (5 $\mu \mathrm{M} \mathrm{Mg})$, a medium $(100 \mu \mathrm{M} \mathrm{Mg})$ or a high (500 $\mu \mathrm{M} \mathrm{Mg}) \mathrm{Mg}$ level, following designated as 'Mg low', 'Mg med' and 'Mg high'. $\mathrm{Mg}$ was given as $\mathrm{Mg}_{2} \mathrm{SO}_{4} .7 \mathrm{H}_{2} \mathrm{O}$. The low and the medium $\mathrm{Mg}$ supply were represented each by 12 plants. The high $\mathrm{Mg}$ level was represented by four plants throughout the whole experiment. After nine days after onset of the experiment (DAO) four plants of the low and four plants of the medium Mg level received three times (10, 17 and $24 \mathrm{DAO}$ ) a $\mathrm{Mg}$ foliar application with $\mathrm{Mg}_{2} \mathrm{SO}_{4} .7 \mathrm{H}_{2} \mathrm{O}$ (together with the wetting agent Silwet ${ }^{\circledR}$ Top $\left(0.1 \%\right.$ (v/v); BASF, Austria), following designated as '+ $\mathrm{f}^{\prime}$. The concentration of the Mg spraying solution was $200 \mathrm{mM} \mathrm{Mg}_{2} \mathrm{SO}_{4} .7 \mathrm{H}_{2} \mathrm{O}$. Each plant received approximately $28 \mathrm{mg} \mathrm{Mg}$ by one $\mathrm{Mg}$ foliar application. 
Plants, which did not receive an foliar application were sprayed only with distilled water plus the wetting agent.

Furthermore, four plants of the low and the medium $\mathrm{Mg}$ level received an additional $\mathrm{Mg}$ supply via the nutrient solution by increasing the $\mathrm{Mg}$ nutrient solution concentration from 5 and $100 \mu \mathrm{M} \mathrm{Mg}$, respectively, to $500 \mu \mathrm{M}$ $\mathrm{Mg}$, following designated as 'to Mg high'. The schematic experimental setup is shown in figure 1. The plants were grown in 5 liter plastic pots with one plant per pot. The nutrient solution was aerated and changed every 3-5 days in dependence on plant growth and water consumption.

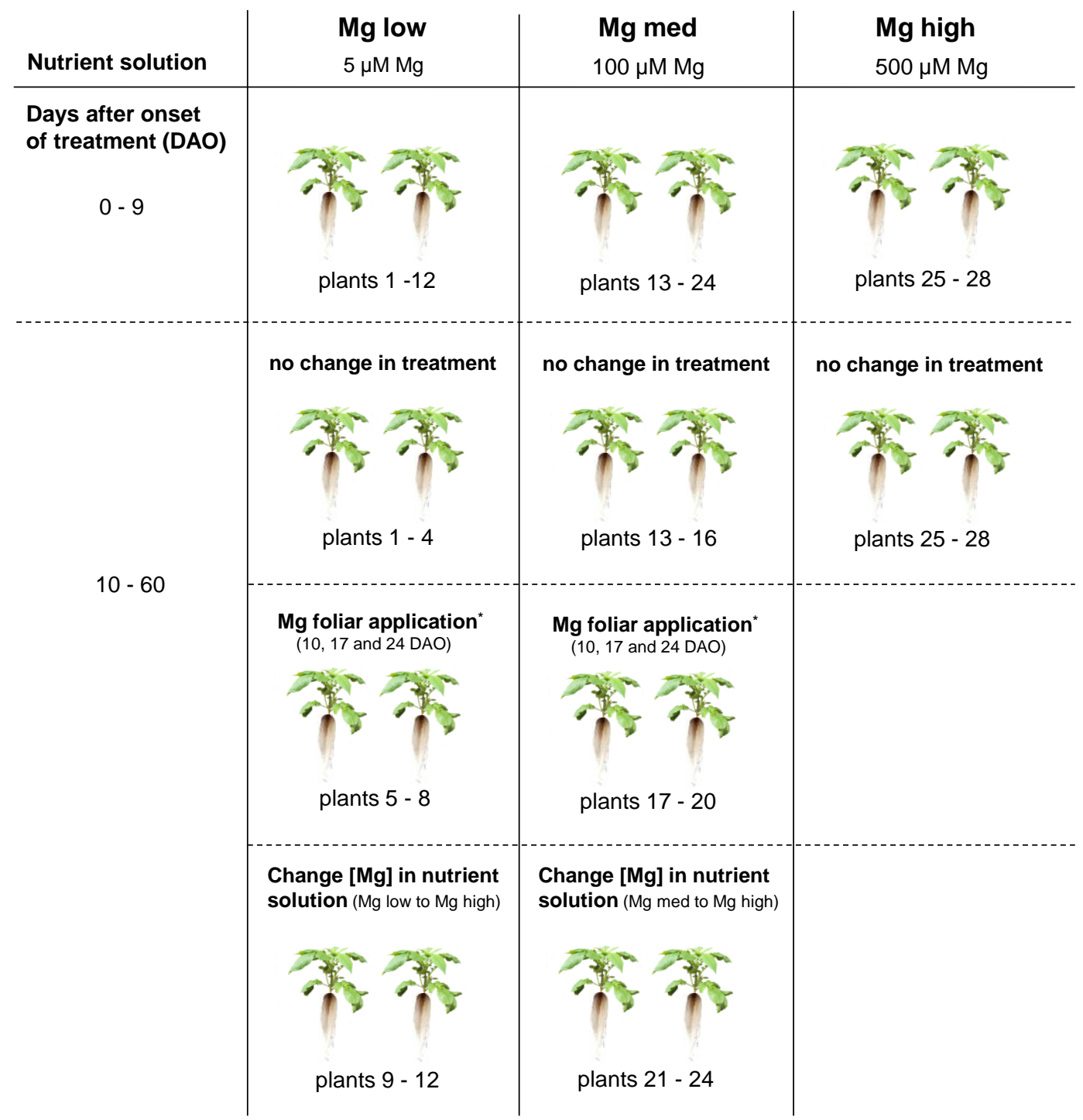

concentration of $\mathrm{Mg}$ foliar application $=0.2 \mu \mathrm{M} \mathrm{Mg} \sim 28 \mathrm{mg} \mathrm{Mg} \mathrm{plant}^{-1}$ and application ${ }^{-1}$

Figure 1: Schematic setup of experiment with three levels of $\mathrm{Mg}$ supply ('Mg low' = $5 \mu \mathrm{M} \mathrm{Mg}$; 'Mg med' = 100 $\mu \mathrm{M} \mathrm{Mg}$; 'Mg high' = $500 \mu \mathrm{M} \mathrm{Mg}$ ) and complementary fertilizations (Mg foliar application and change of $\mathrm{Mg}$ concentration in nutrient solution from 'Mg low' or 'Mg med', respectively, 'to Mg high'). Plants 1-4 ('Mg low'), 13-16 ('Mg med') and 25-28 ('Mg high') remained unchanged throughout the whole experiment. After 9 DAO plants 5-8 ('Mg low') and 17-20 ('Mg med') received three times an Mg foliar application while plants 9-12 ('Mg low') and plants 21-24 ('Mg med') were raised in their Mg concentration of nutrient solution 'to Mg high'. 


\section{Mg determination in fully expanded leaves and roots}

Leaf and root samples were dried at $60^{\circ} \mathrm{C}$ for four days. Afterward, leaves were ground with a mortar and pestle and root samples were ground into $0.5 \mathrm{~mm}$ flour in a hammer mill (DFH 48, Culatti, Switzerland). Leaves, which received an $\mathrm{Mg}$ foliar application, were washed prior drying to get rid of $\mathrm{Mg}$ residues on the leaf surface. Minerals were determined according to an modified method as described by Wheal et al. (2011) and carried out as follows: $100 \mathrm{mg}$ of prepared leaf or root sample was digested with $4 \mathrm{ml}$ of $65 \%(\mathrm{v} / \mathrm{v})$ nitric acid and $2 \mathrm{ml}$ of $30 \%(\mathrm{v} / \mathrm{v})$ hydrogen peroxide at $200^{\circ} \mathrm{C}$ and 40 bar for 75 minutes in a microwave (Ethos 660; MWT AG, Switzerland). The samples were filled up to $25 \mathrm{ml}$ with distilled water and stored in screw cap tubes until analysis. The concentrations of $\mathrm{Mg}$ were examined using inductively coupled plasma optical emission spectrometry (Vista-PRO CCD Simultaneous ICP-OES; Varian Inc., USA).

\section{Chlorophyll quantification in fully expanded leaves}

Leaves were grounded with mortar and pestle in liquid nitrogen and $20 \mathrm{mg}$ was weighed in $2 \mathrm{ml}$ screw cup micro tubes and stored in liquid nitrogen until further use. The plant material was extracted twice with $80 \%$ (v/v) ethanol and a third time with $50 \%(\mathrm{v} / \mathrm{v})$ ethanol. The samples were shaken in a heat block at $95^{\circ} \mathrm{C}$ for 30 minutes. After the third extraction step, the supernatants were combined, the pellet discarded, and the samples stored at $-20^{\circ} \mathrm{C}$ until further analysis.

Chlorophyll was examined by preparing a mix of $50 \mu \mathrm{l}$ ethanolic extract (or $70 \%$ (v/v) ethanol as blank) and 120 $\mu 198 \%$ ethanol per well on a 96-well plate. The optical density (OD) was measured at $645 \mathrm{~nm}$ and $665 \mathrm{~nm}$ in a plate reader (Epoch, 1402203; Biotek, USA), and chlorophyll a and b were calculated according to the following formulas:

$$
\begin{aligned}
& \text { Chlorophyll a }(\mu \mathrm{g} / \text { well })=5.48 \mathrm{~A}_{665}-2.16 \mathrm{~A}_{645} . \\
& \text { Chlorophyll } \mathrm{b}(\mu \mathrm{g} / \mathrm{well})=9.67 \mathrm{~A}_{645}-3.04 \mathrm{~A}_{665} .
\end{aligned}
$$

For the results, the sum of chlorophyll a and b was considered.

\section{Soluble sugar determination in fully expanded leaves}

The soluble sugars glucose, fructose, and sucrose were determined according to Stitt et al. (1989) (modified as described following). The same ethanolic extract as prepared for chlorophyll extraction was used. The method is based on the conversion of the sugars by the added enzymes Hexokinase (HK) (Roche Diagnostics GmbH, 
Germany; Merck, Germany), Phosphoglucose isomerase (PGI) (Roche Diagnostics GmbH, Germany), and Invertase (INV) (Sigma Aldrich, USA). Thereby electrons are released and are transferred to nicotinamide adenine dinucleotide phosphate $\left(\mathrm{NADP}^{+}\right.$) (Roche Diagnostics GmbH, Germany) forming NADPH + H. For dissolving the enzymes a $100 \mathrm{~m} M$ hydroxyethylpiperazine-ethanesulfonic acid (HEPES) buffer (Roth, Germany) $+3 \mathrm{~m} M \mathrm{MgCl}_{2}$ buffer (adjusted with $\mathrm{KOH}$ to $\mathrm{pH}$ 7) was used. Half of the samples were prepared with HK in suspension (Roche Diagnostics $\mathrm{GmbH}): 72 \mu \mathrm{l}$ (108 units) HK was centrifuged three minutes at 11,000 rotations/minute and the pellet was dissolved in $120 \mu \mathrm{l}$ HEPES- $\mathrm{MgCl}_{2}$ buffer; the other half of the samples was prepared with $\mathrm{HK}$ in solid form (Merck, Germany): $0.50 \mathrm{mg}$ was dissolved in $120 \mu \mathrm{l}$ HEPES- $\mathrm{MgCl}_{2}$ buffer. For preparation of PGI $36 \mu \mathrm{l}(25.2$ units) PGI was centrifuged for three minutes at 11,000 rotations/minute and the pellet was dissolved in $120 \mu \mathrm{l}$ HEPES- $\mathrm{MgCl}_{2}$ buffer. For preparation of INV $8.3 \mathrm{mg}$ (2,500 units) INV was dissolved in $120 \mu \mathrm{l}$ HEPES- $\mathrm{MgCl}_{2}$ buffer. A further needed enzyme was Glucose-6-phosphat dehydrogenase (G6P-DH) (Roche Diagnostics GmbH, Germany) which was prepared together with $100 \mathrm{~m} M$ ATP (Sigma-Aldrich, USA) and $45 \mathrm{~m} M$ NADP to a solution. For this, $85 \mu \mathrm{l}$ (60 units) G6P-DH were centrifuged for three minutes at 11,000 rotations/minute and the pellet was dissolved in $15.5 \mathrm{ml}$ HEPES + $\mathrm{MgCl}_{2}$ buffer, $480 \mu \mathrm{l}$ ATP, and $480 \mu \mathrm{l}$ NADP solution. Next, $50 \mu \mathrm{l}$ of the ethanolic extract plus $160 \mu \mathrm{l}$ of the G6P-DH - ATP-NADP solution was added per well on a 96-well plate and shaken for 10 minutes. The converted NADPH was quantified by measuring the OD at $340 \mathrm{~nm}$ in a plate reader (Epoch, 1402203; Biotek, USA) after reaching stable values.

NADPH was calculated with the help of $\Delta$ OD by using the following formula:

$$
\mu M \mathrm{NADPH}=\Delta \mathrm{OD} /(2.85 * 6.22)
$$

The calculated values were indicated as:

$1 M$ NADPH derived from glucose/fructose $=1 M$ glucose $/$ fructose .

$1 M$ NADPH derived from sucrose $=0.5 M$ sucrose $(1$ mole glucose equivalent $)$.

\section{Phenotype, shoot and root growth and root scanning}

The phenotype was documented by taking photos of representative leaflets and roots. Morphological changes of the shoot were recorded by measuring the plant height with a common tapeline and counting the internodes per plant. At harvest the complete shoots were cut off and the total shoot biomasses were assessed. Roots were separated from the shoots and stored at $-20^{\circ} \mathrm{C}$ until root scan analysis. Immediately prior root scanning the roots were thawed, stolons were discarded and the roots were placed in a shell and completely covered with water. Only 
the half of each root was used and the total root length was calculated for the whole root on the basis of the determined dry weight of the scanned root part and the non-scanned root part. Root scanning was conducted with a flat-bed scanner (Epson perfection V700 photo, Epson, Germany) and analyzed with the software WinRhizo 2016 (Regent Instruments Inc. Québec City, Canada). Besides, the total root biomasses were examined and based on the dry weights of shoots and roots the shoot-to-root ratios were determined.

\section{Statistics}

Statistical analysis were performed using R software version 3.4.0 (R Core Team 2016). All data were checked for normal distribution and homoscedasticity. Then, ANOVA was performed to detect differences between treatments followed by multiple contrast tests. Non-parametric Kruskal-Wallis test was performed if normality and/or homoscedasticity were not given. All tests were performed on a significance level of $\mathrm{p}<0.05$.

\section{Results}

\section{Mg status of fully expanded leaves}

The 'Mg low' treated plants exhibited the significant lowest Mg concentrations throughout the experiment (Fig. 2a). A complementary fertilization of $\mathrm{Mg}$ via $\mathrm{Mg}$ foliar application led to increasing $\mathrm{Mg}$ leave concentrations of 'Mg low' plants only at the second and third sampling date while an Mg foliar application of 'Mg med' plants only led to significant increasing Mg concentrations at the second sampling date (Fig. 2b). More distinct effects were detected by a complementary fertilization via the nutrient solution: Immediately after change of the $\mathrm{Mg}$ concentration in the nutrient solution from 5 and $100 \mu \mathrm{M} \mathrm{Mg}$, respectively, up to $500 \mu \mathrm{M} \mathrm{Mg}$ (9 DAO), the Mg leave concentrations increased four to five times compared to 'Mg low' treated plants and up to two times compared to 'Mg med' treated plants (Fig. 2b). The significant highest Mg leave concentrations throughout all sampling dates were determined in 'Mg high' treated plants, closely followed by 'Mg low to Mg high' treated plants (Fig. 2a).

\section{Chlorophyll concentrations of fully expanded leaves}

The chlorophyll concentrations did not show any significant differences between the treatments, only tendencies can be described (Fig. 3): 14 DAO the highest chlorophyll concentrations were quantified in ' $\mathrm{Mg}$ low $+\mathrm{f}^{\prime}$ and 'Mg low to Mg high' treated plants. 35 DAO all treatments showed equal chlorophyll concentrations but with lower values compared to 14 and $56 \mathrm{DAO}$. At the last sampling date (56 DAO) 'Mg low' treated plants exhibited the highest chlorophyll concentrations. 


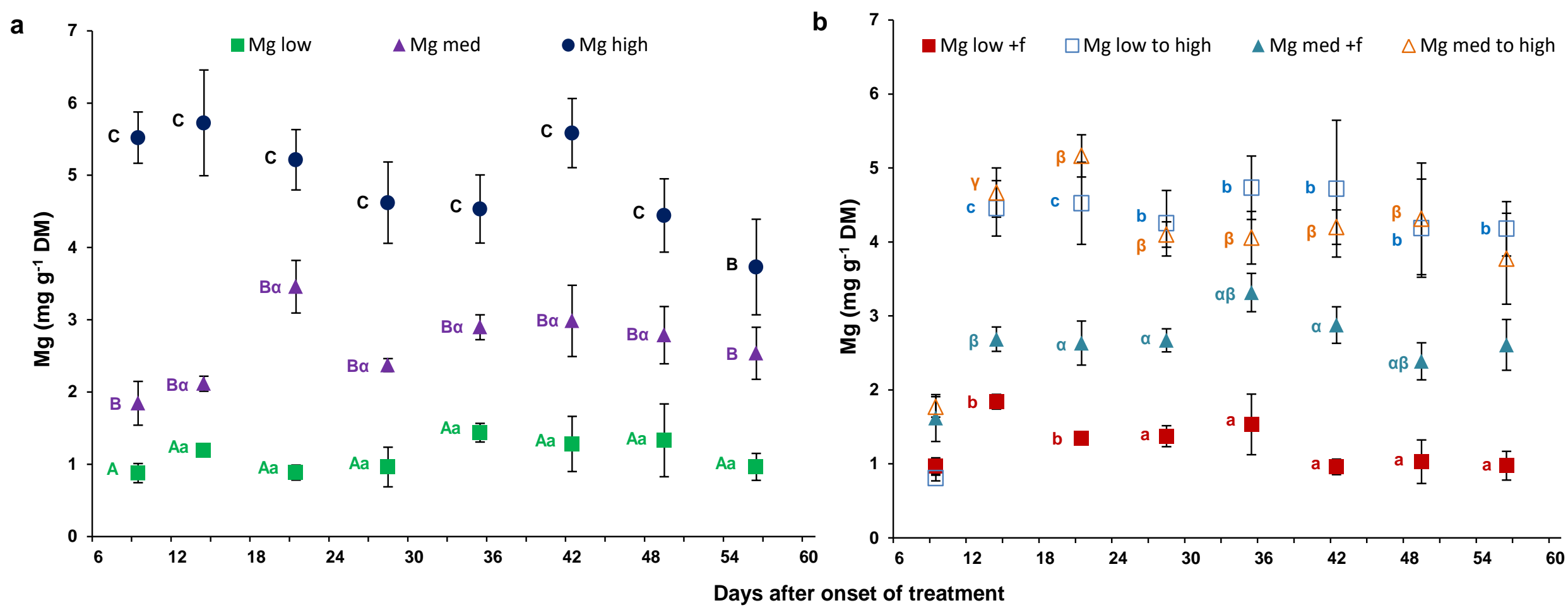

Figure 2: $\mathrm{Mg}$ leave concentrations in 'Mg low', 'Mg med' and 'Mg high' treated plants (a) and impact of complementary fertilization treatments ('+f' and 'to $\mathrm{Mg}$ high') $(\mathrm{n}=4)$ on Mg leave concentrations (b). 'Mg low' $=5 \mu \mathrm{M} \mathrm{Mg}$; 'Mg med' $=100 \mu \mathrm{M} \mathrm{Mg}$; 'Mg high' $=500 \mu \mathrm{M} \mathrm{Mg}$; '+f' = with Mg foliar application; 'to high' = change of the Mg nutrient solution concentration from 5 or 100, respectively, to $500 \mu \mathrm{M} \mathrm{Mg}$. Mg foliar application was conducted on 10, 17 and $24 \mathrm{DAO}$. Mean \pm SE values. Capitals $=$ significant differences between 'Mg low', 'Mg med' and 'Mg high' plants. Small letters = significant differences between 'Mg low', 'Mg low $+\mathrm{f}^{\prime}$ and 'Mg low to Mg high' plants. Greek letters = significant differences between 'Mg med', 'Mg med $+\mathrm{f}$ ' and 'Mg med to Mg high' plants. No indication = no significance. 


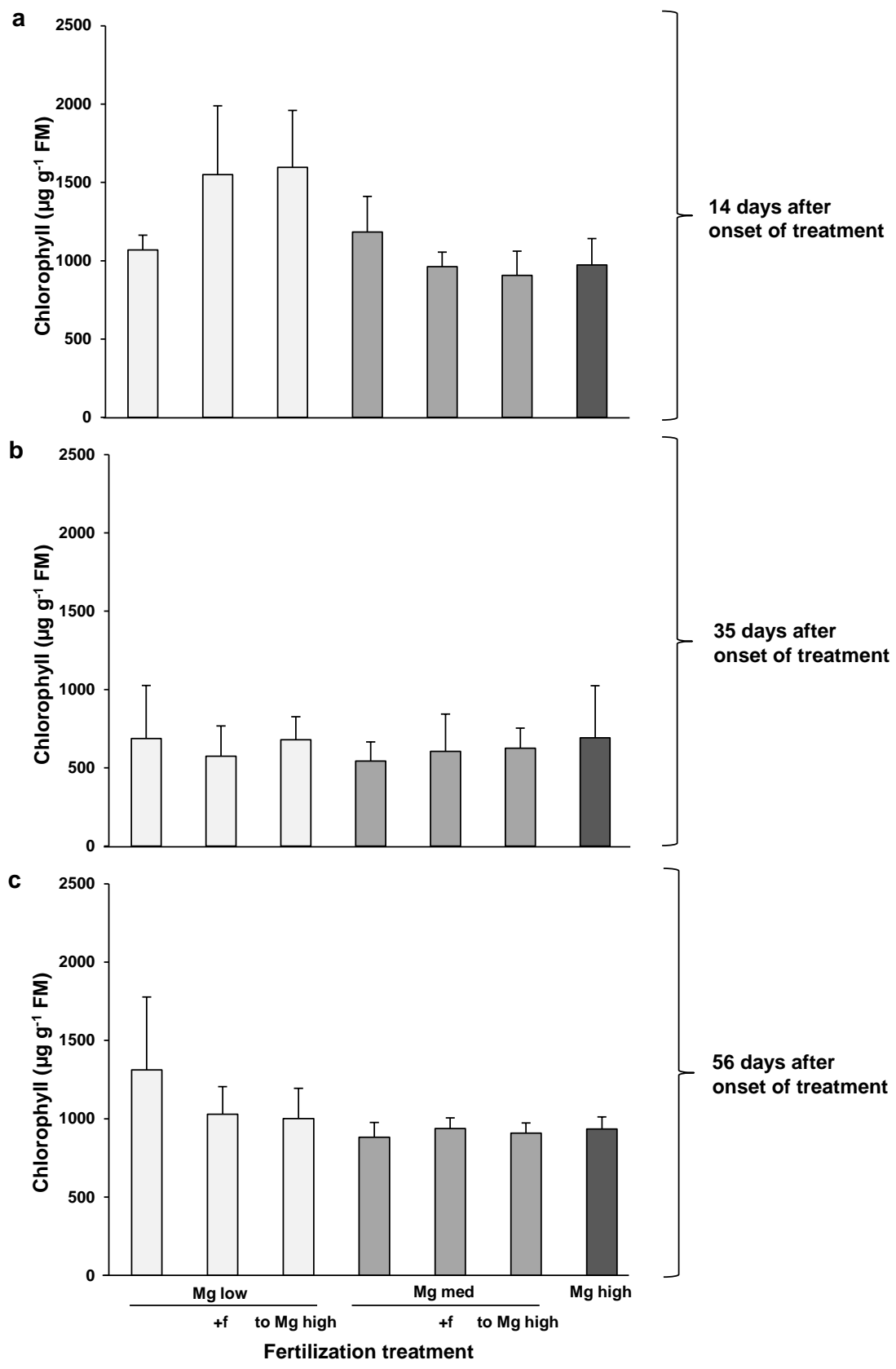

Figure 3: Chlorophyll concentrations in fully expanded leaves of all fertilization treatments at days 14 (a), 35 (b) and 56 (c) after onset of treatment ( $\mathrm{n}=4$ ). 'Mg low' $=5 \mu \mathrm{M} \mathrm{Mg}$; 'Mg med' = $100 \mu \mathrm{M} \mathrm{Mg}$; 'Mg high' = $500 \mu \mathrm{M}$ $\mathrm{Mg}$; '+f' = with $\mathrm{Mg}$ foliar application; 'to high' = change of the Mg nutrient solution concentration from 5 or 100 , respectively, to $500 \mu \mathrm{M} \mathrm{Mg}$. Mean $\pm \mathrm{SE}$ values. Treatments had no significant effect.

\section{Soluble sugar concentrations in fully expanded leaves}

14 and 35 DAO total soluble sugars (glucose, fructose and sucrose) as well as the sum of hexose sugars (glucose and fructose) did not show any significant differences (Fig. 4a and b). But at 35 DAO increasing concentrations of total as well as of hexose sugars became detectable in leaves of 'Mg low' treated plants (Fig. 4b). Meanwhile, plants of all other treatments exhibited up to one third less total soluble sugar concentrations compared to 'Mg low' plants. These differences were not significant at 35 DAO. However, at day 56 DAO similar sugar concentrations 
were determined as on $35 \mathrm{DAO}$ : 'Mg low' plants showed significant higher soluble and hexose sugar concentrations compared to 'Mg med' and 'Mg high' plants (Fig. 4c). Moreover, 'Mg low $+\mathrm{f}^{\prime}$ plants exhibited significant lower total soluble sugar concentrations compared to plants which did not receive $\mathrm{Mg}$ foliar applications ('Mg low' plants).

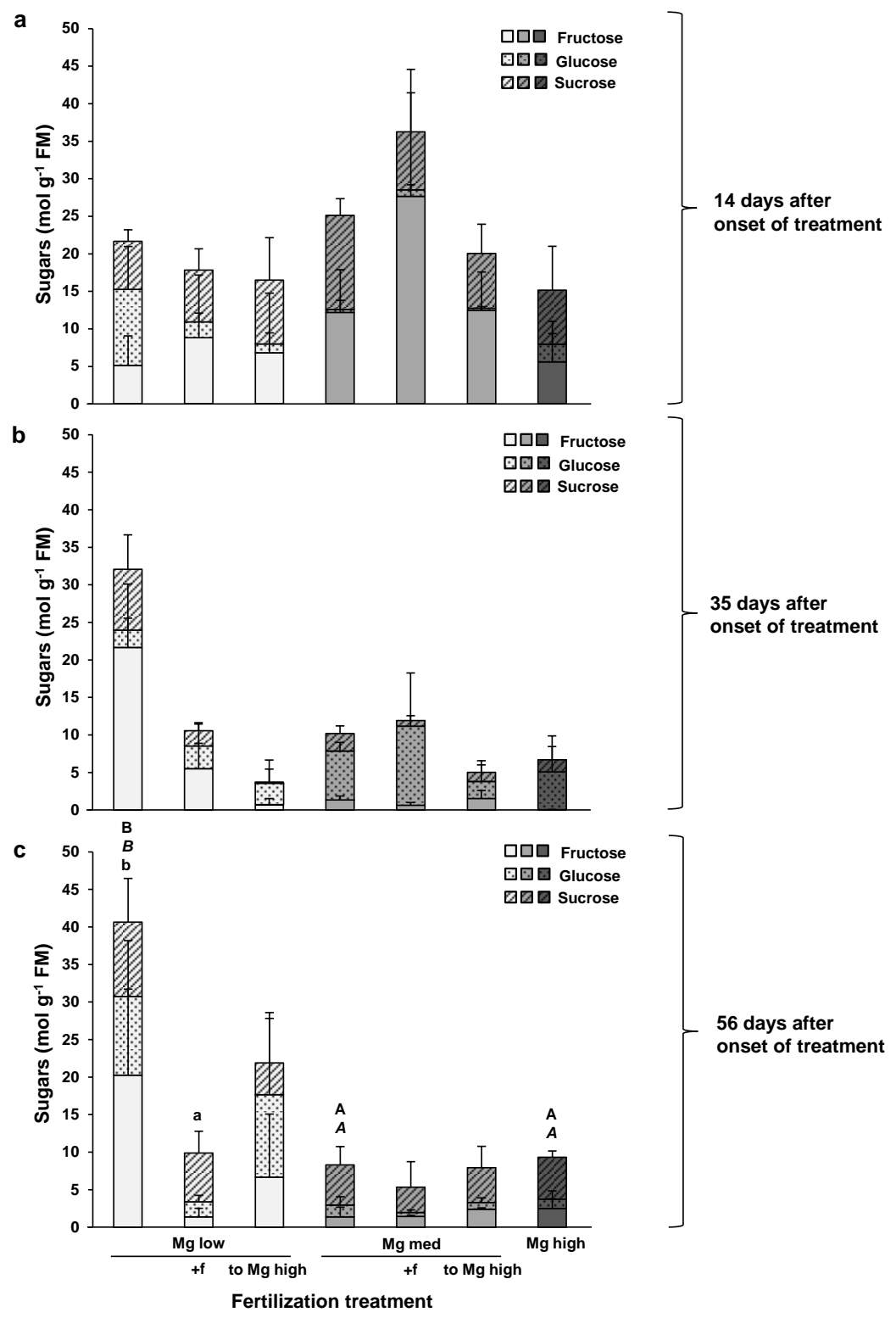

Figure 4: Total soluble and hexose sugar concentrations in fully expanded leaves of all fertilization treatments at days 14 (a), 35 (b) and 56 (c) after onset of treatment ( $\mathrm{n}=2$ - 4). 'Mg low' = $5 \mu \mathrm{M} \mathrm{Mg}$; 'Mg med' = $100 \mu \mathrm{M} \mathrm{Mg}$; 'Mg high' = $500 \mu \mathrm{M} \mathrm{Mg}$; '+f' = with $\mathrm{Mg}$ foliar application; 'to high' = change of the $\mathrm{Mg}$ nutrient solution concentration from 5 or 100 , respectively, to $500 \mu \mathrm{M} \mathrm{Mg}$. Mean \pm SE values. Capitals $=$ significant differences of total sugar sums between 'Mg low', 'Mg med' and 'Mg high' plants. Italic capitals = significant differences of hexose sugars between 'Mg low', 'Mg med' and 'Mg high' plants. Small letters = significant differences of total sugar sums between 'Mg low', 'Mg low $+\mathrm{f}^{\prime}$ and 'Mg low to $\mathrm{Mg}$ high' plants. No indication = no significance. 


\section{Shoot and root growth}

Shoot and root biomass were significantly reduced in 'Mg low' compared to 'Mg med' and 'Mg high' plants (Fig. $5 \mathrm{a}$ and $\mathrm{b}$ ). Additionally, root biomass was more reduced than shoot biomass in 'Mg low' plants what is also reflected in the higher shoot-to-root ratio of 'Mg low' compared to 'Mg high' plants (Fig. 5b). This biomass reduction is pictured in figure 6: Root biomass of 'Mg low' plants appeared smaller compared to roots of 'Mg med' and 'Mg high' treated plants. The complementary fertilization did not affect significantly on shoot as well as on root biomass (Fig. 5 and SM_2), although slight increases due the complementary fertilization treatments of 'Mg low' plants were recorded. 'Mg low' plants showed the lowest quantity of internodes (Fig. 5c) and plant heights (Fig. 5d) but at the last two sampling dates there were no significant differences in quantity of internodes and plant height between 'Mg low', 'Mg med' and 'Mg high' plants.
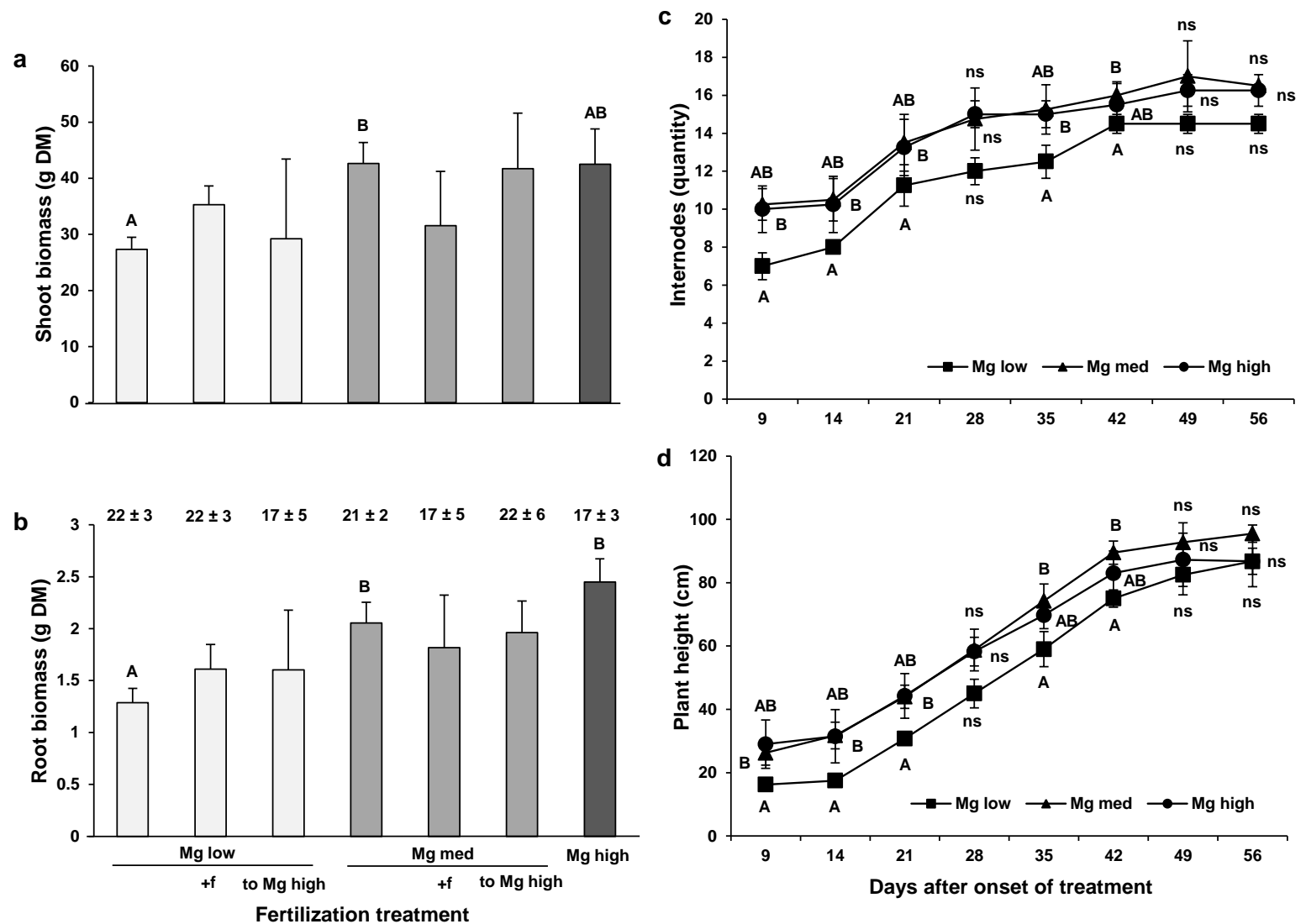

Figure 5: Effect of $\mathrm{Mg}$ deficiency ('Mg low') and complementary fertilization of $\mathrm{Mg}$ ('+f' and 'to $\mathrm{Mg}$ high') on total shoot (a) and total root biomass at harvest with shoot-to-root ratios (mean \pm SE values above bar plot) (b), on quantity of internodes (c) and on plant heights (d) at eight various sampling dates ( $\mathrm{n}=4$ ). 'Mg low' $=5 \mu \mathrm{M} \mathrm{Mg}$; 'Mg med' = $100 \mu \mathrm{M} \mathrm{Mg}$; 'Mg high' = $500 \mu \mathrm{M} \mathrm{Mg}$; '+f' = with Mg foliar application; 'to high' = change of the $\mathrm{Mg}$ nutrient solution concentration from 5 or 100 , respectively, to $500 \mu \mathrm{M} \mathrm{Mg}$. Mean $\pm \mathrm{SE}$ values. Capitals $=$ significant differences between 'Mg low', 'Mg med' and 'Mg high' treated plants. No indication = no significance. 
a

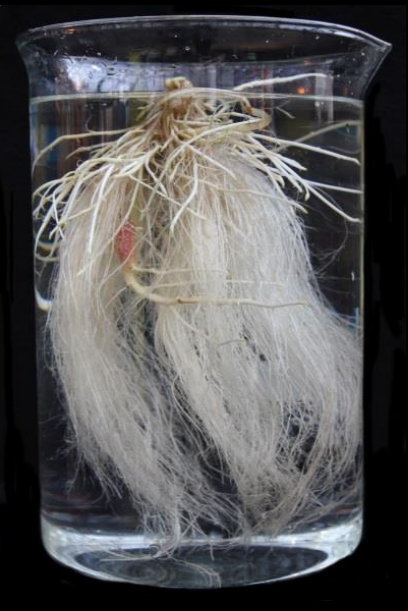

\section{Mg low}

b

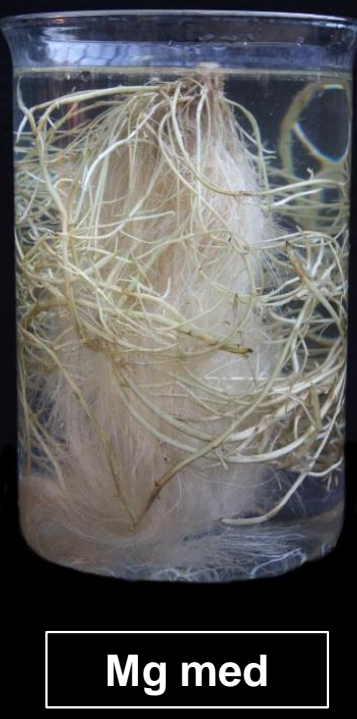

C

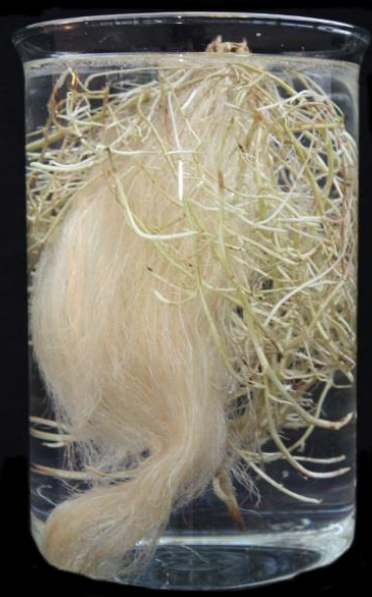

Mg high

Figure 6: Illustration of potato roots at harvest, which were grown in hydroponic culture systems under low (a), medium (b) and high (c) Mg supply.

\section{Total root length and $\mathrm{Mg}$ root status}

Total root length was significantly reduced in 'Mg low' compared to 'Mg high' treated plants. 'Mg med' treated plants exhibited comparable total root lengths as 'Mg high' treated plants, but the differences compared to 'Mg low' treated plants were not significant (Fig. 7). Similar results are presented for the $\mathrm{Mg}$ root concentrations: The significant lowest $\mathrm{Mg}$ concentrations were quantified in roots of 'Mg low' treated plants (Fig. 7). The complementary fertilization treatments did not show a significant impact on the total root length and root $\mathrm{Mg}$ concentrations but tendencies can be stated: Total root length increased by rising the $\mathrm{Mg}$ nutrient solution concentrations from 5 to $500 \mu \mathrm{M} \mathrm{Mg}$ and the root $\mathrm{Mg}$ concentrations increased by rising the $\mathrm{Mg}$ nutrient solution concentrations from 5 and $100 \mu \mathrm{M} \mathrm{Mg}$, respectively, to $500 \mu \mathrm{M} \mathrm{Mg}$. Also an $\mathrm{Mg}$ foliar application to 'Mg low' plants could increase total root length, but to a less extent compared to a raise of the $\mathrm{Mg}$ nutrient solution concentration. 


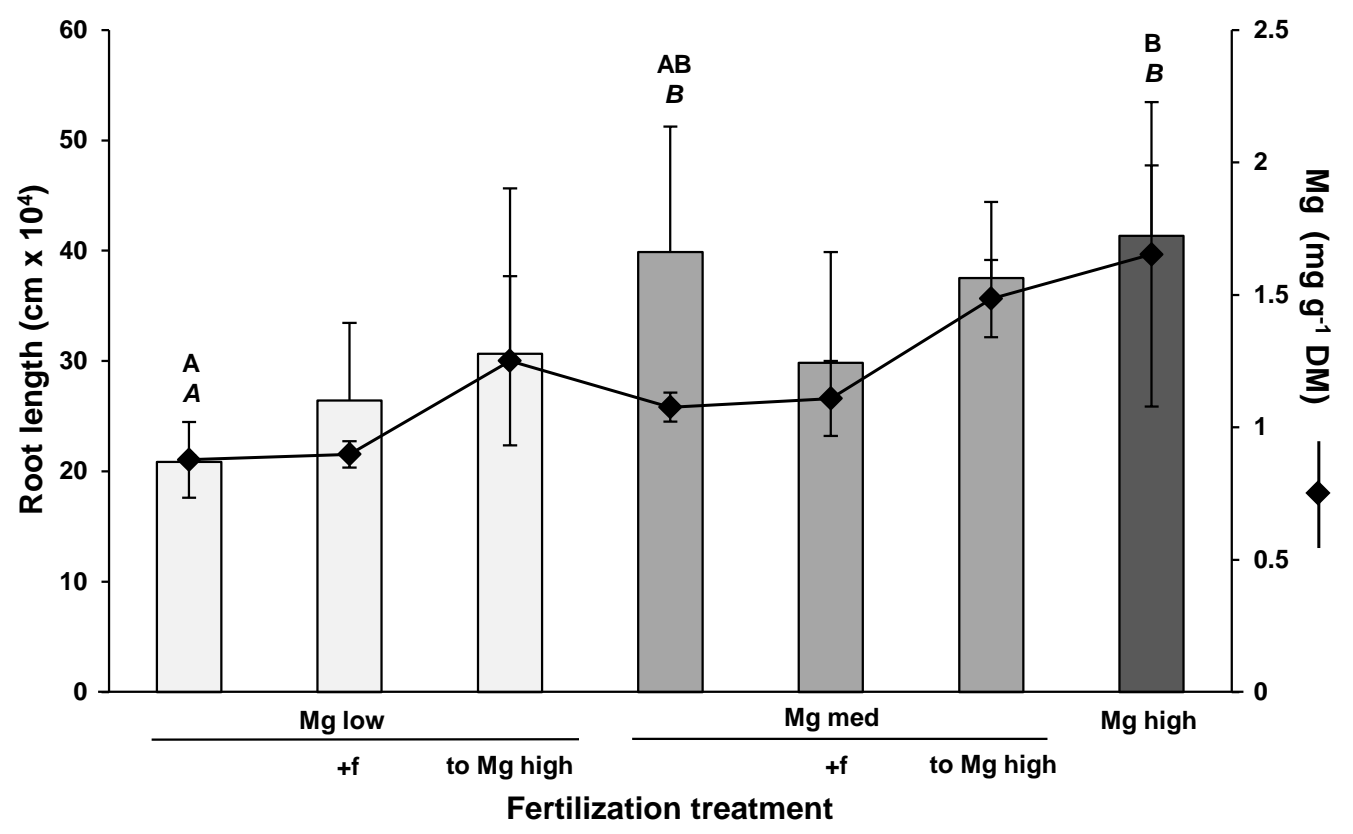

Figure 7: Total root length and root $\mathrm{Mg}$ concentrations in 'Mg low', 'Mg med' and 'Mg high' treated plants and impact of complementary fertilization treatments ('+f' and 'to $\mathrm{Mg}$ high') $(\mathrm{n}=4)$. 'Mg low' $=5 \mu \mathrm{M} \mathrm{Mg}$; 'Mg med' = $100 \mu \mathrm{M} \mathrm{Mg}$; 'Mg high' = $500 \mu \mathrm{M} \mathrm{Mg}$; '+f' = with $\mathrm{Mg}$ foliar application; 'to high' = change of the Mg nutrient solution concentration from 5 or 100 , respectively, to $500 \mu \mathrm{M} \mathrm{Mg}$. Mean $\pm \mathrm{SE}$ values. Capitals $=$ significant differences of total root length between 'Mg low', 'Mg med' and 'Mg high' plants. Italic capitals = significant differences of $\mathrm{Mg}$ root concentrations between ' $\mathrm{Mg}$ low', 'Mg med' and 'Mg high' plants. No indication = no significance.

\section{Discussion}

Following, first results of the $\mathrm{Mg}$ plant status and chlorophyll and sugar leaf concentrations are discussed. Afterwards, in light of these results, the shoot and root growth - with special focus on the root development - is elucidated.

\section{Mg status of the plant}

Mg leave concentrations below $2 \mathrm{mg} \mathrm{g}^{-1} \mathrm{DM}$ are considered critical to ensure optimal plant growth (Bergmann 1993; von Wulffen et al. 2008). Hence, 'Mg low' plants exhibited Mg leave concentrations below values which are presumed to be required for optimal plant growth and development (Fig. 2a). This deficient $\mathrm{Mg}$ status of 'Mg low' plants led to the emergence of typical Mg deficiency symptoms on fully expanded leaves of 'Mg low' treated plants: First, moderate and unclear segregated chlorosis became visible (Fig. 8a) which developed into interveinal leave chlorosis and flat spot-like necrosis (Fig. 8b). Usually, Mg deficiency symptoms first occur on older fully expanded leaves, as $\mathrm{Mg}$ is phloem mobile and therefore translocated to younger developing leaves under scarcity of $\mathrm{Mg}$ (Karley and White 2009), what likewise has been observed in the present study. 


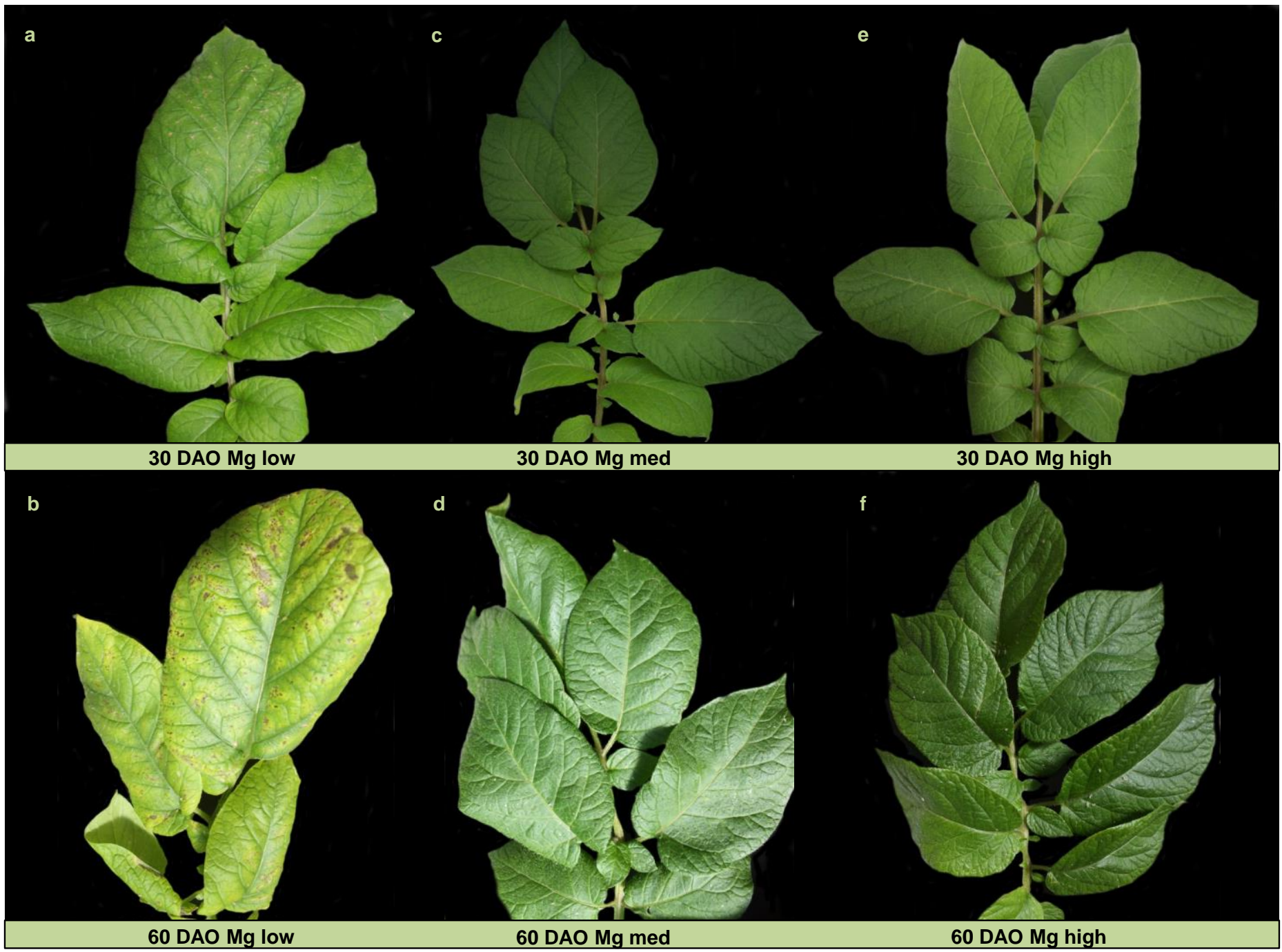

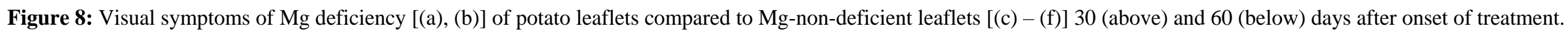


'Mg med' and 'Mg high' treated plants did not show any visible Mg deficiency symptoms (Fig. $8 \mathrm{c}-\mathrm{f}$ ), although at the first two sampling dates also 'Mg med' plants showed Mg leave concentrations in a critical range (Fig. 2a).

An Mg foliar application could not ameliorate a deficient $\mathrm{Mg}$ status of the plant, although a short increase of the $\mathrm{Mg}$ leave concentrations in 'Mg low' and to a less extend in 'Mg med' plants due to the foliar applications was detectable (Fig. 2b). This effect was significant only after the first and the second $\mathrm{Mg}$ foliar application (10 and $17 \mathrm{DAO}$ ) in ' $\mathrm{Mg}$ low' and only after the first $\mathrm{Mg}$ foliar application (10 DAO) in 'Mg med' plants. However, a more efficient effect to restore a limited $\mathrm{Mg}$ nutritional status was realized by raising the $\mathrm{Mg}$ supply via the nutrient solution. $\mathrm{Mg}$ leave concentrations increased up to a level far above values of a critical $\mathrm{Mg}$ supply. Furthermore, these $\mathrm{Mg}$ leave concentrations remained stable throughout all sampling dates.

\section{Leaf chlorophyll and soluble sugar concentrations under $M g$ restriction}

The actual distribution of Mg in the plant strongly depends on the plant's Mg supply (Michael 1941). Between 10 to $20 \%$ of the total Mg pool is supposed to be bound to chlorophyll (Mayland 1990; Verbruggen and Hermans 2013) while the proportion can be even higher in Mg depleted plants (Scott and Robson 1990). Chlorophyll concentrations of fully expanded leaves did not show any significant differences between the various Mg supplied plants in the present study (Fig. 3). This might be due to the fact that in Mg limited plants an higher proportion of the available $\mathrm{Mg}$ was shifted in the synthesis of chlorophyll rather than into other processes or plant structures requiring $\mathrm{Mg}$, as was likewise detected by Scott and Robson (1990) in subterranean clover (Trifolium subterraneum L.).

As described earlier and is illustrated in Fig. $8 \mathrm{~b}$ chlorosis and necrosis appeared in between the leave veins or were spread spot-like over the leaf surface. Therefore, chlorophyll degradation due to Mg deficiency (Cakmak and Kirkby 2008) might be segregated to leaf parts which show clear symptoms of chlorosis and necrosis while leaf parts without these symptoms do not show degradation of chlorophyll. Such an inequality in chlorophyll distribution of leaves might have affected the outcomes of chlorophyll determination.

Beside chlorophyll, soluble sugars in fully expanded leaves were determined. 'Mg low' plants exhibited a distinct accumulation of soluble sugars in leaves with proceeded plant development (Fig. $4 \mathrm{~b}$ and c). A lack of available Mg might have led to an impaired phloem loading process in these plants what resulted in an accumulation of soluble sugars in source leaves. Moreover, beside an increase in total soluble sugars, we determined an increase of hexose sugars in the same leaves (Fig. $4 \mathrm{~b}$ and c). This indicates a raised breakdown of sucrose into hexose sugar units. Similar outcomes were recorded by Huber (1984) in soybean plants (Glycine max L. Merr.) under potassium deficiency. Next 
to $\mathrm{Mg}$ also potassium is essential for the loading of and the distribution within the phloem of photoassimilates (Cakmak et al. 1994a). Huber (1984) argues the increasing breakdown of sucrose into hexose sugars with an increased activity of the sucrose hydrolyzing enzyme invertase following an accumulation of sucrose. Beside, Farhat et al. (2016) detected an accumulation of sugars in Mg deficient Sulla carnosa plants what the authors likewise refer to an increased activity of the enzyme invertase due to an impaired phloem loading process.

The fact, that soluble sugar concentrations did not reveal significant differences between the treatments on 14 DAO (Fig. 4a), can be referred to an less pronounced sink demand of roots at this early growth stage. However, with progressed plant development (35 and 56 DAO) (Fig. 4b and c), an increase of sink demand of developing roots resulted in significant differences between $\mathrm{Mg}$ treatments due to the above described reasons.

\section{Root growth as affected by the Mg supply}

Root growth showed a more severe reduction compared to shoot growth (Fig. 5a-d). For instance, the shoot growth parameters 'quantity of internodes' and 'plant height' did not show any significant difference compared to the higher Mg supplied plants at the end of the growing period (after 49 DAO) (Fig. 5c and d). While the total root biomass decreased up to $50 \%$, the total shoot biomass was at most reduced up to $35 \%$ in 'Mg low' compared to 'Mg med' and 'Mg high' plants (Fig. 5a and b). Also Mengutay et al. (2013) recorded a higher sensitivity of the root compared to the shoot growth in Mg limited maize (Zea mays) and wheat plants (Triticum aestivum) as well as Neuhaus et al. (2014). A higher sensitivity of the roots compared to the shoots to Mg deficiency is also reflected in the shoot-to-root ratios (Fig. 5b): 'Mg low' plants showed the highest shoot-to-root ratios while 'Mg high' plants exhibited the lowest ratio. However, the shoot-to-root ratio of 'Mg med' plants was similar high as of 'Mg low' plants. This is due to the fact that these plants showed a very high shoot biomass production, even higher than 'Mg high' plants (Fig. 5a). By comparison of our outcomes with other studies, our results are in accordance with Cakmak et al. (1994b) and Mengutay et al. (2013) who both demonstrated a severe reduction of root biomass and an increase of the shoot-to-root ratio under $\mathrm{Mg}$ deficiency. Besides, Gruber et al. (2013) found decreased root lengths in Mg deficient Arabidopsis plants. We confirmed these findings for potato in this study: Similar to the total root biomass the total root length showed a reduction up to 50\% in 'Mg low' compared to 'Mg med' and 'Mg high' treated plants (Fig. 7). Cakmak et al. (1994b) and Marschner et al. (1996) refer a reduced root growth mainly to a hampered translocation of photoassimilates under Mg deficiency. However, Marschner et al. (1996) supposed that a further reason for a sucrose accumulation in source leaves might be a depressed sink demand. As discussed previously, our results showed a distinct accumulation of 
soluble sugars in fully expanded leaves of Mg deficient plants (Fig. 4b and c) what could indicate an impaired loading of the phloem with sucrose and thus, a restricted export of photoassimilates from source (fully expanded leaves) to sink organs (roots). On the other hand, it is possible that a reduced sink demand (reduced root growth), likely because of a reduced production of photoassimilates via photosynthesis due to $\mathrm{Mg}$ deficiency, lead to an accumulation of sucrose in source leaves.

Opposite to our findings are the results stated by Hermans and Verbruggen (2005) who intended that $\mathrm{Mg}$ deficiency does not markedly reduce the root development. Hermans and Verbruggen (2005) argue their findings with differential distributions of photoassimilates in dependence on the position of the source leave. Based on the outcomes of ${ }^{14} \mathrm{C}$ labelled sucrose analysis they could draw conclusions about the exact location of source and sink tissue. They illustrated that upper most expanded leaves are mainly translocating sucrose to young developing leaves while older leaves, located closer to the roots, are mainly exporting sucrose to the roots. Furthermore, the upper most expanded leaves were the first plant organs exhibiting symptoms of $\mathrm{Mg}$ deficiency while the older leaves with proximity to the roots did not suffer under Mg scarcity yet. Thus, the authors conclude that the latter leaves still were able to export enough photoassimilates to the roots. Explanation for the divergent findings of the mentioned studies might be the different experimental setups. While Cakmak et al. (1994b) as well as Mengutay et al. (2013) grew their plants under Mg deficiency starting at an early growth stage, Hermans and Verbruggen (2005) grew their plants for a period of three weeks under a sufficient supply of $\mathrm{Mg}$, before setting them into a $\mathrm{Mg}$-free nutrient solution. Hence, it is presumable that the Arabidopsis (Arabidopsis thaliana) seedlings in the experiment of Hermans and Verbruggen (2005) were able to establish already an adequate root biomass in the first weeks of growing under sufficient $\mathrm{Mg}$ supply. Therefore, the above mentioned studies do not oppose each other but results are the outcome of different experimental designs. Moreover, the results presented by Hermans and Verbruggen (2005) may indicate that Mg particularly affects the root development in the first weeks of plant growth.

With view on the previous discussed results, it can be stated that a supply of $100 \mu \mathrm{M} \mathrm{Mg}$ can be considered as sufficient for potato root growth as these plants revealed similar results in root biomass (Fig. 5b), total root length (Fig. 7) and no accumulation of soluble sugars in source leaves (Fig. $4 \mathrm{~b}$ and c) as did plants with $500 \mu \mathrm{M} \mathrm{Mg}$ supply.

The complementary fertilization treatments (' $+\mathrm{f}$ ' as well as 'to high') did not show significant impacts on the root development, although a clear tendency became evident that an additional $\mathrm{Mg}$ supply via the nutrient solution to ' $\mathrm{Mg}$ low' plants increased Mg leaf and root concentrations and total root lengths (Fig. 2b and 7). An Mg foliar application led, compared to an $\mathrm{Mg}$ complementary fertilization via the roots, to an only slight and temporally restricted increase 
of $\mathrm{Mg}$ leaf concentrations and of the total root length (Fig. 2b and 7). This indicates that an Mg foliar application is not an effective tool to restore an $\mathrm{Mg}$ deficient nutrient status and depressed root growth of $\mathrm{Mg}$ deficient plants. By comparison, Neuhaus et al. (2014) showed more distinct effects by an $\mathrm{Mg}$ foliar application on $\mathrm{Mg}$ leaf concentrations and demonstrated a significant increase on root biomass. However, similarly to our findings, a raised supply of $\mathrm{Mg}$ via the nutrient solution resulted in a significant higher root biomass development compared to an $\mathrm{Mg}$ supply via leaves (Neuhaus et al. 2014).

\section{Conclusions}

$\mathrm{Mg}$ deficient plants revealed significant reduced root biomass and total root lengths. This might be referred to an hampered translocation of photoassimilates from source (leaves) to sink organs (roots) due to Mg deficiency as $\mathrm{Mg}$ deficient plants exhibited a sucrose accumulation in source leaves, what indicated an impaired loading of the phloem with sucrose. On the other hand, it is presumable that a reduced root growth due to $\mathrm{Mg}$ deficiency resulted in a decreased sink demand what in turn may shift the direction of sugar fluxes within the plant and results in an accumulation of soluble sugars in source leaves. Furthermore, our results demonstrated that an Mg supply of $100 \mu \mathrm{M}$ $\mathrm{Mg}$ represents a sufficient supply of $\mathrm{Mg}$ for potato root growth. The $\mathrm{Mg}$ complementary fertilization treatments in form of $\mathrm{Mg}$ foliar applications or Mg resupply via the nutrient solution did not show significant impacts on potato root growth. However, an additional Mg supply via the nutrient solution resulted in a clear increase of $\mathrm{Mg}$ leaf and root concentrations and of the total root lengths. Thus, an Mg resupply via the nutrient solution can partly represent an appropriate tool to ameliorate an $\mathrm{Mg}$ deficient nutrient status and reduced root growth due to $\mathrm{Mg}$ deficiency in potato.

\section{Acknowledgements}

We thank the $\mathrm{K}+\mathrm{S} \mathrm{GmbH}$ for the scientific and financial support. We acknowledge to Prof. Ismail Cakmak (Biological Sciences and Bioengineering Program, Faculty of Engineering and Natural Sciences, Sabanci University 34956 Tuzla, Istanbul, Turkey) for his contributions to the experimental setup and conduction of this study. We thank the working group of Plant Nutrition, IAPN and Plant Production, University Göttingen for allowing us to use their devices and their scientific advices. Finally, our thanks go to Hendrik Schierwater for his vigorous support throughout the conduction of this study. 


\section{Supplementary material}

SM_1: Used form and applied amounts ( $\mathrm{mg} \mathrm{kg}^{-1}$ soil) of nutrients under low and sufficient Mg supply of the soil culture system for plant propagation before transfer into nutrient solution.

\begin{tabular}{|c|c|c|}
\hline Nutrient [Form of nutrient] & $\begin{array}{l}\text { Applied amounts } \\
\text { low Mg supply }\end{array}$ & $\begin{array}{l}\text { Applied amounts } \\
\text { sufficient Mg supply }\end{array}$ \\
\hline Magnesium $\left[\mathrm{Mg}_{2} \mathrm{SO}_{4} \times 7 \mathrm{H}_{2} \mathrm{O}\right]$ & 5 & 100 \\
\hline Potassium $\left[\mathrm{K}_{2} \mathrm{SO}_{4}\right]$ & 300 & 300 \\
\hline Nitrogen $\left[\mathrm{Ca}(\mathrm{NO})_{3}\right]$ & 300 & 300 \\
\hline Phosphorus $\left[\mathrm{Ca}\left(\mathrm{PO}_{4}\right)_{2} \times \mathrm{H}_{2} \mathrm{O}\right]$ & 100 & 100 \\
\hline Calcium $\left[\mathrm{CaCO}_{3}\right]$ & 1300 & 1300 \\
\hline Boron $\left[\mathrm{H}_{3} \mathrm{BO}_{3}\right]$ & 2 & 2 \\
\hline Zinc $\left[\mathrm{ZnSO}_{4} \times 7 \mathrm{H}_{2} \mathrm{O}\right]$ & 2 & 2 \\
\hline Molybdenum $\left[\mathrm{Na}_{2} \mathrm{MoO}_{4} \times 2 \mathrm{H}_{2} \mathrm{O}\right]$ & 0.01 & 0.01 \\
\hline Copper $\left[\mathrm{CuSO}_{4} \times 5 \mathrm{H}_{2} \mathrm{O}\right]$ & 2 & 2 \\
\hline Manganese $\left[\mathrm{MnSO}_{4} \times \mathrm{H}_{2} \mathrm{O}\right]$ & 6 & 6 \\
\hline Iron [Fe(III) EDTA (13\% Fe)] & 3 & 3 \\
\hline
\end{tabular}


SM_2: Effect of Mg complementary fertilizations ('+f' and 'to Mg high') on quantity of internodes and on plant heights in $\mathrm{cm}$ at eight various sampling dates $(\mathrm{n}=4)$. Mean \pm SE values. Treatments had no significant effect.

\begin{tabular}{lcccc} 
Internodes & Mg low $\mathbf{+} \mathbf{f}$ & $\begin{array}{c}\text { Mg low to } \\
\text { Mg high } \\
\text { treatment }\end{array}$ & Mg med $\mathbf{f}$ & $\begin{array}{c}\text { Mg med to Mg } \\
\text { high }\end{array}$ \\
\hline $\mathbf{9}$ & $7 \pm 1$ & $9 \pm 1$ & $9 \pm 1$ & $9 \pm 1$ \\
$\mathbf{1 4}$ & $8 \pm 1$ & $9 \pm 1$ & $10 \pm 2$ & $10 \pm 1$ \\
$\mathbf{2 1}$ & $11 \pm 1$ & $11 \pm 1$ & $12 \pm 2$ & $12 \pm 1$ \\
$\mathbf{2 8}$ & $13 \pm 2$ & $12 \pm 0$ & $15 \pm 2$ & $14 \pm 1$ \\
$\mathbf{3 5}$ & $13 \pm 2$ & $13 \pm 0$ & $15 \pm 2$ & $15 \pm 1$ \\
$\mathbf{4 2}$ & $15 \pm 1$ & $14 \pm 1$ & $15 \pm 1$ & $16 \pm 0$ \\
$\mathbf{4 9}$ & $15 \pm 1$ & $14 \pm 1$ & $15 \pm 1$ & $16 \pm 0$ \\
$\mathbf{5 6}$ & $15 \pm 1$ & $14 \pm 1$ & $17 \pm 2$ & $16 \pm 0$ \\
\hline
\end{tabular}

\section{Plant heights}

\begin{tabular}{|c|c|c|c|c|}
\hline 9 & $16 \pm 2$ & $18 \pm 1$ & $22 \pm 1$ & $21 \pm 2$ \\
\hline 14 & $18 \pm 1$ & $19 \pm 1$ & $29 \pm 5$ & $25 \pm 4$ \\
\hline 21 & $35 \pm 2$ & $29 \pm 3$ & $37 \pm 5$ & $38 \pm 2$ \\
\hline 28 & $53 \pm 3$ & $48 \pm 8$ & $52 \pm 5$ & $53 \pm 3$ \\
\hline 35 & $66 \pm 3$ & $61 \pm 7$ & $68 \pm 6$ & $65 \pm 3$ \\
\hline 42 & $80 \pm 3$ & $76 \pm 12$ & $83 \pm 7$ & $82 \pm 2$ \\
\hline 49 & $87 \pm 2$ & $80 \pm 22$ & $91 \pm 9$ & $91 \pm 2$ \\
\hline 56 & $88 \pm 4$ & $80 \pm 22$ & $91 \pm 5$ & $90 \pm 2$ \\
\hline
\end{tabular}




\title{
Chapter 6
}

\section{Cracking and Fracture Properties of Potato (Solanum tuberosum L.) Tubers and their Relation to Dry Matter, Starch and Mineral Distribution}

\author{
Mirjam Koch, Marcel Naumann and Elke Pawelzik
}

Submitted 


\title{
Cracking and Fracture Properties of Potato (Solanum tuberosum L.) Tubers and their Relation to Dry Matter, Starch and Mineral Distribution
}

\author{
Mirjam Koch*, Marcel Naumann and Elke Pawelzik \\ Department for Crop Sciences, Division Quality of Plant Products, Carl-Sprengel-Weg 1, 37075 \\ Göttingen, University of Göttingen, Germany. \\ ${ }^{*}$ Correspondence to: Mirjam Koch, Department for Crop Sciences, Division Quality of Plant Products, \\ Carl-Sprengel-Weg 1, 37075 Göttingen, University of Göttingen, Germany. Tel.: 49(0)551-39-25568. \\ Fax: 49(0)551/39-25570. Email: mirjam.koch@agr.uni-goettingen.de.
}

Running title: Cracking and fracture properties of potato tubers (Solanum tuberosum L.)

\begin{abstract}
BACKGROUND: Potato disorders lead to significant reductions of yield and quality of marketable tubers. Thumbnail cracks are non-infectious physiological disorders of the skin of tubers, which can significantly reduce the tuber appearance and hence, the overall quality. Next to thumbnail cracks, we aimed to characterize fracture properties of the tuber skin. Knowledge regarding physiological reasons that influence the susceptibility of potato tubers towards mechanical impacts and thus towards cracking and fracturing is limited. Tuber dry matter (DM) and starch content were demonstrated to correlate with the rheological properties of tubers, which, in turn, might affect the susceptibility of the tuber towards cracking and fracturing. Aside from this, divalent cations, such as calcium $(\mathrm{Ca})$ and magnesium $(\mathrm{Mg})$, and their distribution in the tuber, might affect the tuber susceptibility for mechanical impacts via cell wall stabilizing properties.
\end{abstract}

RESULTS: Tubers with higher DM, starch and Ca concentrations, respectively, exhibited the highest resistances against mechanical impacts.

CONCLUSIONS: The reason for the increased resistance of tubers against mechanical impacts with higher DM and starch concentrations is assumed to be related to a certain cell structure of these tubers, why a higher strength is needed to damage cell structures. Besides, the relation between higher Ca concentrations and the improved resistance of tubers against mechanical impacts is supposed to be linked with the role of $\mathrm{Ca}$ for linking cell wall polymers and thus stabilizing the cell wall. 
Keywords: thumbnail cracks, fracturability, mineral distributions, dry matter, potato

\section{Introduction}

A majority of the world's potato production is used for fresh consumption; however, in industrial nations there has been a decrease in the consumption of fresh potatoes in recent years (Camire et al. 2009; Lange et al. 2014). At the same time, the demand for a high quality of food products, including vegetables and fruits, has sharply increased (Ali et al. 2010). Visual appearance is a major sensory quality attribute of fruits and vegetables (Zhang et al. 2014). It has been shown that the external appearance of potato tubers is one of the most important factors that influences consumer preferences (Fiers et al. 2010). A symptom that is likely to negatively impact consumer's purchase behavior is the 'thumbnail crack', which is a small curved and few millimeter deep crack of the tuber skin (Fig. 1). These small injuries can significantly decrease the appeal of tubers (Hiller et al. 1985; Bohl and Thornton 2006). Furthermore, such small damage areas can serve as entrance points for secondary infections (Hide et al. 1992) and hence might additionally reduce the quality and quantity of marketable tubers (Šaøec et al. 2006). Thumbnail cracks are classified as non-infectious physiological disorders as they are caused by abiotic factors like unfavorable environmental conditions - for instance, a rapid change of humidity or temperature, or inappropriate agricultural practices causing mechanical impacts during or after harvest (Sparks 1970; Dean and Thornton 1989).

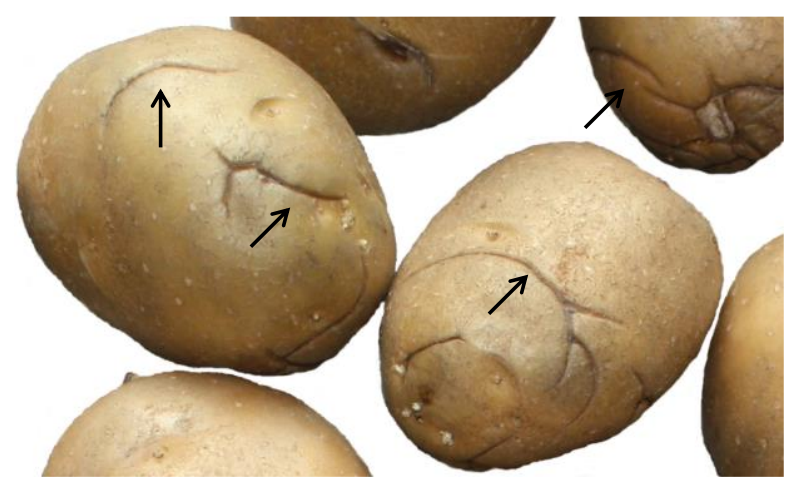

Figure 1: Typical occurrence of the 'thumbnail crack' symptom.

Aside from the tuber's susceptibility for thumbnail cracking, the further characterization of rheological properties of the tuber skin, especially its fracturability due to an applied force was focused in the present study. Determinants of the rheological properties, which, in turn, might affect the susceptibility for cracking or fracturing of the tuber skin are the cultivar (Peters 1996; Kaur et al. 2007), storage conditions (Kaur et al. 2007), soil type (Hesen et al. 1960), or the status of nutrient supply (Hesen et al. 1960; Peters 1996; McNabnay et al. 1999). However, knowledge with respect to the physiological reasons that affect the susceptibly of potato tubers cracking and fracturing is rare. There are indications that the tuber dry matter (DM) and starch concentrations are determinants 
that are correlated with the tuber's rheological properties (Bordoloi et al. 2012). The tuber's DM and starch concentrations may vary considerably between cultivars (Vakis 1978; Jansen et al. 2001). Furthermore, the potassium $(\mathrm{K})$ and magnesium $(\mathrm{Mg})$ status of the plant are both known to affect on the tuber's DM and starch concentrations_-but with divergent outcomes (Laughlin 1966; Miča 1979; Panique et al. 1997; Poberezny et al. 2011). To our knowledge, the impact of $\mathrm{K}$ and Mg nutrition on the tuber's DM and starch concentrations in relation to the formation of thumbnail cracks and fracture properties of the tuber skin has never been investigated.

Moreover, the stability of cell wall and thus of the tissue that forms the tuber periderm, can be affected by divalent cations, such as $\mathrm{Ca}$ and $\mathrm{Mg}$. These divalent cations are supposed to stabilize the cell wall via cross-linking cell wall polymers (Pooviah 1986; Andersson et al. 1994; Weiler and Nover 2008), which might affect the susceptibility of tubers towards cracking or to fracture. In addition, the distribution patterns of DM, starch, and minerals within the tubers themselves might affect the susceptibility of tubers towards forming thumbnail cracks or fractures.

The assumptions of the present study are as follows:

First, a hypothesis is drawn that the tuber's susceptibility to form thumbnail cracks and to fracture will correlate with the tuber DM and starch concentrations, which are, in turn influenced by the $\mathrm{K}$ and $\mathrm{Mg}$ supply and the cultivar. Second, based on the relations between $\mathrm{Ca}$, and likely also $\mathrm{Mg}$, and the cell wall stability, a decreasing susceptibility of the tubers to form thumbnail cracks and to fracture with increasing $\mathrm{Ca}$ and $\mathrm{Mg}$ tuber concentrations are expected. Finally, it is assumed, that distinct distribution patterns of DM, starch, and minerals within the tuber can correlate to the occurrence of thumbnail cracks and on the susceptibility to fracture.

\section{Material and Methods}

\section{Plant Growth Conditions}

In 2015, a field trial with two sites (Müncheberg and Uedem, Germany), four different $\mathrm{K}$ and $\mathrm{Mg}$ fertilization treatments (Table 1), and two cultivars, Omega and Laura, was conducted. Both cultivars are assigned to a medium-early maturity group, but are different in their intended use, cooking type, and tuber shape. While Omega is used as a table potato and a crisp potato, falling under the mealy cooking type with a round-oval tuber shape, Laura is only used as a table potato, with a waxy cooking type and an oval tuber shape (Europlant 2014; Federal Plant Variety Office 2016). Each combination of the fertilization treatment and cultivar was replicated four times. The trial at the site in Müncheberg (following designated as 'Müncheberg') was conducted in a completely randomized block design, while at the trial of the site Uedem (following designated as 'Uedem') two cultivars were grown in two separated blocks, which were themselves completely randomized. The different $\mathrm{K}$ and Mg supplies 
$(\mathrm{F} 1-\mathrm{F} 3$, control $=\mathrm{Ctr})$ are shown in Table 1. 'F1' represents a fertilization regime without $\mathrm{K}$ and without $\mathrm{Mg}$. The fertilization treatment 'F2' was supplied with $\mathrm{K}$, but without $\mathrm{Mg}$. The fertilization treatment 'F3' received Mg, but no $\mathrm{K}$. The 'Ctr' treatment was supplied with $\mathrm{K}$ as well as with $\mathrm{Mg}$, according to common agricultural practice. $\mathrm{K}$ was applied as $\mathrm{K}_{2} \mathrm{O}$ via potassium sulphate $\left(50 \% \mathrm{~K}_{2} \mathrm{O} ; 45 \% \mathrm{SO}_{3}\right)$ and $\mathrm{Mg}$ was applied as $\mathrm{MgO}$ via kieserite $(25 \%$ $\mathrm{MgO} ; 50 \% \mathrm{SO}_{3}$ ). All the other nutrients were provided as shown in Table 1.

Further field trials were performed in 2016 with the two cultivars Omega and Laura, and four different $\mathrm{K}$ and $\mathrm{Mg}$ fertilization treatments at three sites (Müncheberg and Uedem, Germany; Kościan, Poland). The experimental design for the sites 'Müncheberg' and 'Uedem' were the same as the trials conducted in 2015 and the design of the trial at the site Kościan (following designated as 'Kościan') was the same as the design employed in 'Müncheberg' in 2015 and 2016. The climate conditions throughout the vegetation periods (supplementary material (SM), SM_1) and the soil types and the $\mathrm{K}$ and $\mathrm{Mg}$ soil status (SM_2) were documented for all three sites.

Table 1: Nutrient supply (in $\mathrm{kg} \mathrm{ha}^{-1}$ ) of the four fertilization treatments (F1, F2, F3, and Control).

\begin{tabular}{rccccc}
\hline & $\mathrm{K}_{2} \mathbf{O}$ & $\mathrm{MgO}$ & $\mathrm{SO}_{3}$ & $\mathrm{~N}$ & $\mathrm{P}_{2} \mathrm{O}_{5}$ \\
\hline F1 & $\mathrm{x}$ & $\mathrm{x}$ & 535 & $\mathrm{x}$ & 120 \\
$\mathbf{F 2}$ & 300 & $\mathrm{x}$ & 266 & 92 & 120 \\
F3 & $\mathrm{x}$ & 130 & 271 & 90 & 120 \\
Control & 300 & 130 & $\mathrm{x}$ & 185 & 120 \\
\hline
\end{tabular}

\section{Tuber Handling after Harvest and Assignment of Analyses}

After harvest, the tubers were stored at $4^{\circ} \mathrm{C}$ and $70 \%$ relative humidity. All the analyses were conducted across a period of eight weeks after harvest. In 2015, only whole tubers were analyzed. Aside from this, the evaluation of the thumbnail cracks was performed only with tubers from 'Müncheberg', while fracturability was assessed only with tubers from 'Uedem'. DM, starch, $\mathrm{K}, \mathrm{Mg}$ and $\mathrm{Ca}$ concentrations were assessed in tubers from both trials. In 2016, evaluations for the thumbnail crack occurrence were performed with tubers from 'Müncheberg' and 'Kościan'. The determination of fracturability were performed with whole tubers from 'Müncheberg', 'Uedem', and 'Kościan' and with bud- and the stem-ends with tubers from 'Müncheberg' and 'Kościan'. Dry matter, starch, K, $\mathrm{Mg}$, and Calcium (Ca) concentrations and their distributions were assessed in whole tubers from 'Müncheberg', 'Uedem', and 'Kościan' and with the tuber segments bud-end, stem-end, middle, flesh, and skin with tubers from 'Müncheberg' and 'Kościan'. 


\section{Dry Matter and Starch Concentrations}

For DM and starch analyses, an average of 3-5 tubers or tuber segments of 3-5 tubers per treatment was formed. The used tuber quantity was chosen on the basis of tuber size, e.g., three bigger tubers or five smaller tubers. For DM determination, tubers were cut into pieces and the fresh sample weight of the subsample was determined. Afterwards, the sample was dried at $60^{\circ} \mathrm{C}$ for 24 hours and, subsequently, at $105^{\circ} \mathrm{C}$ for four hours and the dry weight was determined.

For starch analysis, tubers were cut into pieces and the samples were freeze-dried for four days in a freeze-dryer (EPSILON 2-40, Christ, Germany). Afterwards, the tubers were grinded to $0.5 \mathrm{~mm}$ of flour in a hammer mill (DFH 48, Culatti, Switzerland). Following this step, the residual moisture was assessed by determining the weight of a subsample of freeze-dried potato flour before and after drying for 12 hours at $105^{\circ} \mathrm{C}$. Starch was quantified according to ICC standard no. 123 (modified). In $100 \mathrm{ml}$ flasks, $25 \mathrm{ml}$ of hydrochloric acid was added twice to 1 $\mathrm{g}$ of potato flour and placed for 15 minutes in a scalding water bath (Memmert, Germany); it was then shaken for the first eight minutes. The flasks were filled up to $90 \mathrm{ml}$ with distilled water and cooled to room temperature. Following this, $5 \mathrm{ml}$ of tungstophosphoric acid $\left(\mathrm{H}_{3} \mathrm{PW}_{12} \mathrm{O}_{40}\right)$ was added and panned. Finally, the flasks were filled up to $100 \mathrm{ml}$ with distilled water and the optical rotation was examined in a polarimeter (Kreipo 0.05, Zeiss, Germany) at $589 \mathrm{~nm}$.

\section{Mineral Concentrations}

Prior analyses, samples were prepared as described for starch determinations. The tuber skin was peeled with a common peeler with an average thickness of peel of $1.2 \mathrm{~mm}$. In 2016, the tubers of the four biological replicates per fertilization treatment were pooled to form three technical replicates when enough tubers were not available. The minerals were assessed following an adjusted method as described by Wheal et al. (2011). From each sample, $100 \mathrm{mg}$ was digested in $4 \mathrm{ml}$ of $65 \%(\mathrm{v} / \mathrm{v})$ nitric acid and $2 \mathrm{ml}$ of $30 \%(\mathrm{v} / \mathrm{v})$ hydrogen peroxide for 75 minutes at $200^{\circ} \mathrm{C}$ and 40 bar in a microwave (Ethos 660; MWT AG, Switzerland). Subsequently, the samples were filled up to $25 \mathrm{ml}$ with distilled water. The concentrations of $\mathrm{K}, \mathrm{Mg}$, and $\mathrm{Ca}$ were examined by using inductively coupled plasma optical emission spectrometry (Vista-PRO CCD Simultaneous ICP-OES; Varian Inc., USA).

\section{Thumbnail Crack Evaluation}

To evaluate the susceptibility to form thumbnail cracks, the tubers were damaged in a controlled way with the help of a drum (Flottwerk H. J. Dames GmbH \& Co. KG, Rotenburg an der Fulda, Germany). Here, the mechanical impacts on the potato tubers were simulated, which might also occur during or after harvest. Each sample was 
assessed to a volume of 6 liters and damaged in the drum for 50 seconds. A continuous tuber temperature of $4^{\circ} \mathrm{C}$ was preserved throughout the analysis. Subsequently, the tubers were stored for five days at room temperature, followed by an evaluation of the thumbnail cracks with grades ranging from $1-9(1=$ very severe occurrence; $3=$ severe occurrence; 5 = medium occurrence; 7 = slight occurrence; 9 = almost no occurrence) according to a standard procedure as has been described by Meyer et al. (2014). The thumbnail cracks were only analyzed on tubers from 'Müncheberg' in both the experimental years and, furthermore, as shown in the supporting information in 2016 from 'Kościan'.

\section{Tuber Skin Fracturability Measured by Penetration Test}

Fracturability of the tuber skin was assessed by using a texture analyzer (Stable Micro Systems Ltd., TA.XT.plus, UK). 'Fracturability' is defined as the complete loss of resistance of the tuber skin due to a certain applied force that causes a destruction of the potato peel and the subjacent soft tissue (SM_3). The measurement was carried out at a speed of $2 \mathrm{~mm}$ per second and a $5-\mathrm{kg}$ measuring cell was used. A stamp of $5 \mathrm{~mm} \varnothing$ penetrated the potato tuber with a depth of $10 \mathrm{~mm}$. To preserve a tuber temperature of approximately $4^{\circ} \mathrm{C}$ throughout the measurement, the tubers were stored in a freezer cabinet immediately after removal from the storage device prior to analysis for one hour (at most).

For assessment of fracturability of the whole potato, at least 20 tubers per treatment were considered for the analyzed potato bud- and the stem-ends of at least 12 tubers were taken. Furthermore, in 2016, the tubers of the four biological replicates per fertilization treatment were pooled into three technical replicates due to the restricted availability of tubers per treatment.

\section{Statistics}

The statistical software R (R Core Team 2016) was used to evaluate the data. The data evaluation was split into two main steps. In a first step, the values from 2015 were considered. Here, the focus was set on the effect of the fertilization treatment and the cultivar. A statistical mixed model was separately defined for each site with fertilization treatment and the cultivars, and the interaction of fertilization treatment and cultivar as fixed effects. The splitting, according to the sites, was necessary because of further influence factors, which were not orthogonal for all sites. The block and the plots (nested in block) were regarded as random factors. The data were assumed to be normally distributed and heteroscedastic due to the different sites. These assumptions are based on graphical residual analyses. Based on these models, Pseudo $\mathrm{R}^{2}$ was calculated and the analyses of variances (ANOVA) were conducted, followed by multiple contrast tests in order to compare the several fertilization treatments and the 
cultivars, respectively. In the second step, the values from 2016 were considered, with a focus on the cultivar and the tuber segment. Only the fertilization treatment 'Ctr' was investigated. The statistical procedure and the assumptions about the data were the same as in the first step. All tests were performed at a significance level of $p$ $<0.05$

\section{Results}

Tuber Cracking and Fracturability and DM, Starch, and Mineral Concentrations based on the Fertilization Treatment and the Cultivar (2015)

The fertilization regime and the cultivar did not show any impact on the occurrence of thumbnail cracks (SM_4a). The fracturability was not influenced by the fertilization treatment as well, but it was significantly different in the cultivars in form of a higher fracturability in Omega compared to Laura (SM_4b).

The fertilization treatment did not affect the DM and starch concentrations in the present study (Table 2). However, there was a significant impact of the cultivar on DM: Tubers of the cultivar Omega from 'Müncheberg' revealed a significantly higher DM in comparison to Laura (Table 2). Similar findings were assessed in tubers from 'Uedem' (Table 2).

Likewise, for the DM and starch concentrations, the fertilization treatment did not cause a significant variation in the tuber $\mathrm{K}$ as well as in the tuber $\mathrm{Ca}$ concentrations. The fertilization treatment 'F1', however, exhibited significantly lower $\mathrm{Mg}$ concentrations in comparison to the 'Ctr' fertilization treatment in tubers from 'Müncheberg' (Table 2). Moreover, Omega showed significantly lower Mg concentrations in comparison to Laura in tubers from this site (Table 2). According to the ANOVA test, there was a significant influence of the cultivar on the Ca concentrations in tubers from both trials (Table 2, below Table). However, the results of multiple contrast tests revealed significantly higher $\mathrm{Ca}$ concentrations only in tubers of the fertilization treatment 'F2' from 'Uedem' (Table 2). 
Table 2: Dry matter (\%), starch (\% in DM), K, $\mathrm{Mg}$, and $\mathrm{Ca}\left(\mathrm{mg} \mathrm{g}^{-1} \mathrm{DM}\right)$ concentrations of the whole tubers of the cultivars Omega and Laura from 'Müncheberg' and 'Uedem' under different K- and Mg-fertilization treatments $(\mathrm{F} 1, \mathrm{~F} 2, \mathrm{~F} 3$, and $\mathrm{Ctr})$ in 2015. Mean \pm SE values $(\mathrm{n}=3-4)$. Levels of significance for cultivar, fertilization, and its interaction tested via the ANOVA test are shown below the table with ${ }^{*},{ }^{* *}$, and ${ }^{* * *}$ for $\mathrm{p}<0.05,0.01$, and 0.001 , respectively. $\mathrm{ns}=$ not significant. Capitals = significant differences between the cultivars of one fertilization treatment, small letters = significant differences between the fertilization treatments, and no indication = no significant differences.

\section{Müncheberg}

\begin{tabular}{|c|c|c|c|c|c|c|c|c|}
\hline \multirow{2}{*}{$\begin{array}{l}\text { Omega } \\
\text { DM }\end{array}$} & \multicolumn{2}{|l|}{ F1 } & \multicolumn{2}{|l|}{ F2 } & \multicolumn{2}{|l|}{ F3 } & \multicolumn{2}{|l|}{ Ctr } \\
\hline & $24.03 \pm 0.39$ & B & $23.69 \pm 1.23$ & B & $23.67 \pm 1.77$ & $\mathrm{~B}$ & $24.30 \pm 0.88$ & B \\
\hline Starch & $63.96 \pm 1.92$ & & $66.06 \pm 2.36$ & & $65.45 \pm 1.09$ & & $63.88 \pm 2.31$ & \\
\hline $\mathbf{K}$ & $23.29 \pm 1.86$ & & $25.29 \pm 0.95$ & & $24.52 \pm 2.15$ & & $26.16 \pm 1.60$ & \\
\hline $\mathbf{M g}$ & $0.90 \pm 0.07$ & $\mathrm{Aa}$ & $1.03 \pm 0.03$ & $A a b$ & $1.05 \pm 0.12$ & $A a b$ & $1.07 \pm 0.03$ & $\mathrm{Ab}$ \\
\hline $\mathrm{Ca}$ & $0.29 \pm 0.06$ & & $0.23 \pm 0.03$ & & $0.26 \pm 0.05$ & & $0.27 \pm 0.07$ & \\
\hline \multicolumn{9}{|l|}{ Laura } \\
\hline DM & $20.85 \pm 1.01$ & $A$ & $20.39 \pm 1.09$ & $A$ & $20.46 \pm 0.53$ & $A$ & $19.90 \pm 0.99$ & $A$ \\
\hline Starch & $61.18 \pm 1.94$ & & $61.87 \pm 3.76$ & & $62.23 \pm 1.64$ & & $65.47 \pm 2.62$ & \\
\hline K & $25.05 \pm 2.60$ & & $27.66 \pm 1.72$ & & $24.87 \pm 1.15$ & & $27.29 \pm 0.94$ & \\
\hline Mg & $1.18 \pm 0.13$ & B & $1.25 \pm 0.03$ & $B$ & $1.21 \pm 0.01$ & $B$ & $1.21 \pm 0.04$ & B \\
\hline $\mathrm{Ca}$ & $0.21 \pm 0.06$ & & $0.25 \pm 0.11$ & & $0.19 \pm 0.05$ & & $0.20 \pm 0.05$ & \\
\hline \multicolumn{9}{|c|}{ Uedem } \\
\hline \multicolumn{9}{|l|}{ Omega } \\
\hline DM & $20.64 \pm 1.94$ & & $21.14 \pm 2.28$ & & $23.12 \pm 1.65$ & $\mathrm{~B}$ & $21.69 \pm 0.68$ & \\
\hline Starch & $68.19 \pm 2.05$ & & $67.91 \pm 2.44$ & & $69.88 \pm 1.02$ & & $69.05 \pm 2.46$ & \\
\hline K & $27.17 \pm 2.86$ & & $29.23 \pm 6.75$ & & $25.96 \pm 0.62$ & & $26.76 \pm 1.10$ & \\
\hline Mg & $1.11 \pm 0.08$ & & $1.27 \pm 0.23$ & & $1.17 \pm 0.05$ & & $1.21 \pm 0.04$ & \\
\hline $\mathrm{Ca}$ & $0.47 \pm 0.03$ & & $0.56 \pm 0.15$ & $\mathrm{~B}$ & $0.45 \pm 0.08$ & & $0.45 \pm 0.06$ & \\
\hline \multicolumn{9}{|l|}{ Laura } \\
\hline DM & $18.75 \pm 1.23$ & & $19.06 \pm 0.40$ & & $19.35 \pm 1.72$ & $A$ & $18.31 \pm 0.76$ & \\
\hline Starch & $65.56 \pm 1.07$ & & $66.42 \pm 2.41$ & & $66.46 \pm 1.26$ & & $65.89 \pm 1.48$ & \\
\hline K & $28.53 \pm 2.22$ & & $27.81 \pm 1.13$ & & $26.79 \pm 2.26$ & & $23.76 \pm 4.92$ & \\
\hline Mg & $1.20 \pm 0.06$ & & $1.20 \pm 0.02$ & & $1.14 \pm 0.07$ & & $1.12 \pm 0.08$ & \\
\hline $\mathrm{Ca}$ & $0.37 \pm 0.03$ & & $0.38 \pm 0.01$ & $A$ & $0.38 \pm 0.05$ & & $0.36 \pm 0.01$ & \\
\hline
\end{tabular}

DM Müncheberg: Cultivar ${ }^{\star \star *}$, fertilization ns, cultivar x fertilization ns; Starch Müncheberg: Cultivar ${ }^{\star *}$, fertilization ns, cultivar $\mathrm{x}$ fertilization $\mathrm{ns;} \mathrm{K}$ Müncheberg: Cultivar *, fertilization **, cultivar x fertilization ns; Mg Müncheberg: Cultivar ***, fertilization *, cultivar x fertilization ns; Ca Müncheberg: Cultivar *, fertilization ns, cultivar x fertilization ns; DM Uedem: Cultivar **, fertilization ns, cultivar x fertilization ns; Starch Uedem: Cultivar *, fretilization ns, cultivar $x$ fertilization ns; K Uedem: Cultivar ns, fertilization ns, cultivar $x$ fertilization ns; Mg Uedem: Cultivar ns, fertilization ns, cultivar $x$ fertilization ns; Ca Uedem: Cultivar ${ }^{* *}$, fertilization $n s$, cultivar $x$ fertilization ns. 
Tuber Cracking and Fracturability and DM, Starch, and Mineral Concentrations based on the Fertilization

Treatment (2016)

Likewise as in the experimental year 2015, in 2016, there was no impact of fertilization treatment on the investigated parameters. Therefore, in 2016, the focus was set on the impact of the cultivar and of the different tuber segments. Here, unless otherwise mentioned, tubers from 'Kościan' (SM_5 and 6) showed negligible deviation in comparison to tubers from 'Müncheberg' and 'Uedem'. Thus, the following results focus on analyses done with tubers from 'Uedem' and 'Müncheberg'.

Tuber Cracking and Fracturability and DM, Starch, and Mineral Concentrations based on the Cultivar and their Distribution in the Tuber (Müncheberg, 2016)

The influence factors cultivar and tuber segment, respectively, did not affect the occurrence of thumbnail cracks, although there was a tendency for a higher occurrence of thumbnail cracks in the cultivar Laura in comparison to Omega (Fig. 2a). However, the influence factors cultivar and tuber segment demonstrated more distinct effects on fracturability: first, Omega showed significantly higher fracturability in comparison to Laura; second, the stemends demonstrated a significantly higher fracturability in comparison to the bud-ends (Fig. 2b).

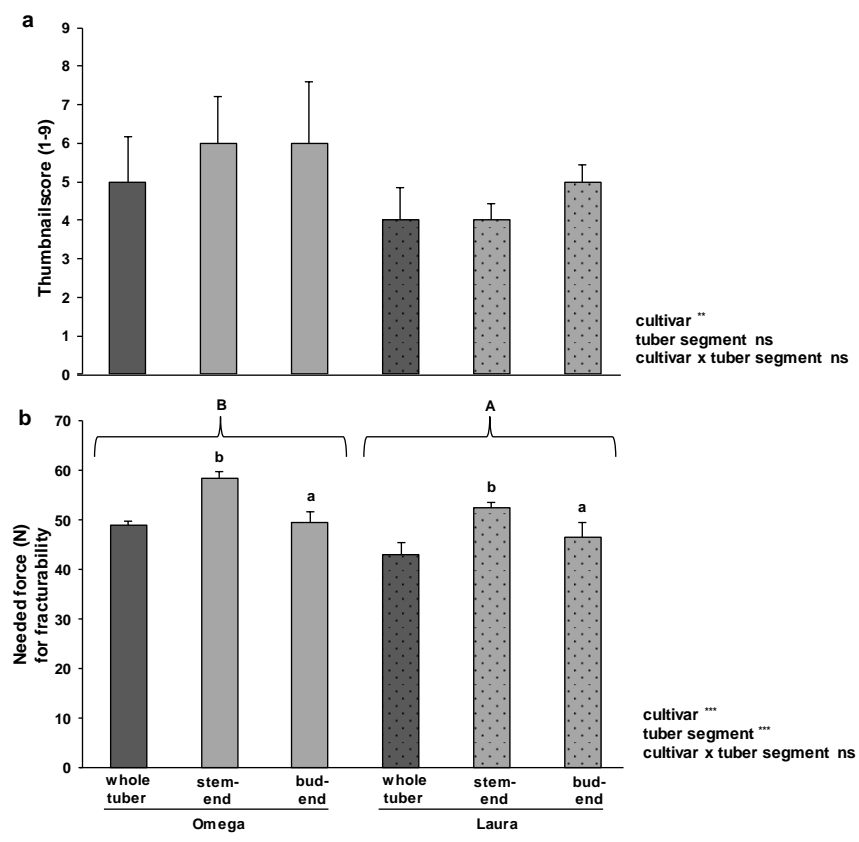

Figure 2: Thumbnail crack occurrence of whole tubers, tuber stem, and bud-ends of the cultivars Omega and Laura from 'Müncheberg' for the control fertilization treatment in $2016(n=4)$ (a). Thumbnail score: $1=$ very severe occurrence, $3=$ severe occurrence, $5=$ medium occurrence, $7=$ slight occurrence, and $9=$ almost no occurrence. Fracturability of whole tubers, the tuber stem, and bud-ends of the cultivars Omega and Laura from 'Müncheberg' for the control fertilization treatment in 2016 ( $n=3)(b)$. Mean \pm SE values. Levels of significance tested via the ANOVA test are shown in the right lower corner with ${ }^{* *}$ and ${ }^{* * *}$ for $\mathrm{p}<0.01$ and 0.001 , respectively. $\mathrm{ns}=$ not significant. Capitals $=$ significant differences between the cultivars of one tuber segment, small letters $=$ significant differences between tuber segments of one cultivar and the storage period, and no indication $=$ no significant differences. 
Tubers revealed significantly higher DM and starch concentrations in Omega in comparison to Laura when the DM and starch concentrations were averaged over all the tuber segments of one cultivar (Table 3 ). The significant lowest DM as well as starch concentrations were examined in the tuber skin (Table 3). There was a tendency of ascertainable lower DM in the bud- in comparison to the stem-ends of the tubers (Table 3).

Opposite to the DM and starch concentrations, the significant highest $\mathrm{K}, \mathrm{Mg}$, and $\mathrm{Ca}$ concentrations were assessed in the tuber skin (Table 3). Furthermore, K showed higher concentrations in the bud- in comparison to the stemends (Table 3). Omega revealed in tendency higher Ca concentrations than Laura, however, these differences were not significant: For instance, the Ca concentrations were up to one-third higher in the tuber skin of Omega in comparison to Laura (Table 3); Due to significant interactions of the influence factors cultivar and the tuber segment, a statistical contrast test between the cultivars of the averaged Ca concentrations over all the tuber parts was unfeasible. Nevertheless, according to the ANOVA test, the cultivar exhibited a significant impact on the Ca concentrations (Table 3, below Table). However, tubers from 'Kościan' revealed significantly higher Ca concentrations in Omega in comparison to Laura when the $\mathrm{Ca}$ concentrations were averaged over all the tuber segments of one cultivar (SM_5), as there were no significant interactions between the influence factors cultivar and tuber segment in tubers from this site (SM_5, below Table). 
Table 3: Dry matter (\%), starch (\% in DM), K, $\mathrm{Mg}$, and $\mathrm{Ca}\left(\mathrm{mg} \mathrm{g}^{-1} \mathrm{DM}\right)$ concentrations of whole tubers and the tuber segments stem- and bud-end, middle, skin, and flesh of the cultivars Omega and Laura from 'Müncheberg' during control fertilization treatment in 2016. Mean \pm SE values $(n=3-4)$. Levels of significance tested via the ANOVA test are shown below the table with ${ }^{*}, * *$, and ${ }^{* * *}$ for $\mathrm{p}<0.05,0.01$, and 0.001 , respectively. ns $=$ not significant. Capitals $=$ significant differences between cultivars, and small letters $=$ significant differences between tuber segments of one cultivar.

\begin{tabular}{|c|c|c|c|c|c|c|c|c|c|c|c|c|c|}
\hline Omega & whole tuber & \multicolumn{2}{|l|}{ stem-end } & \multicolumn{2}{|l|}{ middle } & \multicolumn{2}{|l|}{ bud-end } & \multicolumn{2}{|l|}{ skin } & \multicolumn{2}{|l|}{ flesh } & \multicolumn{2}{|l|}{$\begin{array}{l}\text { Average over } \\
\text { tuber segments }\end{array}$} \\
\hline DM & $24.65 \pm 0.49$ & $24.45 \pm 0.71$ & $b$ & $24.49 \pm 1.29$ & $\mathrm{~b}$ & $22.54 \pm 0.46$ & $a b$ & $17.99 \pm 0.47$ & $\mathrm{a}$ & $23.80 \pm 1.88$ & $\mathrm{~b}$ & $22.65 \pm 2.73$ & B \\
\hline Starch & $68.79 \pm 2.15$ & $70.28 \pm 2.34$ & $b$ & $72.52 \pm 3.03$ & $b$ & $68.76 \pm 2.67$ & $b$ & $46.18 \pm 3.35$ & a & $74.27 \pm 1.66$ & $b$ & $64.43 \pm 11.49$ & B \\
\hline K & $26.04 \pm 0.61$ & $21.17 \pm 0.72$ & $\mathrm{a}$ & $23.09 \pm 0.62$ & $a b$ & $28.16 \pm 1.39$ & $b$ & $35.62 \pm 1.45$ & c & $22.04 \pm 0.83$ & $a b$ & $26.02 \pm 6.01$ & \\
\hline Mg & $1.19 \pm 0.08$ & $0.96 \pm 0.05$ & a & $1.02 \pm 0.05$ & $\mathrm{a}$ & $1.12 \pm 0.01$ & $a b$ & $1.37 \pm 0.03$ & $b$ & $0.97 \pm 0.01$ & a & $1.09 \pm 0.17$ & \\
\hline $\mathrm{Ca}$ & $0.24 \pm 0.01$ & $0.28 \pm 0.04$ & $\mathrm{a}$ & $0.20 \pm 0.01$ & a & $0.30 \pm 0.01$ & $\mathrm{a}$ & $0.93 \pm 0.07$ & $b$ & $0.13 \pm 0.01$ & $\mathrm{a}$ & $0.37 \pm 0.32$ & \\
\hline \multicolumn{14}{|l|}{ Laura } \\
\hline DM & $23.66 \pm 5.71$ & $20.93 \pm 1.17$ & $\mathrm{bc}$ & $18.96 \pm 1.23$ & $a b c$ & $17.23 \pm 0.98$ & $a b$ & $14.75 \pm 0.91$ & a & $20.59 \pm 0.29$ & $\mathrm{~b}$ & $18.49 \pm 2.56$ & $A$ \\
\hline Starch & $58.90 \pm 1.06$ & $64.37 \pm 1.16$ & $\mathrm{bc}$ & $62.59 \pm 0.18$ & $\mathrm{bc}$ & $60.88 \pm 0.89$ & $\mathrm{bc}$ & $44.64 \pm 3.06$ & $\mathrm{a}$ & $68.13 \pm 0.11$ & c & $60.12 \pm 9.06$ & A \\
\hline K & $25.93 \pm 2.94$ & $20.63 \pm 3.31$ & $a b$ & $22.05 \pm 1.58$ & $a b$ & $27.08 \pm 1.66$ & $\mathrm{~b}$ & $36.87 \pm 1.46$ & c & $19.75 \pm 1.27$ & a & $25.28 \pm 7.07$ & \\
\hline Mg & $1.16 \pm 0.07$ & $1.14 \pm 0.04$ & $a b$ & $1.04 \pm 0.04$ & $\mathrm{a}$ & $1.07 \pm 0.04$ & $\mathrm{a}$ & $1.34 \pm 0.03$ & $b$ & $1.05 \pm 0.07$ & $\mathrm{a}$ & $1.13 \pm 0.12$ & \\
\hline $\mathrm{Ca}$ & $0.19 \pm 0.03$ & $0.27 \pm 0.04$ & a & $0.20 \pm 0.04$ & $\mathrm{a}$ & $0.24 \pm 0.04$ & $\mathrm{a}$ & $0.63 \pm 0.05$ & $\mathrm{~b}$ & $0.14 \pm 0.05$ & $a$ & $0.29 \pm 0.19$ & \\
\hline
\end{tabular}

DM: Cultivar ${ }^{* *}$ tuber segment ${ }^{* * *}$, cultivar $\mathrm{x}$ tuber segment $\mathrm{ns}$; Starch: Cultivar ${ }^{*}$, tuber segment ${ }^{* * *}$ cultivar $\mathrm{x}$ tuber segment ns; K: Cultivar ns, tuber segment ${ }^{* * *}$, cultivar $\mathrm{x}$ tuber segment $\mathrm{ns}$;

Mg: Cultivar ns, tuber segment ${ }^{* * *}$, cultivar $x$ tuber segment ${ }^{* *}$; Ca: Cultivar ${ }^{*}$, tuber segment ${ }^{* \star *}$, cultivar $x$ tuber segment ${ }^{* * *}$. 
Fracturability and DM, Starch, and Mineral Concentrations based on the Cultivar (Uedem, 2016)

Omega demonstrated a significant higher fracturability as well as significant higher DM and Ca concentrations in comparison to Laura (Figs. 3a, 3e, and 3f). Aside from this, there was an impact of the cultivar on the starch concentrations that was detected by the ANOVA test, but without the significant effects put forward by a detailed contrast test.

a

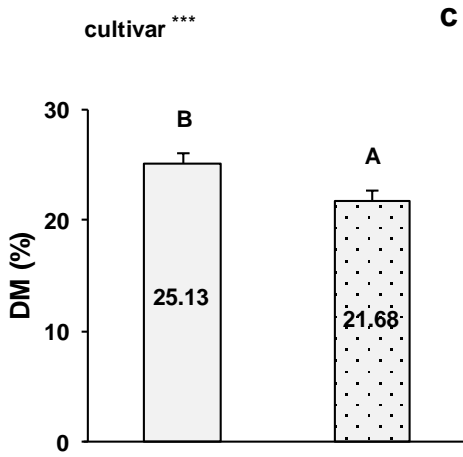

b cultivar $^{* \star}$

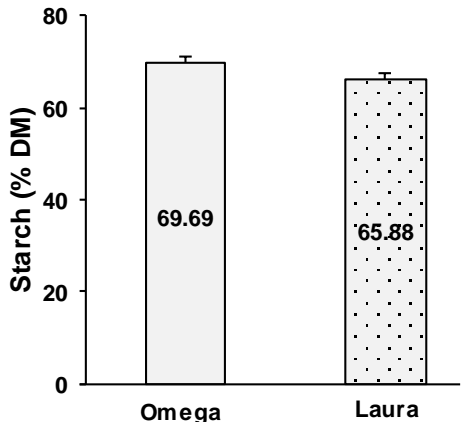

c

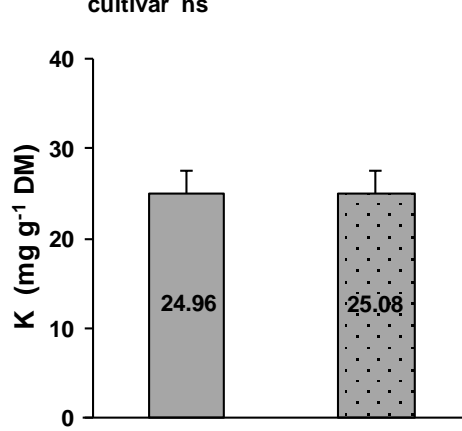

d

cultivar ns

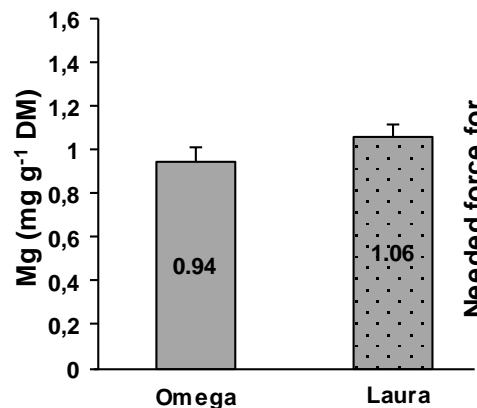

e

cultivar $^{\star \star}$

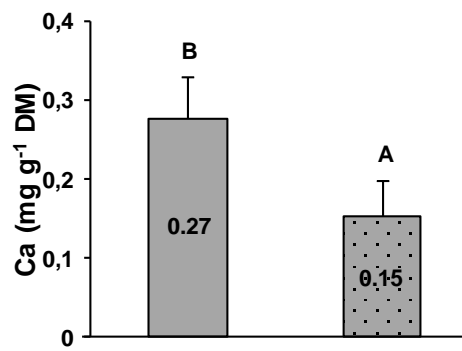

f

Figure 3: Dry matter (a), starch (b), $\mathrm{K}(\mathrm{c}), \mathrm{Mg}(\mathrm{d})$, and $\mathrm{Ca}(\mathrm{e})$ concentrations in relation to the tuber's fracturability (f) of whole tubers of the cultivars Omega and Laura from 'Uedem' with respect to control fertilization treatment in 2016. Mean (shown inside the bars) \pm SE values $(n=4)$. Levels of significance tested via the ANOVA test are shown in the left upper corner with ${ }^{*},{ }^{* *}$, and ${ }^{* * *}$ for $\mathrm{p}<0.05,0.01$, and 0.001 , respectively. ns $=$ not significant. Capitals $=$ significant differences between the cultivars, and no indication $=$ no significant differences.

\section{Discussion}

\section{Effect of Fertilization Treatment}

The fertilization treatment did not show a clear impact on the occurrence of thumbnail cracks and on the fracturability as well as on the DM, starch, and mineral concentrations in both years of the experiment and at all the three field sites. An already sufficient supply of $\mathrm{K}$ and $\mathrm{Mg}$ in the soils of the field sites in the present study is probably reasonable for the lack of a response to the fertilizer application (SM_2). This assumption is strengthened by the fact that even the tuber yield remained unaffected by the $\mathrm{K}$ and $\mathrm{Mg}$ fertilization treatments (SM_7). Therefore, we conclude that a luxury supply of $\mathrm{K}$ and $\mathrm{Mg}$, which goes well beyond a sufficient supply, does not 
have any impact on the investigated parameters. Consequently, the following discussion focuses on the influence of the cultivar and tuber segments on the occurrence of thumbnail cracks and the fracturability as well as on their relationship to the tuber DM, starch, and mineral concentrations.

\section{Thumbnail Crack Occurrence and Fracturability in Relation to the DM, Starch, and Mineral Concentrations}

\section{and Distributions}

The thumbnail crack evaluations did not show any significant influence by the different treatments, except a slight effect due to the cultivar in form of a higher occurrence of thumbnail cracks in Laura in comparison to Omega (Fig. 2a and SM_6a). The sensitivity of Laura to tuber skin damage may be related to its typical tuber shape, which is long-oval—such a trait is more prone to damage (Šaøec et al. 2006) —Omega is round-oval (Europlant 2014; Federal Plant Variety Office 2016). In contrast to the thumbnail evaluations, more distinct differences due to the cultivar and tuber segment became obvious during fracturability. The tubers of Omega exhibited a higher fracturability in comparison to those of Laura (Figs. 2b, 3f, SM_4b, and SM_6b). This might be related to the higher DM and starch concentrations (Fig. 3a and b, Table 2 and 3, and SM_5) of Omega in comparison to Laura. Singh et al. (2008) explored rheological parameters like the fracturability and hardness of potato tubers based on their DM and starch concentrations. The authors determined the highest fracturability and hardness in the cultivars that also exhibited the highest DM and starch concentrations. Equally, Bordoloi et al. (2012) demonstrated clear differences in textural characteristics, such as hardness and cohesiveness, between mealy and waxy potato cultivars, in which the authors refer to microstructural features such as cell size and structure, which, in turn, were closely related to the cultivars' DM and starch concentrations. They argue that mealy cultivars, possessing higher amounts of DM and starch, show smaller cell sizes and a more well-defined cell structure. Similar results were already published by Hudson (1975), who showed that bruising susceptibility of tubers was highest, which had low specific gravity but large cell sizes. Larger cells are thought to be the ones that are first damaged (Konstankiewicz et al. 2001; 2002), while smaller cells exhibit greater surface area per unit volume and thus may need greater strength to be separated or damaged (Šaøec et al. 2006).

Furthermore, the stem-ends of tubers illustrated a superior fracturability compared to bud-ends (Fig. 2b and SM_6b). Meanwhile, the stem-ends exhibited higher DM concentrations in comparison to the bud-ends (Table 3 and SM_5). This might have led to higher resistances of the stem- in comparison to the bud-ends owing to the previously described reasons.

While our results showed increasing DM from the bud- to the stem-end, it was the opposite for K (Table 3 and SM_5). These outcomes are in accordance with Johnston et al. (1968), who also noted increasing DM, but 
decreasing $\mathrm{K}$ concentrations, from the bud-end to the stem-end in potato tubers; the work of Westermann et al. (1994) contained the same observations. Likewise, LeRiche et al. (2009) assessed higher K concentrations at the bud-end compared to the stem-end of potato tubers. On the one hand, $\mathrm{K}$ is supposed to have an positive effect on tuber DM and starch formation, which can be referred to the roles of $\mathrm{K}$ in photosynthesis and the translocation of the assimilates from source, such as photosynthetic active leaves, to sink organs, which are in the case of potato especially roots and tubers. This issue is, for example, described in the reviews by Römheld and Kirkby (2010) or Zörb et al. (2014). On the other hand, K is mainly responsible for regulating the osmotic potential of cell sap, and therefore, of central importance for the maintenance of turgor pressure or cell growth (Mengel and Arneke 1982; Zörb et al. 2014). Thus, we suppose that there is a relationship between decreasing DM, while increasing $\mathrm{K}$ concentrations from the stem to the bud-end due to the osmotic properties of $\mathrm{K}$. K can lead to an increase of cell and tuber water content, which, in turn, can result in a reduction of DM (Schippers 1968; Westermann et al. 1994). Apart from higher DM in Omega in comparison to Laura, Omega showed a clear trend of higher Ca concentrations, especially in the tuber skin (Fig. 3e, Table 2 and 3, SM_5). Our findings are in accordance with Subramanian et al. (2011), who also found markedly high Ca concentrations in the tuber's surface layers in contrast with the tuber's flesh. The plant cell wall has several main constituents; these include pectin, hemicellulose, and cellulose. With approximately $60 \%$, pectin is the main component of the cell walls of potato (van Dijk et al. 2002; Sila et al. 2009). Pectin mainly consists of a complex mixture of polysaccharides, which are cross-linked by the binding of divalent cations, such as $\mathrm{Ca}^{2+}$, on the free carboxyl groups (Pooviah 1986; Weiler and Nover 2008). Thus, Ca can contribute to improve the cell wall stability of plant-based foods (Pooviah 1986). For instance, Conway et al. (1994) demonstrated increased fruit firmness and reduced decay in apples (Malus domestics Borkh.) through postharvest treatment with Ca. Likewise, Glenn and Poovaiah (1990) displayed that Ca-untreated apples (Malus domestics Borkh.) showed in the regions of the middle lamella distended or even separated regions, while cell-to-cell contact was maintained in Ca-treated apples during storage. Based on these relations between Ca and cell wall stability, we assume that Omega showed superior cell wall stability in comparison to Laura, which has contributed to the higher resistance of Omega. Aside from $\mathrm{Ca}, \mathrm{Mg}$ is also supposed to increase cell wall stability via linkage to cell wall polymers (Andersson et al. 1994). However, the results of the present study did not indicate such an effect by $\mathrm{Mg}$.

\section{Conclusions}

The occurrence of thumbnail cracks and fracturability of the tuber were investigated based on the (i) varying K and Mg supply, (ii) the cultivar, (iii) the DM and starch, and the (iv) mineral concentrations. Contrary our initial 
presumption, no clear effect of the fertilization treatment on the investigated rheological properties and on the DM, starch, and mineral concentrations was detectable, likely due to a sufficient supply of $\mathrm{K}$ and $\mathrm{Mg}$ in the soils of the field sites in the present study. However, the present study allowed drawing following conclusions:

1. The cultivar 'Omega' and the tuber segment 'stem-end', which both revealed higher DM and starch concentrations, exhibited a higher resistance against the caused mechanical impacts. The relationship of higher DM and starch concentrations and increased resistance against mechanical impacts might be referred to certain cultivar characteristics of mealy cultivars, which are usually accompanied by higher DM and starch concentrations.

2. The cultivar 'Omega', which exhibited higher Ca concentrations, demonstrated a higher resistance against the caused mechanical impacts. This effect due to higher Ca concentrations can be traced to the role of $\mathrm{Ca}$ in stabilizing cell walls via linking cell wall polymers. A balanced Ca supply, especially of tubers exhibiting lower Ca concentrations, therefore might be of importance to maintain a higher resistance of tubers against mechanical impacts.

\section{Acknowledgements}

We thank K+S KALI GmbH for their financial and technical support as well as the research station Dethlingen (VSD) for offering us their technical equipment and scientific assistance. We thank Karsten Meyer for his very beneficial and scientific contributions to the experimental procedures of the present study. Our thanks go to Dr. Inga Smit for her valuable advices and suggestions. Furthermore, we thank Lena Bergmann and Niklas Hartwig for their vigorous support throughout the conduction of experiments. 


\section{Supplementary material}
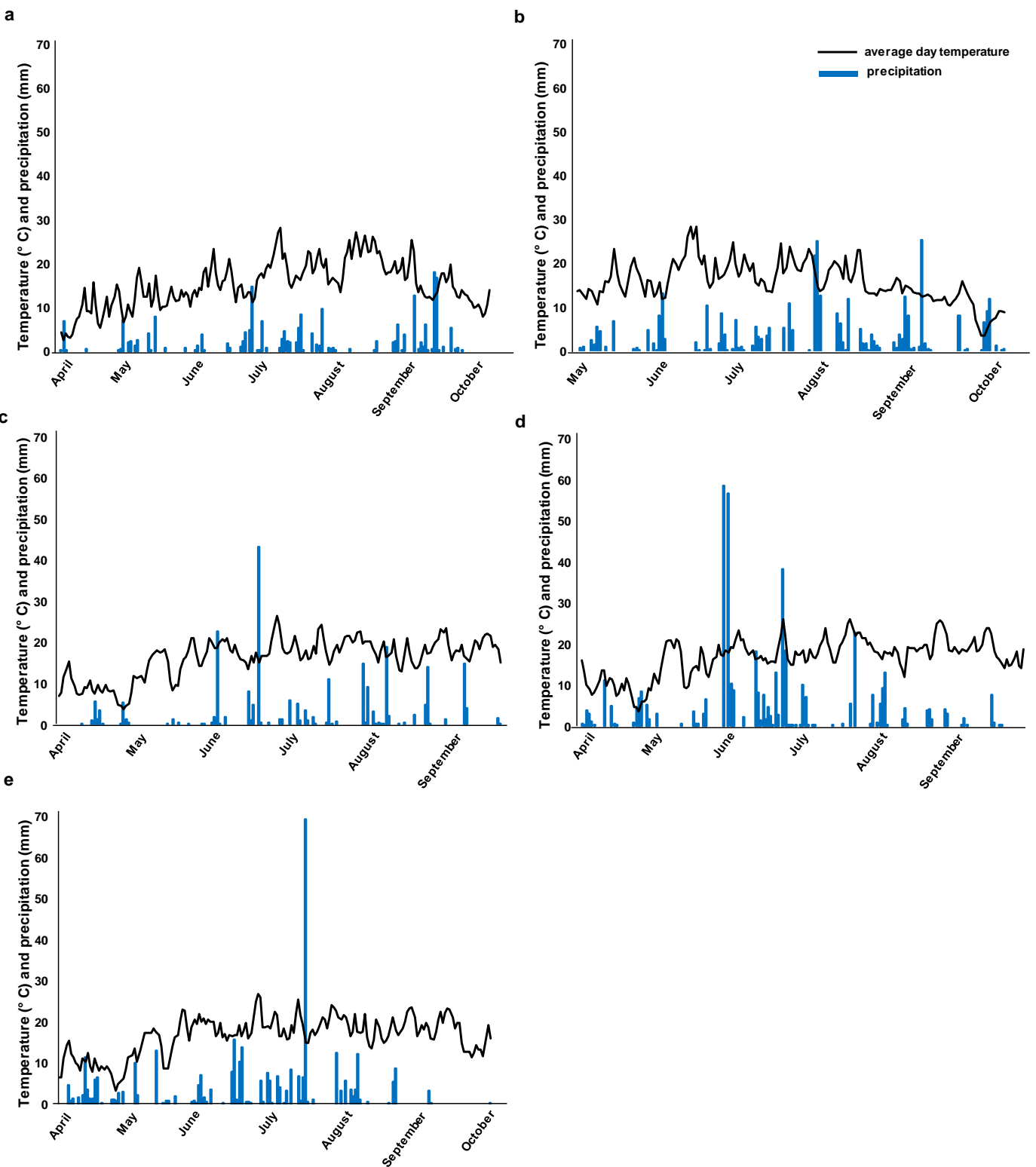

SM_1: Climate conditions (average day temperature in ${ }^{\circ} \mathrm{C}$ and precipitation in $\mathrm{mm}$ ) of the sites Müncheberg (a) and Uedem (b) throughout the vegetation period in 2015 and of the sites Müncheberg (c), Uedem (d), and Kościan (e) throughout the vegetation period in 2016. 


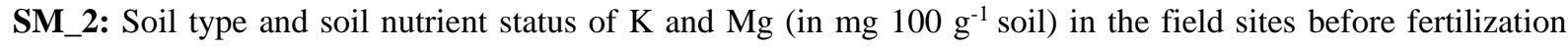
treatments.

\begin{tabular}{lccc}
\hline & Müncheberg $^{\dagger}$ & Uedem $^{\ddagger}$ & Kościan $^{\S}$ \\
\hline Soil type & loamy sand & sandy clay & luvisol \\
$\mathbf{K}$ & 11.7 & 11.0 & 12.5 \\
$\mathbf{M g}$ & 3.8 & 6.5 & 7.4 \\
\hline
\end{tabular}

Date of soil sampling: ${ }^{\dagger}$ February $2015 ;{ }^{\ddagger}$ April $2015 ;{ }^{\S}$ August 2016
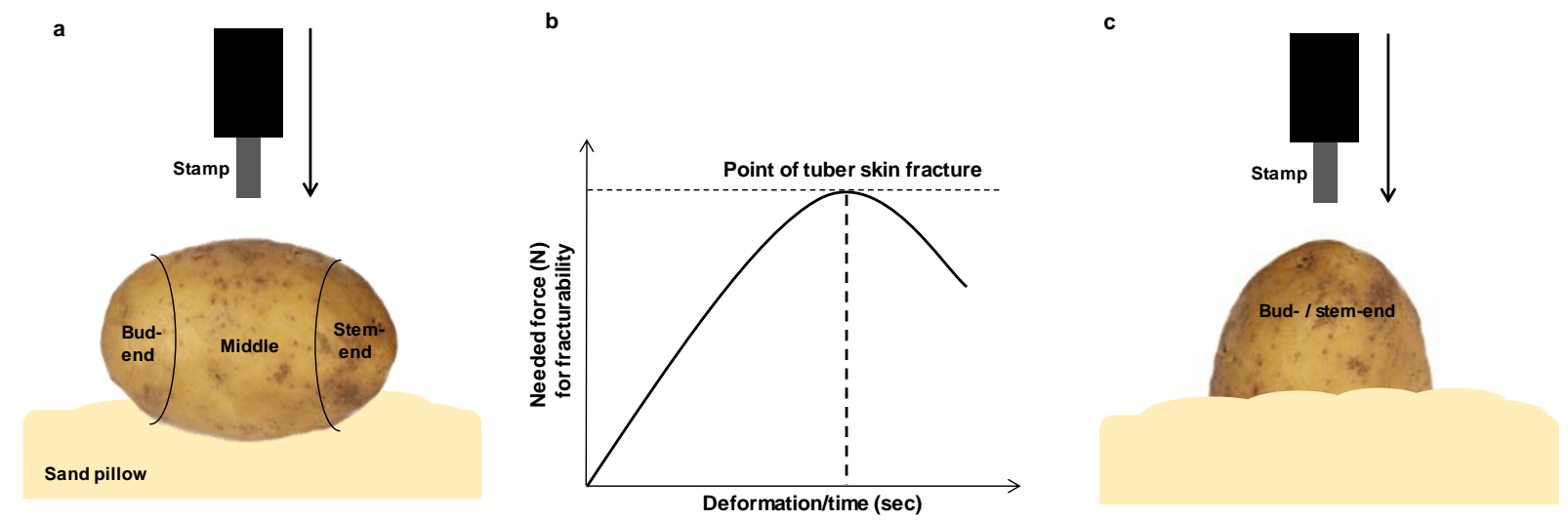

SM_3: Schemes for the conduction of tuber skin penetration analyses and of used tuber parts for determination of fracturability, and DM, starch, and mineral analyses. During penetration of the potato tuber (a), the needed force (N) for fracturability is recorded. This is the point of the highest force $(\mathrm{N})$ on a force-deformation curve (point of tuber skin fracture, b), which is characterized by a subsequent decline of force. A sand pillow was placed below the tuber or tuber segment, respectively, which served as a counter bearing. For the measurements of the whole tuber, the stamp penetrated in the middle of the tuber (a). For measurements of the tuber bud- and stem-ends, the tubers were cut the middle and each half of the tuber was placed with its sliced side on the sand pillow, while the stamp penetrated the opposite bud- or stem-end, respectively (c). 
a

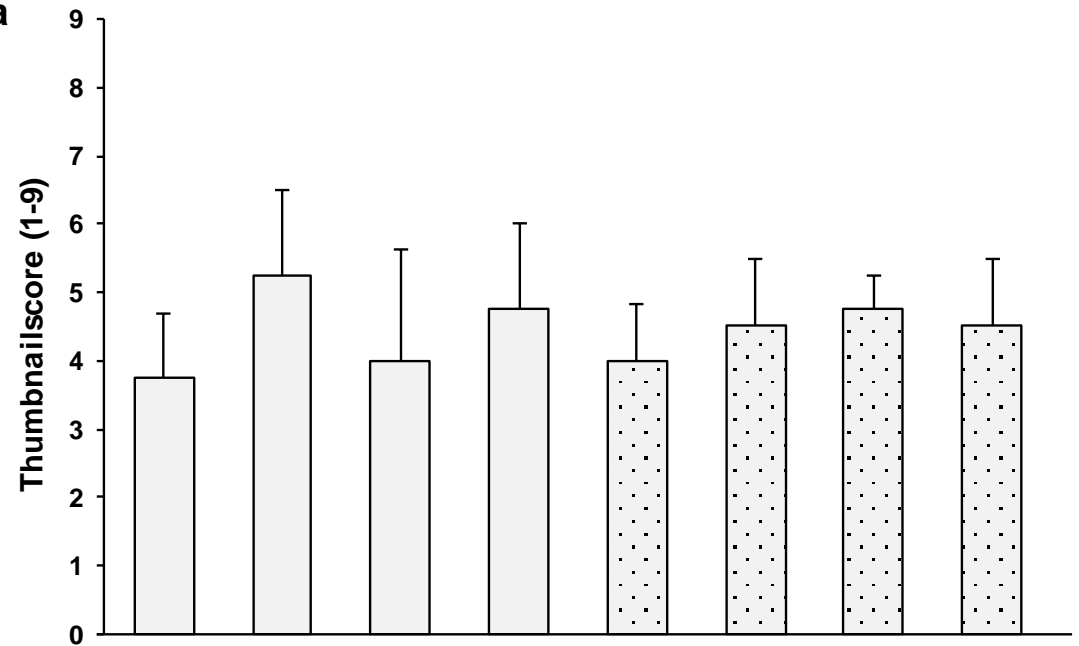

cultivar ns

fertilization ns

cultivar $\mathbf{x}$ fertilization $\mathbf{n s}$
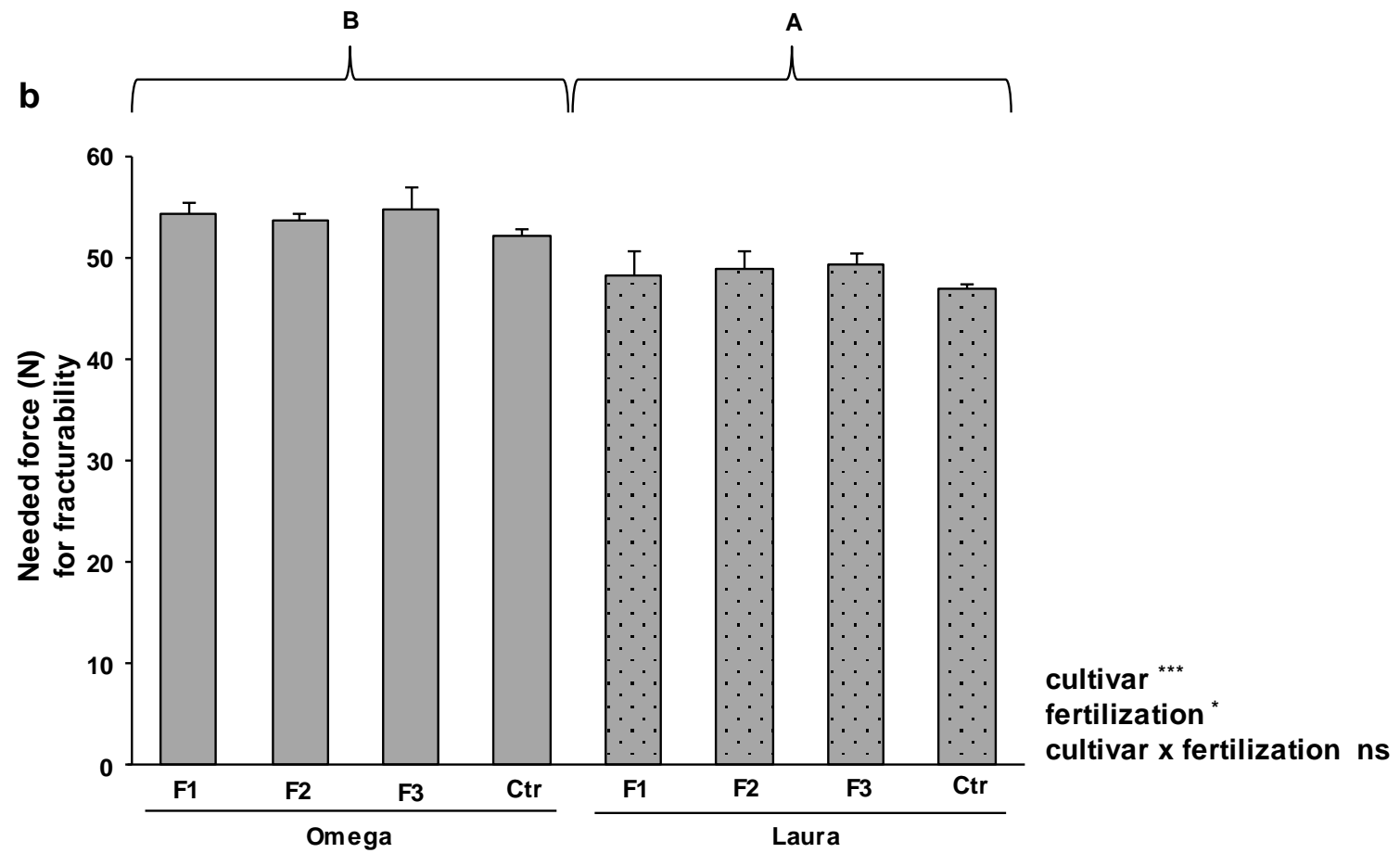

SM_4: Thumbnail crack occurrence of whole tubers of the cultivars Omega and Laura from 'Müncheberg' (a) and the fracturability of whole tubers of the cultivars Omega and Laura from 'Uedem' (b) under different $\mathrm{K}$ and $\mathrm{Mg}$ fertilization treatments in 2015. Mean \pm SE values $(n=4)$. Levels of significance tested via ANOVA are shown in the right lower corner with ${ }^{*}$ and ${ }^{* * *}$ for $\mathrm{p}<0.05$ and 0.001 , respectively. $\mathrm{ns}=$ not significant. Capitals $=$ significant differences between the cultivars of one fertilization treatment, and no indication $=$ no significant differences. 


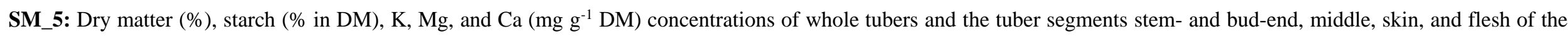

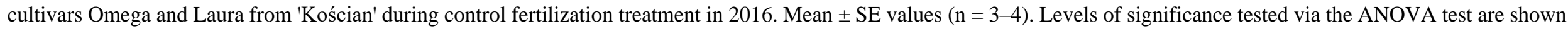

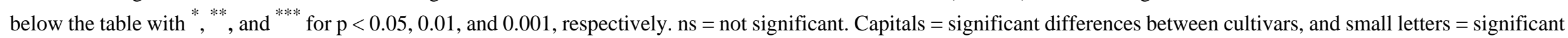
differences between tuber segments of one cultivar.

\begin{tabular}{|c|c|c|c|c|c|c|c|c|c|c|c|c|c|}
\hline Omega & whole tuber & \multicolumn{2}{|l|}{ stem-end } & \multicolumn{2}{|l|}{ middle } & \multicolumn{2}{|l|}{ bud-end } & \multicolumn{2}{|l|}{ skin } & \multicolumn{2}{|l|}{ flesh } & \multicolumn{2}{|c|}{$\begin{array}{l}\text { Average over } \\
\text { tuber segments }\end{array}$} \\
\hline DM & $23.61 \pm 1.19$ & $26.89 \pm 0.73$ & $\mathrm{~b}$ & $24.41 \pm 1.14$ & $a b$ & $24.01 \pm 1.43$ & $a b$ & $20.63 \pm 0.79$ & $\mathrm{a}$ & $26.11 \pm 0.95$ & $b$ & $24.41 \pm 2.42$ & $\mathrm{~B}$ \\
\hline Starch & $68.77 \pm 1.41$ & $70.02 \pm 0.86$ & $\mathrm{~b}$ & $69.95 \pm 1.83$ & $b$ & $65.37 \pm 2.38$ & $b$ & $46.64 \pm 1.06$ & $\mathrm{a}$ & $66.68 \pm 8.88$ & $b$ & $63.74 \pm 9.78$ & B \\
\hline K & $22.97 \pm 1.39$ & $19.12 \pm 1.32$ & $\mathrm{a}$ & $21.98 \pm 3.52$ & $a b$ & $25.49 \pm 2.96$ & $b$ & $33.30 \pm 2.09$ & $c$ & $21.27 \pm 0.97$ & $a b$ & $24.23 \pm 5.56$ & \\
\hline Mg & $1.24 \pm 0.14$ & $1.18 \pm 0.07$ & $\mathrm{a}$ & $1.14 \pm 0.07$ & a & $1.16 \pm 0.07$ & $\mathrm{a}$ & $1.48 \pm 0.06$ & $b$ & $1.12 \pm 0.06$ & $\mathrm{a}$ & $1.21 \pm 0.15$ & \\
\hline $\mathrm{Ca}$ & $0.32 \pm 0.03$ & $0.36 \pm 0.08$ & $\mathrm{a}$ & $0.34 \pm 0.07$ & a & $0.41 \pm 0.03$ & a & $0.93 \pm 0.12$ & $b$ & $0.27 \pm 0.01$ & $a$ & $0.46 \pm 0.27$ & B \\
\hline \multicolumn{14}{|l|}{ Laura } \\
\hline DM & $21.65 \pm 1.49$ & $22.69 \pm 1.24$ & $\mathrm{~b}$ & $20.43 \pm 1.17$ & $a b$ & $20.37 \pm 1.34$ & $a b$ & $16.68 \pm 0.62$ & a & $21.96 \pm 1.27$ & $b$ & $20.43 \pm 2.32$ & A \\
\hline Starch & $63.89 \pm 2.73$ & $66.21 \pm 2.13$ & $\mathrm{~b}$ & $65.08 \pm 2.28$ & $b$ & $64.89 \pm 2.12$ & $\mathrm{~b}$ & $46.20 \pm 1.18$ & $\mathrm{a}$ & $70.06 \pm 1.53$ & $\mathrm{~b}$ & $62.49 \pm 9.34$ & $A$ \\
\hline K & $19.99 \pm 1.55$ & $16.01 \pm 1.14$ & $a$ & $21.55 \pm 2.51$ & $\mathrm{bc}$ & $24.66 \pm 1.99$ & $c$ & $37.35 \pm 4.55$ & $d$ & $19.21 \pm 2.02$ & $b$ & $23.76 \pm 8.23$ & \\
\hline Mg & $1.09 \pm 0.06$ & $1.20 \pm 0.07$ & $\mathrm{a}$ & $1.12 \pm 0.01$ & a & $1.17 \pm 0.05$ & $a$ & $1.52 \pm 0.07$ & $\mathrm{~b}$ & $1.06 \pm 0.02$ & a & $1.21 \pm 0.18$ & \\
\hline $\mathrm{Ca}$ & $0.23 \pm 0.03$ & $0.27 \pm 0.01$ & $a$ & $0.20 \pm 0.02$ & $a$ & $0.26 \pm 0.04$ & $a$ & $0.68 \pm 0.15$ & $\mathrm{~b}$ & $0.17 \pm 0.04$ & a & $0.32 \pm 0.21$ & $A$ \\
\hline
\end{tabular}


a

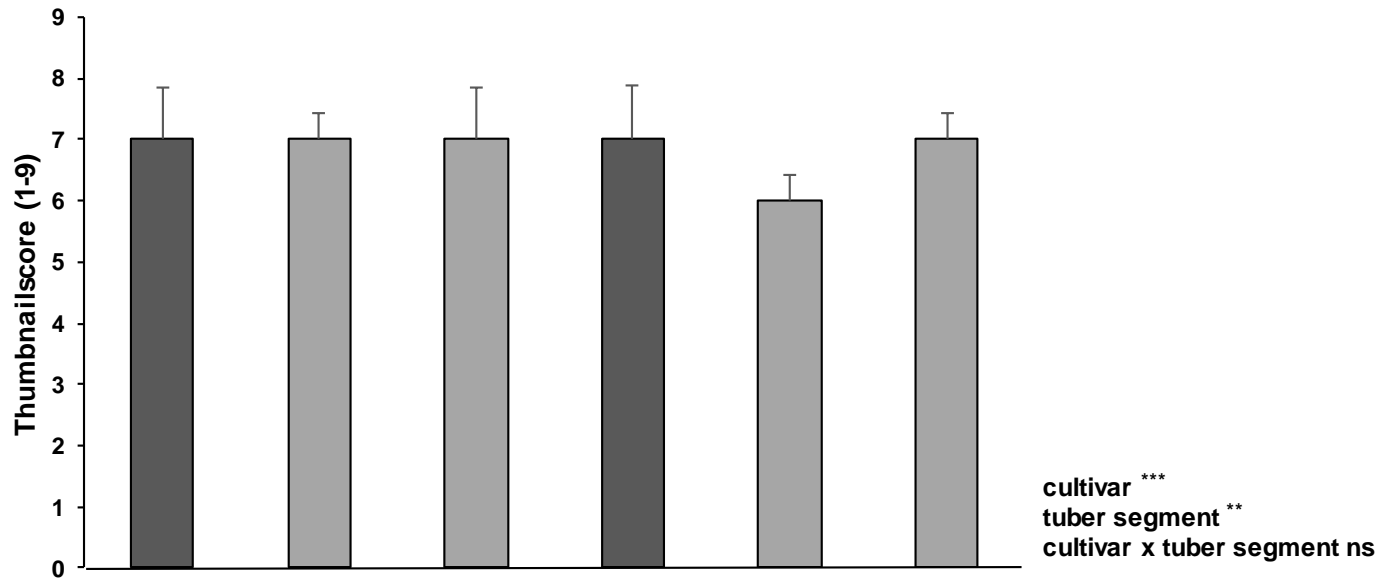

b

B

A

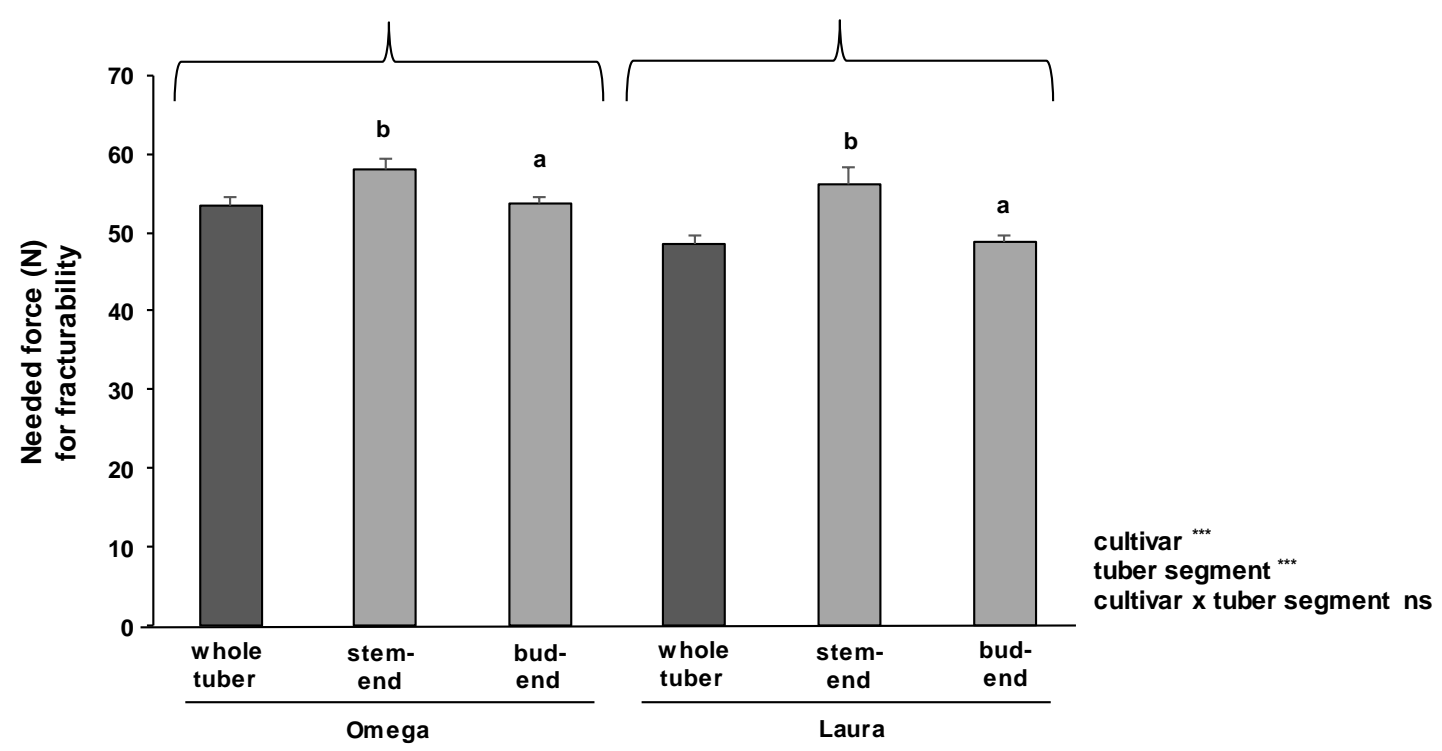

SM_6: Thumbnail crack occurrence of whole tubers, tuber stem- and bud-ends of the cultivars Omega and Laura from 'Kościan' in $2016(\mathrm{n}=4)(\mathrm{a})$. Thumbnail score: 1 = very severe occurrence, $3=$ severe occurrence, $5=$ medium occurrence, $7=$ slight occurrence, and $9=$ almost no occurrence. Fracturability of whole tubers and tuber stem and bud ends of the cultivars Omega and Laura from 'Kościan' the trial at the site in Kościan in $2016(n=3)$ (b). Mean \pm SE values. Levels of significance tested via the ANOVA test are shown in the right lower corner with ${ }^{* *}$ and ${ }^{* * *}$ for $\mathrm{p}<0.01$ and 0.001 , respectively. $\mathrm{ns}=$ not significant. Capitals $=$ significant differences between the cultivars of one tuber segment, small letters = significant differences between stem- and bud end, and no indication = no significant differences. 
SM_7: Effect of fertilization on the tuber yield $\left(\mathrm{dt} \mathrm{ha}^{-1}\right)$ of all the fertilization treatments from 'Müncheberg' and 'Uedem' in 2015 and 'Müncheberg', 'Uedem', and 'Kościan' in 2016. Mean \pm SE values $(n=4)$. The treatments had no significant effect.

2015

\begin{tabular}{|c|c|c|c|c|c|c|c|c|c|}
\hline & & F1 & & F2 & & F3 & & Ctr & \\
\hline \multirow[t]{2}{*}{ Müncheberg } & Omega & $293.1 \pm 51.6$ & ns & $307.6 \pm 52.3$ & ns & $299.5 \pm 52.9$ & ns & $307.2 \pm 49.1$ & ns \\
\hline & Laura & $318.3 \pm 20.1$ & ns & $325.9 \pm 11.9$ & ns & $318.9 \pm 17.2$ & ns & $331.7 \pm 22.1$ & ns \\
\hline \multirow[t]{2}{*}{ Uedem } & Omega & $431.9 \pm 79.5$ & ns & $456.9 \pm 45.8$ & ns & $467.9 \pm 36.6$ & ns & $451.0 \pm 38.9$ & ns \\
\hline & Laura & $544.6 \pm 23.4$ & ns & $556.3 \pm 4.5$ & ns & $536.7 \pm 41.9$ & ns & $537.4 \pm 84.2$ & ns \\
\hline \multicolumn{10}{|c|}{2016} \\
\hline \multirow[t]{2}{*}{ Müncheberg } & Omega & $331.8 \pm 51.6$ & ns & $348.5 \pm 37.5$ & ns & $313.4 \pm 36.6$ & ns & $371.2 \pm 58.9$ & ns \\
\hline & Laura & $340.3 \pm 55.3$ & ns & $370.0 \pm 52.3$ & ns & $351.7 \pm 44.6$ & ns & $362.3 \pm 43.8$ & ns \\
\hline \multirow[t]{2}{*}{ Kościan } & Omega & $497.4 \pm 45.2$ & ns & $267.5 \pm 12.7$ & ns & $519.3 \pm 48.1$ & ns & $558.5 \pm 28.1$ & ns \\
\hline & Laura & $553.2 \pm 38.7$ & ns & $186.3 \pm 59.6$ & ns & $545.8 \pm 53.8$ & ns & $617.2 \pm 54.7$ & ns \\
\hline \multirow[t]{2}{*}{ Uedem } & Omega & $270.4 \pm 27.4$ & ns & $267.5 \pm 12.7$ & ns & $234.6 \pm 31.1$ & ns & $253.3 \pm 22.5$ & ns \\
\hline & Laura & $183.2 \pm 47.0$ & ns & $186.3 \pm 59.6$ & ns & $217.4 \pm 74.9$ & ns & $158.4 \pm 62.9$ & $\mathrm{~ns}$ \\
\hline
\end{tabular}




\section{Chapter 7}

General discussion 


\section{General discussion}

A central factor of influence on potato development and quality is the supply of the plant with nutrients (Westermann 2005). The presented research aimed to investigate the effect of various $\mathrm{K}$ and $\mathrm{Mg}$ supply on potato plant development and quality-related tuber attributes. With regard to this, four research objectives were stated (see chapter 1, section 1.8) whose outcomes are discussed following.

\section{Effect of K and Mg deficiency on (i) production and partitioning of photoassimilates, (ii) above and belowground biomass development, and (iii) tuber quality of potato}

The roles of $\mathrm{K}$ and $\mathrm{Mg}$ for photosynthesis and the translocation of photoassimilates from source to sink organs have been demonstrated in various crop species (Dreyer et al. 2017; Farhat et al. 2016; Jákli et al. 2017; Tränkner et al. 2016). However, the impact of a $\mathrm{K}$ and $\mathrm{Mg}$ deficiency on photosynthesis and the partitioning of photoassimilates in potato were unclear. It could be shown that $\mathrm{K}$ deficiency in potato significantly reduced shoot biomass (what equals a decrease in photosynthetic active biomass), $\mathrm{CO}_{2}$ net assimilation rate, and leave chlorophyll concentrations (Chapter 4, Fig. 1a, 2a and 4b; Chapter 7, Fig. 1) and thus severely impaired photosynthesis. Meanwhile, Mg deficiency did not significantly reduced shoot growth (and thus photosynthetic active biomass), $\mathrm{CO}_{2}$ net assimilation rate (at an early growth stage) nor decreased chlorophyll concentrations. Lastly, it did not severely impair photosynthesis (Chapter 4, Fig. 1c and e, 2a and 4c; Chapter 7, Fig. 1).

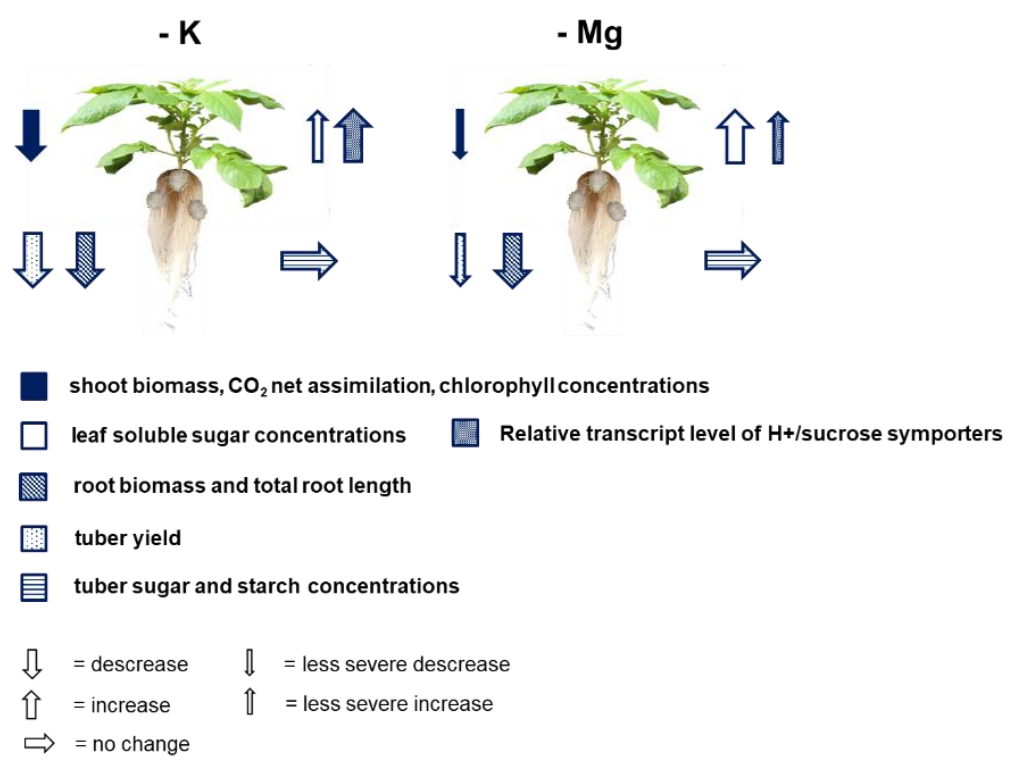

Figure 1: Scheme summarizing the impact of $\mathrm{K}(-\mathrm{K})$ and $\mathrm{Mg}(-\mathrm{Mg})$ deficiency on photosynthesis, translocation of photoassimilates, root biomass, total root length and tuber yield and quality in potato. 
Besides, both $\mathrm{K}$ and Mg deficiency lead to a significant increase of soluble sugars and to an increased transcript level of $\mathrm{H}^{+} /$sucrose symporters in fully expanded leaves, which indicated a hampered allocation of photoassimilates from source to sink organs (Chapter 4, Fig. 5; Chapter 7, Fig. 1). Thereby, the increase of soluble sugars was much more pronounced in $\mathrm{Mg}$ - compared to K-deficient plants. However, the transcript levels of $\mathrm{H}^{+}$/sucrose symporters were less increased under Mg-deficiency. The latter case probably was caused by an impaired sucrose transport due to Mgdeficiency already at an earlier step, namely the efflux of sucrose from mesophyll cells into the apoplast, what is carried out via SWEET transporters (Manck-Götzenberger and Requena 2016). Thus, it is assumed that K-deficiency lead to a sucrose accumulation in the apoplast resulting in an increased transcript level of $\mathrm{H}^{+} /$sucrose symporters. Meanwhile, Mg-deficiency caused sugar accumulation in mesophyll cells, why Mg-deficient plants did not show pronounced increases of transcript levels of $\mathrm{H}^{+} /$sucrose symporters but likely affected another sugar transport system.

Furthermore, it has been shown that the partitioning of photoassimilates was hampered before any impact on photosynthesis under Mg deficiency (Chapter 4). This is in compliance with results shown e.g. by Hermans et al. (2004). Furthermore, the latter assumption may lead to the presumption that $\mathrm{Mg}$ is of higher relevance for the translocation of photoassimilates rather than for the production of photoassimilates via photosynthesis.

$\mathrm{K}$ and $\mathrm{Mg}$ deficiency caused a reduction of root biomass and total root length (Chapter 4, Fig. 2b and c; Chapter 5, Fig. $5 \mathrm{~b}$ and 7). This coincided with a significant increase of soluble sugars in source leaves of $\mathrm{K}$ and especially $\mathrm{Mg}$ deficient plants (Chapter 4, Fig. 5a; Chapter 5, Fig. 4b and c), indicating a restricted translocation of photoassimilates from source leaves to sink organs (roots in this case). Thus, a relation between the translocation of photoassimilates and root growth is assumed, as plants, which exhibited a distinct sugar accumulation in source leaves also revealed decreased root growth. Moreover, both studies (Chapter 4 and 5) imply a higher sensitivity of root compared to shoot growth under Mg deficiency whereas $\mathrm{K}$ deficiency led to an equivalent reduction of root as well as of shoot growth (Chapter 7, Fig. 1). It is likely, that this also can be referred to the previous made assumption that $\mathrm{Mg}$ is of greater relevance for the translocation of photoassimilates rather than for photosynthesis while it is the opposite for K.

Another aim of this thesis was to test whether a resupply of Mg (via leaves or roots) can ameliorate deficiency symptoms such as depressed root growth or lack in $\mathrm{Mg}$. A Mg foliar application led to a very temporally increase of $\mathrm{Mg}$ leave concentrations with a subsequent decrease to equal $\mathrm{Mg}$ concentrations as before the application of $\mathrm{Mg}$ deficient plants (Chapter 5, Fig. 2b). Shoot and root biomass and total root length revealed also a very slight increase upon Mg foliar application (Chapter 5, Fig. 5a, b, and 7). Meanwhile, a complementary fertilization of Mg via the roots exhibited much more pronounced effects, especially in form of increased $\mathrm{Mg}$ leaf (Chapter 5, Fig. 2b) and root 
concentrations (Chapter 5, Fig. 7) and in form of an increase of the total root length compared to the Mg deficient plants (Chapter 5, Fig. 7). By comparison, Jezek et al. (2015) demonstrated that an Mg foliar application sufficiently improved the $\mathrm{Mg}$ status of the plant but the authors did not investigate root growth. Though, Neuhaus et al. (2014) could show an significant increase of a Mg foliar application on root biomass. However, a rise of the Mg supply via the nutrient solution exhibited much more distinct effects - similarly to our findings.

K deficient plants showed a more severe reduction of tuber yield compared to Mg deficient plants (Chapter 4, Fig. 2f; Chapter 7, Fig. 1) and a greater reduction of photosynthesis compared to the partitioning of photoassimilates, while it was the opposite for $\mathrm{Mg}$ deficient plants. This indicates that a hampered photosynthesis impairs tuber yield more severe compared to the translocation of photoassimilates. However, it is also conceivable that not a decrease of photosynthesis resulted in reduced sink growth but a decreased sink demand in form of reduced tuber yield and/or root growth resulted in a decrease of photosynthesis as has been argued by Marschner et al. (1996).

Surprisingly, with respect to our initial expectation that $\mathrm{K}$ and $\mathrm{Mg}$ deficiency will negatively affect tuber quality, we could not determine significant differences in tuber sugar and starch concentrations of various $\mathrm{K}$ and $\mathrm{Mg}$ supplied plants (Chapter 4, SM_5b and c). Only a slight tendency in form of a decrease of hexose sugars (glucose and fructose) was revealed in plants with high $\mathrm{K}$ and sufficient Mg supply (Chapter 4, SM_5b, K3+Mg plants). However, the total amount of tuber sugar and starch per plant showed significant differences: Medium and high K supplied plants showed significant higher sugar and starch yields per plant compared to low K supplied plants and Mg sufficient supplied plants (K2 and $\mathrm{K} 3+\mathrm{Mg}$ ) exhibited significant higher starch yields compared to $\mathrm{Mg}$ deficient supplied plants (K2 and K3-Mg) (Chapter 4, Fig. 6). These findings can be referred to the significant reduction of tuber yields due to $\mathrm{K}$ and Mg deficiency, respectively (Chapter 4, Fig. 2f).

\section{Influence of $\mathrm{K}$ and $\mathrm{Mg}$ interactive effects on $\mathrm{K}$ and $\mathrm{Mg}$ concentrations of different plant tissues and biomass}

\section{development}

Nutrient interactions between ions often have been research issue - however with contradictory outcomes. With respect to interactions between $\mathrm{K}$ and $\mathrm{Mg}$ there have been reports about antagonistic (Hossner and Doll 1970), synergistic (Ding et al. 2006) and neutral (Allison et al. 2002) interactive effects. One aim of the present study was to clarify the nature of interactive effects between $\mathrm{K}$ and $\mathrm{Mg}$ in potato. Antagonism between $\mathrm{K}$ and $\mathrm{Mg}$ usually is referred to competitive uptake mechanism of $\mathrm{K}$ and $\mathrm{Mg}$ from the soil solution. While $\mathrm{Mg}$ transporters are highly unspecific and take up other cations than $\mathrm{Mg}, \mathrm{K}$ transporters are very specific (with the expectation of sodium as has been shown by 
Castillo et al. (2015)) and the uptake of $\mathrm{K}$ is ensured under low as well as under high $\mathrm{K}$ concentrations in the soil solution (Britto and Kronzucker 2008; Karley and White 2009; Mayland 1990). Indeed, our results demonstrated significant decreased $\mathrm{Mg}$ concentrations in leaves with increasing $\mathrm{K}$ supply (Chapter 4, Table 2), indicating an antagonistic effect of $\mathrm{K}$ on $\mathrm{Mg}$. However, tubers and roots exhibited significant higher $\mathrm{Mg}$ concentrations with higher $\mathrm{K}$ supply (Chapter 4, Fig. 3b), indicating a synergistic effect of $\mathrm{K}$ on the tuber and root $\mathrm{Mg}$ concentrations. These outcomes can be argued by the following reasons. Usually, plants show higher K concentrations in the shoot compared to the roots (Karley and White 2009; White 1997) what likewise is reflected in our results (Chapter 4, Fig. 3a). As the plant strives to preserve a balance between cations and anions (Kirkby and Mengel 1967), it is likely that the higher K concentrations in the shoot led to lower Mg concentrations while lower $\mathrm{K}$ concentrations in roots and tubers led to higher Mg concentrations. Likewise, the significant highest $\mathrm{Mg}$ concentrations were determined in leaves of plants with the lowest $\mathrm{K}$ supply (Chapter 4, Table 2; K1+Mg plants). Moreover, it is feasible that an antagonistic interaction mechanism is located in the translocation from root to shoot (and probably not in the uptake from soil solution into the roots) as has been suggested by Ohno and Grunes (1985). This antagonistic interaction mechanism may have led to a depletion of $\mathrm{Mg}$ in leaves whereas Mg enriched in roots and tubers compared to leaves. Lastly, it cannot be validated an overall antagonistic effect between $\mathrm{K}$ and $\mathrm{Mg}$ in potato. Likewise, although increasing $\mathrm{K}$ supply revealed a synergistic effect on the tuber and root $\mathrm{Mg}$ concentrations, it cannot be confirmed an overall synergistic effect of $\mathrm{K}$ on $\mathrm{Mg}$ in potato.

\section{Relation between tuber DM and mineral concentrations and distributions on the one hand and resistance of}

\section{the tuber skin against mechanical impacts on the other hand}

Inappropriate agricultural practices causing mechanical impacts during or after harvest or adverse environmental conditions can result e.g. in cracking of tuber skin (Dean and Thornton 1989; Sparks 1970). Such cracks can significantly reduce the quality of the tubers and the appeal to consumers (Bohl and Thornton 2006). Beside those abiotic reasons which might cause tuber cracking, further causes can be, for instance, the cultivar, the soil type or storage conditions. However, there is only little information about physiological parameters which affect the tuber resistance against mechanical impacts and thus their susceptibility for cracking. In the present thesis (Chapter 6), a focus was set on the elucidation of factors that correlate with the symptom 'thumbnail crack' what is a few millimeter deep crack of the tuber skin. Besides, the fracturability of the tuber skin was investigated in order to further characterize the susceptibility of the tuber skin against mechanical impacts. The results suggest that DM and starch concentrations 
might be associated with the resistance against mechanical impacts. The higher the DM and starch concentrations, the higher was the resistance of the tuber skin towards mechanical impacts (e.g. Chapter 6, Fig. 3). A relation between DM and starch on the one hand and rheological parameters in form of increasing values for fracturability, hardness and cohesiveness (meaning improved resistance against mechanical impacts) on the other hand also has been reported by Bordoloi et al. (2012) and Singh et al. (2008). Bordoloi et al. (2012) elucidate this relation by the observation that tubers which exhibit higher DM and starch concentrations showed smaller cell sizes and a more advantageous cell structure. Larger cells are the first to be damaged whereas smaller cells show a greater surface area per unit volume why a greater strength would be needed to separate or damage smaller compared to larger cells (Konstankiewicz et al. 2002; Šaøec et al. 2006).

A further parameter which positively correlated with the resistance against mechanical impacts on the tuber skin was the tuber Ca concentration. Divalent cations like $\mathrm{Ca}$ are known to improve cell wall stability as they are binding to cell wall polymers and thus stabilize the cell walls (Poovaiah 1986; Weiler and Nover 2008). This relation between Ca and cell wall stability has been well proven in apple, for example (Conway et al. 1994; Glenn and Poovaiah 1990). Beside $\mathrm{Ca}$, likewise for $\mathrm{Mg}$ an improving impact on the cell wall stability is discussed (Andersson et al. 1994). However, our outcomes (Chapter 6) cannot confirm such a contribution of $\mathrm{Mg}$.

Another research objective of the present thesis was to test how $\mathrm{K}$ and Mg supply might affect physiological parameters which in turn affect the resistance of the tuber against mechanical impacts (Chapter 6). Various studies reported about an impact of the K and Mg supply on DM and starch of potato tubers (Miča 1979; Panique et al. 1997; Poberezny and Wszelaczynska 2011; Westermann et al. 1994). In the field trials there was no influence of different $\mathrm{K}$ and $\mathrm{Mg}$ treatments on the DM and starch concentrations (e.g. Chapter 6, Table 2). Besides, there was no impact of the different $\mathrm{K}$ and $\mathrm{Mg}$ treatments on the tuber yield in the field trials (Chapter 6, SM_7). Likewise, in the pot experiment presented in chapter 4, no impact of different $\mathrm{K}$ and $\mathrm{Mg}$ supply on the DM and starch concentrations were assessed (Chapter 4, SM_5a). Though, significant higher tuber starch amounts per plant with increasing $\mathrm{K}$ and Mg supply were examined in this study (Chapter 4, Fig. 6). However, these differences in tuber starch yield can be rather referred to the differences of tuber yield resulted from the different treatments of $\mathrm{K}$ and $\mathrm{Mg}$ (Chapter 4, Fig. 2f), as discussed previously in section 7.1, than to a direct effect of $\mathrm{K}$ and $\mathrm{Mg}$ supply on starch. The reason for no effect of the different $\mathrm{K}$ and $\mathrm{Mg}$ supply on tuber yield in the field trials (Chapter 6) but for an effect in the pot experiment (Chapter 4) can be referred to an already sufficient soil $\mathrm{K}$ and $\mathrm{Mg}$ status of the field sites soils (Chapter 6, SM_2) compared to a deficient soil $\mathrm{K}$ and Mg status of the soil used in the pot experiment (Chapter 4). 
Clear relations between DM and the cultivar and the tuber segment have been identified: The cultivar Omega revealed a significant higher resistance against mechanical impacts on the tuber skin compared to Laura (Chapter 6, e.g. Fig. 2 and 3) while Omega exhibited significant higher DM compared to Laura (Chapter 6, e.g. Fig. 3 and Table 3). Besides, the tuber segment 'stem end' showed a higher resistance against mechanical impacts compared to the 'bud end' (Chapter 6, e.g. Fig. 2) with coincident higher DM in the stem compared to the bud end (Chapter 6, e.g. Table 3). The higher $\mathrm{DM}$ in stem ends might be related with the distribution pattern of $\mathrm{K}$ within the tuber that was lower in the stem compared to the bud end (Chapter 6, e.g. Table 3). $\mathrm{K}$ is known for its osmotic properties (Mengel and Arneke 1982) why decreasing $\mathrm{K}$ concentrations may lead to an decrease of cell and tuber water content while DM is increasing (Schippers 1968; Westermann et al. 1994). This might explain why the bud ends were more prone for damages. As mentioned before, Omega revealed a higher resistance against mechanical impacts compared to Laura. A similar relation as for DM and the cultivar Omega with respect to the tuber resistance against mechanical impacts was examined between $\mathrm{Ca}$ and the cultivar Omega: Next to higher DM, Omega revealed higher Ca concentrations (Chapter 6, e.g. Fig. 3 and Table 3).

\section{Appropriate $\mathrm{K}$ and Mg supply for the potato crop}

A search of the ISI web of Science (see chapter 1, section 1.5) demonstrated that there is little awareness about both the importance of $\mathrm{Mg}$ supply and about a suitable combined supply of $\mathrm{K}$ and $\mathrm{Mg}$ for potato plant development and tuber quality. The present research contributes to improve the current knowledge regarding the roles of $\mathrm{K}$ and $\mathrm{Mg}$ for potato plant development and tuber quality formation. While for $\mathrm{Mg}$ a higher importance for the partitioning of photoassimilates within the plant was indicated, K showed a higher relevance for the production of photoassimilates (Fig. 1). But only under sufficient supply of both nutrients an appropriate tuber and starch yield and root development was realized (e.g. Chapter 4, Fig. 2a, b, c and f, and 6b). Results of the present study could not examine a definite antagonistic or synergistic effect between $\mathrm{K}$ and $\mathrm{Mg}$. However, it is likely that the antagonistic effect is also causing a synergistic effect (as described in section 7.2) and thus, both effects are related with each other. Nevertheless, although plants with the highest $\mathrm{K}$ supply (K3+Mg, Chapter 4) showed the lowest Mg concentrations in leaves (Chapter 4, Table 2), there was no indication for an adverse effect on plant development (e.g. shoot and root biomass, total root length and tuber yield; Chapter 4, Fig. 2). Based on the outcomes of this study it can be concluded that an appropriate combined supply of $\mathrm{K}$ and $\mathrm{Mg}$ for potato production and tuber quality is reflected in a ratio of $\mathrm{K}$ and $\mathrm{Mg}$ of $3: 1$ (300 $\mathrm{mg} \mathrm{K} \mathrm{kg}{ }^{-1}$ soil : $100 \mathrm{mg} \mathrm{Mg} \mathrm{kg}^{-1}$ soil). This ratio was, for instance, represented by $\mathrm{K} 2+\mathrm{Mg}$ plants (Chapter 4, Table 1). 


\section{Chapter 7: General discussion}

The doubled supply of $\mathrm{K}(\mathrm{K} 3+\mathrm{Mg}$ plants, representing a $\mathrm{K}$ to $\mathrm{Mg}$ ratio of $6: 1)$ did not exhibit a significant increase in biomass development (including root and shoot biomass, total root length and tuber yield) and no improvement of important tuber quality attributes such as tuber sugar and starch concentrations and yields. 


\section{Summary}

Knowledge regarding the importance of $\mathrm{K}$ and $\mathrm{Mg}$ for potato plant development and tuber quality is limited. $\mathrm{K}$ and $\mathrm{Mg}$ are nutrients, besides other crucial roles, for photosynthesis and the partitioning of photoassimilates within the plant. Hence, a negative effect of a $\mathrm{K}$ and $\mathrm{Mg}$ deficiency on tuber yield and quality can be expected as tubers are strong sink organs being highly dependent on the production of photoassimilates and its translocation down to the tubers.

This thesis aimed to examine the extent to which a $\mathrm{K}$ and $\mathrm{Mg}$ deficiency may affect potato plant development, tuber yield and tuber quality with view on the roles of $\mathrm{K}$ and $\mathrm{Mg}$ for photosynthesis and the partitioning of photoassimilates. Both $\mathrm{K}$ - and $\mathrm{Mg}$-deficiency lead to reduced $\mathrm{CO}_{2}$ net assimilation and photosynthetic active biomass production, with stronger reductions in $\mathrm{K}$-compared to Mg-deficient plants. Low $\mathrm{K}$ - as well as low Mg supply resulted in accumulation of sugars in source leaves, especially in Mg-deficient plants. This is indicative for a restricted phloem loading. Besides, $\mathrm{K}$ and $\mathrm{Mg}$ restricted plants exhibited an impaired root length development what is supposed to be a result of a restricted source to sink transport of photoassimilates. However, while low K-deficiency resulted in a sharp increase of transcript levels of $\mathrm{H}^{+} /$sucrose symporters, which are responsible to load the phloem with sucrose, this was less pronounced under Mg-deficiency. The latter case is probably the result of an impaired sucrose transport due to Mg-deficiency already at an earlier step, namely the efflux of sucrose from mesophyll cells into the apoplast. Therefore, it is assumed that $\mathrm{K}$ - and Mg-deficiency caused sugar accumulation in seperated cell compartments of source leaves leading to a different impact on the gene expression of sucrose transport systems. Tuber sugar and starch concentrations, however, remained unaffected under the various treatments. Nevertheless, the total amount of tuber sugar and starch per plant decreased significantly upon $\mathrm{K}$ - and Mg-deficiency.

A further research objective of this thesis was the external appearance of potato tubers what is an important quality attribute of potato tubers. The external appearance of potato tubers has been shown to mainly influence the customer's purchase behavior. Thus, external blemishes, such as cracks of the tuber skin, significantly reduce the quality and the appeal of tubers for consumers. One factor, which is influencing on the development of cracks is the susceptibility of the tuber skin for mechanical impacts. Knowledge regarding physiological parameters which influence the resistance of the tuber skin towards mechanical impacts is rare. The present thesis revealed that tuber DM and starch concentrations can be considered as such parameters. The cultivar, which exhibited higher DM and starch concentrations, demonstrated higher resistance against mechanical impacts. Tuber DM and starch concentration were shown to correlate with the rheological characteristics of tubers due to related characteristics of tubers exhibiting higher 
DM and starch concentrations such as smaller cell sizes (as smaller cells need a greater strength to be separated or damaged) and an advantageous cell structure (Bordoloi et al. 2012). Besides, tubers with higher Ca concentrations showed an increased resistance against mechanical impacts. This may be related to the contribution of Ca for cell wall stability. Ca is binding to cell wall polymers of the plant cell wall and thus is stabilizing the cell wall and therefore the tuber periderm that is forming the tuber skin. 


\section{References}

Ahmad I, Maathuis FJM (2014) Cellular and tissue distribution of potassium: Physiological relevance, mechanisms and regulation. J Plant Physiol 171:708-714.

Ahmed A, Zaki M, Shafeek M, Helmy Y, El-Baky MA (2015) Integrated use of farmyard manure and inorganic nitrogen fertilizer on growth, yield and quality of potato (Solanum tuberosum L.). Int J Curr Microbiol App Sci 4:325-349.

Adams E, Shin R (2014) Transport, signaling, and homeostasis of potassium and sodium in plants. J Integr Plant Biol 56:231-249.

Addiscott TM (1974) Potassium and the distribution of calcium and magnesium in potato plants. J Sci Food Agric 25:1173-1183.

Ahmed SS, Müller K (1979) Seasonal changes and the effect of nitrogen- and potash-fertilization on the solanine and $\alpha$-chaconine content in various parts of the potato plant. Zeitschrift für Pflanzenernährung und Bodenkunde 142:275-279.

Ali J, Kapoor S, Moorthy J (2010) Buying behaviour of consumers for food products in an emerging economy. BFJ 112:109-24.

Allison MF, Fowler JH, Allen EJ (2002) Factors affecting the magnesium nutrition of potatoes (Solanum tuberosum). The Journal of Agricultural Science 137:397-409.

Altunkaya A, Gökmen V (2008) Effect of various inhibitors on enzymatic browning, antioxidant activity and total phenol content of fresh lettuce (Lactuca sativa). Food Chem 107:1173-1179.

Alva AK, Hodges T, Boydston RA, Collins HP (2002) Effects of irrigation and tillage practices on yield of potato under high production conditions in the Pacific Northwest. Commun Soil Sci Plant Anal 33:1451-1460.

Andersson A, Gekas V, Lind I, Oliveira F, Öste R, Aguilfra JM (1994) Effect of preheating on potato texture. Crit Rev Food Sci Nutr 34:229-251.

Andre CM et al. (2014) The potato in the human diet: a complex matrix with potential health benefits. Potato Res 57:201-214.

Andrews M, Raven JA, Lea PJ (2013) Do plants need nitrate? The mechanisms by which nitrogen form affects plants. Ann Appl Biol 163:174-199.

Anschütz U, Becker D, Shabala S (2014) Going beyond nutrition: regulation of potassium homoeostasis as a common denominator of plant adaptive responses to environment. J Plant Physiol 171:670-687

Arsovski AA, Zemke J, Haagen BD, Kim SH, Nemhauser JL (2018) Phytochrome B regulates resource allocation in

Brassica rapa. J Exp Bot 69: 2837-2846.

Arvanitoyannis IS, Vaitsi O, Mavromatis A (2008) Physico-chemical and sensory attributes in conjunction with multivariate analysis of two potato (Solanum tuberosum L.) cultivars after 90 days of storage: an exploratory authentication study. Int J Food Sci Technol 43:1960-1970.

Asif M, Yilmaz O, Ozturk L (2017) Potassium deficiency impedes elevated carbon dioxide-induced biomass enhancement in well watered or drought-stressed bread wheat. J Plant Nutr Soil Sci 180:474-481.

Bamberg J, Moehninsi, Navarre R, Suriano J (2015) Variation for tuber greening in the diploid wild potato solanum microdontum. AJPR 92:435-443.

Barber SA (1995) Soil nutrient bioavailability: a mechanistic approach. John Wiley \& Sons.

Barczak B, Nowak K (2015) Effect of sulphur fertilisation on the content of macroelements and their ionic ratios in potato tubers. J Elementol 20.

Baritelle AL, Hyde GM (2003) Specific gravity and cultivar effects on potato tuber impact sensitivity. Postharvest Biol Technol 29:279-286.

Bártová V, Diviš J, Bárta J, Brabcová A, Švajnerová M (2013) Variation of nitrogenous components in potato (Solanum tuberosum L.) tubers produced under organic and conventional crop management. Eur J Agron 49:20-31.

Belitz H, Grosch W, Schieberle P (2009) Food chemistry, 4th revised and extended edn. Berlin (DE): Springer.

Belknap WR, Portis AR (1986) Activation and carbon dioxide exchange kinetics of ribulose-1, 5-bisphosphate carboxylase/oxygenase: negative cooperativity with respect to magnesium. Biochemistry 25:1864-1869.

Bergmann W (1993) Ernährungsstörungen bei Kulturpflanzen: Entstehung, visuelle und analytische Diagnose, $3^{\text {rd }}$ Edn. Fischer, Jena.

Beringer H, Koch K, Lindhauer MG (1990) Source: sink relationships in potato (Solanum tuberosum) as influenced by potassium chloride or potassium sulphate nutrition. In: van Beusichem ML (ed) Plant Nutrition Physiology and Applications: Proceedings of the Eleventh International Plant Nutrition Colloquium, 30 July4 August 1989, Wageningen, The Netherlands. Springer Netherlands, Dordrecht, pp 639-642. 
Bohl WH, Thornton MK (2006) Thumbnail cracks of potato tubers. University of Idaho Extension.

Bordoloi A, Kaur L, Singh J (2012) Parenchyma cell microstructure and textural characteristics of raw and cooked potatoes. Food Chem 133:1092-1100.

Bradshaw JE, Ramsay G (2009) Potato origin and production. In: Singh J, Kaur L (eds) Advances in potato chemistry and technology. Elsevier, pp 1-26.

Braumann I, Stein N, Hansson M (2014) Reduced chlorophyll biosynthesis in heterozygous barley magnesium chelatase mutants. Plant Physiol Biochem 78:10-14.

Brazinskiene V, Asakaviciute R, Miezeliene A, Alencikiene G, Ivanauskas L, Jakstas V, Viskelis P, Razukas A (2014) Effect of farming systems on the yield, quality parameters and sensory properties of conventionally and organically grown potato (Solanum tuberosum L.) tubers. Food Chem 145:903-909.

Britto DT, Kronzucker HJ (2008) Cellular mechanisms of potassium transport in plants. Physiol Plantarum 133:637650.

Brown CR (1993) Origin and history of the potato. Am Potato J 70:363-373.

Brown CR et al. (2012) Stability and broad-sense heritability of mineral content in potato: Calcium and magnesium. Am J Potato Res 89:255-261.

Bucher M, Kossmann J (2011) Molecular physiology of the mineral nutrition of the potato Potato Biology and Biotechnology: Advances and Perspectives: Advances and Perspectives:311.

Burton W (1974) Requirements of the users of ware potatoes. Potato Res 17:374-409.

Burton WG (1983) The Potato. Journal of Plant Foods 5:53-66.

Cabezas-Serrano AB, Amodio ML, Cornacchia R, Rinaldi R, Colelli G (2009) Suitability of five different potato cultivars (Solanum tuberosum L.) to be processed as fresh-cut products. Postharvest Biol Technol 53:138144.

Cakmak I, Hengeler C, Marschner H (1994a) Changes in phloem export of sucrose in leaves in response to phosphorus, potassium and magnesium deficiency in bean plants. J Exp Bot 45:1251-1257.

Cakmak I, Hengeler C, Marschner H (1994b) Partitioning of shoot and root dry matter and carbohydrates in bean plants suffering from phosphorus, potassium and magnesium deficiency. J Exp Bot 45:1245-1250.

Cakmak I (2005) The role of potassium in alleviating detrimental effects of abiotic stresses in plants. J Plant Nutr Soil Sci 168:521-530.

Cakmak I, Kirkby EA (2008) Role of magnesium in carbon partitioning and alleviating photooxidative damage. Physiol Plantarum 133:692-704.

Cakmak I, Yazici AM (2010) Magnesium: a forgotten element in crop production. Better Crops 94:23-25.

Cameron KC, Di HJ, Moir JL (2013) Nitrogen losses from the soil/plant system: a review. Ann Appl Biol 162:145173.

Camire ME, Kubow S, Donnelly DJ (2009) Potatoes and human health. Crit Rev Food Sci Nutr 49:823-840.

Castillo JP et al. (2015) Mechanism of potassium ion uptake by the $\mathrm{Na}^{+} / \mathrm{K}^{+}$-ATPase. Nat Commun 6:1-8.

Ceylan Y, Kutman UB, Mengutay M, Cakmak I (2016) Magnesium applications to growth medium and foliage affect the starch distribution, increase the grain size and improve the seed germination in wheat. Plant Soil 406:145156.

Chen D, Cao B, Wang S, Liu P, Deng X, Yin L, Zhang S (2016) Silicon moderated the K deficiency by improving the plant-water status in sorghum. Scientific Reports 6: 22882.

Chen ZC, Ma JF (2013) Magnesium transporters and their role in Al tolerance in plants. Plant Soil 368:51-56.

Christensen DH, Madsen MH (1996) Changes in potato starch quality during growth. Potato Res 39:43-50.

Clarkson DT (1984) Calcium transport between tissues and its distribution in the plant. Plant Cell Environ 7:449-456.

Clough GH (1994) Potato Tuber Yield, Mineral Concentration, and Quality after Calcium Fertilization. J Am Soc Hortic Sci 119:175-179.

Collier GF, Wurr DCE, Huntington VC (1978) The effect of calcium nutrition on the incidence of internal rust spot in the potato. J Agric Sc 91:241-243.

Conway WS, Sams CE, Wang CY, Abbott JA (1994) Additive effects of postharvest calcium and heat treatment on reducing decay and maintaining quality in apples. J Am Soc Hortic Sci 119:49-53.

Cowan JA (2002) Structural and catalytic chemistry of magnesium-dependent enzymes. Biometals 15:225-235.

Daniels-Lake B, Prange R, Walsh J, Hiltz K, Bishop S, Munro-Pennell K (2014) Effects of simulated harvest injury and relative humidity during the first week post-harvest on potato (Solanum tuberosum L.) tuber weight loss during subsequent storage. J Hortic Sci Biotechnol 89:167-172.

Dao L, Friedman M (1994) Chlorophyll, Chlorogenic Acid, Glycoalkaloid, and Protease Inhibitor Content of Fresh and Green Potatoes. J Agr Food Chem 42:633-639.

De Kok LJ et al. (2005) Pathways of plant sulfur uptake and metabolism-an overview. Landbauforschung Völkenrode, Special:5-13. 
De Wilde T, De Meulenaer B, Mestdagh F, Govaert Y, Vandeburie S, Ooghe W, Fraselle S, Demeulemeester K, Van Peteghem C, Calus A, Degroodt J-M, Verhé R (2006) Influence of Fertilization on Acrylamide Formation during Frying of Potatoes Harvested in 2003. J Agr Food Chem 54:404-408.

Dean BB, Thornton R (1989) Thumbnail cracking of potatoes. Spud Topics 35.

Delgado E, Sulaiman MI, Pawelzik E (2001) Importance of chlorogenic acid on the oxidative potential of potato tubers of two German cultivars. Potato Res 44:207-218.

Deng W et al. (2006) Overexpression of an Arabidopsis magnesium transport gene, AtMGT1, in Nicotiana benthamiana confers Al tolerance. J Exp Bot 57:4235-4243.

Diem B, Godbold D (1993) Potassium, calcium and magnesium antagonism in clones of Populus trichocarpa. In: Plant Nutrition-from Genetic Engineering to Field Practice. Springer, pp 613-616.

Ding Y, Luo W, Xu G (2006) Characterisation of magnesium nutrition and interaction of magnesium and potassium in rice. Ann Appl Biol 149:111-123.

Drewnowski A, Rehm CD (2013) Vegetable cost metrics show that potatoes and beans provide most nutrients per penny. PLoS One 8:e63277.

Dreyer I, Gomez-Porras JL, Riedelsberger J (2017) The potassium battery: a mobile energy source for transport processes in plant vascular tissues. New Phytol 216:1049-1053.

Edwards EJ, Cobb AH (1999) The effect of prior storage on the potential of potato tubers (Solanum tuberosum L) to accumulate glycoalkaloids and chlorophylls during light exposure, including artificial neural network modelling. J Sci Food Agri 79 (10):1289-1297.

Edwards EJ, Saint RE, Cobb AH (1998) Is there a link between greening and light-enhanced glycoalkaloid accumulation in potato tuberosum tubers (Solanum tuberosum L)? J Sci Food Agric 76:327-333

Ekin Z (2011) Some analytical quality characteristics for evaluating the utilization and consumption of potato (Solanum tuberosum L.) tubers. Afr J Biotechnol 10:6001-6010.

Elmore JS, Briddon A, Dodson AT, Muttucumaru N, Halford NG, Mottram DS (2015) Acrylamide in potato crisps prepared from 20 UK-grown varieties: Effects of variety and tuber storage time. Food Chem 182:1-8.

Elmore JS, Mottram DS, Muttucumaru N, Dodson AT, Parry MAJ, Halford NG (2007) Changes in free amino acids and sugars in potatoes due to sulfate fertilization and the effect on acrylamide formation. J Agr Food Chem 55:5363-5366.

Eppendorfer WH, Eggum BO (1994) Effects of sulphur, nitrogen, phosphorus, potassium, and water stress on dietary fibre fractions, starch, amino acids and on the biological value of potato protein. Plant Food Hu Nutr 45:299313.

Ernst H, Wulkow A, Pawelzik E (2008) Qualitätsmangel Schwarzfleckigkeit. Einfluss antioxidativer Substanzen auf die Schwarzfleckigkeitsneigung von Kartoffeln. Kartoffelbau 59:408-412.

Europlant (2014) Anbauempfehlung Omega.

Evans D, Mondy NI (1984) Effect of magnesium fertilization on glycoalkaloid formation in potato tubers. J Agr Food Chem 32:465-466.

Evans L, Fischer R (1999) Yield potential: its definition, measurement, and significance. Crop Sci 39:1544-1551.

Ezekiel R, Singh N, Sharma S, Kaur A (2013) Beneficial phytochemicals in potato - a review. Food Res Int 50:487496.

Fageria V (2001) Nutrient interactions in crop plants. J Plant Nutr Soil 24:1269-1290.

FAO/WHO (2011) Evaluation of certain contaminants in food: Seventy-second report of the Joint FAO/WHO Expert Committe on Food Additives. (vol 959, World Health Organization)

FAO (2017) http://www.fao.org/faostat/en/\#data/QC. 10 December 2017.

Farhat N, Smaoui A, Maurousset L, Porcheron B, Lemoine R, Abdelly C, Rabhi M (2016) Sulla carnosa modulates root invertase activity in response to the inhibition of long-distance sucrose transport under magnesium deficiency. Plant Biol 18:1031-1037.

Farré EM, Tiessen A, Roessner U, Geigenberger P, Trethewey RN, Willmitzer L (2001) Analysis of the compartmentation of glycolytic intermediates, nucleotides, sugars, organic acids, amino acids, and sugar alcohols in potato tubers using a nonaqueous fractionation method. Plant Physiol 127:685-700.

Federal Plant Variety Office (2016) Descriptive Variety List Potatoes 2016.

Feltran JC, Lemos LB, Vieites RL (2004) Technological quality and utilization of potato tubers. Sci Agric 61:593-597.

Fiers M, Chatot C, Edel-Hermann V, Le Hingrat Y, Konate AY, Gautheron N, Guillery E, Alabouvette C, Steinberg C (2010) Diversity of microorganisms associated with atypical superficial blemishes of potato tubers and pathogenicity assessment. Eur J Plant Pathol 128:353-371.

Firman D, Allen E (2007) Agronomic practices. In: Vreugdenhil D, Bradshaw J, Gebhardt C, Govers F, Mackerron DKL, Taylor MA, Ross HA (eds) Potato biology and biotechnology: advances and perspectives (1st edition). Elsevier, pp 719-738. 
Friedman M (2006) Potato glycoalkaloids and metabolites: Roles in the plant and in the diet. J Agr Food Chem 54:8655-8681.

Galili G, Amir R (2013) Fortifying plants with the essential amino acids lysine and methionine to improve nutritional quality. Plant Biotechnol J 11:211-222.

Gerardeaux E, Jordan-Meille L, Constantin J, Pellerin S, Dingkuhn M (2010) Changes in plant morphology and dry matter partitioning caused by potassium deficiency in Gossypium hirsutum (L.). Environ Exper Bot 67:451459.

Gerendas J, Führs H (2013) The significance of magnesium for crop quality. Plant Soil 368 (1-2):101-128.

Gerendás J, Heuser F, Sattelmacher B (2007) Influence of nitrogen and potassium supply on contents of acrylamide precursors in potato tubers and on acrylamide accumulation in french fries. J Plant Nutr 30:1499-1516.

Giordanengo P, Vincent C, Alyokhin A (2013) Insect pests of potato vol 101166. Elsevier, vol 635.219.

Glenn GM, Poovaiah B (1990) Calcium-mediated postharvest changes in texture and cell wall structure and composition in 'Golden Delicious' apples. J Am Soc Hortic Sci 115:962-968.

Gransee A, Führs H (2013) Magnesium mobility in soils as a challenge for soil and plant analysis, magnesium fertilization and root uptake under adverse growth conditions. Plant Soil 368:5-21.

Grant CA, Flaten DN, Tomasiewicz DJ, Sheppard SC (2001) The importance of early season phosphorus nutrition. Can J Plant Sci 81:211-224.

Grommers HE, van der Krogt DA (2009) Potato starch: production, modifications and uses. In: BeMiller J, Whistler R (eds) Starch (3rd edition). Academic Press, San Diego, pp 511-539.

Gruber BD, Giehl RFH, Friedel S, von Wirén N (2013) Plasticity of the Arabidopsis root system under nutrient deficiencies. Plant Physiol 163:161-179.

Guo W, Nazim H, Liang Z, Yang D (2016) Magnesium deficiency in plants: An urgent problem. Crop J 4:83-91.

Haase NU (2003) Estimation of dry matter and starch concentration in potatoes by determination of under-water weight and near infrared spectroscopy. Potato Res 46:117-127.

Haase NU, Plate J (1996) Properties of potato starch in relation to varieties and environmental factors. Starch - Stärke 48:167-171.

Hamouz K, Lachman J, Dvořák P, Orsák M, Hejtmánková K, Čížek M (2009) Effect of selected factors on the content of ascorbic acid in potatoes with different tuber flesh colour. Plant Soil Environ 55 (7):281-287.

Hawker JS, Marschner H, Krauss A (1979) Starch synthesis in developing potato tubers. Physiol Plantarum 46:25-30.

Hawkes JG (1956) Taxonomic studies on the tuber - bearing Solanums. 1: Solanum tuberosum and the tetraploid species complex. Proc Linn Soc Lond 166:97-144.

Hawkes JG (1990) The potato: evolution, biodiversity and genetic resources. Belhaven Press, London. ISBN: 1852930454.

Hayashi H, Chino M (1990) Chemical composition of phloem sap from the uppermost internode of the rice plant. Plant Cell Physiol 31:247-251.

Haynes RJ (1990) Active ion uptake and maintenance of cation-anion balance: A critical examination of their role in regulating rhizosphere $\mathrm{pH}$. Plant Soil 126:247-264.

Hermans C, Johnson GN, Strasser RJ, Verbruggen N (2004) Physiological characterisation of magnesium deficiency in sugar beet: acclimation to low magnesium differentially affects photosystems I and II. Planta 220:344-355.

Hermans C, Bourgis F, Faucher M, Strasser RJ, Delrot S, Verbruggen N (2005) Magnesium deficiency in sugar beets alters sugar partitioning and phloem loading in young mature leaves. Planta 220:541-549.

Hermans C, Verbruggen N (2005) Physiological characterization of Mg deficiency in Arabidopsis thaliana. J Exp Bot 56:2153-2161.

Hermans C, Hammond JP, White PJ, Verbruggen N (2006) How do plants respond to nutrient shortage by biomass allocation? Trends Plant Sci 11:610-617.

Hesen JC, Kroesbergen E (1969) Mechanical damage to potatoes I. Europ Potato J 3:30-46.

Hide GA, Lapwood DH (1992) Disease aspects of potato production. In: Harris PM (ed) The potato crop: the scientific basis for improvement. Springer, Dordrecht, Netherlands, pp 403-437.

Hijmans RJ (2001) Global distribution of the potato crop. AJPR 78:403-412.

Hiller LK, Keller DC, Thornton RE (1985) Physiological disorders of potato tubers. In: Li, PH (ed) Potato physiology. Academic Press, Orlando, pp 389-455.

Hiltrop P (1999) Rohstoffqualitäten für Pommes frites und andere vorgebackene Kartoffelprodukte. Die erzeugung von kartoffeln zur industriellen verarbeitung. Agrimedia GmbH: Bergen, Germany.

Hirschi KD (2004) The calcium conundrum. Both versatile nutrient and specific signal. Plant Physiol 136:2438-2442.

Hopkins BG, Horneck DA, MacGuidwin AE (2014) Improving phosphorus use efficiency through potato rhizosphere modification and extension. AJPR 91:161-174. 
Hoppo SD, Elliott DE, Reuter DJ (1999) Plant tests for diagnosing phosphorus deficiency in barley (Hordeum vulgare L.). Aust J Exp Agr 39:857-872.

Hossner LR, Doll EC (1970) Magnesium fertilization of potatoes as related to liming and potassium. Soil Sci Soc Am J 34:772-774.

Hu W et al. (2016) Potassium (K) supply affects K accumulation and photosynthetic physiology in two cotton (Gossypium hirsutum L.) cultivars with different K sensitivities. Field Crops Res 196:51-63.

Hu W, Coomer TD, Loka DA, Oosterhuis DM, Zhou Z (2017) Potassium deficiency affects the carbon-nitrogen balance in cotton leaves. Plant Physiol and Biochem115: 408-417.

Huamán Z, Spooner DM (2002) Reclassification of landrace populations of cultivated potatoes (Solanum sect. Petota). Am J Bot 89:947-965.

Huber SC (1984) Biochemical basis for effects of K-deficiency on assimilate export rate and accumulation of soluble sugars in soybean leaves. Plant Physiol 76:424-430

Hudson DE (1975) The relationship of cell size, intercellular space, and specific gravity to bruise depth in potatoes. AJPR 52:9-14.

Hütsch BW, Osthushenrich T, Faust F, Kumar A, Schubert S (2016) Reduced sink activity in growing shoot tissues of maize under salt stress of the first phase may be compensated by increased PEP-carboxylase activity. J Agron Crop Sci 202:384-393

Ierna A, Pandino G, Lombardo S, Mauromicale G (2011) Tuber yield, water and fertilizer productivity in early potato as affected by a combination of irrigation and fertilization. Agric Water Manag 101:35-41.

Imsande J (1998) Iron, sulfur, and chlorophyll deficiencies: A need for an integrative approach in plant physiology. Physiol Plantarum 103:139-144.

IPNI (2012) 4R plant nutrition manual: A manual for improving the management of plant nutrition, Metric Version, (Bruulsema TW, Fixen PE, Sulewski, GD, eds). International Plant Nutrition Insitute (IPNI).

Izmirlioglu G, Demirci A (2015) Enhanced bio-ethanol production from industrial potato waste by statistical medium optimization. Int J Mol Sci 16:24490-24505.

Jacoby B (1961) Calcium-magnesium ratios in the root medium as related to magnesium uptake by citrus seedlings. Plant Soil 15:74-80

Jagatee S, Behera S, Dash PK, Sahoo S, Mohanty RC (2015) Bioprospecting starchy feedstock ${ }^{\text {ee }}$ s for bioethanol production: a future perspective. JMRR 3:24-42

Jákli B, Tränkner M, Senbayram M, Dittert K (2016) Adequate supply of potassium improves plant water-use efficiency but not leaf water-use efficiency of spring wheat. J Plant Nutr Sci 179:733-745.

Jákli B, Tavakol E, Tränkner M, Senbayram M, Dittert K (2017) Quantitative limitations to photosynthesis in K deficient sunflower and their implications on water-use efficiency. J Plant Physiol 209:20-30.

Jakobsen ST (1992) Interaction between plant nutrients: 1. theory and analytical procedures. Acta Agric Scand B 42:208-212.

Jansen G, Flamme W, Schüler K, Vandrey M (2001) Tuber and starch quality of wild and cultivated potato species and cultivars. Potato Res 44:137-46.

Jarvis MC (1984) Structure and properties of pectin gels in plant-cell walls. Plant Cell Environ 7:153-164.

Jenkins PD, Ali H (2000) Phosphate supply and progeny tuber numbers in potato crops. Ann Appl Biol 136:41-46.

Jezek M, Geilfus C-M, Bayer A, Mühling K-H (2015) Photosynthetic capacity, nutrient status, and growth of maize (Zea mays L.) upon $\mathrm{MgSO}_{4}$ leaf-application. Front Plant Sci 5:1-10.

Jobling SA, Westcott RJ, Tayal A, Jeffcoat R, Schwall GP (2002) Production of a freeze-thaw-stable potato starch by antisense inhibition of three starch synthase genes. Nat Biotechnol 20:295-299.

Johnston AM, Bruulsema TW (2014) 4R nutrient stewardship for improved nutrient use efficiency. Procedia Engineering 83:365-370.

Johnston FB, Hoffman I, Petrasovits A (1968). Distribution of mineral constituents and dry matter in the potato tuber. AJPR 45:287-92.

Jordan-Meille L, Pellerin S (2004) Leaf area establishment of a maize (Zea Mays L.) field crop under potassium deficiency. Plant Soil 265:75-92.

Kakoschke N, Kemps E, Tiggemann M (2014) Attentional bias modification encourages healthy eating. Eat Behav 15:120-124.

Karikka KJ, Dudgeon LT, Hauck HM (1944) Influence of variety, location, fertilizer, and storage on the ascorbic acid content of potatoes grown in New York State. J Agric Res 68:49-63.

Karley AJ, White PJ (2009) Moving cationic minerals to edible tissues: potassium, magnesium, calcium. Curr Opin Plant Biol 12:291-298.

Kärenlampi SO, White PJ (2009) Chapter 5 - Potato Proteins, Lipids, and Minerals. In: Advances in Potato Chemistry and Technology. Academic Press, San Diego, pp 99-125. 
Kaur L, Singh J, Singh N, Ezekiel R (2007) Textural and pasting properties of potatoes (Solanum tuberosum L.) as affected by storage temperature. J Sci Food Agric 87:520-6.

Kaur L, Singh J (2009) Novel applications and non-food uses of potato: Future perspectives in nanotechnology. In: Advances in potato chemistry and technology. $\mathrm{p} 425$.

Keijbets MJH (2008) Potato processing for the consumer: developments and future challenges. Potato Res 51:271281.

Kellermeier F, Chardon F, Amtmann A (2013) Natural variation of Arabidopsis root architecture reveals complementing adaptive strategies to potassium starvation Plant Physiol 161:1421-1432

Kelling KA, Hensler RF, Speth PE (2015) Importance of early-season nitrogen rate and placement to Russet Burbank potatoes. Am J Potato Res 92:502-510.

King JC, Slavin JL (2013) White potatoes, human health, and dietary guidance. Adv Nutr 4:393S-401S.

Kirkby EA, Mengel K (1967) Ionic balance in different tissues of the tomato plant in relation to nitrate, urea, or ammonium nutrition. Plant Physiol 42:6-14

Kirkby EA, Pilbeam DJ (1984) Calcium as a plant nutrient. Plant Cell Environ 7:397-405.

Kirkman MA (2007) Global markets for processed potato products. In: Vreugdenhil D, Bradshaw J, Gebhardt C, Govers F, Mackerron DKL, Taylor MA, Ross HA (eds) Potato biology and biotechnology: advances and perspectives (1st edition). Elsevier, pp 27-43.

Kita A (2002) The influence of potato chemical composition on crisp texture. Food Chem 76:173-179.

Kita A (2014) The effect of frying on fat uptake and texture of fried potato products. Eur J Lipid Sci Technol. 116:735740.

Klein LB, Chandra S, Mondy NI (1981) Effect of magnesium fertilization on the quality of potatoes. Yield, discoloration, phenols, and lipids. J Agr Food Chem 29:384-387.

Klein LB, Chandra S, Mondy NI (1982) Effect of magnesium fertilization on the quality of potatoes: total nitrogen, nonprotein nitrogen, protein, amino acids, minerals and firmness. J Agr Food Chem 30:754-757.

Klikocka H, Kobialka A, Juszczak D, Glowacka A (2015) The influence of sulphur on phosphorus and potassium content in potato tubers (Solanum Tuberosum L.). J Elementol 20:621-629.

Kolbe H, Stephan-Beckmann S (1997) Development, growth and chemical composition of the potato crop (Solanum tuberosum L.). II. Tuber and whole plant. Potato Res 40:135-153.

Konstankiewicz K, Czachor H, Gancarz M, Król A, Pawlak K, Zdunek A (2002) Cell structural parameters of potato tuber tissue. Int Agrophys 16:119-128.

Konstankiewicz K, Pawlak K, Zdunek A (2001) Influence of structural parameters of potato tuber cells on their mechanical properties. Int Agrophys 15:243-246.

Koprivova A, Kopriva S (2016) The Importance of having sulfur. J Genet Genomics.

Kratzke MG, Palta JP (1985) Evidence for the existence of functional roots on potato tubers and stolons: Significance in water transport to the tuber. Am Potato J 62 (5):227-236. doi:10.1007/bf02852802

Kratzke MG, Palta JP (1986) Calcium accumulation in potato tubers: role of the basal roots. HortScience 21 (4):10221024

Lange FD, Kawchuk LM (2014) Growth strategies for a declining market- the German fresh potato market. AJPR 91:440-446.

Laughlin WM (1966) Effect of soil applications of potassium, magnesium sulfate and magnesium sulfate spray on potato yield, composition and nutrient uptake. AJPR 43:403-11.

Last AR, Wilson SA (2006) Low-carbohydrate diets. Am Fam Physician 73:1942-1948.

Lazarevic B, Horvat T, Poljak M (2014) Effect of acid aluminous soil on photosynthetic parameters of potato (Solanum tuberosum L.). Potato Res 57:33-46

Lee M (2006) The Solanaceae: foods and poisons. J R Coll Physicians Edinb 36:162-169.

Legge RL, Thompson JE, Baker JE, Lieberman M (1982) The effect of calcium on the fluidity and phase properties of microsomal-membranes isolated from post-climacteric Golden Delicious apples. Plant Cell Physiol 23:161169.

Leigh R, Wyn Jones R (1984) A hypothesis relating critical potassium concentrations for growth to the distribution and functions of this ion in the plant cell. New Phytol 97:1-13

LeRiche EL, Wang-Pruski G, Zheljazkov VD (2009) Distribution of elements in potato (Solanum tuberosum L.) tubers and their relationship to after-cooking darkening. HortScience 44:1866-1873.

Lin S, Sattelmacher B, Kutzmutz E, Mühling KH, Dittert K (2004) Influence of nitrogen nutrition on tuber quality of potato with special reference to the pathway of nitrate transport into tubers. J Plant Nutr 27:341-350.

Liu H-Y, Sun W-N, Su W-A, Tang Z-C (2006) Co-regulation of water channels and potassium channels in rice. Physiol Plantarum 128:58-69. 
Lombardo S, Lo Monaco A, Pandino G, Parisi B, Mauromicale G (2013) The phenology, yield and tuber composition of 'early' crop potatoes: A comparison between organic and conventional cultivation systems. Renew Agric Food Syst 28:50-58.

López-Bucio J, Cruz-Ramírez A, Herrera-Estrella L (2003) The role of nutrient availability in regulating root architecture. Curr Opin Plant Biol 6:280-287.

Lulai EC, Orr PH (1979) Influence of potato specific gravity on yield and oil content of chips. Am Potato J 56:379390.

Maga JA, Fitzpatrick TJ (1980) Potato glycoalkaloids. Crit Rev Food Sci Nutr 12:371-405.

Manck-Götzenberger J, Requena N (2016) Arbuscular mycorrhiza symbiosis induces a major transcriptional reprogramming of the potato SWEET sugar transporter family. Front Plant Sci 7: 487.

Marschner H (2011) Marschner's mineral nutrition of higher plants (3rd edition). Elsevier.

Marschner H, Kirkby E, Cakmak I (1996) Effect of mineral nutritional status on shoot-root partitioning of photoassimilates and cycling of mineral nutrients. J Exp Bot 47:1255-1263.

Matthäus B, Haase NU (2014) Acrylamide - Still a matter of concern for fried potato food? Eur J Lipid Sci Technol 116:675-687.

Mauromicale G, Ierna A, Marchese M (2006) Chlorophyll fluorescence and chlorophyll content in field-grown potato as affected by nitrogen supply, genotype, and plant age. Photosynthetica 44:76-82.

Mayland H (1990) Magnesium in plants: uptake, distribution, function, and utilization by man and animals. In: Sigel H, Sigel A (eds) Metal ions in biological systems: Volume 26: Compendium on magnesium and its role in biology, nutrition and physiology. Marcel Dekker, New York and Basel, Switzerland, pp 33-56.

McAinsh MR, Pittman JK (2009) Shaping the calcium signature. New Phytol 181:275-294.

McArthur D, Knowles NR (1993) Influence of vesicular-arbuscular mycorrhizal fungi on the response of potato to phosphorus deficiency. Plant Physiol 101:147-160.

McGarry A, Hole CC, Drew RLK, Parsons N (1996) Internal damage in potato tubers: a critical review. Postharvest Biol Technol 8:239-258.

McGill CR, Kurilich AC, Davignon J (2013) The role of potatoes and potato components in cardiometabolic health: A review. Annals of Medicine 45:467-473.

McGregor I (2007) The fresh potato market. In: Vreugdenhil D, Bradshaw J, Gebhardt C, Govers F, Mackerron DKL, Taylor MA, Ross HA (eds) Potato biology and biotechnology: advances and perspectives (1st edition). Elsevier, pp 3-25.:3-26

McGuire RG, Kelman A (1984) Reduced severity of Erwinia soft rot in potato tubers with calcium content. Phytopathology 74:1250-1256.

McNabnay M, Dean BB, Bajema RW, Hyde GM (1999). The effect of potassium deficiency on chemical, biochemical and physical factors commonly associated with blackspot development in potato tubers. AJPR 76:53-60.

McMillan M, Thompson J (1979) An outbreak of suspected solanine poisoning in schoolboys. QJM 48:227-243.

Medeiros Vinci R, Mestdagh F, De Meulenaer B (2012) Acrylamide formation in fried potato products - Present and future, a critical review on mitigation strategies. Food Chem 133:1138-1154.

Mengel K, Arneke W-W (1982) Effect of potassium on the water potential, the pressure potential, the osmotic potential and cell elongation in leaves of Phaseolus vulgaris. Physiol Plant 54:402-408.

Mengel K, Kirkby E (2001) Principles of plant nutrition., 5th edn (Kluwer Academic Publishers: Dordrecht, The Netherlands).

Mengutay M, Ceylan Y, Kutman UB, Cakmak I (2013) Adequate magnesium nutrition mitigates adverse effects of heat stress on maize and wheat. Plant Soil 368:57-72.

Meyer KP, Hofferbert R, Peters R, Pawelzik E (2014) Potato tuber impact sensitivity is influenced by periderm magnesium and calcium contents. 19th Triennial Conference of the European Association for Potato Research.

Miča B (1979) Einfluß von abgestuften N-, P-, K-Gaben und Zusatzgaben von Ca und Mg auf den Stärke-und Zuckergehalt von Kartoffeln. Starch - Stärke 31:275-278.

Miča B, Vokal B (1983) Einfluss von Magnesium und Calcium auf Ertrag und bedeutende Inhaltsstoffe von Kartoffelknollen. Potato Res 26:383-391.

Michael G (1941) Über die Aufnahme und Verteilung des Magnesiums und dessen Rolle in der höheren grünen Pflanze. J Plant Nutr Soil 25:65-120.

Michel A (2015) Biotic and abiotic factors affecting potato yields in Canterbury, New Zealand.

Mondy N, Ponnampalam R (1986) Potato quality as affected by source of magnesium fertilizer: nitrogen, minerals, and ascorbic acid. J Food Sci 51:352-354.

Mondy NI, Gosselin B, Ponnampalam R (1987) Effect of soil applications of magnesium sulfate and dolomite on the quality of potato tubers. AJPR 64:27-34. 
Mondy NI, Mobley EO, Gedde-Dahl SB (1967) Influence of potassium fertilization on enzymatic activity, phenolic content and discoloration of potatoes. J Food Sci 32:378-381.

Mondy NI, Ponnampalam R (1985) Effect of magnesium fertilizers on total glycoalkaloids and nitrate-N in Katahdin Tubers. J Food Sci 50:535-536.

Mondy NI, Ponnampalam R (1986) Potato quality as affected by source of magnesium fertilizer: Nitrogen, minerals, and ascorbic acid. J Food Sci 51:352-354.

Muttucumaru N, Powers SJ, Elmore JS, Mottram DS, Halford NG (2013) Effects of nitrogen and sulfur fertilization on free amino acids, sugars, and acrylamide-forming potential in potato. J Agr Food Chem 61:6734-6742.

Narwal RP, Kumar V, Singh JP (1985) Potassium and magnesium relationship in cowpea (Vigna unguiculata (L.) Walp.). Plant Soil 86:129-134.

Neuhaus C, Geilfus C-M, Mühling K-H (2014) Increasing root and leaf growth and yield in Mg-deficient faba beans (Vicia faba) by $\mathrm{MgSO}_{4}$ foliar fertilization. J Plant Nutr Soil Sci 177:741-747.

Ngadze E, Coutinho TA, Icishahayo D, van der Waals JE (2014) Effect of calcium soil amendments on phenolic compounds and soft rot resistance in potato tubers. Crop Prot 62:40-45.

Nitsch A (2003) Kartoffelbau. AgriMedia.

Nitsos RE, Evans HJ (1969) Effects of univalent cations on the activity of particulate starch synthetase. Plant Physiol 44:1260-1266.

Noctor G, Foyer CH (1998) Ascorbate and glutathione: keeping active oxygen under control. Annu Rev Plant Biol 49:249-279.

Nowicki M, Fooled MR, Nowakowska M, Kozik EU (2012) Potato and Tomato Late Blight Caused by Phytophthora infestans: An Overview of Pathology and Resistance Breeding Plant Dis 96:4-17.

Obidiegwu JE, Bryan GJ, Jones HG, Prashar A (2015) Coping with drought: stress and adaptive responses in potato and perspectives for improvement. Front Plant Sci 6.

Oddo E, Inzerillo S, La Bella F, Grisafi F, Salleo S, Nardini A (2011) Short-term effects of potassium fertilization on the hydraulic conductance of Laurus nobilis L. Tree Physiology 31: 131-138.

Ohno T, Grunes D (1985) Potassium-magnesium interactions affecting nutrient uptake by wheat forage Soil Science Society of America Journal 49:685-690.

Oosterhuis DM, Loka DA, Raper TB (2013) Potassium and stress alleviation: Physiological functions and management of cotton. J Plant Nutr Soil Sci 176:331-343.

Ozgen S, Karlsson BH, Palta JP (2006) Response of potatoes (cv russet burbank) to supplemental calcium applications under field conditions: Tuber calcium, yield, and incidence of internal brown spot. Am J Potato Res 83:195204.

Palta JP (2010) Improving potato tuber quality and production by targeted calcium nutrition: the discovery of tuber roots leading to a new concept in potato nutrition. Potato Res 53:267-275.

Panique E, Kelling KA, Schulte EE, Hero DE, Stevenson WR, James RV (1997) Potassium rate and source effects on potato yield, quality, and disease interaction. AJPR 74:379-398.

Pawelzik E, Möller K (2014) Sustainable potato production worldwide: the challenge to assess conventional and organic production systems. Potato Res 57:273-290.

Pelucchi C, Franceschi S, Levi F, Trichopoulos D, Bosetti C, Negri E, La Vecchia C (2003) Fried potatoes and human cancer. Int J Cancer 105:558-560.

Perrenoud S (1993) Fertilising for high yield potato. IPI Bulletin.

Peters R (1996) Damage of potato tubers, a review. Potato Res 39:479-484.

Pfaffl M (2007) Relative quantifictaion. In: Dorak, MT (ed) Real-time PCR. Taylor \& Francis. pp 63-82.

Poberezny J, Wszelaczynska E (2011) Effect of bioelements (N, K, Mg) and long-term storage of potato tubers on quantitative and qualitative losses Part II. Content of dry matter and starch. J Elementol 16:237-246.

Poovaiah B (1986) Role of calcium in prolonging storage life of fruits and vegetables. Food Technol 40:86-89.

Pottosin, II, Schonknecht G (2007) Vacuolar calcium channels. J Exp Bot 58:1559-1569.

Praeger U, Herppich WB, König C, Herold B, Geyer M (2009) Changes of water status, elastic properties and blackspot incidence during storage of potato tubers. J Appl Bot Food Qual 83:1-8.

Prosser IM, Purves JV, Saker LR, Clarkson DT (2001) Rapid disruption of nitrogen metabolism and nitrate transport in spinach plants deprived of sulphate. J Exp Bot 52:113-121.

R Core Team (2016) R: A language and environment for statistical computing. R Foundation for Statistical Computing, Vienna, Austria.

Raghothama KG (2000) Phosphate transport and signaling. Curr Opin Plant Biol 3:182-187.

Rajiv, Kawar PG (2016) Enriched potato for mitigating hidden hunger. In: Singh U, Praharaj CS, Singh SS, Singh NP (eds) Biofortification of food crops. Springer India, New Delhi, pp 433-457. Print ISBN: 978-481-322-27142714. Online ISBN: 2978-2781-2322-2716-2718. 
Raschke K (1975) Stomatal action. Ann Rev Pl Physiol 26:309-340.

Regmi A (2001) Changing structure of global food consumption and trade: an introduction. In: Regmi A (ed) Changing Structure of Global Food Consumption and Trade. pp 1-3.:1

Rens L, Zotarelli L, Alva A, Rowland D, Liu G, Morgan K (2016) Fertilizer nitrogen uptake efficiencies for potato as influenced by application timing. Nutr Cycl Agroecosys 104:175-185.

Rice JM (2005) The carcinogenicity of acrylamide. Mutat Res Genet Toxicol Environ Mutagen 580:3-20.

Rich AE (2013) Potato diseases. Academic Press.

Robson A, Pitman M (1983) Interactions between nutrients in higher plants. In: Läuchli A, Bieleski RL (eds) Inorganic plant nutrition. Springer, Berlin, Heidelberg, pp 147-180. Print ISBN: 978-3-642-68887-4. Online ISBN: 9783-642-68885-0. In.

Rogozińska I, Pawelzik E, Poberezny J, Delgado E (2005) The effect of different factors on the content of nitrate in some potato varieties. Potato Res 48:167-180.

Rogozińska I, Wojdya T (1999) Der Einfluß variierter Düngung, einer Pflanzenschutzmittel-Anwendung und der Lagerung auf den Glykoalkaloid-Gehalt in Kartoffelknollen zweier Sorten. Potato Res 42:79-88.

Römheld V, Kirkby EA (2010) Research on potassium in agriculture: needs and prospects. Plant Soil 335:155-180.

Rosen CJ, Kelling KA, Stark JC, Porter GA (2014) Optimizing phosphorus fertilizer management in potato production. AJPR 91:145-160.

Rumberg B, Siggel U (1969) $\mathrm{pH}$ changes in the inner phase of the thylakoids during photosynthesis. Naturwissenschaften 56:130-132.

Šaøec P, Hamouz K, Šaøec O, Dvoøák P (2006) Susceptibility to mechanical damage of potatoes cultivated in different environmental conditions. Int Agrophysics 20:47-53.

Sattelmacher B, Gerendas J, Thoms K, Brück H, Bagdady NH (1993) Interaction between root growth and mineral nutrition. Environ Exp Bot 33:63-73.

Sattelmacher B, Horst WJ, Becker HC (1994) Factors that contribute to genetic variation for nutrient efficiency of crop plants. J Plant Nutr Soil Sci 157:215-224.

Sayre RN, Nonaka M, Weaver ML (1975) French fry quality related to specific gravity and solids content variation among potato strips within the same tuber. Am Potato J 52:73-82.

Schick R, Klinkowski M (1962) Die Kartoffel: ein Handbuch. VEB Deutscher Landwirtschaftsverlag.

Schippers PA (1968) The influence of rates of nitrogen and potassium application on the yield and specific gravity of four potato varieties. Europ Potato J 11:23-33.

Scott B, Robson A (1990) Distribution of magnesium in subterranean clover (Trifolium subterraneum L.) in relation to supply. Aust J Agric Res 41:499-510.

Senbayram M, Gransee A, Wahle V, Thiel H (2015) Role of magnesium fertilisers in agriculture: plant-soil continuum. Crop Pasture Sci 66:1219-1229.

Shabala S, Pottosin I (2014) Regulation of potassium transport in plants under hostile conditions: implications for abiotic and biotic stress tolerance. Physiol Plantarum 151:257-279.

Sila DN, Van Buggenhout S, Duvetter T, Fraeye I, De Roeck A, Van Loey A, Hendrickx M (2009) Pectins in processed fruits and vegetables: Part II-structure-function relationships. CRFSFS 8:86-104.

Silva IRd, Ferrufino A, Sanzonowicz C, Smyth TJ, Israel DW, Carter Júnior TE (2005) Interactions between magnesium, calcium, and aluminum on soybean root elongation. Rev Bras Ciênc Solo 29:747-754

Silva J, França M, Gomide F, Magalhaes J (2013) Different nitrogen sources affect biomass partitioning and quality of potato production in a hydroponic system. AJPR 90:179-185.

Singh J, Kaur L, McCarthy OJ, Moughan PJ, Singh H (2008) Rheological and textural characteristics of raw and parcooked Taewa (Maori potatoes) of New Zealand. J Texture Stud 39:210-230.

Singh S, Lal S (2012) Effect of potassium nutrition on potato yield, quality and nutrient use efficiency under varied levels of nitrogen application Potato Journal 39.

Smith SE, Smith FA (2012) Fresh perspectives on the roles of arbuscular mycorrhizal fungi in plant nutrition and growth Mycologia 104:1-13.

Smith SJ, van Aardenne J, Klimont Z, Andres RJ, Volke A, Delgado Arias S (2011) Anthropogenic sulfur dioxide emissions: 1850-2005. Atmos Chem Phys 11:1101-1116.

Smith O (1977) Potatoes: Production, Storing, Processing. Avi Publishing Company.

Song W, Liu S, Meng L, Xue R, Wang C, Liu G, Dong C, Wang S, Dong J, Zhang Y (2015) Potassium deficiency inhibits lateral root development in tobacco seedlings by changing auxin distribution. Plant and Soil 396: 163173.

Song W et al. (2017) Differential response of first-order lateral root elongation to low potassium involves nitric oxide in two tobacco cultivars. J Plant Growth Regul:1-14. 
Sparks WC (1970) Thumbnail cracks in potatoes; what causes them, how to reduce them? Idaho Univ Ext Idaho Curr Inform Ser.

Sperrazza JM, Spremulli LL (1983) Quantitation of cation binding to wheat germ ribosomes: Influences on submit association equilibria and ribosome activity. Nucleic Acids Res 11:2665-2679.

Spillman W (1923) Application of the law of diminishing returns to some fertilizer and feed data. Journal of farm Economics 5:36-52.

Sprengel C (1828) Von den Substanzen der Ackerkrume und des Untergrundes. Journal für Technische und Ökonomische Chemie 2:423-474.

Spooner D, Salas A (2006) Structure, biosystematics, and genetic resources of potato. Handbook of Potato Production, Improvement and Post-Harvest Management. pp 1-39.

Spooner DM, Hijmans RJ (2001) Potato systematics and germplasm collecting, 1989-2000. AJPR 78:237-268.

Stanley R, Jewell S (1989) The influence of source and rate of potassium fertilizer on the quality of potatoes for french fry production. Potato Res 32:439-446.

Stearns LD, Petry TA, Krause MA (1994) Potential food and nonfood utilization of potatoes and related byproducts in North Dakota. Department of Agricultural Economics, Agricultural Experiment Station, North Dakota State University.

Stitt M, Lilley RM, Gerhardt R, Heldt HW (1989) Metabolite levels in specific cells and subcellular compartments of plant leaves. Methods Enzymol 174:518-552.

Strebel O, Duynisveld WHM (1989) Nitrogen supply to cereals and sugar beet by mass flow and diffusion on a silty loam soil. Zeitschrift für Pflanzenernährung und Bodenkunde 152:135-141.

Subramanian NK, White PJ, Broadley MR, Ramsay G (2011) The three-dimensional distribution of minerals in potato tubers. Ann Bot 107:681-691.

Talburt WF, Smith O (1987) Potato processing. Van Nostrand Reinhold.

Tanner CB, Weis GG, Curwen D (1982) Russet Burbank rooting in sandy soils with pans following deep plowing. Am Potato J 59:107-112.

Tian J, Chen J, Ye X, Chen S (2016) Health benefits of the potato affected by domestic cooking: A review. Food Chem 202:165-175.

Tränkner M, Tavakol E, Jákli B (2018) Functioning of potassium and magnesium in photosynthesis, photosynthate translocation and photoprotection. Physiol Plantarum, doi number: https://doi.org/10.1111/ppl.12747.

Vakis NJ (1978) Specific gravity, dry matter content and starch content of 50 potato cultivars grown under Cyprus conditions. Potato Res 21:171-81.

Van Bel AJE (2003) The phloem, a miracle of ingenuity. Plant Cell Environ 26:125-149.

van der Ploeg RR, Bohm W, Kirkham MB (1999) On the origin of the theory of mineral nutrition of plants and the law of the minimum. Soil Sci Soc Am J 63:1055-1062.

van Dijk C, Beekhuizen J-G, Gibcens T, Boeriu C, Fischer M, Stolle-Smits T (2002) Texture of cooked potatoes (Solanum tuberosum). 2. Changes in pectin composition during storage of potatoes. J Agric Food Chem 50:5089-5097.

Van Keulen H, Stol W (1995) Agro-ecological zonation for potato production. In: Potato Ecology And modelling of crops under conditions limiting growth. Springer, Dordrecht, pp 357-371.

van Lierop W, Tran TS, Banville G, Morissette S (1982) Effect of liming on potato yields as related to soil pH, Al, $\mathrm{Mn}$, and Ca. Agronomy Journal 74:1050-1055.

van Loon CD (1981) The effect of water-stress on potato growth, development, and yield. AJPR 58:51-69.

van Loon KD (2007) The seed potato market. In: Vreugdenhil D, Bradshaw J, Gebhardt C, Govers F, Mackerron DKL, Taylor MA, Ross HA (eds) Potato biology and biotechnology: advances and perspectives (1st edition). Elsevier, pp 45-51.

Verbruggen N, Hermans C (2013) Physiological and molecular responses to magnesium nutritional imbalance in plants. Plant Soil 368:87-99.

von Liebig JF (1841) Die Organische Chemie in Ihrer Anwendung auf Agricultur und Physiologie. Braunschweig: Vieweg.

von Liebig JF (1855) Die Grundsätze der Agricultur-Chemie mit Rücksicht auf die in England angestellten Untersuchungen.

von Wulffen U, Roschke M, Kape H (2008) Richtwerte für die Untersuchung und Beratung sowie zur fachlichen Umsetzung der Düngeverordnung (DüV). Landesamt für Verbraucherschutz, Landwirtschaft und Flurneuordnung (LVLF), Güterfelde, Brandenburg, Germany. Available at https://www.oberhavel.de/media/custom/2244_5397_1.PDF?1366704690 (accessed 5 June 2018).

Vos J (1995) Nitrogen and the growth of potato crops. In: Potato ecology and modelling of crops under conditions limiting growth. Springer, Dordrecht, pp 115-128. 
Vos J, van der Putten PEL (1998) Effect of nitrogen supply on leaf growth, leaf nitrogen economy and photosynthetic capacity in potato. Field Crop Res 59:63-72.

Vreugdenhil D (1985) Source-to-sink gradient of potassium in the phloem. Planta 163:238-240.

Walker CJ, Weinstein JD (1994) The magnesium-insertion step of chlorophyll biosynthesis is a two-stage reaction. Biochem J 299:277-284.

Walker DJ, Leigh RA, Miller AJ (1996) Potassium homeostasis in vacuolate plant cells. PNAS 93:10510-10514.

Walker TS, Schmiediche PE, Hijmans RJ (1999) World trends and patterns in the potato crop: An economic and geographic survey. Potato Res 42:241-264.

Wang M, Zheng Q, Shen Q, Guo S (2013) The Critical Role of Potassium in Plant Stress Response. Int J Mol Sci 14:7370-7390.

Wang Y, Wu W-H (2013) Potassium transport and signaling in higher plants. Annu Rev Plant Biol 64:451-476.

Wang-Pruski G, Nowak J (2004) Potato after-cooking darkening. AJPR 81:7-16.

Waterer D (2002) Impact of high soil pH on potato yields and grade losses to common scab. Can J Plant Sci 82:583586.

Weiler EW, Nover L (2008) Allgemeine und molekulare Botanik. Georg Thieme Verlag, Stuttgart, New York. ISBN: 9783131476616.

Westermann D (2005) Nutritional requirements of potatoes. AJPR 82:301-307.

Westermann DT, James DW, Tindall TA, Hurst RL (1994) Nitrogen and potassium fertilization of potatoes: Sugars and starch. Am Potato J 71:433-453.

Whalley HJ, Knight MR (2013) Calcium signatures are decoded by plants to give specific gene responses. New Phytol 197:690-693.

Wheal MS, Fowles TO, Palmer LT (2011) A cost-effective acid digestion method using closed polypropylene tubes for inductively coupled plasma optical emission spectrometry (ICP-OES) analysis of plant essential elements. Anal Methods 3:2854-2863.

White PJ (1997) The regulation of $\mathrm{K}^{+}$influx into roots of rye (Secale cereale L.) seedlings by negative feedback via the $\mathrm{K}^{+}$flux from shoot to root in the phloem. J Exp Bot 48:2063-2073.

White PJ, Bradshaw JE, Finlay M, Dale B, Ramsay G, Hammond JP, Broadley MR (2009) Relationships between yield and mineral concentrations in potato tubers. HortScience 44:6-11.

White PJ, Broadley MR (2003) Calcium in plants. Ann Bot 92:487-511.

White PJ, Broadley MR (2009) Biofortification of crops with seven mineral elements often lacking in human diets iron, zinc, copper, calcium, magnesium, selenium and iodine. New Phytol 182:49-84.

Winkelmann H (1992) Potassium fertiliser application to potatoes. Kartoffelbau 43:412-418.

Woodrow IE, Berry JA (1988) Enzymatic regulation of photosynthetic $\mathrm{CO}_{2}$ fixation in C-3 plants. Annu Rev Plant Phys 39:533-594.

Yuguan $\mathrm{Z}$ et al. (2009) Effects of cerium on key enzymes of carbon assimilation of spinach under magnesium deficiency. Biol Trace Elem Res 131:154-164.

Zebarth BJ, Bélanger G, Cambouris AN, Ziadi N (2012) Nitrogen fertilization strategies in relation to potato tuber yield, quality, and crop N recovery. In: Sustainable potato production: global case studies. Springer, pp 165186.

Zhang B, Huang W, Li J, Zhao C, Fan S, Wu J, Liu C (2014) Principles, developments and applications of computer vision for external quality inspection of fruits and vegetables: A review. Food Res Int 62:326-43.

Zhang JL, George E (2002) Changes in the extractability of cations (Ca, $\mathrm{Mg}$ and $\mathrm{K}$ ) in the rhizosphere soil of Norway spruce (Picea abies) roots. Plant Soil 243:209-217.

Zhao D, Oosterhuis DM, Bednarz CW (2001) Influence of potassium deficiency on photosynthesis, chlorophyll content, and chloroplast ultrastructure of cotton plants. Photosynthetica 39:103-109.

Zörb C, Senbayram M, Peiter E (2014) Potassium in agriculture - Status and perspectives. J Plant Physiol 171:656669.

Zorn W, Marks G, Heß H, Bergmann W (2016) Handbuch zur visuellen Diagnose von Ernährungsstörungen bei Kulturpflanzen. Springer-Verlag. 



\section{Danksagung}

Ich danke Frau Prof. Dr. Elke Pawelzik, die es ermöglicht hat, dass ich diese Arbeit durchführen konnte. Ich danke für jede Unterstützung während der Konzeption der Arbeit, bei der Durchführung der Versuche, bei der Erstellung der Manuskripte oder auch von Vorträgen. Ich bin sehr dankbar für das entgegengebrachte Vertrauen, die Förderung und die stete Motivation während meiner Arbeit. Außerdem bin ich sehr dankbar für den Freiraum, der mir bei meiner Arbeit gewährt wurde, wodurch es mir beispielsweise ermöglicht war, einen Forschungsaufenthalt in Belgien durchzuführen. Weiterhin danke ich für die einmalige Gelegenheit, als Teilnehmerin und Mitorganisatorin an einem Alumni Seminar in Indonesien mitwirken zu können.

Ich danke Herrn Dr. Marcel Naumann und Frau Dr. Inga Smit für all Ihre Unterstützung bei der Durchführung dieser Arbeit, die kritischen Diskussionen und die vielen hilfreichen konzeptionellen und fachlichen Beiträge zu dieser Arbeit.

Ich danke der $\mathrm{K}+\mathrm{S} \mathrm{GmbH}$ - mit besonderem Dank an Frau Dr. Heike Thiel und Herrn Dr. Hans-Peter König - für die finanzielle Unterstützung, ohne die diese Arbeit so nicht möglich gewesen wäre.

Mein Dank gilt dem ZALF Müncheberg - mit besonderem Dank an Herrn Dr. Barkusky und Frau Krüger -, der BioChem agrar GmbH - mit besonderem Dank an Herrn Ulrich Janssen-, sowie Herrn Prof. Dr. Grzebisz und Herrn Dr. Witczak für die angenehme und unkomplizierte Zusammenarbeit bei der Durchführung und der Organisation der Feldversuche.

Ich danke der Europlant Pflanzenzucht GmbH für die Bereitstellung des Pflanzgutes für die Versuche dieser Arbeit.

Ich danke der Versuchsstation Dethlingen - mit besonderem Dank an Herrn. Dr. Peters und Herrn Wulf -, für jede fachliche Unterstützung und die Bereitstellung Ihrer Gerätschaften für die Durchführung der „,thumbnail-crack“ Analysen.

Mein Dank geht an Herrn Karsten Meyer (BNA Böhlendorf Zuchtstation) und Herrn Dr. Hans-Reinhard Hofferbert (Böhm-Nordkartoffel Agrarproduktion GmbH \& Co. OHG) für die fachliche Beratung und Hilfestellungen.

Herzlichst möchte ich mich bei allen Mitarbeitern der Abteilung „Qualität pflanzlicher Erzeugnisse“ für das angenehme Arbeitsklima und jeden Beitrag zum Gelingen dieser Arbeit bedanken. Ich danke Frau Gunda Jansen, 
Frau Bettina Egger und Frau Evelyn Krüger für all die Hilfe bei der Durchführung und Umsetzung der Versuche. Herrn Hilmer danke ich, der stets behilflich bei allen Problemen technischer Art war.

Bei der Abteilung „Pflanzenernährung und Ertragsphysiologie“ sowie dem IAPN möchte ich mich für den Zugang und die gewährte Nutzung aller Gerätschaften sowie für die Einführung in die Nutzung dieser bedanken, insbesondere bei Frau Susanne Koch, Frau Dr. Birgit Pfeiffer sowie Herrn Dr. Bálint Jákli.

Ich danke der Abteilung „Pflanzenbau“ für die Bereitstellung Ihrer Geräte und für die fachliche Einführung und Hilfestellungen dabei. Besonders bedanke ich mich bei Juliane Streit.

Herrn Prof. Dr. Klaus Dittert, Frau Prof. Dr. Nathalie Verbruggen und Herrn Dr. Christian Hermans möchte ich danken, die es mir ermöglicht haben, dass ich einen zweimonatigen Forschungsaufenthalt im „Laboratory of physiology and molecular genetics of plants“ an der „Interfaculty school of bioengineers“ der Freien Universität Brüssel, Belgien durchführen konnte. Ich danke Herrn Dr. Christian Hermans und allen Mitarbeitern des „Laboratory of physiology and molecular genetics of plants“ für all die wissenschaftlichen und konzeptionellen Beiträge und Hilfestellungen bei meiner Arbeit während dieses Aufenthaltes und auch im Anschluss an diesen.

Ich danke Herrn Prof. Dr. Ismail Cakmak und Herrn Dr. Prof. Klaus Dittert für Ihre grundlegenden konzeptionellen Beiträge für die Durchführung entscheidender Versuche dieser Arbeit.

Ich bedanke mich bei allen Bachelor- und Masterstudenten, studentischen und wissenschaftlichen Hilfskräften und Praktikanten für all Ihre Motivation, Flexibilität, tatkräftige Unterstützung, Ideen, Beiträge und die schöne und unkomplizierte Arbeitsatmosphäre. Besonders danke ich Matthies Busse, Lena Bergmann, Niklas Hartwig, Hendrik Schierwater, Stephan Scholz, Henner Kabitzsch und Jana Brehmer.

Meinen Mit-Doktoranden Daniela Schlein, Annika Lingner, Larissa Kanski, Bashar Daoud, Frederike Wenig, Josiah Chiveu, Leila Shafea, Erika Cut und Adnan danke ich für die Verschönerung meiner Arbeit der letzten Jahre! Ihr habt für eine tolle Arbeitsatmosphäre gesorgt!

Ich bedanke mich bei Mario Hasler für seine überaus große Hilfsbereitschaft bei der Bewältigung meiner Statistik!

Ich danke meinem Bruder Nikolas, meiner Schwägerin Margarethe und meiner kleinen Nichte Hanna für die mannigfaltige Unterstützung. Ich bin euch für alles sehr dankbar! 
Meiner Freundin Lorelai möchte ich danken, dass sie so eine wunderbare Freundin ist und dass sie immer für mich da ist!

Mein allergrößter Dank geht an meinen Freund Christoph-Martin, der bei allem hinter mir steht, mich bei allem unterstützt und mir den Rücken stärkt! Danke, dass ich immer auf dich zählen kann! 